\title{
Ray of light : evaluating the feasibility and effectiveness of routine psychosocial screening in cancer patients receiving radiotherapy
}

Citation for published version (APA):

Braeken, A. P. B. M. (2012). Ray of light : evaluating the feasibility and effectiveness of routine psychosocial screening in cancer patients receiving radiotherapy. [Doctoral Thesis, Maastricht University]. Datawyse / Universitaire Pers Maastricht. https://doi.org/10.26481/dis.20120627ab

Document status and date:

Published: 01/01/2012

DOI:

10.26481/dis.20120627ab

Document Version:

Publisher's PDF, also known as Version of record

Please check the document version of this publication:

- A submitted manuscript is the version of the article upon submission and before peer-review. There can be important differences between the submitted version and the official published version of record.

People interested in the research are advised to contact the author for the final version of the publication, or visit the DOI to the publisher's website.

- The final author version and the galley proof are versions of the publication after peer review.

- The final published version features the final layout of the paper including the volume, issue and page numbers.

Link to publication

\footnotetext{
General rights rights.

- You may freely distribute the URL identifying the publication in the public portal. please follow below link for the End User Agreement:

www.umlib.nl/taverne-license

Take down policy

If you believe that this document breaches copyright please contact us at:

repository@maastrichtuniversity.nl

providing details and we will investigate your claim.
}

Copyright and moral rights for the publications made accessible in the public portal are retained by the authors and/or other copyright owners and it is a condition of accessing publications that users recognise and abide by the legal requirements associated with these

- Users may download and print one copy of any publication from the public portal for the purpose of private study or research.

- You may not further distribute the material or use it for any profit-making activity or commercial gain

If the publication is distributed under the terms of Article $25 \mathrm{fa}$ of the Dutch Copyright Act, indicated by the "Taverne" license above, 


\section{Ray of Light}

Evaluating the feasibility and effectiveness of routine psychosocial screening in cancer patients receiving radiotherapy 
The studies presented in this dissertation were conducted under the auspices of the School for Public Health and Primary Care (CAPHRI) and the School for Oncology \& Developmental Biology (GROW) at Maastricht University. CAPHRI is part of the Netherlands School for Primary Care Research (CaRe), which has been acknowledged since 1995 by the Royal Netherlands Academy of Art and Sciences (KNAW)

ISBN 9789461591432

(C) Copyright A Braeken, June 2012

Cover art: N. Caris

Printed: Datawyse/ Universitaire Pers Maastricht 


\title{
Ray of Light
}

\section{Evaluating the feasibility and effectiveness of routine psychosocial screening in cancer patients receiving radiotherapy}

\author{
Proefschrift \\ ter verkrijging van de graad van doctor \\ aan de Universiteit Maastricht, \\ op gezag van de Rector Magnificus Prof. mr. G.P.M.F. Mols, \\ volgens het besluit van het College van Decanen, \\ in het openbaar te verdedigen, \\ op woensdag 27 juni 2012 om 14.00 uur \\ door
}

Anna P. B. M. (Vivian) Braeken

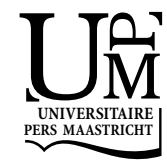




\section{Promotores}

Prof. dr. G.I.J.M. Kempen

Prof. dr. L. Lechner

\section{Co-promotor}

Dr. F.C.J.M. van Gils

\section{Beoordelingscommissie}

Prof. dr. H.W. van den Borne (voorzitter)

Dr. B.G. Baumert

Prof. dr. R. Sanderman (Rijksuniversiteit Groningen, Groningen)

Prof. dr. I.M. Verdonck-de Leeuw (Vrije Universiteit, Amsterdam)

Prof. dr. G.D.E.M. van der Weijden 
"To provide a basis for understanding the determinants of disease and arriving at rational treatments and patterns of health care, a medical model must also take into account the patient, the social context in which he lives and the complementary system devised by society to deal with the disruptive effects of illness, that is, the physician role and the health care system.

This requires a biopsychosocial model".

George Engel 



\section{Contents}

Preface 9

Chapter 1 General Introduction 11

Chapter 2 Psychometric properties of the Screening Inventory of 27

Psychosocial Problems (SIPP) in Dutch cancer patients treated with radiotherapy

Chapter 3 The effectiveness of the Screening Inventory of

Psychosocial Problems (SIPP) in cancer patients treated with radiotherapy: design of a cluster randomised controlled trial

Chapter 4 The usefulness and feasibility of a screening instrument to identify psychosocial problems in patients receiving curative radiotherapy: a process evaluation

Chapter 5 Does routine screening for psychosocial problems improve referral to caregivers and patient-radiotherapist communication? A cluster randomised controlled trial

Chapter 6 Effect of psychosocial screening on psychological distress and quality of life in cancer patients

Chapter 7 Psychometric Properties of the Dutch version of the Mental Adjustment to Cancer Scale in Dutch Cancer Patients

Chapter 8 General discussion

References

Appendix

The Screening Inventory of Psychosocial Problems (SIPP):

English and Dutch version

Summary

Samenvatting

Dankwoord 



\section{Preface}

This thesis considers the feasibility and effectiveness of using the Screening Inventory of Psychosocial Problems (SIPP) among cancer patients. Several aspects of screening for psychosocial problems among such patients are addressed, including the prevalence of psychosocial problems, the psychometric properties of the SIPP and the feasibility and effectiveness of using the SIPP in a radiation department.

\section{Outline of the thesis}

The thesis comprises eight chapters. The first chapter (Chapter 1) provides a general background on cancer treatment among cancer patients including radiotherapy, patients' psychosocial problems and/or needs and psychosocial care in the Netherlands. The chapter ends by stating the aims of the thesis. Chapter 2 reports on the reliability and construct validity of the SIPP, a Dutch screening instrument to identify multidimensional aspects of psychosocial problems in cancer patients. Chapter 3 describes the design of the main study, a cluster randomised controlled trial, which evaluates the effects of using the SIPP in a radiotherapy department. It gives a detailed description of the process of selection of the participants, measurements and procedures. Chapter 4 deals with the findings of an evaluation of patients' and radiotherapists' perspectives of the usefulness and feasibility of the SIPP in daily practice. The effects of using the SIPP among cancer patients receiving radiotherapy are described in Chapters 5 and 6. In Chapter 5 we explore whether using the SIPP improves referral to psychosocial caregivers and facilitates communication between patients and radiotherapists. Chapter 6 describes the effect of using the SIPP on the extent of psychological problems and health-related quality of life over a period of 12 months. As we were interested in the measurement of adjustment to cancer in daily practice, Chapter 7 deals with the usefulness and psychometric properties of the Dutch version of the Mental Adjustment to Cancer scale (MAC-scale). The final chapter (Chapter 8) starts with a summary of the main findings of the thesis, after which methodological and theoretical considerations are briefly discussed. The chapter ends with a discussion of the implications of the current findings and recommendations for clinical practice and future research. 


\section{Chapter 1}

\section{General Introduction}


CHAPTER 1 


\section{Introduction}

\section{Cancer}

Cancer has been characterised as a disease of aging. ${ }^{1}$ The number of people being diagnosed with cancer is rising as more people live to an old age. Over recent decades the number of people diagnosed with cancer and living longer has increased due to earlier diagnosis and improved treatment. ${ }^{2}$ In the Netherlands, roughly ten people are diagnosed with cancer per hour and one in three can expect to be diagnosed with cancer at some point in their lifetime. ${ }^{3}$

Cancer is a term for a large group of diseases, all involving unregulated cell growth. The cells divide and grow uncontrollably, forming malignant tumours, and invade nearby parts of the body. Cancer represents acute life-threatening illnesses and serious chronic conditions, both of which are associated with physical problems. ${ }^{4}$ The treatment is complex, involving many disciplines and treatment modalities such as surgery, radiotherapy (radiation), chemotherapy and hormone therapy. ${ }^{1}$ Surgery and radiotherapy are local treatments whilst chemotherapy and hormone therapy are systemic treatments. About $50 \%$ of all cancer patients receive radiation at some point during their illness, either alone or in combination with other treatment modalities (for more detailed information about radiotherapy (see Box 1).5-7 The benefits of combining several treatment methods are increased effectiveness of the treatment and minimisation of treatment side effects. Nevertheless, many treatments have been found to have short- and long-term consequences including weight gain and cardiac and lung toxicity, which affect day-to-day functioning, leading to functional decline ${ }^{4}$ and psychosocial morbidity. ${ }^{8}$

Cancer has an impact not only on physical functioning but also on psychological and social aspects of life. ${ }^{9}$ In 1977, the American psychiatrist George Engel introduced the biopsychosocial model in medicine. ${ }^{10}$ This model uses a holistic approach, consisting of three separate but interdependent domains: biological, psychological, and social, each as systems of the body (Figure 1). These biopsychosocial factors are involved in the causes, manifestation, course, and outcome of health and disease. ${ }^{11,12}$ 


\section{Radiotherapy}

Radiotherapy is the medical use of radiation and is one of the most effective forms of cancer treatment. ${ }^{5}$ Radiation induces DNA lesions within the tumour cells. These lesions, if unrepaired, mean that the cells are unable to divide and grow, which ultimately results in cell death. Radiotherapy aims to cause maximum damage in cancer cells and minimum damage in normal tissue cells 5,13 , and although both tumour and normal cells are damaged, the latter are able to repair themselves. ${ }^{13}$

The most common type of radiotherapy is external radiotherapy, which means that the radiation is administered from a machine (linear accelerator) outside the body. Before treatment, the tumour and the surrounding normal tissues are accurately targeted using a CT or PET scan. The patient's skin is marked to guide the placement of treatment fields and to ensure that the same area is treated in each radiation session. In each session the radiation technologist positions the patient correctly on the treatment table using the skin marks. The linear accelerator directs the high intensity X-rays to specific areas of the patient's body from several angles. During treatment the patient is left alone in the treatment room but is observed by the radiation technologists via TV-monitors in a separate control room.

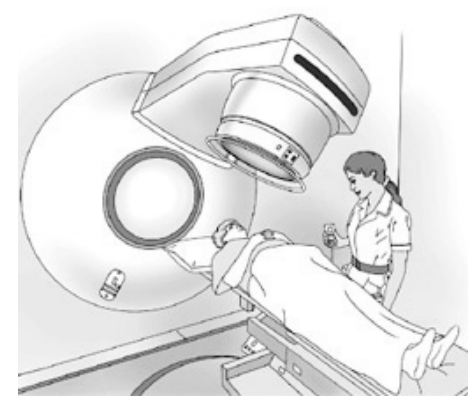

External radiation treatment is given in several treatment fractions over 1 day to 6 weeks and four to five times a week depending on the site of the tumour and the aim of treatment. Radiation can cause a variety of side effects (e.g. diarrhoea, nausea and tiredness) during treatment and in the months or years following treatment..$^{5,13}$

Box 1 Radiotherapy

The moment a patient receives a cancer diagnosis, the brain's sensory cortex simultaneously registers the information and sets in motion biological changes that for example cause the heart to pound faster. The patient may experience an almost immediate fear of death that may later escalate to anxiety or depression. ${ }^{14}$ Being anxious or depressed may prompt changes in behaviour, such as social withdrawal. The psychosocial factors: anxiety, depression, worse relationships or less social support, may affect recovery and the progression of cancer. $^{15}$ The biopsychosocial model states that the functioning of the body can affect the mind, and the workings of the mind can affect the body. ${ }^{10}$ 


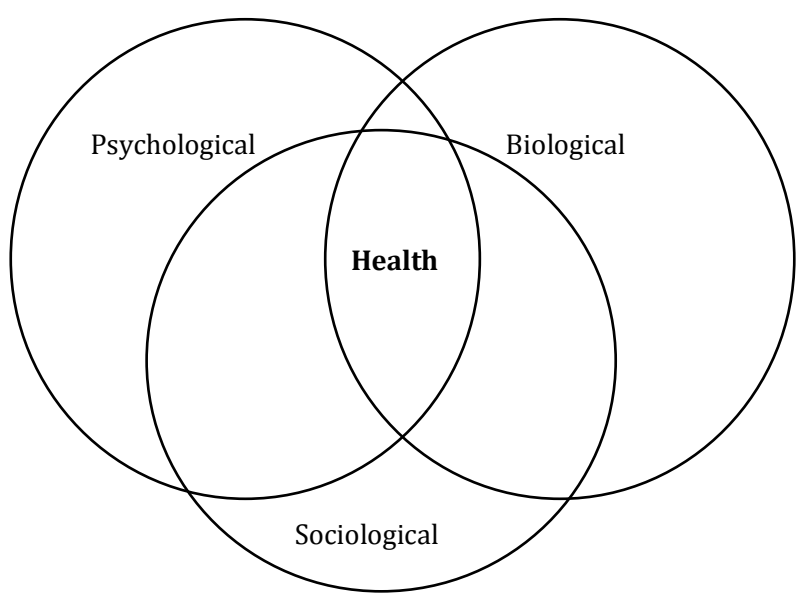

Figure 1 Biopsychosocial model

\section{Psychosocial problems among cancer patient}

When patients receive the diagnosis of cancer they may experience emotional responses that usually last a few days to a week, followed by a period of mixed symptoms of anxiety and depression. ${ }^{16}$ In the absence of a crisis, the emotional responses would be considered as pathological, but in this context, they would be considered as normal feelings. These responses resolve over several weeks as the patient enters the adaptation phase.${ }^{17}$ Patients vary in how well they adjust to or cope with cancer, ${ }^{18}$ with adjustment being dependent on various factors (Figure 2). ${ }^{19}$

The factors can be grouped into society-based factors, patient-based factors and cancer-based factors. ${ }^{16}$ Society-based factors are the beliefs held by a society about cancer, for example that cancer is associated with death, resulting in a stigma for cancer patients. Patient-based factors are related to the patient's personality, emotional maturity, social support and patient's coping style., 96

A coping style that comprises a passive approach to solving problems (e.g. helplessness/hopelessness) is associated with poor psychological adjustment to cancer. ${ }^{20-24}$ Predictors associated with poor coping are social isolation, low socio-economic status, alcohol or drug abuse, prior psychiatric history, rigidity of coping strategies, a pessimistic philosophy of life, absence of a supportive system, and stressors (such as financial or family obligations). ${ }^{16}$ 


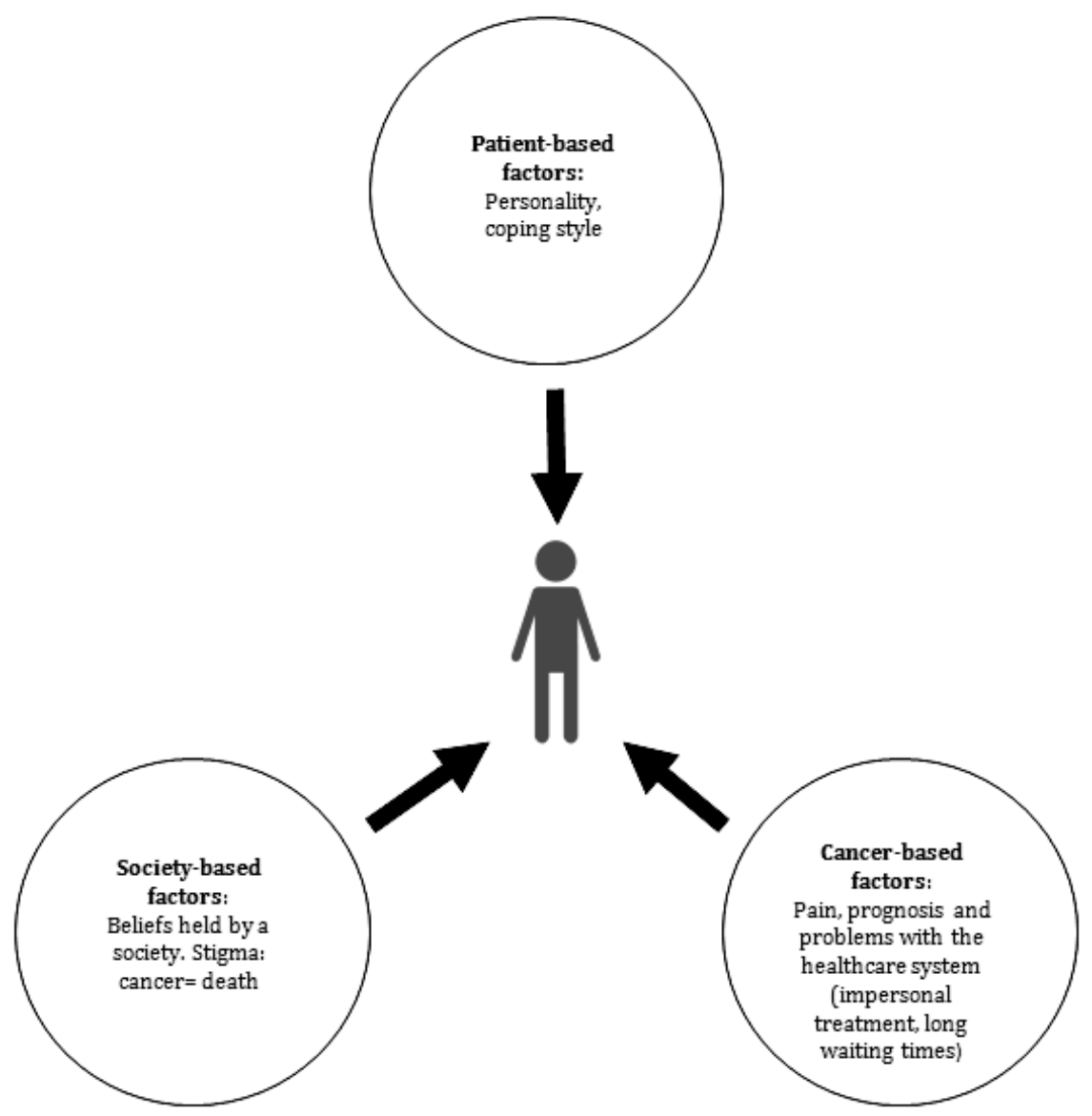

Figure 2 Factors related to adaption to cancer

Cancer-related factors are related to the disease with which the patient has to cope: the stage and site of the illness (e.g. lung, breast), physical symptoms such as pain, and the prognosis. Another important aspect is the way in which physicians and nurses conduct their work. All these factors interact and determine the degree of adjustment to cancer at any given point in time. ${ }^{16}$

Most but not all patients cope well with cancer. Studies on the prevalence of psychosocial problems among cancer patients show an incidence of 5 to $58 \%,{ }^{25-}$ ${ }^{34}$ depending on the method and point of assessment and the study population. ${ }^{9}$ Psychosocial problems differ in severity and vary from common "normal" feelings of vulnerability, sadness and worries to severe disabling symptoms such as clinical depression and anxiety. ${ }^{35}$ They can be present at any stage during the cancer trajectory. 9,36 
In the diagnostic phase the patient's life may undergo drastic transformations that affect their emotions. Uncertainty is the main issue in this phase. Patients may experience acute grief, anger, and symptoms of anxiety and depression.13,37${ }^{39}$ In the treatment phase, cancer patients may experience problems related to coping with body mutilation (e.g. breast amputation) and side-effects (e.g. nausea, diarrhoea), and an overall fear of the "unknown" (e.g. fear of the x-ray devices). ${ }^{9,37}$ Radiotherapy treatment takes 5 to 6 weeks with four to five treatment sessions a week, and the need to travel can be burdensome. The post-treatment phase has been reported as one of the most difficult phases. In this phase the consequence of having a life-threatening illness becomes more evident. During treatment the focus is on the possibility of a cure. Following treatment, when regular contact with healthcare professionals has ceased, the focus is on the long-term and general consequences for life. ${ }^{9}$ Patients will be worried about a second malignancy or the recurrence of cancer. Furthermore, there will be problems related to ongoing employment and social life. ${ }^{37,40}$ The people who have been supportive to the patient may assume that all is now well and focus their attention on the outer world instead of the cancer. ${ }^{37}$ In this phase, it is also clear that patients' anxiety levels rise in anticipation of a follow-up visit for routine scans ${ }^{41}$. The majority of cancer patients remain cancer free but for some patients the cancer returns. Recurrence of the cancer can lead to more prominent psychosocial problems. ${ }^{9}$ Physical symptoms such as pain, lack of energy and appetite remind patients of their poor prognosis. Patients' responses may include disbelief, complete or partial denial, anxiety, anger and depression ${ }^{37}$. Patients may have to cope with their loss of expectations of the future, the loss of their family and friends, and the loss of functioning, independence and their social roles. ${ }^{9}$ In the terminal phase patients will suffer from pain, an extreme lack of energy and loss of independence and body functions. ${ }^{9}$ By this phase many patients will have accepted their situation to a greater extent than they did in the earlier phases. However, a number of patients will have a fear of the process of dying ${ }^{37}$ and some will continue to fight against the disease. ${ }^{9}$

When the levels of psychosocial problems exceed the normal level and seriously impair patients' quality of life, and slow down their return to normal activities and paid employment ${ }^{42}$, the possibility of a psychiatric disorder should be considered. ${ }^{43}$ The most common types of psychiatric disorders among cancer patients are: minor and major depression, adjustment disorders (with depressed and/or anxious mood), and anxiety disorders (Table 1).27,44 
Table 1 Summary of the diagnostic DSM-IV criteria for the most common types of psychiatric disorders among cancer patients

\begin{tabular}{|c|c|c|}
\hline $\begin{array}{l}\text { Diagnostic } \\
\text { Category }\end{array}$ & DSM-IV Criteria45 & $\begin{array}{l}\text { Symptom } \\
\text { Duration }\end{array}$ \\
\hline Major depression & \multicolumn{2}{|c|}{$\begin{array}{l}\geq 5 \text { Depressive symptoms (e.g. insomnia/hypersomnia, poor } \geq 2 \text { weeks } \\
\text { concentration, weight loss, low energy) including depressed } \\
\text { mood and/or anhedonia, causing significant impairment in } \\
\text { social, occupational, or other important areas of functioning. }\end{array}$} \\
\hline Minor depression & $\begin{array}{l}\text { 2-4 Depressive symptoms (e.g. insomnia/hypersomnia, } \\
\text { poor concentration, weight loss, low energy) including } \\
\text { depressed mood and/or anhedonia, causing significant } \\
\text { impairment in social, occupational, or other important areas } \\
\text { of functioning. }\end{array}$ & $\geq 2$ weeks \\
\hline Adjustment disorder & $\begin{array}{l}\text { Emotional or behavioural symptoms in response to an } \\
\text { identifiable stressor(s) occurring within } 3 \text { months of the } \\
\text { onset of the stressor(s), causing significant impairment in } \\
\text { social, occupational, or other important areas of functioning. } \\
\text { The stress-related disturbance does not meet the criteria for } \\
\text { mood (depression) or anxiety disorder and is not merely an } \\
\text { exacerbation of a pre-existing mood (depression) or anxiety } \\
\text { disorder. }\end{array}$ & $\leq 6$ months \\
\hline $\begin{array}{l}\text { Generalised anxiety } \\
\text { disorder }\end{array}$ & $\begin{array}{l}\geq 3 \text { Anxiety symptoms (e.g. irritability, muscle tension, } \\
\text { restlessness) including excessive anxiety and worry about } \\
\text { a number of events or activities, difficulties controlling } \\
\text { worry, causing impairment in social, occupational, or other } \\
\text { important areas of functioning. }\end{array}$ & $\geq 6$ months \\
\hline $\begin{array}{l}\text { Panic attack (anxiety } \\
\text { disorder) }\end{array}$ & $\begin{array}{l}\geq 4 \text { Anxiety symptoms (e.g. sweating, shaking, chest pain, } \\
\text { lightheaded, feelings of unreality) including a discrete } \\
\text { period of intense fear of discomfort. }\end{array}$ & $\begin{array}{l}\text { Abrupt and } \\
\text { reaches a peak } \\
\text { in } 10 \text { minutes }\end{array}$ \\
\hline
\end{tabular}

\section{Psychosocial care: screening of psychosocial problems}

In cancer patients psychosocial problems may be part of a "normal" response to the diagnosis. Nevertheless in many patients they may persist, causing additional burden during treatment and affecting many oncology outcomes, such as non-compliance with therapy. ${ }^{34}$ Psychosocial interventions may be appropriate for those patients in whom psychosocial problems do not decrease over time. Such interventions can help patients to cope better with very distressing situations $^{37}$, and may improve health-related outcomes including quality of life..$^{38,46,47}$ Moreover, treatment of psychosocial problems at an early stage may prevent further deterioration and the development of psychiatric co-morbidity. ${ }^{25,48}$ However, the integration of psychosocial care into medical care remains difficult due to additional barriers on the part of patients and physicians. ${ }^{8}$ Psychosocial problems frequently remain unacknowledged and unaddressed in cancer care. ${ }^{36,49}$ Less than one third of cancer patients with psychosocial problems are correctly referred to a psychosocial caregiver. ${ }^{50}$ 
Although psychosocial caregivers (e.g. social workers, psychologists, psychiatrists) may be needed to deal with a patient's psychosocial problems, physicians and nurses without specialised psychological skills may check and screen psychosocial status. ${ }^{9}$ The assessment methods for psychosocial problems among cancer patients vary. The gold standard for assessment of a large number of psychosocial problems including major depression and adjustment disorders is a (semi)-structured clinical interview based on DSM-IV. ${ }^{39}$ However, the latter takes at least 1 hour and is therefore not feasible in most clinical oncology settings. Therefore, self-reported screening instruments are mostly used to identify psychosocial problems. It should be noted that these instruments are not intended to be diagnostic but are considered as a case-finding tool, and patients with suspicious outcomes should be referred for a more definitive examination. ${ }^{39}$ Nevertheless the use of screening instruments may prevent the underdiagnosis of psychosocial problems. ${ }^{25}$ Besides recognition of psychosocial problems, self-reported screening instruments have proven to be good tools for facilitating communication between cancer patients and physicians with respect to psychosocial problems. ${ }^{46,51,52}$

\section{Aim of this thesis}

Besides physical impairment, many cancer patients experience significant psychosocial problems, which makes minimising their emotional burden an important public health concern. ${ }^{1}$ Over the last 30 years interest in psychosocial oncology has grown significantly and psychosocial oncology has been evolving as an important subspecialty of cancer care ${ }^{39,53}$ National guidelines with regard to psychosocial oncology have been produced in the United Kingdom ${ }^{54}$, United States ${ }^{55}$, Australia ${ }^{56}$ and Canada. ${ }^{57}$ These guidelines provide advice on supporting cancer patients and their families throughout the cancer trajectory. In 2009 the Dutch Health Care Inspectorate conducted an investigation examining the quality of oncology care in the Netherlands. ${ }^{58}$ One of the conclusions was that interest in and attention to psychosocial care was unsatisfactory. This resulted in the decision that routine screening for psychosocial problems in cancer patients should be incorporated as a standard in all hospitals and radiation departments in the Netherlands by 2010. In the same period the Dutch Society for Psychosocial Oncology formulated and published a guideline regarding the need for psychosocial care in cancer patients with the aim that every adult cancer patient who receives ambulatory hospital care should be routinely screened for psychosocial distress. $^{59}$

Several studies suggested that using screening instruments was indeed helpful in identifying and discussing psychosocial problems in daily practice. However, the availability of a screening instrument does not guarantee that the instrument is accurate for screening or case finding. On the other hand sufficient to good psychometric properties do not guarantee that a screening instrument 
is suitable for use. ${ }^{60,61}$ In evaluating a screening instrument the first step should be to evaluate the instrument's psychometric properties, including reliability, validity, sensitivity and specificity. If this evaluation is successful, the second step should be to evaluate the feasibility and effect of using a screening instrument in daily practice on several outcomes (e.g. number of referrals, communication, quality of life). ${ }^{60}$ However, large-scale, well designed, randomised controlled trials establishing evidence of the effect of psychosocial screening are lacking. ${ }^{33}$ Prior to the start of our study in 2006 only four research groups in other countries had carried out randomised controlled trials to evaluate the potential effects of psychosocial screening on cancer patients' health-related outcomes, such as psychological well-being and quality of life. In the meantime three other international research groups have carried out randomised controlled trials (see Table 2 for an overview).60 Moreover, no randomised controlled trials have been conducted in radiotherapy settings and/or in the Netherlands. Thus, as indicated in Table 2, data on the effects of screening for psychosocial distress among cancer patients remain inconclusive. 
Table 2 Randomised controlled trials of the effect of screening for distress among cancer patients ${ }^{39,60}$

\begin{tabular}{|c|c|c|c|c|}
\hline & $\begin{array}{l}\text { Maunsell et al. } \\
(1996)^{62}\end{array}$ & $\begin{array}{l}\text { McLachlan et al. } \\
(2001)^{63}\end{array}$ & Detmar et al. $(2002)^{64}$ & Velikova et al. (2004) ${ }^{65}$ \\
\hline $\begin{array}{l}\text { dey } \\
\text { sign }\end{array}$ & $\begin{array}{l}\text { Randomised } \\
\text { control trial. } \\
\text { Patients were } \\
\text { randomly allo- } \\
\text { cated into the } \\
\text { intervention or } \\
\text { control group }\end{array}$ & $\begin{array}{l}\text { Randomised control } \\
\text { trial (multicentre). } \\
\text { Patients were ran- } \\
\text { domly allocated } \\
\text { into the interven- } \\
\text { tion or control } \\
\text { group in a } 2: 1 \\
\text { ratio per clinic }\end{array}$ & $\begin{array}{l}\text { Randomised crossover } \\
\text { trial. Crossover: ran- } \\
\text { domisation of physi- } \\
\text { cians who switched } \\
\text { condition midway } \\
\text { through. A minimum of } \\
10 \text { patients per physi- } \\
\text { cian per condition } \\
\text { were recruited }\end{array}$ & $\begin{array}{l}\text { Randomised controlled } \\
\text { trial. Patients were } \\
\text { randomly allocated into } \\
\text { the intervention or to } \\
\text { the attention control/ } \\
\text { f control group }\end{array}$ \\
\hline Samp & $\begin{array}{l}251 \text { women newly } \\
\text { diagnosed with } \\
\text { breast cancer }\end{array}$ & $\begin{array}{l}450 \text { patients with } \\
\text { different tumour } \\
\text { types and treat- } \\
\text { ments }\end{array}$ & $\begin{array}{l}214 \text { patients with } \\
\text { different tumour types } \\
\text { undergoing palliative } \\
\text { chemotherapy. } \\
10 \text { physicians }\end{array}$ & $\begin{array}{l}286 \text { patients with dif- } \\
\text { ferent tumour types and } \\
\text { treatments. } 28 \text { physi- } \\
\text { cians }\end{array}$ \\
\hline $\begin{array}{l}\text { esponse } \\
\text { te }\end{array}$ & Patients: $89.0 \%$ & Patients: & $\begin{array}{l}\text { Patients: } 71.0 \% \text { and } \\
\text { physicians: } 80.0 \%\end{array}$ & Pat \\
\hline $\begin{array}{l}\text { Interven- } \\
\text { tion }\end{array}$ & $\begin{array}{l}12 \text { monthly tele- } \\
\text { phone distress } \\
\text { screenings. Pa- } \\
\text { tients with high } \\
\text { distress were } \\
\text { contacted by a } \\
\text { social worker } \\
\text { within } 2 \text { weeks }\end{array}$ & $\begin{array}{l}\text { Completing ques- } \\
\text { tionnaires via a } \\
\text { touch screen com- } \\
\text { puter. For the inter- } \\
\text { vention group } \\
\text { screening results } \\
\text { were available to } \\
\text { the physician }\end{array}$ & $\begin{array}{l}\text { Patients completed the } \\
\text { questionnaire before } \\
\text { each visit. A summary } \\
\text { of the screening results } \\
\text { were available to the } \\
\text { physician }\end{array}$ & $\begin{array}{l}\text { Completing question- } \\
\text { naires via a touch screen } \\
\text { computer before each of } \\
\text { s their clinic encounters. } \\
\text { For the intervention } \\
\text { group screening results } \\
\text { were available to the } \\
\text { physician }\end{array}$ \\
\hline & $\begin{array}{l}\text { Intervention } \\
\text { (n=123) vs. con- } \\
\text { trol: usual care } \\
\text { ( } n=127 \text { ). All pa- } \\
\text { tients received a } \\
\text { minimal psycho- } \\
\text { social follow-up } \\
\text { care programme } \\
\text { from a social } \\
\text { worker at initial } \\
\text { treatment (usual } \\
\text { care). Follow-up: } \\
\text { at baseline and } 3 \\
\text { and } 12 \text { months } \\
\text { telephone follow- } \\
\text { up }\end{array}$ & $\begin{array}{l}\text { Intervention } \\
(\mathrm{n}=296) \text { vs. control } \\
(\mathrm{n}=154) \text {. All pa- } \\
\text { tients completed } \\
\text { questionnaires via } \\
\text { a touch screen } \\
\text { computer. A nurse } \\
\text { formulated an } \\
\text { individual plan } \\
\text { including referrals. } \\
\text { Follow-up: at } 2 \text { and } \\
6 \text { months same } \\
\text { computer-based } \\
\text { questionnaires as } \\
\text { at baseline. At } 6 \\
\text { months assessment } \\
\text { of satisfaction with } \\
\text { overall care }\end{array}$ & $\begin{array}{l}\text { Intervention ( } \mathrm{n}=100) \\
\text { vs. control (n=114). All } \\
\text { patients and physicians } \\
\text { answered several } \\
\text { questions at the first } \\
\text { and fourth study visits. } \\
\text { Following the fourth } \\
\text { study visit, patients in } \\
\text { the intervention group } \\
\text { completed a question- } \\
\text { naire and a telephone } \\
\text { interview regarding } \\
\text { the feasibility of the } \\
\text { intervention. All par- } \\
\text { ticipating physicians } \\
\text { underwent a semi- } \\
\text { structured interview }\end{array}$ & $\begin{array}{l}\text { Intervention (n=144) vs. } \\
\text { lattention control group } \\
\text { s(n=70) and control } \\
\text { group: usual care } \\
\text { (n=72). Patients in the } \\
\text { attention control group } \\
\text { completed question- } \\
\text { naires via a touch screen } \\
\text { computer but the } \\
\text { screening results were } \\
\text { not available to the } \\
\text { physician. The other } \\
\text { control group received } \\
\text { no screening. Follow-up: } \\
\text { questionnaires at base- } \\
\text { line, } 2,4 \text { and } 6 \text { months } \\
\text { (at home) }\end{array}$ \\
\hline $\begin{array}{l}\text { Interven- } \\
\text { tion screen- } \\
\text { ing instru- } \\
\text { ment }\end{array}$ & GHQ & $\begin{array}{l}\text { Computer-based } \\
\text { questionnaires: } \\
\text { CNQ, EORTCQLQ- } \\
\text { C30, BDI }\end{array}$ & EORTC QLQ-C30 & $\begin{array}{l}\text { Computer-based ques- } \\
\text { tionnaires: EORTC QLQ- } \\
\text { C30 and the HADS }\end{array}$ \\
\hline
\end{tabular}




\begin{tabular}{|c|c|c|c|c|}
\hline & $\begin{array}{l}\text { Maunsell et al. } \\
(1996)^{62}\end{array}$ & $\begin{array}{l}\text { McLachlan et al. } \\
(2001)^{63}\end{array}$ & Detmar et al. (2002) 64 & Velikova et al. (2004)65 \\
\hline $\begin{array}{l}\text { Staff train- } \\
\text { ing }\end{array}$ & $\begin{array}{l}\text { No report on } \\
\text { staff training }\end{array}$ & $\begin{array}{l}\text { No instructions } \\
\text { were given regard- } \\
\text { ing use of the pa- } \\
\text { tient-reported } \\
\text { information. }\end{array}$ & $\begin{array}{l}\text { Physicians were } \\
\text { trained in interpreta- } \\
\text { tion of the results of } \\
\text { the questionnaire }\end{array}$ & $\begin{array}{l}\text { Physicians were trained } \\
\text { in interpretation of the } \\
\text { results of the question- } \\
\text { naires }\end{array}$ \\
\hline $\begin{array}{l}\text { Primary } \\
\text { outcome }\end{array}$ & Distress & $\begin{array}{l}\text { QoL, needs and } \\
\text { satisfaction with } \\
\text { care }\end{array}$ & $\begin{array}{l}\text { Discussion of quality } \\
\text { of life issues }\end{array}$ & QoL over time \\
\hline $\begin{array}{l}\text { Other out- } \\
\text { comes }\end{array}$ & $\begin{array}{l}\text { Qol, depression } \\
\text { and anxiety, physi- } \\
\text { cal health, return } \\
\text { to usual activities, } \\
\text { employment, } \\
\text { marital satisfac- } \\
\text { tion }\end{array}$ & Level of depression & $\begin{array}{l}\text { Physician's awareness } \\
\text { of QoL, management } \\
\text { activities (referral, } \\
\text { ordering tests), patient } \\
\text { and physician satisfac- } \\
\text { tion, level of QoL, } \\
\text { evaluation of interven- } \\
\text { tion }\end{array}$ & $\begin{array}{l}\text { FACT-G, communica- } \\
\text { tion, clinical manage- } \\
\text { ment }\end{array}$ \\
\hline $\begin{array}{l}\text { Results/ } \\
\text { conclusions }\end{array}$ & $\begin{array}{l}\text { No effect on QoL. } \\
\text { For all patients the } \\
\text { distress levels } \\
\text { decreased over the } \\
\text { study period }\end{array}$ & $\begin{array}{l}\text { No overall effect on } \\
\text { QoL, psychosocial } \\
\text { functioning or } \\
\text { esatisfaction with } \\
\text { care. For patients } \\
\text { with at least moder- } \\
\text { ate depression an } \\
\text { intervention effect } \\
\text { on depression was } \\
\text { found }\end{array}$ & $\begin{array}{l}\text { Intervention effect on } \\
\text { more frequently dis- } \\
\text { cussed QoL issues and } \\
\text { more patients with at } \\
\text { least moderate health } \\
\text { - problems were identi- } \\
\text { fied. Most patients and } \\
\text { all physicians reported } \\
\text { that the intervention } \\
\text { facilitated patient- } \\
\text { physician communi- } \\
\text { cation. Greater per- } \\
\text { centage of patients in } \\
\text { the intervention group } \\
\text { received counselling } \\
\text { for health problems }\end{array}$ & $\begin{array}{l}\text { An effect on QoL for the } \\
\text { patients who completed } \\
\text { the computer-based } \\
\text { questionnaire. An inter- } \\
\text { vention effect (with } \\
\text { feedback) on emotional } \\
\text { functioning and } \\
\text { physician-patient com- } \\
\text { munication was found }\end{array}$ \\
\hline Limitations & $\begin{array}{l}\text { Minimal psychoso- } \\
\text { cial follow-up } \\
\text { care programme } \\
\text { made it difficult } \\
\text { to show an inter- } \\
\text { vention effect }\end{array}$ & $\begin{array}{l}\text { - No protection } \\
\text { against contamina- } \\
\text { tion bias }{ }^{60} \text {. Criteria } \\
\text { may have resulted } \\
\text { in well-functioning } \\
\text { patients }\end{array}$ & $\begin{array}{l}\text { No protection against } \\
\text { contamination bias }{ }^{60} \text {. } \\
\text { Limited physician } \\
\text { sample }\end{array}$ & $\begin{array}{l}\text { No protection against } \\
\text { contamination bias }\end{array}$ \\
\hline
\end{tabular}


Table 2 Randomised controlled trials of the effect of screening for distress among cancer patients ${ }^{39,60}$ (continued)

\begin{tabular}{|c|c|c|c|}
\hline & Boyes et al. $(2006)^{66}$ & Rosenbloom et al. (2007) ${ }^{67}$ & Carlson et al. $(2010)^{68}$ \\
\hline $\begin{array}{l}\text { Study } \\
\text { design }\end{array}$ & $\begin{array}{l}\text { Randomised controlled trial. } \\
\text { Two groups with consenting } \\
\text { patients allocated alternately } \\
\text { into treatment and control } \\
\text { groups }\end{array}$ & $\begin{array}{l}\text { Randomised controlled } \\
\text { trial. Patients were ran- } \\
\text { domly allocated into the } \\
\text { intervention group or into } \\
\text { one of the two control } \\
\text { groups }\end{array}$ & $\begin{array}{l}\text { Randomised controlled } \\
\text { trial. Patients were ran- } \\
\text { domly allocated into one of } \\
\text { the three screening condi- } \\
\text { tions }\end{array}$ \\
\hline Sample & $\begin{array}{l}95 \text { patients with different } \\
\text { tumour types and treatments }\end{array}$ & $\begin{array}{l}213 \text { patients with metas- } \\
\text { tatic breast, lung and colo- } \\
\text { rectal cancer receiving } \\
\text { chemotherapy }\end{array}$ & $\begin{array}{l}1,134 \text { new patients with } \\
\text { breast and lung cancer and } \\
\text { with different treatments }\end{array}$ \\
\hline $\begin{array}{l}\text { Response } \\
\text { rate }\end{array}$ & Patients: $75.0 \%$ & Unknown & Patients: $89.0 \%$ \\
\hline & $\begin{array}{l}\text { nCompleting a questionnaire via } \\
\text { a touch screen computer before } \\
\text { first visit. For the intervention } \\
\text { group screening results were } \\
\text { available to the physician }\end{array}$ & $\begin{array}{l}\text { A QoL assessment including } \\
\text { e a structured interview at } \\
\text { baseline, and } 1 \text { and } 2 \\
\text { month check-ups. QoL } \\
\text { results were available to } \\
\text { the oncology nurse }\end{array}$ & $\begin{array}{l}\text { gMinimal screening and full } \\
\text { screening: completing } \\
\text { questionnaires via a tablet } \\
\text { computer before consulta- } \\
\text { tion or triage: full screening } \\
\text { including optional phone } \\
\text { triage with referral }\end{array}$ \\
\hline Method & $\begin{array}{l}\text { Intervention (n=42) vs. } \\
\text { control ( } \mathrm{n}=38) \text {. Screening } \\
\text { for both groups but the } \\
\text { screening results of patients } \\
\text { of the control group were not } \\
\text { available to the physician. } \\
\text { Follow-up: assessment at } \\
\text { baseline and three subsequent } \\
\text { consecutive visits }\end{array}$ & $\begin{array}{l}\text { Intervention (n=69) vs. } \\
\text { control group with QoL } \\
\text { assessment ( } \mathrm{n}=73 \text { ) vs. } \\
\text { control group: usual care } \\
\text { (n=71). Results of patients } \\
\text { in the control group with } \\
\text { usual care were not avail- } \\
\text { able to the nurses. Follow- } \\
\text { up: assessment at baseline } \\
\text { and at } 6 \text { months. QoL was } \\
\text { also assessed after } 1 \text {, } 2 \text { and } \\
3 \text { months for patients of the } \\
\text { assessment control group } \\
\text { and the intervention group }\end{array}$ & $\begin{array}{l}\text { Minimal screening ( } \mathrm{n}=365) \\
\text { vs. full screening }(\mathrm{n}=391) \\
\text { vs. triage }(\mathrm{n}=378) \text {. Results } \\
\text { of the group with minimum } \\
\text { screening were not avail- } \\
\text { able to the physician. Fol- } \\
\text { low-up: assessment after } 3 \\
\text { months for all groups }\end{array}$ \\
\hline
\end{tabular}

InterventionHADS, SCNS, 12 items related toFACT-G plus a structured DT and PSSCAN

screening chemo-therapy (physical symp-interview

instrument toms)

\begin{tabular}{llll}
$\begin{array}{l}\text { Staff } \\
\text { training }\end{array}$ & No staff training & No staff training & No staff training \\
$\begin{array}{l}\text { Primary } \\
\text { outcome }\end{array}$ & $\begin{array}{l}\text { Anxiety and depression, } \\
\text { physical symptoms }\end{array}$ & $\begin{array}{l}\text { Level of QoL and satisfac- } \\
\text { tion }\end{array}$ & Distress \\
\hline
\end{tabular}




\begin{tabular}{|c|c|c|c|}
\hline & Boyes et al. (2006)66 & Rosenbloom et al. (2007) ${ }^{67}$ & Carlson et al. $(2010)^{68}$ \\
\hline $\begin{array}{l}\text { Other out- } \\
\text { comes }\end{array}$ & $\begin{array}{l}\text { Desire for help, assessment } \\
\text { acceptability (patients and } \\
\text { physicians) }\end{array}$ & $\begin{array}{l}\text { FACT-G, FLIC, POMS, PSQ- } \\
\text { III. }\end{array}$ & $\begin{array}{l}\text { Anxiety and depression, } \\
\text { effects of referral to re- } \\
\text { sources on distress, anxiety } \\
\text { and depression }\end{array}$ \\
\hline $\begin{array}{l}\text { Results/ } \\
\text { conclusions }\end{array}$ & $\begin{array}{l}\text { No intervention effect on psy- } \\
\text { chological well-being was } \\
\text { found. For all patients the } \\
\text { anxiety levels decreased over } \\
\text { the study period. Both physi- } \\
\text { cians and patients were posi- } \\
\text { tive about the intervention. } \\
\text { Only three patients reported } \\
\text { that screening results were } \\
\text { discussed }\end{array}$ & $\begin{array}{l}\text { No significant differences } \\
\text { in QoL or satisfaction } \\
\text { over time across the } \\
\text { three groups }\end{array}$ & $\begin{array}{l}\text { Fewer patients with lung } \\
\text { cancer in the triage group } \\
\text { continued to have high } \\
\text { distress at } 3 \text { months com- } \\
\text { pared to the other groups. } \\
\text { Breast cancer patients in } \\
\text { the full screening and triage } \\
\text { group had lower distress at } \\
3 \text { months than those with } \\
\text { minimal intervention. } \\
\text { Referral to psychosocial } \\
\text { care was a predictor of } \\
\text { decreased anxiety and } \\
\text { depression }\end{array}$ \\
\hline Limitations & $\begin{array}{l}\text { No protection against contami- } \\
\text { nation bias }{ }^{60} \text {. Small sample size. } \\
\text { Patients functioned very well } \\
\text { at baseline which limited } \\
\text { detection of changes }\end{array}$ & $\begin{array}{l}\text { Protection against con- } \\
\text { tamination bias as } \\
\text { screening results were } \\
\text { not provided directly to } \\
\text { treating nurse, but } \\
\text { indirectly through the } \\
\text { research nurse }\end{array}$ & $\begin{array}{l}\text { No protection against } \\
\text { contamination bias }^{60} \text {. In- } \\
\text { and exclusion criteria may } \\
\text { have resulted in well- } \\
\text { functioning patients }\end{array}$ \\
\hline
\end{tabular}

BDI: Beck Depression Inventory; CNQ: Cancer Needs Questionnaire; DT: Distress Thermometer; EORTCQLQ-C30: European Organisation for Research and Treatment of Cancer Quality of Life Questionnaire Core 30; FACT-G: Functional assessment of Cancer Therapy-General; FLIC: Functional Living Index Cancer; GHQ: General Health Questionnaire; HADS: Hospital Anxiety and Depression Scale; POMS: Profile of Mood Status; PSQ-III: Medical Outcomes Study Patient Satisfaction Questionnaire-III; PSSCAN: Psychological Screen for Cancer.

The main objective of this thesis is to explore the usefulness, feasibility and effectiveness of routine psychosocial screening using the Dutch "Screening Inventory of Psychosocial Problems" (SIPP) on patients' outcomes in a radiotherapy setting. The SIPP comprises 24 items (see Appendix) and measures four dimensions of psychosocial distress: physical complaints ( 7 items), psychological complaints (10 items), social problems (4 items), and sexual problems (3 items). The specific research questions of the thesis are:

- What is the reliability and validity of the SIPP to identify potential psychosocial problems in cancer patients?

- To what extent is using the SIPP considered useful and feasible by patients and radiotherapists?

- What is the effectiveness of using the SIPP on:

- The percentages of patients referred to psychosocial caregivers by their radiotherapists?

- Patients' satisfaction with radiotherapist-patient communication? 
- The extent of psychological distress and health-related quality of life in the short and the long term?

In addition, we studied the validity and usefulness of the Dutch version of the Mental Adjustment to Cancer scale (MAC-scale) for validation purposes of the SIPP. Furthermore, we wanted to get insight in the way cancer patients receiving RT respond to their illness. 


\section{Chapter 2}

\section{Psychometric properties of the Screening Inventory of Psychosocial Problems (SIPP) in Dutch cancer patients treated with radiotherapy}

This chapter was published as:

A. P. B. M. Braeken, L. Lechner, R. M. A. Houben, F. C. J. M. van Gils,

G. I. J. M. Kempen (2011)

Psychometric properties of the Screening Inventory of Psychosocial Problems (SIPP) in Dutch cancer patients treated with radiotherapy

European Journal of Cancer Care, 20(3), pp. 305-314 


\section{Abstract}

Background: The Screening Inventory of Psychosocial Problems (SIPP) was developed to assess psychosocial distress in Dutch cancer patients. It is short, easily completed by patients and quickly interpreted by medical staff.

Methods: In this study, we investigated the psychometric properties of the SIPP in 289 Dutch cancer patients treated with radiotherapy. The SIPP was administered alongside the Hospital Anxiety and Depression Scale (HADS) and the Mental Adjustment to Cancer (MAC) scale. In-depth structured clinical interviews were also conducted with 76 patients.

Results: Results indicate that the psychometric properties of the SIPP are promising with respect to its reliability, construct validity as evaluated with confirmatory factor analysis, and convergent and divergent validity. Receiver operating characteristics analysis showed that the SIPP successfully differentiates between patients known to have symptoms of distress and those who do not.

Conclusion: The SIPP is therefore a reliable and valid instrument for identifying distress in cancer patients. It differs from previously developed instruments in that it measures different domains of distress in only a few minutes, and provides opportunity for patients to indicate whether they would like to discuss identified problem areas. Due to its convenient format, the SIPP may easily be used to assess psychosocial distress in cancer patients as a routine part of the clinical consultation. 


\section{Introduction}

Cancer often leads to psychosocial distress involving depressive symptoms and anxiety. ${ }^{25,29,31}$ Previous studies have shown that the prevalence of distress among cancer patients varies from 5 to $53 \%$ depending on the study population and the method of assessment used to identify distress. ${ }^{29,31,34,52,69-77}$ Different factors may be associated with psychosocial distress. Some medical factors such as tumour type and socio-demographic characteristics such as lower age have been associated with increased psychosocial distress in some studies. ${ }^{52,69,75,78,79}$ Certain mental adjustment responses to cancer have also been associated with distress, with negative adjustment responses being related to an increased danger of distress in cancer patients. ${ }^{69,79-81}$ Patients commencing radiotherapy treatment are likely to experience additional stressors such as anxiety or fear about the treatment ${ }^{78}$, and it is acknowledged that a lack of emotional support may lead to higher levels of psychosocial distress in such patients. ${ }^{82,83}$

It is well known that medical staff often fail to detect psychosocial distress in their patients, and it is consequently undertreated. ${ }^{29,34,84}$ Distress may influence several health and treatment related outcomes however, such as adherence to therapy 46,76 and quality of life. ${ }^{38,46,76,85}$

In order to detect and treat psychosocial distress in cancer patients, effective screening is an important component of $\mathrm{care}^{76}$ and the use of screening instruments may prevent the underdiagnosis of this important patient problem 71,84 . The effective management of sub-clinical psychosocial distress may prevent further deterioration in the patient and the development of possible psychiatric disorders. ${ }^{25}$ Using a screening instrument may also facilitate better communication between patients and medical staff. ${ }^{34,51,52}$

The Screening Inventory of Psychosocial Problems (SIPP) is a selfadministered questionnaire that strives to systematically identify psychosocial distress in cancer patients. This questionnaire was originally developed in the Netherlands by Pruyn et al in 1997 when it was originally called the 'integral checklist' and contained 51 items. ${ }^{86}$ The integral checklist was revised into a shorter form by Versloot ${ }^{87}$ and tested in several Dutch pilot-studies. ${ }^{88,89}$ The checklist was subsequently renamed the "Screening Inventory of Psychosocial Problems" (SIPP) and the current version now contains 24 items.

Although a number of well-validated psychosocial screening instruments including the Hospital Anxiety and Depression Scale (HADS) ${ }^{90}$, the Brief Symptom Inventory (BSI) ${ }^{27}$ and the General Health Questionnaire (GHQ) ${ }^{91}$ already exist, these instruments require considerable time and effort to complete, score, and interpret; and this may prevent their systematic use in clinical oncology settings. ${ }^{71,92,93}$ For example, 8 items in the HADS require reversed scoring after which depression and anxiety subscale totals cannot be compounded. Compared to these instruments, the much shorter Distress Thermometer ${ }^{43}$ is easier to administer and to score, but such a rough single item visual analogue scale may 
not offer sufficient accuracy or reliability when ascertaining psychosocial distress $^{94}$, and it cannot differentiate between different domains of distress or necessarily facilitate improved communication between medical staff and patients. Furthermore, most instruments such as the HADS only focus on a single element of psychosocial distress such as depressive symptoms and/or anxiety ${ }^{71,76}$, and are not typically developed specifically for cancer patients. Feasible screening instruments within oncology should meet all the following criteria: be brief, fit onto one page ${ }^{89}$, be easy to complete in order to avoid further distress by excessive questioning ${ }^{95}$, be easy to score and interpret by medical staff96; and be specifically developed for use in cancer patients. They should also facilitate better communication between medical staff and patients about psychosocial distress. ${ }^{34,52}$

Although it contains 24 items, the SIPP is a short instrument and is therefore easy for cancer patients to complete. It takes on average, only three minutes to complete since the patient has only to respond to the 24 items with a tick to indicate "yes", "sometimes" or "no" in relation to their presence. The scoring method enables clinicians to identify the presence and the severity of psychosocial distress at a single glance, and unlike other tools, the SIPP was specifically developed for use in cancer patient populations to assess the multidimensional concept of distress in a few minutes.

Although the SIPP is being used as a screening inventory in several hospitals and radiation departments within the Netherlands, the psychometric properties of the tool have not been well established in a large-scale study until now. Thus, the aim of the study reported in this paper was to examine the reliability of the SIPP, its construct validity (factor structure), and convergent validity against a range of previously published and validated tools. Its divergent validity was also assessed by comparing scores with positive and negative adjustment responses, patient age, sex, and tumour site. In addition, the sensitivity and specificity of the SIPP were tested using structured clinical interviews with 76 patients.

\section{Methods}

\section{Patients and research design}

Patients were eligible for inclusion in the study if they received radiotherapy treatment for their cancer at the MAASTRO radiation-oncology clinic in the southern Dutch city of Maastricht, and met the following inclusion criteria: diagnosis of lung, breast, prostate or gynaecological cancer, sufficient comprehension of the Dutch language, aged 18 years or over, and able to provide written informed consent for inclusion in the study.

A total of 889 patients treated between January 2006 and March 2008 were identified as potentially eligible for inclusion in the study, of which 289 agreed 
to participate (response 32.5\%). Ethical approval for the study was obtained from MAASTRO's medical ethics committee, one condition of which was that patients were not included in more than one clinical trial at any given time. It should be noted that several clinical intervention studies were ongoing during the time-span for this study, and this may account for the apparent low response rate.

The study used a design with several measurements to explore the psychometric properties of the SIPP. The SIPP was administered routinely to all patients at the clinic immediately before their first consultation with the radiotherapist. The radiotherapist received the completed questionnaire and could use this to monitor for obvious signs of patient reported psychosocial distress. At this consultation, patients were asked by the radiotherapist to participate in the study and those agreeing to do so received a package containing information about the study, an informed consent form, and several questionnaires including the SIPP. Patients completed these questionnaires at home and returned them by stamped addressed envelope to the clinic. Since the SIPP was assessed twice, as part of the routine clerking procedure for all patients prior to their first consultation and approximately three days later, these data were used for testretest analysis.

For additional analysis, 94 of the 289 patients were approached by telephone and asked to participate in a face to face interview. Seventy-six patients (45 with prostate cancer, 10 with gynaecological cancer, 16 with lung cancer and 5 with breast cancer) were subsequently interviewed at the MAASTRO Clinic (response rate $81 \%$ ) in the first or second week of their radiotherapy treatment. Patient selection was based on the availability of the interviewer and the patient without regard to other characteristics in a process which is usually described as convenience sampling. The trained administrator who conducted the structured clinical interviews had no knowledge of the results of the patients' previously reported psychosocial distress measurements using the SIPP or comparable tools used in the study.

\section{Measures}

The Screening Inventory of Psychosocial Problems

The Screening Inventory of Psychosocial Problems (SIPP) comprises 24 items (see Appendix A). The items are rated on a three-point scale of " 0 " (No) to " 2 " (Yes). The SIPP measures four dimensions of psychosocial distress: physical complaints (7 items, score-range $0-14$ ), psychological complaints (10 items, score-range $0-20$ ), and social problems (4 items, score-range $0-8$ ). The tool also contains two items on sexual problems with one item to verify whether the patient would like help or advice for their sexual problems (total 3 items, score- 
range 0-6 with the option "Not Applicable"). Higher scores indicate poorer function in each of the items.

\section{The Hospital Anxiety and Depression Scale}

The Hospital Anxiety and Depression Scale (HADS) was developed to identify symptoms of anxiety, depressive symptoms and psychological distress in medically ill patients. Questions about physical symptoms are not included ${ }^{97}$. The HADS is a valid 97,98 and widely used instrument in oncology settings 25,43,71,75,77,84,93,98-103 although not specifically designed for these settings. The HADS contains 14 items with four possible answers which result in a score ranging from 0 to 21 on both the anxiety (7 items) and depression (7 items) subscales. The total score of the HADS (score-range 0-42) can be used as a global measure of psychological distress ${ }^{101}$ with higher scores indicating a higher level of anxiety or depression.

\section{The Mental Adjustment to Cancer scale}

The Mental Adjustment to Cancer scale (MAC-scale) was developed to measure mental adjustment of patients after a diagnosis of cancer. ${ }^{80,104}$ It is a widely used questionnaire for cancer patients $77,81,105-107$ and comprises a 40 -item self-rating questionnaire for which there are two scoring methods. The first method includes 5 separate subscales: fighting spirit, anxious preoccupation, fatalism, avoidance, and helplessness/hopelessness. The second method, which we used for our analysis, combines and rearranges different subscales into the summary positive adjustment scale (positive adjustment response) and the summary negative adjustment sale (negative adjustment response). ${ }^{104}$ The summary positive adjustment scale contains 17 items (score range 17-68) and the summary negative adjustment scale contains 16 items (score range 16-64). Higher scores on both subscales indicate a better adjustment response to the cancer diagnosis. The psychometric properties of the Dutch version of the Mental Adjustment to Cancer (MAC) scale in Dutch cancer patients have been reported elsewhere. ${ }^{108}$

\section{The Structured Clinical Interview}

The structured clinical interview for DSM IV (SCID-I) is a semi-structured interview used to identify psychiatric disorders in patients. ${ }^{109}$ The SCID-I is widely used in clinical research and is considered to be the current research standard. ${ }^{99,102}$ In this study, the SCID-I was used to identify anxiety (e.g. panic disor-

der) and mood disorders (e.g. major depression) because these are the most common distress-related problems in cancer patients.

\section{Sociodemographic and medical data}

The patients reported their age, sex, marital status and level of education. Medical data (i.e. tumour site) were extracted from the medical records of the patient. 


\section{Statistical analysis}

The first three subscales (physical, psychological and social) were used for analysis. The subscale regarding sexual problems was not included in this study because of the amount of missing data. Of all the patients, $24.6 \%$ had at least one of three items of this subscale missing and another $10.4 \%$ did not answer any of the items leading us to exclude the subscale from all other analyses.

The reliability of the SIPP subscales was determined from internal consistency (Cronbach's alpha) and the intra-class correlation coefficient (ICC, method one-way random). In order to analyse the construct validity of the SIPP, a confirmatory factor analysis was executed for each of the three remaining subscales, as well as item-rest correlation analysis. For all other analyses, nonparametric tests were used because the data were not normally distributed and/or, the distribution of patients across the tumour groups was skewed. Convergent validity of the SIPP was assessed using Spearman rank correlations between the SIPP and the HADS. Divergent validity was assessed by examining associations between the SIPP and positive and negative adjustment responses as measured with the MAC-scale (Spearman rank correlation) and patient characteristics using the Kruskal Wallis (>2 group) and/or the Mann Whitney U test (for pair-wise comparisons). The relationship between the SIPP scores and clinical or sub-clinical symptoms identified during structured clinical interviews using SCID-I was evaluated with receiver operating characteristics (ROC) analysis. The analysis generates a curve, and the area under the curve (AUC) represents the discriminatory ability of a test across a full range of scores. ${ }^{110}$ An AUC of one represents the perfect discriminatory ability of a test whereas an AUC of 0.50 represents no discriminatory ability..$^{93}$ In addition to ROC analysis, sensitivity and specificity were calculated at various cut-off scores.

If less than $10 \%$ of the items were missing from the subscales in any of the self-report questionnaire measures, these were substituted by means of a corrected item mean substitution. ${ }^{111}$ This was only done for the analysis regarding convergent and divergent validity, and for sensitivity and specificity. For all other analyses, the raw data were used.

All data analysis except confirmatory factor analysis were performed using SPSS version 15.0 whilst the confirmatory factor analysis was performed using LISREL 8.71.112 The level of statistical significance was set at 0.05 (two-tailed) and for post hoc pair-wise comparisons; a two-tailed Holm-Bonferroni correction was applied. 


\section{Results}

\section{Patient characteristics}

Most of the 289 patients were male (86.2\%), married or living with a partner (84.8\%), had an elementary level of education (43.9\%), and had prostate cancer $(70.5 \%)$. The mean age was 67.8 years $(S D=8.9)$ years. Sociodemographic and medical characteristics of the patients are shown in Table 1 . With respect to non-respondents $(n=600)$, most were male $(75.5 \%)$, had prostate cancer $(55 \%)$ and a mean age of 67.8 years $(S D=10.2)$ years. Significant differences were found between respondents and non-respondents regarding sex and tumour site, but no significant difference was found regarding age.

Table 1 Patient characteristics $(n=289)$

\begin{tabular}{|c|c|c|c|}
\hline Variables & & $\mathrm{n}$ & $\%$ \\
\hline \multicolumn{4}{|l|}{ Age (years) } \\
\hline Mean (SD) & $67.8(8.9)$ & & \\
\hline Median & 68.3 & & \\
\hline Range & $23-91$ & & \\
\hline \multicolumn{4}{|l|}{ Sex } \\
\hline Male & & 249 & 86.2 \\
\hline \multicolumn{4}{|l|}{ Marital status } \\
\hline Married/ living together & & 245 & 84.8 \\
\hline \multicolumn{4}{|l|}{ Educational level } \\
\hline Elementary level of education & & 127 & 43.9 \\
\hline High school level of education & & 93 & 32.2 \\
\hline Higher Education/University & & 67 & 23.1 \\
\hline Unknown & & 2 & 0.8 \\
\hline \multicolumn{4}{|l|}{ Diagnosis } \\
\hline Prostate & & 204 & 70.6 \\
\hline Lung & & 58 & 20.1 \\
\hline Breast & & 8 & 2.8 \\
\hline Gynaecological & & 19 & 6.5 \\
\hline \multicolumn{4}{|l|}{ WHO-performance scale } \\
\hline 0 & & 194 & 67.1 \\
\hline 1 & & 44 & 15.2 \\
\hline 2 & & 12 & 4.2 \\
\hline 3 & & 1 & 0.4 \\
\hline Unknown & & 38 & 13.1 \\
\hline
\end{tabular}

*The World Health Organization (WHO) performance scale is used to quantify the functional status of cancer patients.

Higher scores indicate poorer functional status. 
Fifteen of the 76 patients (19.7\%) who were interviewed using the SCID-I were diagnosed with clinical or sub-clinical symptoms of distress. The interview identified nine patients with clinical symptoms of whom four had an adjustment disorder and five a major depressive disorder. The interview identified six patients with sub-clinical symptoms (i.e. those symptoms that do not fulfil standard diagnostic criteria for the diagnosis of an anxiety or mood disorder) including three patients with minor depression, two with symptoms of anxiety, and one with symptoms of both anxiety and depression.

\section{Psychometric tests and scale statistics}

\section{Reliability}

Internal consistency values for the three SIPP subscales evaluated were 0.79 or above, except for the social problems subscale $(\alpha=0.51)$ (Table 2). The internal consistency coefficient for the total SIPP was 0.91 . For the physical complaints, psychological complaints and social problems subscales, the stability (testretest) of patients' responses over three days yielded an intra-class correlation coefficient (ICC) of $0.86(n=214), 0.88(n=206)$ and $0.74(n=213)$, respectively. The total score of the SIPP yielded an ICC of $0.91(n=174)$.

Table 2 Descriptive data and Cronbach's alpha of the SIPP

\begin{tabular}{lllll}
\hline $\begin{array}{l}\text { Questionnaires (number of items, } \\
\text { theoretical score range) }\end{array}$ & Mean & SD & Min-Max & $\begin{array}{l}\text { Cronbach's } \\
\text { alpha }\end{array}$ \\
\hline SIPP & & & & \\
$\quad$ Physical complaints (7, 0-14) & 2.93 & 3.00 & $0-13$ & 0.79 \\
$\quad$ Psychological complaints (10,0-20) & 4.41 & 4.75 & $0-20$ & 0.91 \\
Social problems $(4,0-8)$ & 0.79 & 1.25 & $0-6$ & 0.51 \\
Total score $(21,0-42)$ & 8.06 & 7.58 & $0-36$ & 0.91 \\
\hline
\end{tabular}

${ }^{\text {a }} n$ varies from 251-284 patients

SIPP, Screening Inventory of Psychosocial Problems

\section{Construct validity}

A confirmatory factor analysis was performed through LISREL. Polychoric correlations between each item were used as input, and an unweighted least squares estimation method was chosen due to the ordinal property of the SIPP. Results showed that a three-factor model fitted the data very well. The model had a non-normed fit index of 0.99 and a chi-square of 303.7 ( $\mathrm{df}=186 ; p<0.001$ ).

Six items of the physical complaints subscale correlated more strongly with their own subscale than with the psychological complaints and social problems subscales. All items of the psychological complaints subscale were more strongly correlated with their own subscale than with the other two subscales. Three 
items of the social problems subscale were more strongly correlated with the psychological complaints subscale than with their own subscale. Given the volume of psychometric results obtained from the analysis, the inter-item correlations are not reported in detail in this paper, but can be provided on request by contacting the corresponding author.

\section{Convergent validity}

Table 3 presents correlations between the SIPP and the HADS. The highest correlation with the SIPP was found between the total score of the HADS and the total score of the SIPP $(\mathrm{r}=0.78, p<0.001)$. The lowest correlation was found between the social problems subscale of the SIPP and the HADS depression subscale $(\mathrm{r}=0.43, p<0.001)$.

Table 3 Spearman correlations between the SIPP, HADS and MAC-scales

\begin{tabular}{llllll}
\hline & $\begin{array}{l}\text { HADS- } \\
\text { Anxiety }\end{array}$ & $\begin{array}{l}\text { HADS- } \\
\text { Depression }\end{array}$ & $\begin{array}{l}\text { HADS-total } \\
\text { score }\end{array}$ & $\begin{array}{l}\text { MAC- Summary } \\
\text { Positive } \\
\text { Adjustment }\end{array}$ & $\begin{array}{l}\text { MAC-Summary } \\
\text { Negative } \\
\text { Adjustment }\end{array}$ \\
\hline $\begin{array}{l}\text { SIPP } \\
\quad \text { Physical complaints }\end{array}$ & $\mathbf{0 . 4 9}$ & $\mathbf{0 . 6 0}$ & $\mathbf{0 . 5 9}$ & $\mathbf{- 0 . 1 4}$ & $\mathbf{0 . 4 0}$ \\
$\quad \begin{array}{l}\text { Psychological } \\
\text { complaints }\end{array}$ & $\mathbf{0 . 7 6}$ & $\mathbf{0 . 6 4}$ & $\mathbf{0 . 7 6}$ & $\mathbf{- 0 . 2 0}$ & $\mathbf{0 . 4 9}$ \\
$\quad$ & & & & & \\
$\quad \begin{array}{l}\text { Social problems } \\
\text { Total score }\end{array}$ & $\mathbf{0 . 4 6}$ & $\mathbf{0 . 4 3}$ & $\mathbf{0 . 4 8}$ & -0.12 & $\mathbf{0 . 3 5}$ \\
\hline
\end{tabular}

SIPP, Screening Inventory of Psychosocial Problems; HADS, Hospital Anxiety and Depression Scale; MAC-scale, Mental Adjustment to Cancer Scale.

A Holm-Bonferroni correction was applied and all correlations in bold were significant.

\section{Divergent Validity}

In relation to the adjustment responses to cancer, the SIPP correlated positively with the negative adjustment response and negatively with the positive adjustment response with the exception of the social problems subscale (Table 3). When we looked at the age of the patients, we found that patients younger than 65 years scored higher in the physical (median $=3.00, p<0.01$ ) and psychological complaints subscales (median $=4.00, p<0.05$ ), and the total score of the SIPP (median=8.00, $p<0.01$ ) than patients aged 65 years or older (medians 2.00, 2.00, and 5.00, respectively). Women scored significantly higher on physical complaints (median $=5.00, p<0.001$ ) and psychological complaints subscales (median=6.00, $p<0.001$ ), and on the total score of the SIPP (median=12.00, $p<0.001$ ) than men (medians 2.00, 3.00 and 5.21, respectively).

Patients with prostate cancer reported lower scores on the physical complaints subscale (median=1.00) than patients with lung cancer (median=4.00, $p<$ .001 ), breast cancer (median $=4.00, p<0.01$ ) and gynaecological tumours (median=6.67, $p<0.001$ ). Patients with prostate cancer also reported fewer psycho- 
logical complaints (median=2.62) than patients with lung cancer (median=5.00, $p<.01$ ), breast cancer (median $=5.50, p<0.05$ ) or gynaecological tumours (median $=9.00, p<0.05$ ). They also reported less psychosocial distress on the total scores of the SIPP (median=5.00) than patients with lung cancer (median=10.00, $p<.001$ ), breast cancer (median $=8.50, p<0.01$ ) or gynaecological tumours (me$\operatorname{dian}=13.00, p<0.01$ ).

Receiver Operating Characteristics (ROC) Analysis

The validity of the physical and psychological complaints subscales in the SIPP was established with the SCID-I diagnoses for anxiety and mood disorders. The AUC for clinical symptoms (highly distressed) and for sub-clinical symptoms (moderately distress) was 0.92 (CI $0.85,0.98$ ) and 0.83 (CI $0.73,0.92$ ) respectively when the SIPP physical complaints subscale was used. The AUC for clinical symptoms was 0.98 (CI 0.94, 1.01) and the AUC for sub-clinical symptoms was 0.93 (CI 0.86, 0.99) when the SIPP psychological problems subscale was used. Table 4 summarizes the sensitivity and specificity values for various cut-off scores on physical and psychological complaints subscales for both clinical and sub-clinical symptoms of distress as assessed with the SCID-I. 
Table 4 Sensitivity and specificity of physical and psychological complaints of the SIPP

\begin{tabular}{|c|c|c|c|c|c|}
\hline $\begin{array}{l}\text { Cut-off points SIPP } \\
\text { for clinical distress } \\
\text { symptoms }\end{array}$ & $\begin{array}{l}\text { Sensitivity } \\
(\%)\end{array}$ & $\begin{array}{l}\text { Specificity } \\
(\%)\end{array}$ & $\begin{array}{l}\text { SCID-I } \\
\text { Cut-off points SIPP } \\
\text { for subclinical dis- } \\
\text { tress symptoms }\end{array}$ & $\begin{array}{l}\text { Sensitivity } \\
(\%)\end{array}$ & $\begin{array}{l}\text { Specificity } \\
(\%)\end{array}$ \\
\hline \multicolumn{6}{|l|}{ Physical complaints } \\
\hline $0 / 1$ & 100.0 & 20.3 & $0 / 1$ & 100.0 & 22.4 \\
\hline $1 / 2$ & 100.0 & 35.9 & $1 / 2$ & 100.0 & 39.7 \\
\hline $2 / 3$ & 100.0 & 50.0 & $2 / 3$ & 100.0 & 55.2 \\
\hline $3 / 4$ & 100.0 & 62.5 & $3 / 4$ & 84.6 & 65.5 \\
\hline $4 / 5$ & 100.0 & 71.9 & $4 / 5$ & 76.9 & 74.1 \\
\hline $5 / 6$ & 100.0 & 79.7 & $5 / 6$ & 69.2 & 81.0 \\
\hline $6 / 7$ & 85.7 & 87.5 & $6 / 7$ & 46.2 & 86.2 \\
\hline $7 / 8$ & 57.1 & 90.6 & $7 / 8$ & 30.8 & 89.7 \\
\hline $8 / 9$ & 42.9 & 92.2 & $8 / 9$ & 23.1 & 91.4 \\
\hline $9 / 10$ & 28.6 & 93.7 & $9 / 10$ & 15.4 & 93.1 \\
\hline $10 / 11$ & 28.6 & 95.3 & $10 / 11$ & 15.4 & 94.8 \\
\hline $11 / 12$ & 14.3 & 98.4 & $11 / 12$ & 7.7 & 98.3 \\
\hline \multicolumn{6}{|l|}{$\begin{array}{l}\text { Psychological } \\
\text { complaints }\end{array}$} \\
\hline $0 / 1$ & 100.0 & 15.6 & $0 / 1$ & 100.0 & 17.2 \\
\hline $1 / 2$ & 100.0 & 31.2 & $1 / 2$ & 100.0 & 34.5 \\
\hline $2 / 3$ & 100.0 & 53.1 & $2 / 3$ & 100.0 & 58.6 \\
\hline $3 / 4$ & 100.0 & 65.6 & $3 / 4$ & 100.0 & 72.4 \\
\hline $4 / 5$ & 100.0 & 71.9 & $4 / 5$ & 84.6 & 75.9 \\
\hline $5 / 6$ & 100.0 & 73.4 & $5 / 6$ & 84.6 & 77.6 \\
\hline $6 / 7$ & 100.0 & 84.4 & $6 / 7$ & 76.9 & 87.9 \\
\hline $7 / 9$ & 100.0 & 85.9 & $7 / 9$ & 69.2 & 87.9 \\
\hline $9 / 10$ & 100.0 & 89.1 & $9 / 10$ & 69.2 & 91.4 \\
\hline $10 / 11$ & 85.7 & 92.2 & $10 / 11$ & 61.5 & 94.8 \\
\hline $11 / 12$ & 85.7 & 96.9 & $11 / 12$ & 53.8 & 98.3 \\
\hline $12 / 13$ & 71.4 & 96.9 & $12 / 13$ & 46.2 & 98.3 \\
\hline $13 / 15$ & 57.1 & 98.4 & $13 / 15$ & 38.5 & 100.0 \\
\hline $15 / 18$ & 57.1 & 100.0 & $15 / 18$ & 30.8 & 100.0 \\
\hline $18 / 20$ & 14.3 & 100.0 & $18 / 20$ & 7.7 & 100.0 \\
\hline
\end{tabular}

SIPP, Screening Inventory of Psychosocial Problems; SCID, Structured Clinical interview.

Suggested cut-off scores are in bold according to different cut-off points in detecting clinical and subclinical symptoms of psychosocial distress.

\section{Discussion}

The study aimed to investigate the psychometric properties of the SIPP and found that the internal consistency values of the subscales and the scale as a whole were high. The only exception concerned the social problems subscale. This could be partly explained by the items of the subscale which measure different constructs such as inadequate social support and financial problems. 
Furthermore, it comprises only four items. The SIPP showed an acceptable level of test-retest reliability over a short time period for all subscales. The results also show that the SIPP has good construct validity as shown by confirmatory factor analysis and by inter-item correlations.

The reported correlations between the SIPP and the HADS suggest a good level of convergent validity. There was a consistent pattern of moderate to high correlations between the SIPP subscales and those of the HADS. The SIPP contains different subscales and measures a variety of symptoms of distress such as physical complaints and social problems in comparison to the HADS, but as expected, the psychological complaints subscale correlated more strongly with the HADS than these other SIPP subscales. Divergent validity was supported by moderate correlations between the SIPP and adjustment responses to cancer, which accords with the literature in that positive adjustment responses to cancer tend to be related to lower distress levels $69,80,81$ whilst negative adjustment responses are related to more distress. ${ }^{69,79-81}$ In addition, divergent validity was also supported by the findings that younger patients and women reported more distress on the physical and psychological complaints subscales and the total score of the SIPP. These findings are consistent with several other studies. $29,75,76,78,113,114$ In this study, patients with prostate cancer reported less psychosocial distress than the other patient groups and in general, these patients reported relatively fewer complaints related to their illness or its treatment, and tended to have a better prognosis than other patient groups and show better functioning 114.

Finally, with regard to the ROC analysis, the AUC scores indicated that the SIPP discriminated between the presence or absence of distress symptoms with a good level of accuracy. This is important as the consequences of false-positive screening of clinical symptoms of distress may have practical and financial implications. ${ }^{71,106}$ In addition, the consequences of failing to accurately identify clinical signs of distress (false-negative screening) may have significant clinical and personal impact for patients. ${ }^{106}$ Therefore, we suggest cut-off scores of 5/6 for physical complaints and $9 / 10$ for psychological complaints with respect to clinical symptoms, resulting in $100 \%$ sensitivity and a lower specificity $79.7 \%$ and $89.2 \%$, respectively) given that the consequences of false-negative screening for sub-clinical symptoms are less significant than for clinical symptoms. Therefore, with regard to sub-clinical symptoms, we suggest the best balance between sensitivity and specificity. More specifically, a cut-off point of $4 / 5$ for physical complaints, and a cut-off score of $5 / 6$ for psychological complaints with respect to sub-clinical symptoms gave a sensitivity of $76.9 \%$ and $84.6 \%$, and a specificity of $74.1 \%$ and $77.6 \%$, respectively.

Our study does have some limitations. The findings cannot be generalised to all cancer patients, since our study population was rather homogeneous and consisted primarily (although not exclusively) of prostate cancer patients receiving radiotherapy. Furthermore, the low rate of participation should be con- 
sidered as a limitation which might potentially limit the generalisability of its findings. Patterns of selective response and attrition may have led to an underestimation of reported associations, although the effect of attrition may be more disturbing for descriptive results than for measures of association. ${ }^{115}$ Furthermore, the rather low reported rate of participation might be an underestimation because we have no knowledge how many of the 889 patients passing through the clinic whilst the study was being conducted actually met the inclusion criteria. Neither do we have information on why certain participants were not asked to participate in the study by the radiotherapist. We know however, that many patients would have been enrolled on one or other of the clinical intervention studies taking place at the same time as ours, and this precluded them from being included in our psychosocial study. We do not know whether clinician or patient preference dictated this choice, but in spite of these limitations, the data provide a good indication of the psychometric quality of the SIPP when used among specific cancer patient populations including prostate, lung, breast and gynaecology patients. It is recommended however, that the study be replicated elsewhere in order to ascertain the usefulness of the SIPP in other cancer populations.

We also excluded data relating to the sexual problems subscale from our analysis because of the large amount of missing data. This suggests that patients may not wish to commit such information to paper or consider it inappropriate to the assessment of their psychosocial state, but they may simply have preferred to discuss such issues directly with their physician. Further research into this aspect of the SIPP is therefore required.

We conclude that there is sufficient psychometric evidence to support the use of the SIPP as a useful screening instrument for psychosocial distress in cancer patients. The SIPP differs from other instruments in that it measures the multidimensional concept of distress (physical, psychological, social, financial, and sexual) in only a couple of minutes. Furthermore, the SIPP is specifically developed for use in cancer patients, is easy to score, and is quickly interpreted by medical staff. The score pattern enables medical staff to recognise the presence and severity of the patient's psychosocial distress at a single glance, and it also provides referral advice in relation to the patient's self-reported scores (see Appendix A). The convenience of the SIPP increases its usefulness in relation to the routine assessment of patients' psychosocial distress levels in busy clinical outpatient departments, and it can be quickly and easily implemented into such a unit's clinical procedures. Routine use of the SIPP may also improve the systematic evaluation of patients' psychosocial distress levels and their subsequent needs before, during, and after cancer treatment. It may also improve communication between the physician and the patient, and therefore meets another important criterion for an adequate screening instrument. The contribution of the screening tool to improved doctor-patient communication, multi-professional 
team working and referral patterns for psychological support should also be investigated in future studies.

\section{Appendix A}

Having cancer may lead to various complaints.

Please indicate which of the following complaints apply to you.

\begin{tabular}{|c|c|c|c|c|}
\hline & Yes $^{\mathrm{a}}$ & Sometimes $^{\mathrm{a}}$ & $\mathrm{No}^{\mathrm{a}}$ & Not Applicable \\
\hline \multicolumn{5}{|l|}{ Subscale 1} \\
\hline Fatigue & $(17.6)^{\mathrm{b}}$ & $(39.1)^{b}$ & $(41.5)^{b}$ & \\
\hline Sleep disorder & $(15.6)$ & $(27.7)$ & $(54.7)$ & \\
\hline Weight loss & $(9.3)$ & $(5.2)$ & (83.7) & \\
\hline Lack of appetite & $(6.2)$ & $(10.7)$ & $(80.6)$ & \\
\hline Restriction in daily functioning & $(15.2)$ & $(27.3)$ & $(56.4)$ & \\
\hline Dizziness & $(3.5)$ & $(20.1)$ & $(73.7)$ & \\
\hline Pain & $(7.3)$ & $(17.3)$ & $(73.4)$ & \\
\hline \multicolumn{5}{|l|}{ Subscale 2} \\
\hline Worrying & $(14.5)$ & $(49.5)$ & $(34.9)$ & \\
\hline Restlessness & $(10.7)$ & $(36.0)$ & $(52.2)$ & \\
\hline Sense of loneliness & $(6.2)$ & $(13.8)$ & $(78.9)$ & \\
\hline Sense of distress & $(9.7)$ & $(26.3)$ & $(61.5)$ & \\
\hline Sense of loss & $(8.7)$ & $(16.6)$ & $(70.9)$ & \\
\hline Inability to control emotions & $(11.1)$ & $(28.4)$ & $(59.2)$ & \\
\hline Reduced self-confidence & $(6.2)$ & $(19.7)$ & $(72.0)$ & \\
\hline Fear of cancer or treatment & $(16.6)$ & $(31.1)$ & $(50.5)$ & \\
\hline Feeling low & $(5.9)$ & $(27.0)$ & $(65.7)$ & \\
\hline Sense of desperation & $(4.2)$ & $(10.7)$ & $(83.7)$ & \\
\hline \multicolumn{5}{|l|}{ Subscale 3} \\
\hline $\begin{array}{l}\text { Feel uncomfortable discussing } \\
\text { illness with others }\end{array}$ & (5.9) & $(14.9)$ & $(78.9)$ & \\
\hline Lack of social support & $(3.8)$ & $(8.0)$ & $(87.2)$ & \\
\hline Financial problems & $(2.4)$ & $(5.2)$ & $(91.7)$ & \\
\hline $\begin{array}{l}\text { Would you like to discuss } \\
\text { these problems with someone? }\end{array}$ & $(6.6)$ & $(15.9)$ & $(75.1)$ & \\
\hline \multicolumn{5}{|l|}{ Subscale 4} \\
\hline \multicolumn{5}{|l|}{ Intimacy problems with partner } \\
\hline \multicolumn{5}{|l|}{ Less interest in sex } \\
\hline $\begin{array}{l}\text { Would you like to discuss these } \\
\text { problems with someone? }\end{array}$ & & & & \\
\hline
\end{tabular}

aFor computing scores, "Yes" $=2$; "Sometimes" $=1$ and "No" $=0$.

bThe percentages between brackets refer to the prevalence of distress in the current study.

Note, there were some missing items.

Subscale 4 was not assessed in this study. 

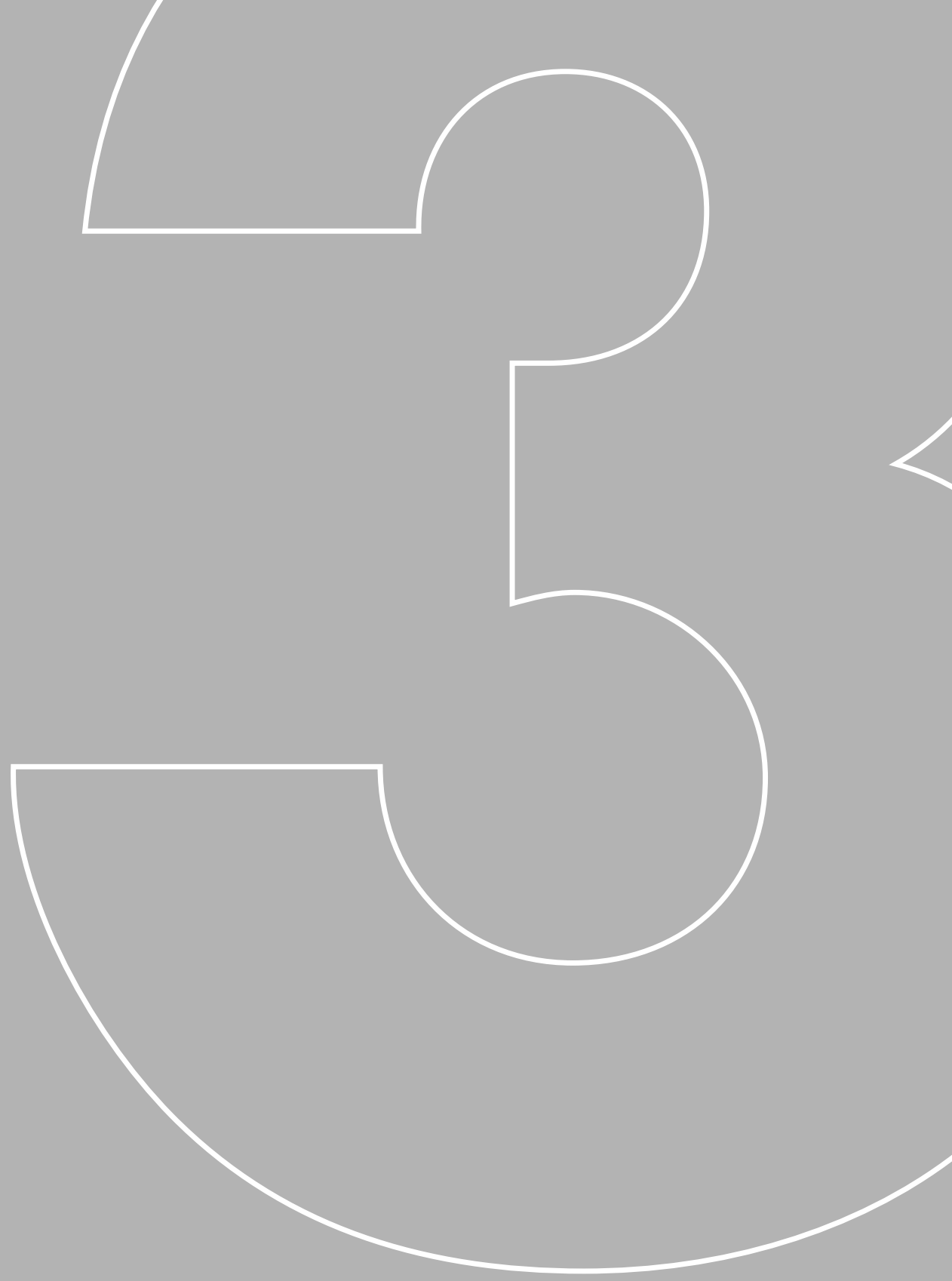


\section{The effectiveness of the Screening Inventory of Psychosocial Problems (SIPP) in cancer patients treated with radiotherapy: design of a cluster randomised controlled trial}

This chapter was published as:

A. P. B. M. Braeken, L. Lechner, F. C. J. M., van Gils, R. M. A. Houben, D. Eekers, T. Ambergen, G. I. J. M. Kempen (2009)

The effectiveness of the Screening Inventory of Psychosocial Problems (SIPP) in cancer patients treated with radiotherapy: design of a cluster randomised controlled trial

BMC Cancer, 9, pp. 177 


\section{Abstract}

Background: The Screening Inventory of Psychosocial Problems (SIPP) is a short, validated self-reported questionnaire to identify psychosocial problems in Dutch cancer patients. The one-page 24-item questionnaire assesses physical complaints, psychological complaints and social and sexual problems. Very little is known about the effects of using the SIPP in consultation settings. Our study aims are to test the hypotheses that using the SIPP (a) may contribute to adequate referral to relevant psychosocial caregivers, (b) should facilitate communication between radiotherapists and cancer patients about psychosocial distress and (c) may prevent underdiagnosis of early symptoms reflecting psychosocial problems. This paper presents the design of a cluster randomised controlled trial (CRCT) evaluating the effectiveness of using the SIPP in cancer patients treated with radiotherapy.

Methods: A CRCT is developed using a Solomon Four Group design (two intervention and two control groups) to evaluate the effects of using the SIPP. Radiotherapists, instead of cancer patients, are randomly allocated to the experimental or control groups. Within these groups, all included cancer patients are randomised into two subgroups: with and without pre-measurement. Self-reported assessments are conducted at four times: a pre-test at baseline before the first consultation and a post-test directly following the first consultation, and three and 12 months after baseline measurement. The primary outcome measures are the number and types of referrals of cancer patients with psychosocial problems to relevant (psychosocial) caregivers. The secondary outcome measures are patients' satisfaction with the radiotherapist-patient communication, psychosocial distress and quality of life. Furthermore, a process evaluation will be carried out. Data of the effect-evaluation will be analysed according to the intention-totreat principle and data regarding the types of referrals to health care providers and patient satisfaction about the with radiotherapists will be analysed by means of descriptive techniques. The process evaluation data will also be analysed by means of descriptive techniques.

Discussion: Using the SIPP may prevent underdiagnosis of early symptoms reflecting psychosocial problems, should facilitate communication between physicians and patients about psychosocial distress and may contribute to adequate referral to relevant (psychosocial) caregivers.

Trial Registration: NCT00859768 


\section{Background}

Cancer is a leading cause of death worldwide, accountable for 7.9 million deaths (around 13\% of all deaths) in $2007 .{ }^{48}$ Cancer and its treatment may lead to psychosocial distress involving symptoms of depression and anxiety, and turmoil in the lives of patients and their families. ${ }^{29,70}$ Patients entering radiotherapy treatment (RT) suffer from specific distress such as fear of RT and its side effects. ${ }^{78}$ The prevalence rates of psychosocial distress in cancer patients as reported in numerous studies vary from 5 to $53 \%$, depending on the study population and the method of distress assessment. 25,27,29,33,38,47,71

Nevertheless, psychosocial distress in cancer patients is often underdiagnosed by medical staff in oncology settings. ${ }^{34,116}$ Recognition and treatment of psychosocial distress in cancer patients is crucial.13,34 Even when psychosocial distress is on a sub-clinical level, it should be managed to prevent further deterioration to psychiatric disorders like major depression or adjustment disorder 25. Psychiatric disorders affect many oncology outcomes, such as compliance with therapy and quality of life. ${ }^{34}$ Effective treatment of psychosocial distress may affect the course of the disease and improve patients' quality of life. ${ }^{13,85}$ Therefore, it is important to identify and treat cancer patients with psychosocial distress at an early stage.

Validated screening instruments are useful tools to recognise psychosocial distress in cancer patients. ${ }^{70}$ Besides recognition of psychosocial distress, selfreported questionnaires have proven to be good instruments to facilitate communication between patients and physicians with respect to psychosocial distress. $^{34,117}$ Although a number of well-validated screening instruments exist, including the Hospital Anxiety and Depression Scale ${ }^{90}$, the Brief Symptom Inventory ${ }^{27}$ and the General Health Questionnaire ${ }^{91}$, these instruments require time and effort in administering and scoring, which may prevent their systematic use in clinical oncology settings. ${ }^{71,92,93}$ Feasible screening instruments should meet the following criteria: be very brief, preferably fitting on one page ${ }^{118}$; be easy to complete (to avoid further distress by excessive questioning) ${ }^{119}$; be easy to score and interpret by medical staff 96; and facilitate communication between physicians and patients about psychosocial distress..$^{34,117}$ The Screening Inventory Psychosocial Problems (SIPP) is a valid and reliable Dutch questionnaire (see methods section). The SIPP was specifically developed for use in Dutch cancer patients and for measuring a variety of distress symptoms. ${ }^{86}$

Although the SIPP is being used in several hospitals and health care facilities in the Netherlands, there is still little known about the effects of using this questionnaire in consultation settings. ${ }^{86}$ Therefore, we performed a study to assess the effectiveness of the SIPP in a clinical oncology setting. This paper presents the design of a cluster randomised controlled trial (CRCT) evaluating the effectiveness of using the SIPP in Dutch patients with the most common cancer types treated with radiotherapy. 


\section{Aims}

Primary aims are to study the effect of the SIPP on the number and types of referrals of cancer patients with psychosocial problems to psychosocial caregivers. Secondary aims are to study the effects of the SIPP on: 1) patients' satisfaction with the radiotherapist-patient communication during first consultation, 2) psychological distress in both the short- and long-term, and 3) quality of life in both the short- and long-term. Additionally, a process evaluation will be performed. The aim of the process evaluation is to gain insight into factors potentially influencing the effectiveness of the SIPP and factors facilitating future implementation of the SIPP in oncology care settings, if the SIPP proves to be effective.

\section{Methods/Design}

\section{Study Design}

The design of this study is a CRCT because it is less prone to contamination bias. ${ }^{120-122}$ In addition, we used a Solomon Four Group design. The Solomon Four Group design is an experimental design with two experimental groups and two control groups (Figure 1). Pre-test measures are used for one experimental and one control group. Following exposure of both experimental groups to the intervention, post-test measures are assessed in all four groups.

\begin{tabular}{llll}
\hline & & Time & \\
\hline & $\begin{array}{l}\text { Period 1 } \\
\text { (pre) }\end{array}$ & $\begin{array}{l}\text { Period 2 } \\
\text { (post) }\end{array}$ \\
\cline { 2 - 4 } Experimental group & 01 & $\mathrm{X}$ & 02 \\
Control group & 03 & $\mathrm{X}$ & 04 \\
Experimental group & & & 05 \\
Control group & & 06 \\
\hline
\end{tabular}

0 , observation; $\mathrm{X}$, intervention

Figure 1 General description of the Solomon Four Group design

\section{Intervention}

The SIPP is a short, valid and reliable 24-item self-reported questionnaire that systematically identifies psychosocial problems in Dutch cancer patients. The psychometric properties of the SIPP were studied in an earlier study. This questionnaire was originally developed in the Netherlands by Pruyn and colleagues in 1997 (then named the Integral Checklist) ${ }^{86}$, and was further adapted in several Dutch pilot studies. ${ }^{118,123}$ The SIPP assesses: 
- physical complaints (seven items, score range 0-14),

- psychological complaints (10 items, score range 0-20),

- $\quad$ social and financial problems (four items, score range 0-8), and

- sexual problems (three items, score range 0-6 with an additional option of "not applicable" (N/A)).

Items are rated on a three-point scale of 0 (no) to 2 (yes). Higher scores indicate poorer functioning.

Before the start of the study, the radiotherapists in the experimental condition are trained in using and interpreting the SIPP. According to the intervention procedure, the patient receives the SIPP at two different time points during their RT period: just before the first consultation with the radiotherapist (one to three weeks before starting RT) and before the last consultation with the radiotherapist at the end of the RT period (five to nine weeks after completing the first SIPP). At both times, the completed SIPP is handed to the radiotherapist at the start of the consultation. The radiotherapist checks the scores of the SIPP to get an overview of potential psychosocial problems and the patient's needs for psychosocial care. Psychosocial problems are discussed with the patient during the consultation. Referral to a psychosocial caregiver at the Institute Verbeeten in Tilburg occurs only with the permission of the patient.

\section{Care as usual}

Patients in the control group receive care as usual. No recent guidelines for the systematic assessment of psychosocial problems in cancer patients exist at the Institute Verbeeten. In the control group, radiotherapists may refer patients to psychosocial caregivers (social workers) at the Institute Verbeeten. However, this occurs according to the radiotherapist's judgment about the presence or absence of psychosocial problems in patients. Referrals to psychosocial caregivers at the Institute Verbeeten will be registered in both the patient's records and by the psychosocial caregivers.

\section{Recruitment of the study population}

Recruitment of cancer patients takes place at the Institute Verbeeten, a radiation oncology department in Tilburg, the Netherlands. Only cancer patients receiving RT are eligible for this study.

The following inclusion criteria are used: 1) patients with the most common cancer types such as lung, prostate, bladder, rectum, breast, cervix, endometrial, skin carcinoma and Non-Hodgkin; 2) patients 18 years of age or older and 3) patients with no metastases. Exclusion criteria are: 1) patients receiving palliative treatment, $\leq 10$ fractions of RT; 2) patients unable to read and speak Dutch and 3) patients unable to complete questionnaires. Patients who meet the inclusion criteria are sent information about the study. Those willing to participate in 
the study are asked to sign a consent form and are only allowed to participate after completing and returning it.

\section{Randomisation and stratification}

To reduce contamination bias, radiotherapists, instead of patients, are randomly allocated to the experimental or control groups. First, the radiotherapists are stratified according to the general percentages of incoming patients they referred to a (psychosocial) caregiver in the period 2006-2007. Within their stratum, they are either randomly assigned to the experimental or to the control condition (see Figure 2). Thus, in both conditions there are equal numbers of radiotherapists who previously referred relatively more and less cancer patients to (psychosocial) caregivers. Patients are linked to their radiotherapist. Therefore, they are randomised to the experimental condition with or without pre-measurement or to the control condition with or without pre-measurement through their radiotherapist (see Figure 2). Patients who visit their radiotherapists in odd weeks are assigned to the experimental/control condition with a pre-measurement and patients who visit their radiotherapists in even weeks are assigned to the experimental/control condition without a pre-measurement. Radiotherapists of the experimental condition are asked not to discuss this study with their colleagues of the control condition. 


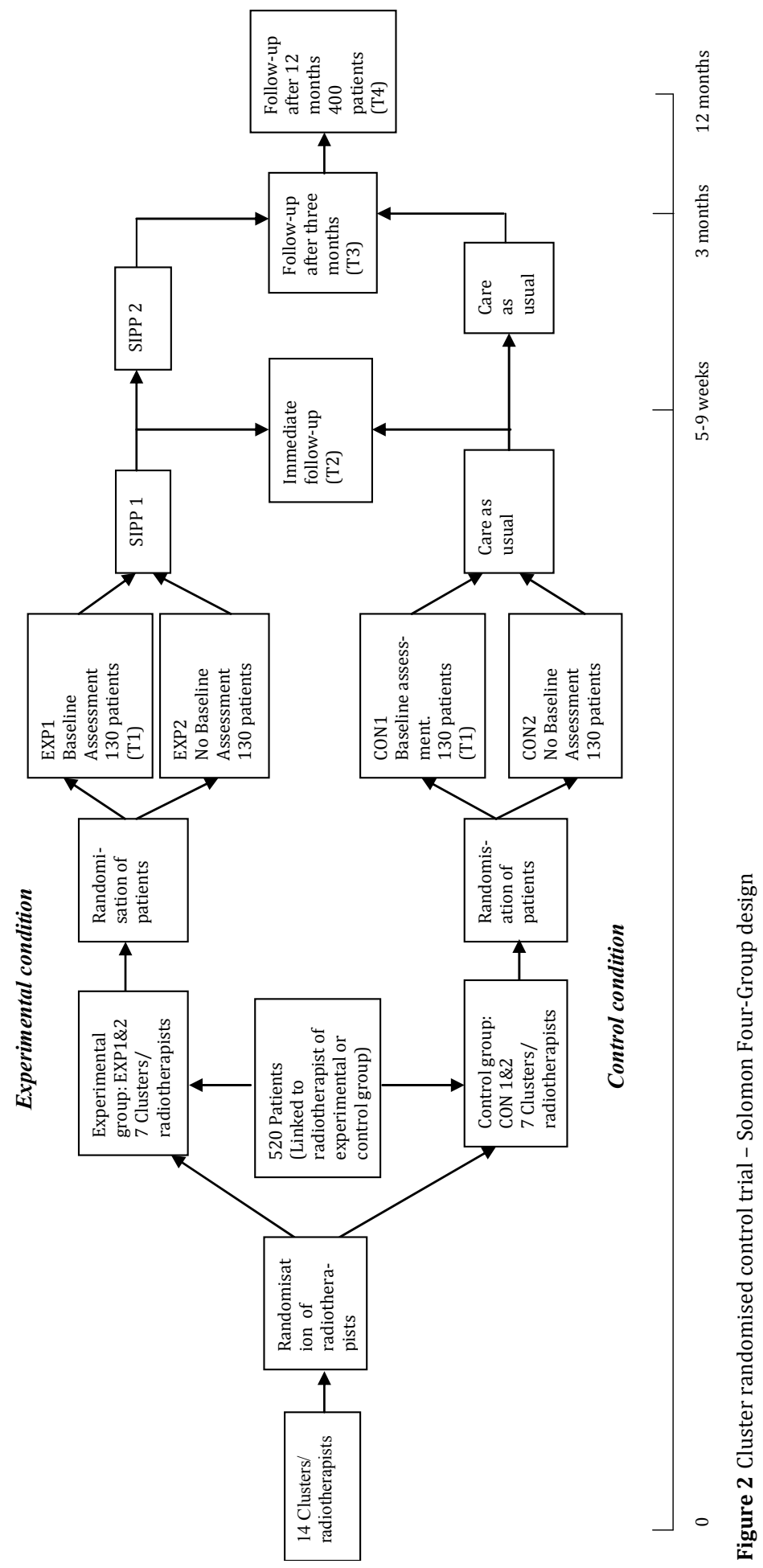




\section{Sample size and power analysis}

This study is powered on the primary outcome measures, i.e. the effect of the SIPP on the number and types of referrals of patients with psychosocial problems to relevant (psychosocial) caregivers. Sample size calculation shows that 92 patients per condition are required to compare the number of referred patients to (psychosocial) caregivers between conditions with a $80 \%$ power and a significance level of 0.05 (one-sided). ${ }^{124}$ This calculation is based on results reported by Pruyn and colleagues. ${ }^{86}$ In their study, the use of the Integral Checklist resulted in more referrals from 2 to $11 \%$. This means that for our study a total of 368 patients have to be included for the analyses.

The consequence of adopting a CRCT is that the outcome for each patient can no longer be assumed as independent . ${ }^{122}$ Such a lack of independency has implications for study size and power .125 The standard sample size has to be inflated to take account of the cluster design by using an estimate of the Intra Cluster Correlation (ICC) 126 121,122,127. For our study, no appropriate ICC was available. Therefore, as in the CRCT of Cumming and colleagues ${ }^{128}$, we assume an ICC of 0.005 as appropriate because the variance of our outcome measurements between clusters can be considered low compared to the variability between the patients within a cluster. To retain power, the standard sample size should be multiplied by the design effect $(d, d=1+\rho(m-1))$, where $m$ is the size of a cluster unit and $\rho$ the ICC. ${ }^{121,129}$ We therefore multiplied our standard sample size with a design effect (d) of 1.13 . With an expected dropout rate of $20 \%$, the corrected sample size for the CRCT is determined at 520 .

It is to be noted that stratification by baseline value of the outcome variable decreases the sample size required. ${ }^{127}$ In our study, radiotherapists are stratified according to the general percentages of incoming patients they referred to a (psychosocial) caregiver. Stratification of this primary outcome variable reduces the between-cluster variability in the primary outcome. In a study by Elridge and colleagues the sample size required decreases of almost $50 \%$ by using stratification of the primary outcome. ${ }^{127}$ To be on the safe side regarding the power of our study we decided not to correct for stratification of the radiotherapists. Recruitment and data collection is anticipated to continue for 24 months.

\section{Measures}

\section{Outcome measures}

Table 1 presents the primary and secondary outcome measurements and time of assessment. 


\section{Primary outcome measures}

Table 1 Primary and secondary outcome measures of the effect evaluation

\begin{tabular}{llllll}
\hline Variables & No. of items & T1 & T2 & T3 & T4 \\
\hline $\begin{array}{l}\text { Primary outcome measures: } \\
\quad \text { Number and types of referrals }\end{array}$ & $8 / \mathrm{NA}$ & - & - & $\mathrm{Q}$ & $\mathrm{Q} / \mathrm{DR}$ \\
$\quad \begin{array}{l}\text { Secondary outcome measures: } \\
\quad \text { Patients' satisfaction with the }\end{array}$ & 5 & - & $\mathrm{Q}$ & - & - \\
$\quad \begin{array}{l}\text { radiotherapist-patient communication } \\
\text { Extent of psychological symptoms: }\end{array}$ & & & & & \\
$\quad$ Symptoms of anxiety and depression (HADS) & 14 & $\mathrm{Q}$ & - & $\mathrm{Q}$ & $\mathrm{Q}$ \\
$\quad$ General psychological distress (GHQ-12) & 12 & $\mathrm{Q}$ & - & $\mathrm{Q}$ & $\mathrm{Q}$ \\
$\quad$ Quality of life (EORTC QLQ-C30) & 30 & $\mathrm{Q}$ & - & $\mathrm{Q}$ & $\mathrm{Q}$ \\
Additional variables: & & & & & \\
$\quad \begin{array}{l}\text { Socio-demographic variables } \\
\quad \text { Medical variables }\end{array}$ & 4 & - & $\mathrm{Q}$ & - & - \\
\hline
\end{tabular}

HADS: Hospital Anxiety and Depression Scale90; GHQ-12: General Health Questionnaire-12 items91; EORTC QLQ-C30: European Organisation for Research and Treatment of Cancer Quality of life Questionnaire 30 items. 130

T1: Before first consultation (baseline, only groups with pre-measurement); T2: After consultation; T3: Three months after baseline; T4: 12 months after baseline; N/A: not applicable; Q: questionnaire; DR: data record.

The primary outcome measures are the number and types of referrals of patients with psychosocial problems to psychosocial workers at the Institute Verbeeten and/or to external health care providers (e.g. psychologists, psychiatrists). The number and types of referrals to (psychosocial) caregivers are measured at three months (T3) and 12 months (T4) after baseline assessment with a self-developed questionnaire by the patient and from registration records of the psychosocial caregivers at the Institute Verbeeten. This questionnaire comprises eight items on whether the patient is referred to a psychosocial caregiver and the types of problems the patient has experienced (e.g. financial, psychological, and sexual). The psychosocial caregivers at the Institute Verbeeten collect data from all referred patients, including types of problems, number of sessions needed and further referral to an external (psychosocial) caregiver.

\section{Secondary outcome measures}

The secondary outcomes are classified in three dimensions: 1) patients' satisfaction with the radiotherapist-patient communication during the first consultation; 2) extent of psychological symptoms at T3 and T4; and 3) patients' quality of life at $\mathrm{T} 3$ and $\mathrm{T} 4$.

Patients' satisfaction with the radiotherapist-patient communication is measured directly after the first consultation with the radiotherapist (T2) by the patient completing a self-developed questionnaire comprising five items. The 
first four items measure whether physical complaints, psychological complaints and social and sexual problems were discussed with the radiotherapist (item range 1 (yes) to 3 (no) plus "not applicable"). The fifth item measures the patient's general opinion (item range 1 (very bad) to 6 (very good)) about the communication with the radiotherapist during the first consultation.

The extent of psychological symptoms is measured with the Hospital Anxiety and Depression Scale (HADS) ${ }^{90}$ and the Goldberg's General Health Questionnaire-12 item version (GHQ-12) ${ }^{91}$ Patients complete these self-reported questionnaires at baseline and at $\mathrm{T} 3$ and $\mathrm{T} 4$.

The HADS is a valid, reliable and useful instrument ${ }^{90}$ that is widely used in studies among cancer patients. ${ }^{131-137}$ It is considered unbiased by coexisting general medical conditions because its questions do not refer to somatic symptoms associated with depression. ${ }^{98}$ The HADS consists of a brief subscale of anxiety and a subscale of depression. Both subscales comprise seven items. Ratings by patients are made on four-point scales $(0-3$, with 3 indicating greatest distress). Higher scores on each subscale indicate a greater presence of problems. ${ }^{90,138,139}$

The GHQ-12 is a well-validated instrument ${ }^{91}$ that has been used in numerous studies among cancer patients.77,131,133,140 It is a standardised measure of psychiatric morbidity across a wide range of patients. ${ }^{139}$ It was intended for use in general practice settings as a screening instrument for detecting verifiable psychiatric morbidity (generally anxiety and depression). It measures "usual state" rather than chronic (long-term) problems. ${ }^{139}$ The GHQ assesses with 12 items whether the patient considers him- or herself better, the same, worse or much worse over the previous four weeks than he/she "usually" is. Those who indicate that their symptoms are unchanged or have decreased receive a score of 0 , while those who report that their symptoms have increased receive a score of 1 . Total scores range from 0 to $12 .{ }^{91}$

Quality of life is measured using the European Organisation for Research and Treatment of Cancer, Quality of life Questionnaire (EORTC QLQ-C30). ${ }^{130}$ The EORTC QLQ-C30 is validated and widely used. ${ }^{126,141-144}$ It is a 30 -item cancerspecific measure that assesses health-related quality of life. The EORTC QLQC30 comprises:

- five functional subscales: physical (five items), role (two items), emotional (four items), cognitive (two items) and social functioning (two items);

- a subscale about global health status and quality of life during the past week (two items);

- three symptom scales: nausea/vomiting (two items), fatigue (three items) and pain (two items); and

- six single items measuring appetite loss, insomnia, constipation, diarrhoea, dyspnoea and financial difficulties due to illness or treatment.

The items on the five functional scales and three symptom scales have fourpoint response choices of 1 (not at all), 2 (a little), 3 (quite a bit) and 4 (very 
much). Categories 3 and 4 are regarded as indicators of clinically-significant symptom levels. Both items of the subscale about global health status and quality of life use a seven-point visual analogue scale (VAS) ranging from 1 (very poor) to 7 (excellent). ${ }^{139}$ Patients completed the self-reported questionnaire EORTC QLQ-C30 at baseline and at T3 and T4.

\section{Additional variables}

Socio-demographic and medical variables are gathered to provide insight into the characteristics of the sample and to interpret the outcomes of the study.

Socio-demographic variables age, gender, marital status and educational level are assessed directly after the first consultation with the radiotherapist (T2).

Medical variables before RT include cancer site, adjuvant chemo-treatment, TNM-classification and Karnofsky Performance Index (KPI). The TNMclassification is a systematic way of describing the size, location and spread of a tumour. Once established, it must remain unchanged in the patient's record because the definitive TNM-classification is determined just before either initiation of treatment or making the decision not to treat. ${ }^{145}$ The KPI emphasises physical performance and dependency. The scale is weighted towards physical dimensions of quality of life rather than social and psychological dimensions. Patients are assigned to categories by a physician. The KPI takes no account of the patient's feelings. The KPI varies from 100 (normal, no complaints, no evidence of disease) to 0 (dead). ${ }^{139}$ Medical data are extracted from patient records.

\section{Process evaluation}

The aim of the process evaluation is to gain insight into factors potentially influencing the effectiveness of using the SIPP and factors facilitating future implementation of the SIPP. Process evaluation data are collected using selfdeveloped questionnaires completed by patients of the intervention groups directly after their first consultation with the radiotherapist and by radiotherapists directly after the first consultation and twice during the total recruitment period of patients. Table 2 provides a short overview of process evaluation measures. The process evaluation outcome measures are:

- nine items on the opinion of radiotherapists about the usefulness of the SIPP in general, e.g. "Did you find discussing the SIPP with the patient useful?" (item range 0 (not useful) to 10 (very useful));

- four items on the opinion of radiotherapists about the usefulness of the SIPP after each consultation with a specific patient, e.g. "How much extra time (in minutes) does discussing the results of the SIPP take?";

opinion of the patients about the usefulness of the SIPP after the first consultation, e.g. "Did you find discussing the SIPP with the radiotherapist useful?" (item range 0 (not useful) to 10 (very useful); and 
- two open questions for suggestions for improvement of the intervention or other remarks.

Table 2 Outcome measures of the process evaluation

\begin{tabular}{|c|c|c|c|c|c|}
\hline Variables & No. of items & $\mathrm{T} 1$ & $\mathrm{~T} 2$ & $\mathrm{~T} 3$ & $\mathrm{~T} 4$ \\
\hline $\begin{array}{l}\text { Radiotherapists' opinion about the } \\
\text { usefulness of the SIPP in general }\end{array}$ & 9 & - & - & - & $\mathrm{Q}$ \\
\hline $\begin{array}{l}\text { Radiotherapists' opinion about the } \\
\text { usefulness of the SIPP after first consultation }\end{array}$ & 4 & - & $\mathrm{Q}$ & - & - \\
\hline $\begin{array}{l}\text { Radiotherapists' suggestions for impro- } \\
\text { vement of the intervention or other remarks }\end{array}$ & 2 & - & - & - & $\mathrm{Q}$ \\
\hline $\begin{array}{l}\text { Patients' opinion about the usefulness of the } \\
\text { SIPP after first consultation }\end{array}$ & 3 & - & Q & - & - \\
\hline $\begin{array}{l}\text { Patients' suggestions for improvement of the } \\
\text { intervention or other remarks }\end{array}$ & 2 & - & Q & - & - \\
\hline
\end{tabular}

T1: Before first consultation (baseline, only groups with pre-measurement); T2: After consultation; T3: Three months after baseline; T4: 12 months after baseline; $Q=$ questionnaire.

\section{Statistical analysis}

Descriptive techniques will be used to describe patients' background characteristics. To detect potential differences between the experimental and control groups at the start of the study, the baseline levels of psychological distress and quality of life will be compared. Furthermore, to identify potential differences between the two experimental groups and the two control groups (both with and without pre-measurement) at T3 the extent of psychological distress and quality of life will be compared. If these latter differences emerge, the four groups need to be handled separately in the analyses, i.e. the experimental and control groups with pre-measurement and the experimental and control groups without pre-measurement will be compared separately. If not, the two experimental groups and the two control groups will be combined in one group.

Data of the effect evaluation will be analysed according to the intention-totreat principle. Univariate, multivariate and descriptive techniques are applied to estimate the effect of the intervention by comparing the experimental with the control groups with regard to the primary and secondary outcomes at the follow-up measurements and by comparing the pre-test (T1) with post-tests (T3 and T4). Potential confounding factors and baseline differences will be checked and included in the model if necessary. Since dependency between outcome variables from the same cluster may exist, as well as between repeated measurements within patients, multilevel modelling will be carried out. Furthermore, multilevel modelling minimizes the loss of data through dropout by including all available data from participants in the analyses. Dropout will be described. 
The process evaluation data (collected from radiotherapists and patients of the experimental groups) will be analysed by means of descriptive techniques.

\section{Ethics}

The Medical Ethics Committee of the Twee Steden Hospital in Tilburg, the Netherlands, granted approval for conducting this study.The protocol is registered in the ClinicalTrials.gov register number NCT00859768.

\section{Discussion}

This study will provide insight into the actual systematic effects of using the SIPP in consultation settings. It is important to know the possible effects of using the SIPP on aspects such as communication between physicians and patients, early recognition and treatment of psychosocial problems, the extent and severity of experienced psychological problems among cancer patients and the quality of life of patients over a long period. Until now, there have been no RCTs on the effectiveness of the SIPP on aspects such as quality of life among cancer patients and the extent of psychological distress that cancer patients experience over a long period after the initial radiation or other treatment of the cancer. Until now, there have also been no reports on the differences in number of patients receiving psychosocial help because of using the SIPP.

The design of this study is a CRCT. Cluster randomisation is applied because randomisation at the patient level may jeopardise the validity of the study since patients of the experimental and control conditions may visit the same radiotherapist for consultation. Furthermore, radiotherapists may alter their communication style, attitude or may pay more attention to patients' psychosocial distress because of using the SIPP. The Solomon Four Group design is chosen in order to check for potential pre-measurement effects on intervention outcomes. 146

In this study, we decided to include patients with the most common cancer types and with a reasonably good prognosis because patients were asked to complete questionnaires 12 months after baseline measurement.

One limitation of this study is that the results can not be generalised to all Dutch cancer patients since our study population consisted of cancer patients that received RT. Further studies outside the radiotherapy setting would be required to generalise the results.

\section{Future implementation}

Using the SIPP may prevent underdiagnosis of early symptoms reflecting psychosocial problems and may contribute to adequate referrals to psychosocial 
caregivers. Therefore, using the SIPP may lead to a reduction of psychological problems and a better quality of life among Dutch cancer patients in both the short- and long-term. If the SIPP proves to be effective, the results of this study may help motivate physicians to use the SIPP as a standard method for early detection of psychosocial problems in oncology departments in the Netherlands and abroad.

\section{Progress of the study}

Recruitment of eligible patients commenced in April 2008 and will end in July 2009, resulting in 520 eligible patients being included in the study. The followup period will continue until July 2010. Results will be published in relevant journals. 
STUDY DESIGN 


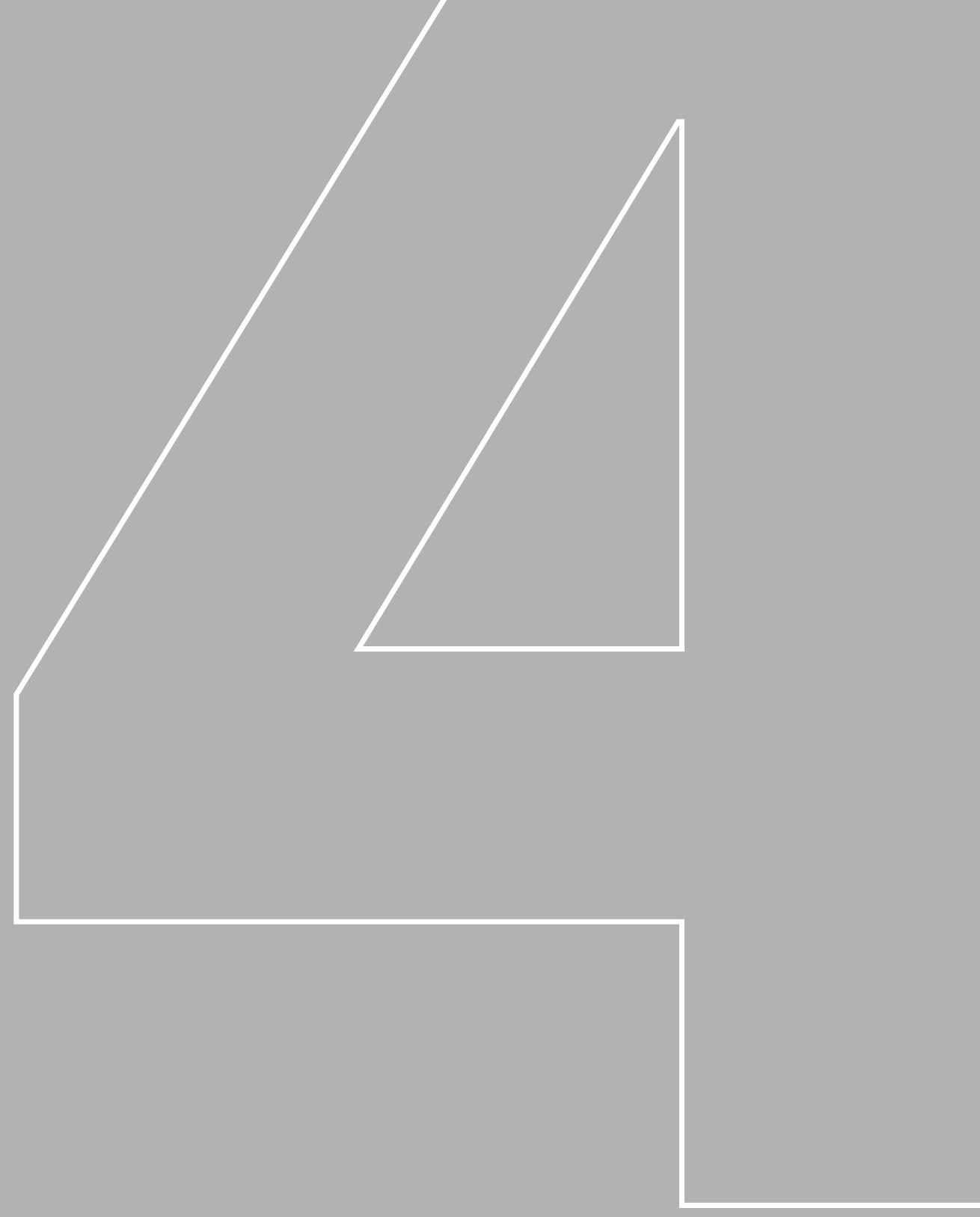




\section{The usefulness and feasibility of a screening instrument to identify psychosocial problems in patients receiving curative radiotherapy: a process evaluation}

This chapter was published as:

Anna P. B. M. Braeken, Gertrudis I. J. M. Kempen, Daniëlle Eekers, Francis C. J. M. van Gils, Ruud M. A. Houben, and Lilian Lechner (2011)

The usefulness and feasibility of a screening instrument to identify psychosocial problems in patients receiving curative radiotherapy: a process evaluation

BMC Cancer, 11, pp. 479 


\section{Abstract}

Background: Psychosocial problems in cancer patients are often unrecognized and untreated due to the low awareness of the existence of these problems or pressures of time. The awareness of the need to identify psychosocial problems in cancer patients is growing and has affected the development of screening instruments. This study explored the usefulness and feasibility of using a screening instrument (SIPP: Screening Inventory of Psychosocial Problems) to identify psychosocial problems in cancer patients receiving curative radiotherapy treatment (RT).

Methods: The study was conducted in a radiation oncology department in the Netherlands. Several methods were used to document the usefulness and feasibility of the SIPP. Data were collected using self-report questionnaires completed by seven radiotherapists and 268 cancer patients.

Results: Regarding the screening procedure 33 patients were offered to consult a psychosocial care provider (e.g. social worker, psychologist) during the first consultation with their radiotherapist. Of these patients, 31 patients suffered from at least sub-clinical symptoms and two patients hardly suffered from any symptoms. Patients' acceptance rate 63.6\% (21/33) was high. Patients were positive about the content of the SIPP (mean scores vary from 8.00 to 8.88 , out of a range between 0 and 10) and about the importance of discussing items of the SIPP with their radiotherapist (mean score=7.42). Radiotherapists' perspectives about the contribution of the SIPP to discuss the different psychosocial problems were mixed (mean scores varied from 3.17 to 4.67). Patients were more positive about discussing items of the SIPP if the radiotherapists had positive attitudes towards screening and discussing psychosocial problems.

Conclusions: The screening procedure appeared to be feasible in a radiotherapy department. In general, patients' perspectives were at least moderate. Radiotherapists considered the usefulness and feasibility of the SIPP generally to be lower, but their evaluations were mixed. A positive attitude to using screening instruments like the SIPP needs to be encouraged among radiotherapists, as this may not only improve the usefulness of a screening instrument, but also patients' satisfaction with care. 


\section{Background}

Cancer, as well as its sometimes invasive and aggressive treatment, has a great impact on a patient's life. Previous studies have highlighted that cancer patients undergoing radiotherapy treatment (RT) may experience psychosocial problems such as symptoms of depression and anxiety 28,147 , which may negatively affect health and treatment-related outcomes. ${ }^{47} \mathrm{It}$ is important to detect psychosocial problems at an early stage because treatment of sub-clinical symptoms of psychosocial problems may prevent further deterioration in the patient and the development of psychiatric co-morbidity . ${ }^{25}$ Yet, psychosocial problems are often unrecognized and untreated due to the low awareness of the existence of psychosocial problems or pressures of time. ${ }^{36,49}$ Furthermore, physicians are more focused on physical symptoms ${ }^{34,148,149}$, and may feel more able to help with physical problems than with emotional ones. ${ }^{116}$ Another aspect is that cancer patients do not tend to report psychological problems to their physician; some patients may regard psychosocial care as stigmatizing and on this basis be reluctant to seek help. ${ }^{49,150}$

Awareness of the need for identifying psychosocial problems is growing, resulting in the development of screening instruments. ${ }^{51}$ Several studies examined the use of screening instruments. ${ }^{43,51,105,151,152}$ Most studies reported that using these instruments gave better insight into patients' psychosocial problems and facilitated patient-physician communication on the topics of the instrument.34,51,65 Our study, a randomized controlled trial recently showed that using a simple screening instrument in a radiation oncology department can be valuable in timely treatment of these problems but, however, no significant effects were observed for the number of referred patients, nor for improvement of the patients-radiotherapist communication (paper submitted, article available on request).

In parallel to this trial, a process evaluation was carried out. The purpose of this process evaluation was to evaluate the feasibility and usefulness of this screening instrument (SIPP: Screening Inventory of Psychosocial Problems) and to identify factors that may explain the lack of effectiveness on referral patterns and patients-radiotherapist communication in patients receiving curative RT. The specific aims were:

- To gain insight into the procedure of using the SIPP in a radiation oncology department.

- To investigate the degree to which the SIPP was considered useful and feasible by both radiotherapists and cancer patients. Feasibility, including acceptability, of screening instruments is an important aspect that determines successful implementation of such tools in radiation oncology departments. ${ }^{153,154}$

- To investigate whether perspectives of patients and radiotherapists on the usefulness and feasibility of the SIPP are associated. We hypothesized that 
more positive attitudes of radiotherapists towards discussing psychosocial problems in daily practice will result in more positive perspectives on the usefulness of the SIPP among patients. Previous studies have reported that the way physicians address psychosocial problems affects how patients perceive the interactions with their physician. ${ }^{39,155}$

\section{Methods}

\section{Study design and participants}

This process evaluation study, part of a larger clustered randomized controlled trial ${ }^{156}$, used several methods to document the usefulness and feasibility of the SIPP, a screening instrument to identify different psychosocial problems in cancer patients (see Appendix A). The study was conducted between April 2008 and October 2009 at Institute Verbeeten (BVI), a radiation oncology department in the city of Tilburg in the south of the Netherlands. Patients with the following characteristics were included: cancer diagnosis of lung, prostate, bladder, rectum, breast, cervix, skin, endometrial or non-Hodgkin lymphoma; age over 18 years; patients without metastases; and able to provide written informed consent. Exclusion criteria were: receiving palliative treatment; receiving $\leq 10$ fractions of radiotherapy treatment; unable to read and speak Dutch and unable to complete questionnaires (e.g., too sick). Seven radiotherapists working at BVI were randomly included in this study. Patients were linked to their radiotherapist. This study was approved by the Medical Ethics Committee of the Twee Steden Hospital in Tilburg, the Netherlands.

\section{Intervention}

The SIPP was chosen as the intervention screening instrument because it is a Dutch, simple screening instrument designed to identify multiple aspects of psychosocial problems in cancer patients. ${ }^{157}$ Furthermore, it is used in several hospitals and studies. ${ }^{86,152,158,159}$ Psychometric properties of the SIPP were studied recently and found acceptable. ${ }^{157}$ The SIPP comprises 24 items and assesses physical complaints (seven items, Cronbach's alpha $=0.76$ ), psychological complaints (10 items, Cronbach's alpha $=0.89$ ), social problems (four items, Cronbach's alpha $=0.56$ ), and sexual problems (three items, Cronbach's alpha=0.51). Items are rated on a three-point scale of "0" (No), "1" (Sometimes) and "2" (Yes) with an additional option of "Not Applicable" (score 0) for the sexual problems subscale (for items see additional file). Higher scores indicate higher levels of psychosocial problems. Prevalence rates of patients with at least sub-clinical and clinical symptoms of psychosocial problems were assessed with the SIPP by using suitable cut-off scores (see footnote Table 1).157 
Patients received the SIPP before the first consultation with their radiotherapist and before the consultation at the end of their RT period since these time points were considered relevant for psychosocial support. ${ }^{160}$ At both time points, the completed SIPP was handed to the radiotherapist at the start of the consultation. Radiotherapists had to check and discuss the scores of the SIPP to get an impression of potential psychosocial problems and patients' needs for psychosocial care. Radiotherapists were asked to indicate on the SIPP whether patients were offered an appointment with a psychosocial care provider (e.g. psychologist, social worker, physician or nurse) and whether patients accepted their offer.

The study protocol was explained to the radiotherapists and other involved personnel at BVI (e.g. physician-assistants). ${ }^{156}$ Radiotherapists were trained in using and interpreting the SIPP, including interpretation of scores and the type of potential psychosocial problems and the need for psychosocial care during a one-hour training session. Training was given by the researcher and two social workers. Suitable cut-off scores for symptoms were explained to radiotherapists. A manual was prepared with interpretation of the scores.

\section{Measurement}

Baseline characteristics of the patients and radiotherapists

Socio-demographic variables were assessed directly after the first consultation (Table 2). Medical status before RT included cancer site, tumour classification (TNM) and the Karnofsky Performance Index. Variables were extracted from patients' medical records. Socio-demographic variables of the radiotherapists such as age, sex and number of years of work experience were obtained via personnel records of BVI.

\section{Questionnaire to assess patients' perspectives}

Data on patients' perspectives of the usefulness and feasibility of the SIPP were collected using a self-report questionnaire. The questionnaire was completed directly after the first consultation (see Figure 1). This questionnaire included: one open-ended question about the time (in minutes) taken to complete the screening instrument; 11 items including written statements assessing experiences with the instrument (Table 3: items 2-12) and two open questions for suggestions for improvement of the SIPP and other remarks (Table 3: items 1314). The 11 items were rated on a scale ranging from 0 to 10 . Higher scores indicated a more positive opinion. The items $2-4$ were related to the content of the SIPP (total score range 0-30, Cronbach's alpha $=0.68$ ) and the items $5-12$ concerned patients' perspectives about communication (total score range 0-80, Cronbach's alpha $=0.84$ ). 
Questionnaires to assess radiotherapists' perspectives

Data on the radiotherapists' perspectives on the usefulness and feasibility of the SIPP were collected using a self-report questionnaire completed by radiotherapists directly after the first consultation with a patient. This questionnaire contained three items including written statements assessing experiences with the SIPP (Table 4: items 1-3) and one open question about the time (in minutes) that was required to discuss the SIPP with the patient (Table 4: item 4). The three items were each rated on a scale ranging from 0 to 10 (items 1-3, total score range $0-30$, Cronbach's alpha $=0.89$ ). Higher scores indicated a more positive evaluation. Seven and 13 months after the start of the study, the radiotherapists completed a questionnaire on the general usefulness and feasibility of the SIPP. This included nine items with written statements assessing experiences with the SIPP (Table 4: items 5-13) and two open questions for suggestions for improvement of the instrument or other remarks. The nine items were rated on a scale ranging from 0 to 10 (items 5-13, total score range $0-90$, Cronbach's alpha=0.98). Higher scores indicated a more positive opinion. It should be noted that the last three items (items 11-13) were measured only the second time (13 months after the start of the study).

\section{Data analysis}

Mean differences between the scores on the first SIPP and second SIPP were analyzed by using a paired t-test. Quantitative data of the process study were analyzed by means of descriptive statistics (e.g. length of time to complete the SIPP, scores on the instruments). Qualitative data (e.g. answers to open questions) were categorized. For describing patients' and radiotherapists' different perspectives on the items of the $0-10$ point scales, the scores were categorized in negative (score $\leq 4$ ), moderate (scores of 5 and 6) and positive perspectives (score $\geq 7$ ). We used mean scores for separate items as well as sum scores for scales across items. Associations between patients' and radiotherapists' perspectives on the usefulness and feasibility of the SIPP were analyzed with Pearson correlations. Non-parametric tests were used if data were not normally distributed. Analyses were performed with SPSS software (version 17.0; SPSS Inc., Chicago, IL). The level of statistical significance was set at 0.05 (two-tailed).

\section{Results}

\section{Baseline characteristics of the patients and radiotherapists}

Sociodemographic and medical characteristics of the 268 patients are listed in Table . Figure 1 shows the flowchart of the number of patients in each stage of the screening procedure. In total, 23 patients did not complete the SIPP the first 
$(n=5)$ or second $(n=18)$ time, of which one patient did not complete the SIPP at both times. In total, 7 patients (2.6\%) did not complete the process evaluation forms.

The SIPP was applied by seven radiotherapists. Three were female. The mean age was 44.6 ( $S D=10.0$ ) years (range 30 to 63 years), and on average they had worked for 14.1 years (range 4 to 35 years) as a radiotherapist.

The process evaluation forms on the usefulness and feasibility of the SIPP after each first consultation with the patient were completed by five radiotherapists for 146 patients. Two radiotherapists never completed this form. One radiotherapist never checked the SIPP for potential psychosocial problems for all his 54 participating patients. So, questions in the evaluation form after each first consultation were not applicable for him/her. The other radiotherapist reported that completing the form after each patient took too much time.

Six radiotherapists completed twice the overall (i.e. not patient-specific) process evaluation forms on the usefulness and feasibility of the SIPP. Two radiotherapists did not complete the first or second process evaluation form due to the fact that one radiotherapist had treated only one participating patient and another radiotherapist no longer worked at the BVI at about 8 months after the start of the study. 


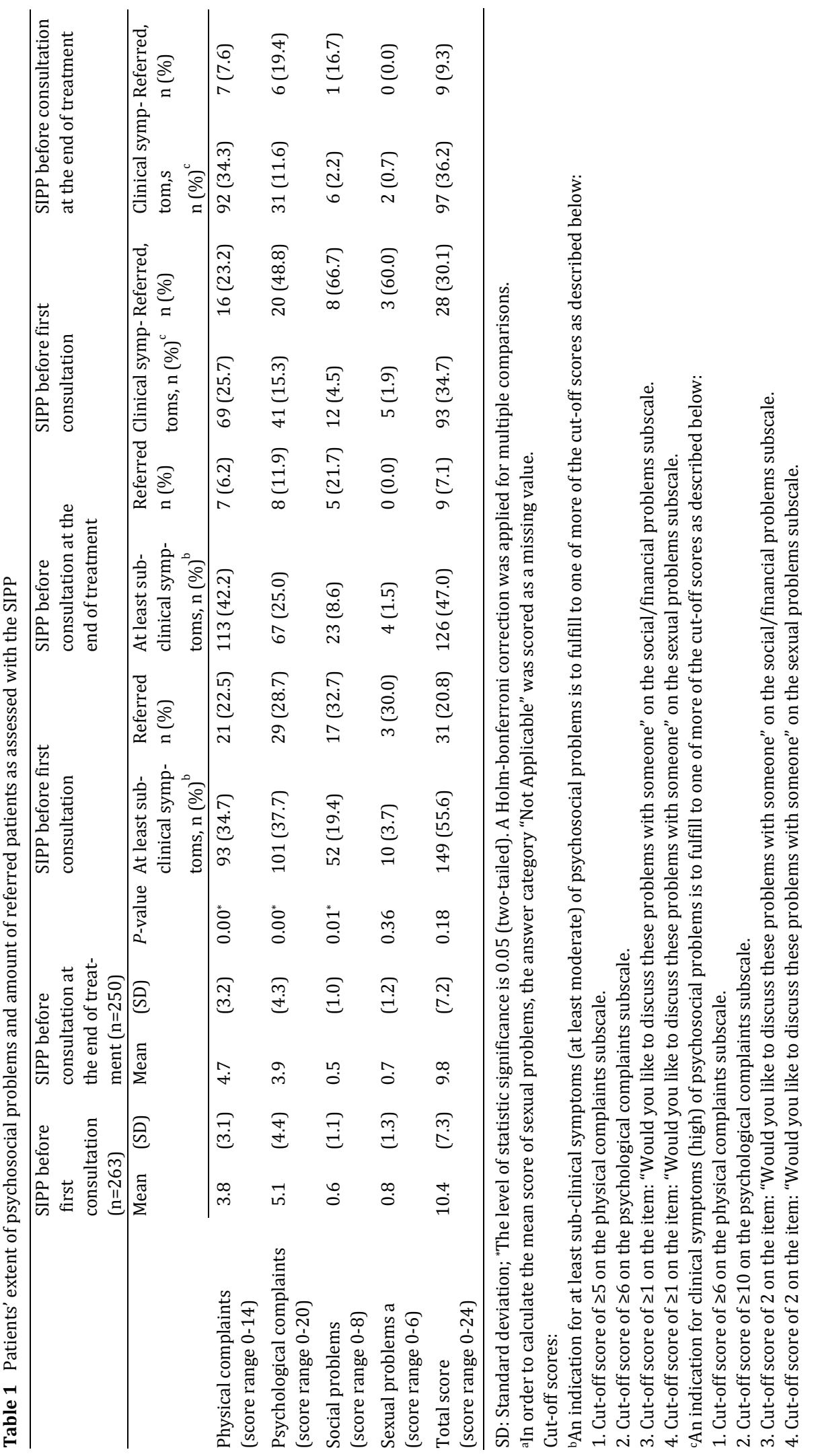




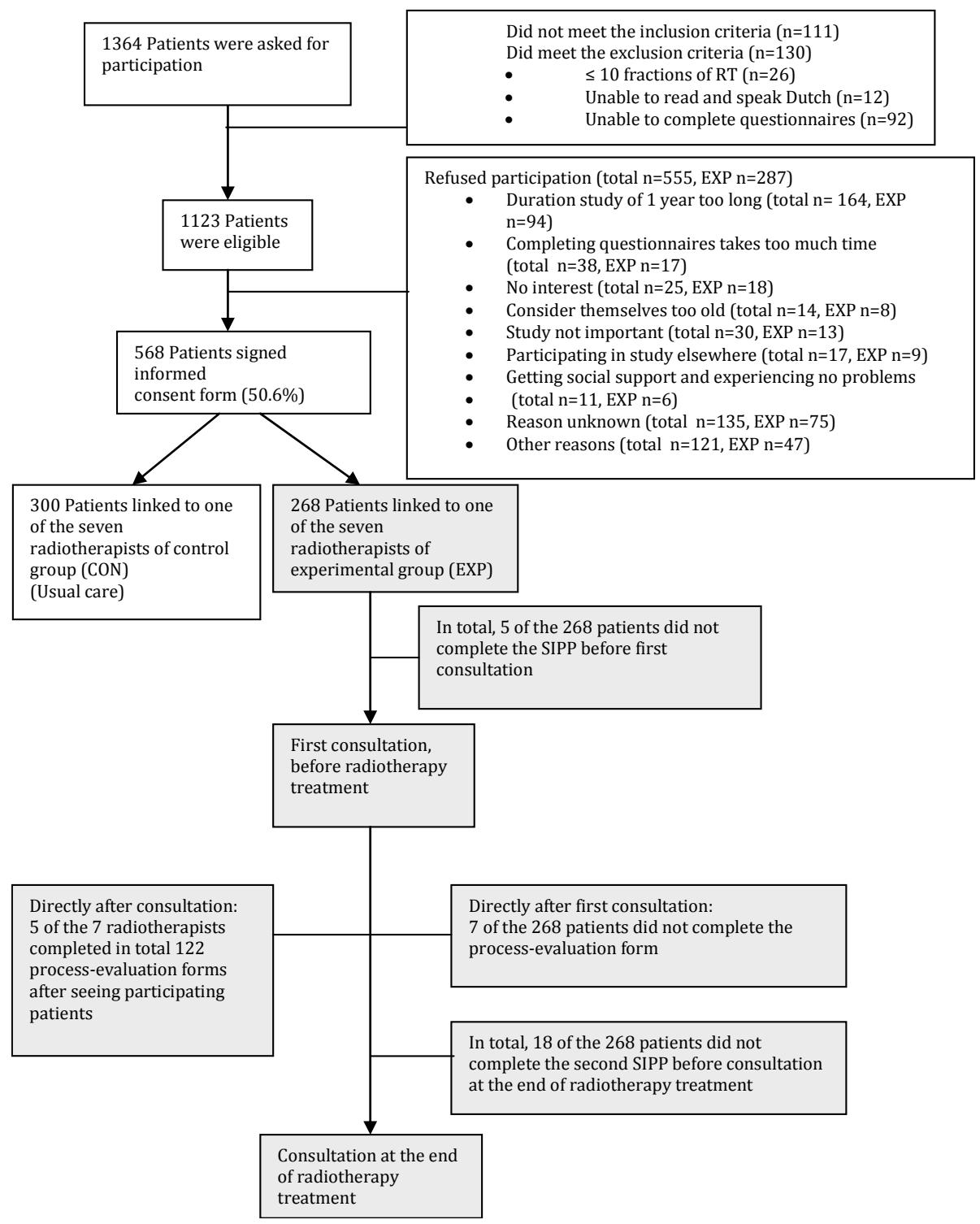

Figure 1 CONSORT flow diagram of the patients' inclusion procedure and data collection process evaluation (grey blocks) 


\section{Psychosocial problems as assessed with the SIPP}

Table 2 shows patients' extent of psychosocial problems measured with the SIPP at the two time points before the consultation with the radiotherapists. Furthermore, the numbers of referred patients with symptoms of psychosocial problems to a caregiver are presented. At the end of the RT patients reported a significantly lower extent of psychological and social problems (paired t-test, $P$ $<0.01$ and $P=0.01$, respectively), but significantly more physical complaints (paired t-test, $P<0.01$ ) than during the first consultation. During the first consultation a total of 33 patients were offered the opportunity to consult a psychosocial care provider as a result of the screening procedure. Of these 33 patients, 31 patients suffered from at least sub-clinical symptoms, of which 28 patients suffered from clinical symptoms (Table 2) and two patients hardly suffered from any symptoms of psychosocial problems at all (not tabulated). Since 28 of the 31 patients suffered from clinical symptoms this indicates that three patients suffered only from sub-clinical symptoms. Twenty-one patients accepted the recommendation and were referred to a psychosocial care provider (not tabulated). During the consultation at the end of the RT, all nine patients who were offered the opportunity to consult a caregiver suffered from clinical symptoms (Table 2).

\section{Patients' perspectives on the usefulness and feasibility of the SIPP}

Ratings of patients' perspectives about completing and discussing the SIPP after the first consultation are described in Table 3. On average, completing the SIPP took 5.3 minutes and $71.6 \%$ of the patients completed the SIPP in five minutes or less (not tabulated). Patients were positive about the content of the SIPP. The mean scores on the three items of the instruments' content subscale (items 2-4) varied from 8.0 to 8.9 . Regarding communication aspects, most patients $(67.5 \%)$ were positive about the importance of discussing items of the SIPP with their radiotherapist. However, patients were not positive about the usefulness of the SIPP to discuss psychosocial complaints and sexual problems.

\section{Patients' suggestions for improvement of the SIPP}

Five patients made suggestions for improvement. One patient suggested adding an item on cognitive functioning, and one patient suggested adding an item about medication use. Furthermore, one patient considered it important to ask about problems at work, while another patient reported that questions on specific tumours or treatment of specific complaints were lacking. One patient would have preferred an item about receiving care at home. 
Table 2 Characteristics of the patients $(n=268)$

\begin{tabular}{|c|c|c|c|}
\hline Variables & & $\mathrm{n}$ & $\%$ \\
\hline \multicolumn{4}{|l|}{ Age (years) } \\
\hline Mean (SD) & $62.4(10.8)$ & & \\
\hline Range & $30.0-88.0$ & & \\
\hline \multicolumn{4}{|l|}{ Sex } \\
\hline Female & & 183 & 68.3 \\
\hline \multicolumn{4}{|l|}{ Marital status } \\
\hline Married/ living together & & 207 & 77.2 \\
\hline Unknown & & 5 & 1.9 \\
\hline \multicolumn{4}{|l|}{ Educational level } \\
\hline Elementary & & 103 & 38.4 \\
\hline High school & & 116 & 43.3 \\
\hline Higher Education/University & & 43 & 16.0 \\
\hline Unknown & & 6 & 2.2 \\
\hline \multicolumn{4}{|l|}{ Diagnosis } \\
\hline Prostate/Bladder & & 50 & 18.7 \\
\hline Lung & & 21 & 7.8 \\
\hline Breast & & 145 & 54.1 \\
\hline Cervix/ Endometrial & & 9 & 3.4 \\
\hline Rectum & & 40 & 14.9 \\
\hline Non-Hodgkin Lymphoma & & 3 & 1.1 \\
\hline \multicolumn{4}{|l|}{ T-status (size of the primary tumor) } \\
\hline Tin-situ & & 7 & 2.6 \\
\hline $\mathrm{T} 1 / \mathrm{T} 2$ & & 152 & 56.7 \\
\hline $\mathrm{T} 3 / \mathrm{T} 4$ & & 58 & 21.6 \\
\hline Unknown & & 51 & 19.0 \\
\hline \multicolumn{4}{|c|}{$\mathrm{N}$-status (degree of spread lymph nodes) } \\
\hline No & & 141 & 52.6 \\
\hline $\mathrm{N} 1 / \mathrm{N} 2$ & & 64 & 23.9 \\
\hline N3/N4 & & 5 & 1.9 \\
\hline Unknown & & 58 & 21.6 \\
\hline \multicolumn{4}{|l|}{ M-status (presence of metastasis) } \\
\hline M0 & & 203 & 75.7 \\
\hline Unknown & & 65 & 24.3 \\
\hline \multicolumn{4}{|l|}{ Karnofsky Performance Indexa } \\
\hline $100 / 90$ & & 194 & 72.4 \\
\hline $80 / 70$ & & 24 & 8.9 \\
\hline Unknown & & 50 & 18.7 \\
\hline \multicolumn{4}{|l|}{ Chemo therapy } \\
\hline Before radiotherapy treatment & & 66 & 24.6 \\
\hline During radiotherapy treatment & & 25 & 9.3 \\
\hline \multicolumn{4}{|c|}{$\begin{array}{l}\text { Time frame between start and end of the } \\
\text { radiotherapy treatment (days) }\end{array}$} \\
\hline Mean (SD) & $38(6.7)$ & & \\
\hline Median & 37 & & \\
\hline Range & $(16-65)$ & & \\
\hline
\end{tabular}

SD: Standard deviation

a Score range $0-100$, higher score indicates better physical functioning 


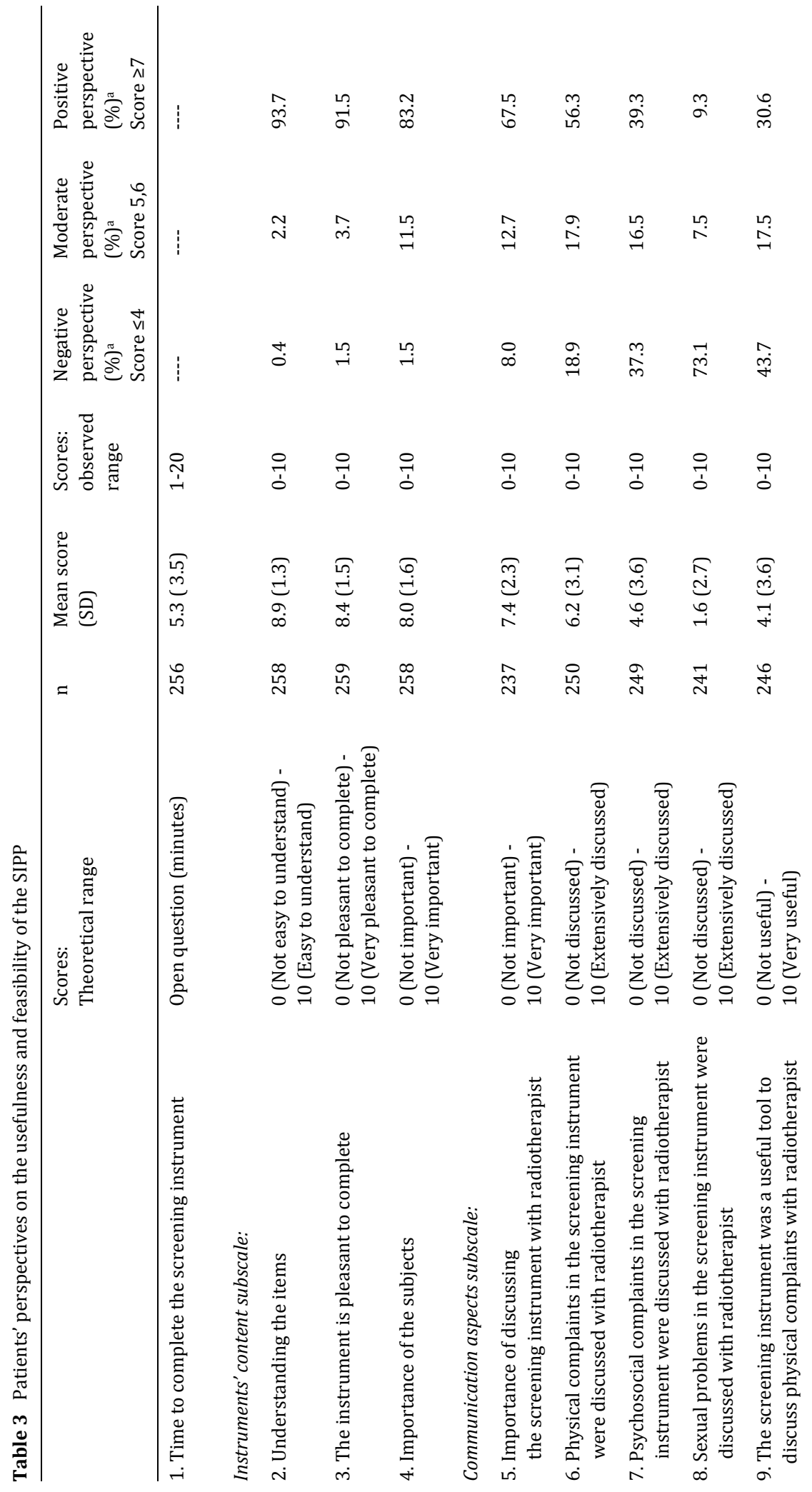




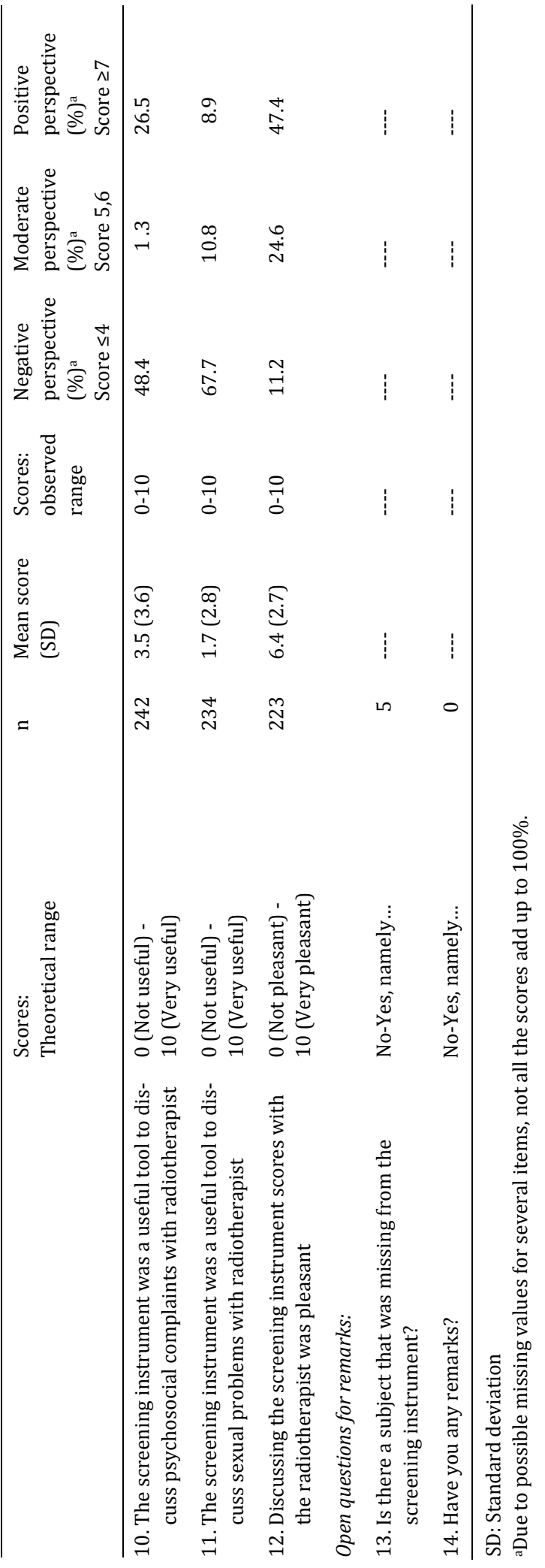




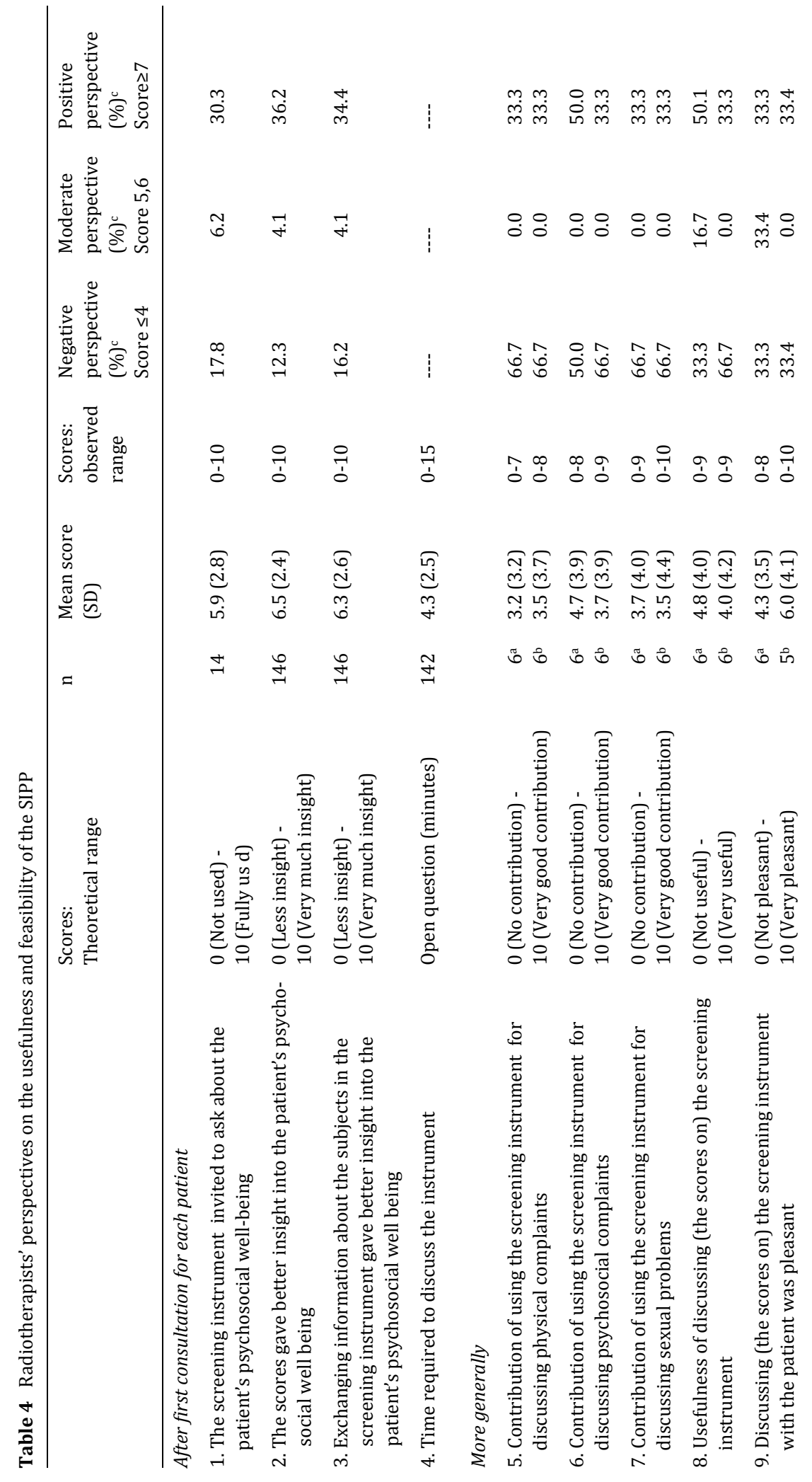




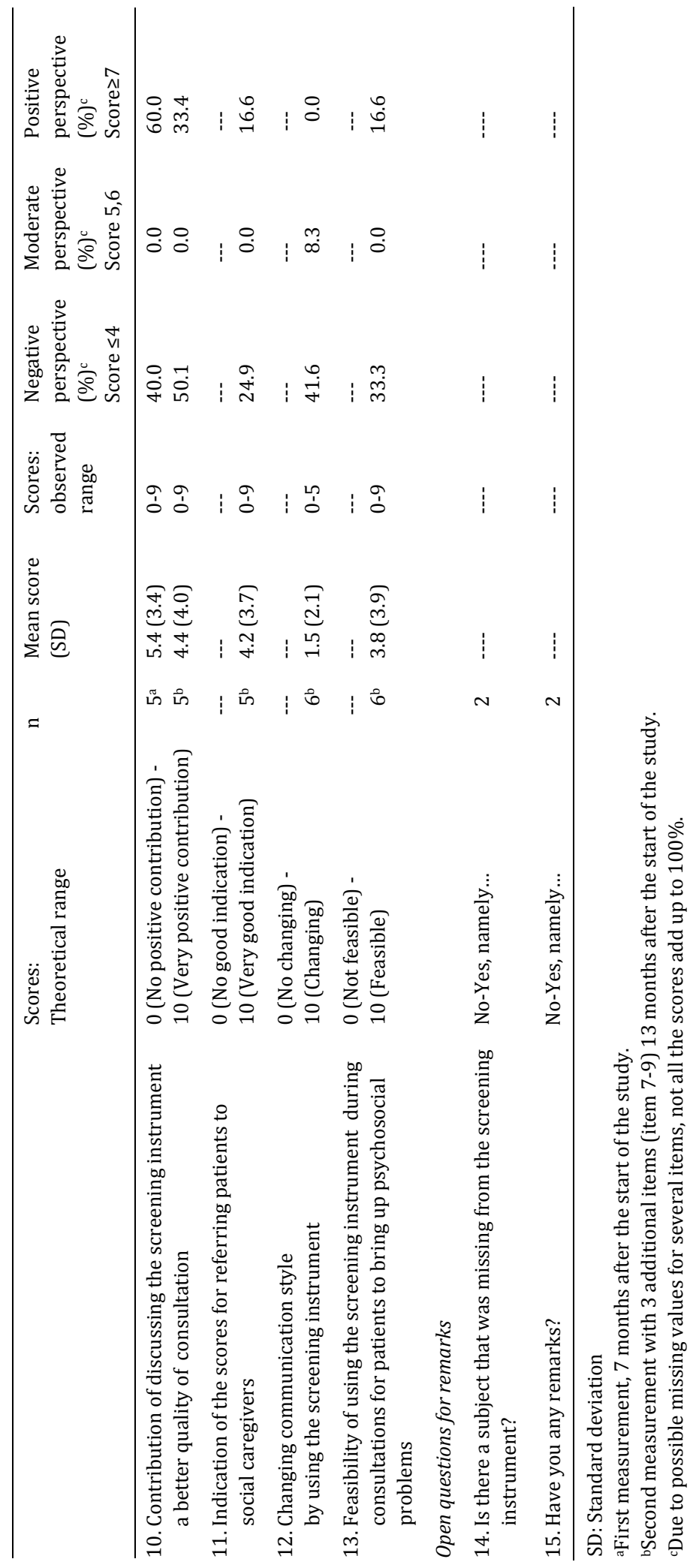




\section{Radiotherapists' perspectives on the usefulness and feasibility of the SIPP}

Ratings of radiotherapists' perspectives on using the SIPP after the first consultation are presented in the upper part of Table 4.

In $90.1 \%$ of all consultations, the time required to discuss the instrument was less than five minutes (not tabulated). With respect to specific evaluation after each consult, radiotherapists were most positive about the fact that the SIPP gave better insight into the psychosocial well-being of the patient. They were less positive about the fact that the SIPP invited them to ask about the patients' psychosocial well-being.

Radiotherapists' overall perspectives on using the SIPP were measured at two time points: about seven and 13 months after the start of the study. Their overall perspectives on the usefulness and feasibility of the SIPP was mixed (mean scores varied from 1.5 to 6.0; see lower part of Table 4). Three radiotherapists considered the SIPP to be useful and feasible. None of the radiotherapists was positive about changing their communication style by using the SIPP.

\section{Radiotherapists' suggestions for improvement of the SIPP}

Two radiotherapists made suggestions for improvement. One preferred a tumour-specific questionnaire above a disease-specific questionnaire and another suggested an item about whether patients already received psychosocial support. Regarding feasibility, one radiotherapist suggested that physicianassistants should discuss the screening instrument with the patients.

\section{Associations between patients' and radiotherapists' perspectives on the usefulness of the screening instrument}

Radiotherapists who considered the screening instrument a useful tool to ask about psychosocial well-being aspects (Table 4, item 8) were more likely to discuss psychosocial complaints $(\mathrm{r}=0.2, P=0.01)$ and sexual problems $(\mathrm{r}=0.3, P$ $<0.01$ ) with their patients (Table 3, items 7 and 8, respectively). Patients were more likely to report that discussing the items of the SIPP with their radiotherapist was pleasant (Table 3, item 12) if the radiotherapist considered the SIPP to be a useful tool to ask about psychosocial well-being $(\mathrm{r}=0.2, P<0.05)$ (Table 4 , item 8).

\section{Discussion}

This study explored the usefulness and feasibility of using a screening instrument as the SIPP in a radiation oncology department according to radiotherapists and patients. Nearly all patients completed the SIPP twice, at the beginning 
and at the end of RT, which is an indication of an acceptable feasibility of the screening instrument. Just as previous studies reported that not all radiotherapists were willing to use psychosocial screening instruments ${ }^{66,154}$ in our study also one radiotherapist was not willing to use the screening instrument.

The prevalence rate of psychosocial problems among patients receiving RT with curative intent was in line with previous studies. ${ }^{28,102}$ During the treatment trajectory patients seemed to experience different problems at different time points; the extent of psychological and social problems was lower at the end of $\mathrm{RT}$, while the extent of physical complaints was higher at this time point. The latter was probably due to the high extent of side-effects at the end of RT since patients had received the maximum radiation doses. Displaying similarities with other studies $68,161,162$, a relative small proportion of patients suffering from at least sub-clinical (7.1\%-20.8\%) or clinical (9.3\%-30.1\%) symptoms of psychosocial problems were offered the opportunity to visit a psychosocial care provider by their radiotherapist (Table 2). An explanation might be that psychosocial problems were discussed sufficiently during the consultation, which meant that receiving psychosocial support by a psychosocial care provider was not considered necessary any more ${ }^{163}$. Another explanation might be that according to Livingston and colleagues, physicians may be uncomfortable referring patients at a time when patients are overloaded with information (e.g. treatment, and side-effects) ${ }^{164}$, as is the case during a first consultation. Also, physicians tend to ignore raw scores on questionnaires when they have to add them up and interpret them themselves, resulting in under diagnosis of patients suffering from psychosocial problems. ${ }^{165}$ The latter can be prevented by using a computer-based screening instrument that forwards the screening data and presents the results directly to physicians. However, Boyes and colleagues reported that giving physicians feedback about patients' psychosocial well-being rarely contributed to physicians' decision making about patient management. ${ }^{66}$ Furthermore, contrary to other studies $63,68,166-170$, our results showed that when offered during the first consultation, the majority of the patients (63.6\%) accepted psychosocial care. It seemed that receiving psychosocial support was acceptable for patients at that time point. A previous study reported that patients' need and acceptance for psychosocial support seemed to be related to timing. ${ }^{63}$ Still, it should be taken into account that about one-third of the patients did not wish to be referred to a psychosocial care provider, which may imply that for some patients a barrier emerged that impeded acceptance of referral. 169

There is a discrepancy between radiotherapists' and patients' perspectives of the usefulness and feasibility of the SIPP. Patients' perspectives of the usefulness and feasibility of the SIPP were moderate to good in general. Comparable with the study of Pruyn and colleague ${ }^{86}$, two-thirds of the patients were very positive on the importance of discussing the screening instrument with their radiotherapist. Regarding the radiotherapists' perspectives, only a minority of 
radiotherapists considered the SIPP to be useful and feasible. Despite the latter, it is important to note that our outcomes showed a positive association between radiotherapists' opinion about the scores as good indicators into patients' wellbeing and discussing psychological problems. However, it can be vice versa: radiotherapists who traditionally more often discuss psychosocial problems were those who indicated that the screening instrument gave better insight into patients' problems. Furthermore, discussing the screening instrument was more pleasant for patients when the radiotherapists were positive about discussing it. This confirms our hypothesis that if radiotherapists have positive attitudes towards discussing psychosocial problems patients' perspectives of the usefulness of the tool will be more positive. Moreover, it also indicates the importance of patient-physician communication for high-quality care, as it may influence patients' satisfaction with care. ${ }^{151,155,171}$

Some results of this study were remarkable. Radiotherapists were quite positive about the usefulness and feasibility of the screening instrument when they evaluated the SIPP directly after each first consultation with their patient, but more negative when the usefulness and feasibility was evaluated in general and not related to a specific consultation. A reasonable explanation is the different numbers of radiotherapists who completed the questionnaires in both situations. As reported earlier, two radiotherapists did not report their opinion after each consultation. Yet, despite the assumption that using a screening instrument may initiate better communication between patients and medical staff 34,51 , none of the radiotherapists were convinced that using the screening instrument would change their communication style.

This study has several strong elements: the large number of patients that was included as well as the perspectives of both patients and radiotherapists. The study has limitations as well. First, the study was conducted in a single radiotherapy department, and although the number of patients was large, the number of radiotherapists was limited. This reduces the options for generalization of the results. Second, because the SIPP had not yet been incorporated into routine care, the radiotherapists might have gained insufficient experience to check the SIPP scores and patients' needs for psychosocial care. Partly, this could explain why radiotherapists considered the usefulness and feasibility of the screening instrument generally as low, while actual scores were mixed.

Recommendations for improving the use of a screening instrument in practice include encouraging screening at several time points as patients' needs and extent of psychosocial problems may change during the treatment trajectory. Furthermore, an important issue is to change and improve the physicians' attitudes regarding psychosocial care. This is relevant since physicians' attitudes toward discussing emotional problems may influence detection of psychosocial problems ${ }^{39}$ and are linked with patients' satisfaction. ${ }^{151}$ Additional skills training among physicians may be needed to improve recognition and management of psychosocial problems in cancer patients. ${ }^{172}$ However, it could also be that 
nurses rather than physicians prove to be the most suitable health care professionals to discuss psychosocial problems with cancer patients. Studies reported that nurses were more willing to use screening tools than physicians. ${ }^{154}$ Further research is necessary to optimize the use of screening instruments that may identify cancer patients' extent of psychosocial problems and improve healthrelated outcomes.

\section{Conclusion}

Overall, we can conclude that the SIPP screening procedure appeared to be feasible in a radiotherapy department and that the screening procedure appears to be valued positively by most cancer patients, but not by all radiotherapists. It is useful to reflect on the fact that two-thirds of the patients rated the discussion with their radiotherapist about psychosocial problems as (highly) important. So, improving radiotherapists' attitudes towards discussing emotional problems and using screening instruments may not only improve the usefulness of a screening instrument like the SIPP, but also patients' satisfaction with care. 


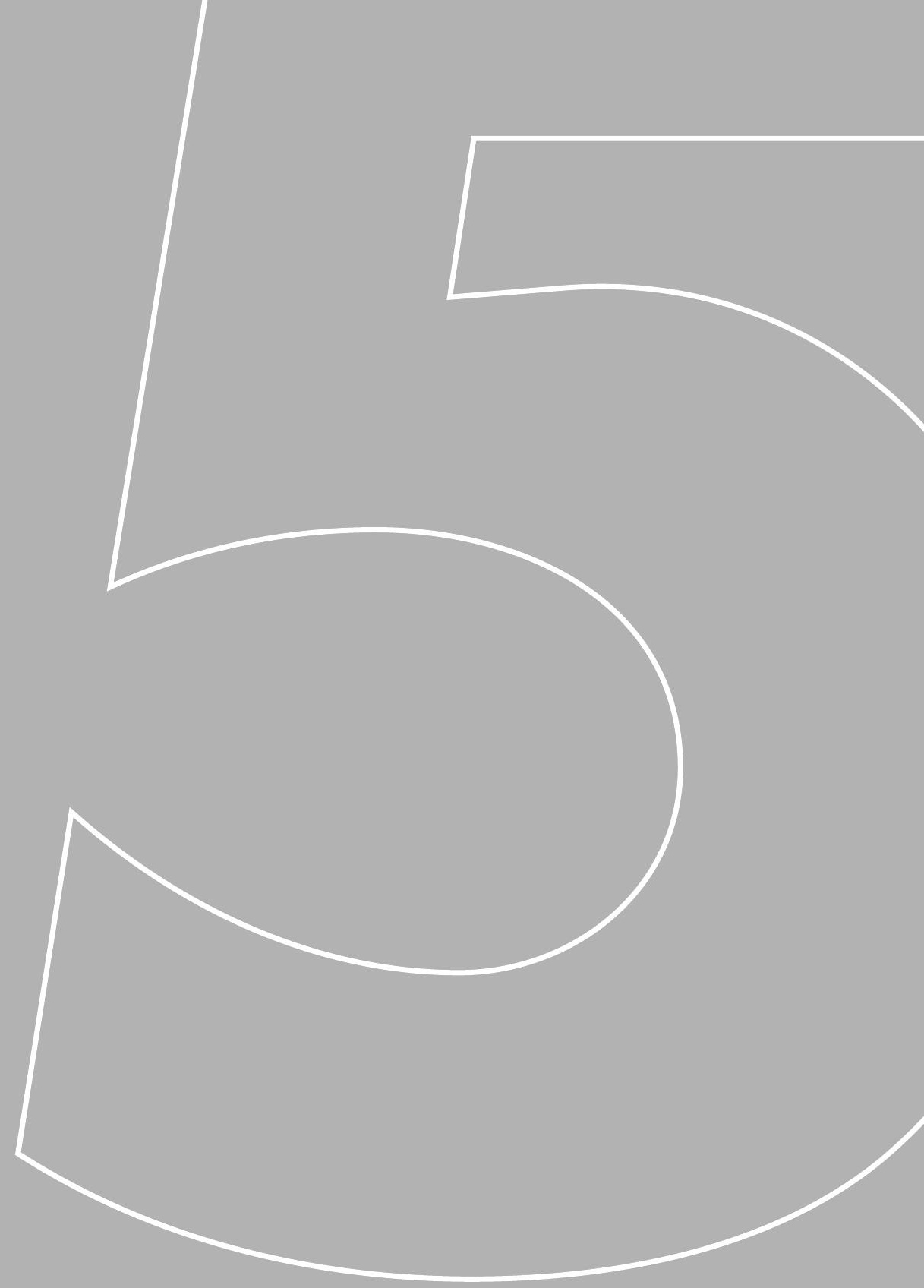




\section{Does routine screening for psychosocial problems improve referral to caregivers and patient-radiotherapist communication? A cluster randomized controlled trial}

This chapter has been submitted as:

Anna P. B. M. Braeken, Lilian Lechner, Daniëlle Eekers, Ruud M. A. Houben, Francis C. J. M. van Gils, Ton Ambergen and Gertrudis I. J. M. Kempen Does routine screening for psychosocial problems improve referral to caregivers and patient-radiotherapist communication?

A cluster randomized controlled trial 


\begin{abstract}
Purpose: Several studies have been published on the development and use of screening instruments to identify psychosocial problems in cancer patients. However, it is worth noting that randomized controlled trials to study the effectiveness of these instruments rarely include patients receiving radiotherapy. This study tests whether using a screening instrument improves referral to psychosocial caregivers and facilitates communication between patients and radiotherapists.
\end{abstract}

Methods: A cluster randomized controlled trial was used. In total, 14 radiotherapists and their 568 cancer patients were randomly allocated between groups. Patients in the experimental group were asked to complete a screening instrument: the Screening Inventory of Psychosocial Problems (SIPP) at two different time points. All experimental $(n=268)$ and control $(n=300)$ patients were requested to complete questionnaires concerning psychosocial care and patient-physician communication.

Results: Patients who completed a screening instrument were referred to social workers at an earlier stage than patients who did not $(p<0.01)$. No intervention effects were observed for numbers of referred patients, or for improvement of patient-radiotherapist communication. In both groups, almost half of the patients evaluated their satisfaction regarding communication with their radiotherapist as very good.

Conclusions: Our results suggest that a simple screening procedure to identify cancer patients with psychosocial problems can be valuable for the timely treatment of these problems to prevent further development of psychiatric disorders. Future efforts should be directed at adequate timing of screening and enhancing physicians' awareness regarding the importance of identifying, discussing and treating psychosocial problems in cancer patients. 


\section{Background}

Cancer can cause substantial suffering and disturbance of psychosocial functioning. ${ }^{63}$ About $30 \%$ of cancer patients experience psychosocial problems, such as anxiety and depression. ${ }^{47,173}$ Radiotherapy (RT) is an effective but invasive treatment for malignant tumours. Patients receiving RT are likely to experience additional stressors such as fear about treatment and side effects.49,78 Their need for psychosocial care appears to be high. ${ }^{160}$

The detection of psychosocial problems is important because treatment at an early stage may improve quality of life 85,150 , and minimize the likelihood of developing psychological disorders. ${ }^{48}$ However, psychosocial distress often remains unrecognized by physicians. Reasons may be low awareness of the existence of psychosocial problems and time pressure. ${ }^{36,49}$ Thereby, physicians primarily focus on physical symptoms ${ }^{34,148,149}$, and feel more able to help with physical rather than psychological problems. ${ }^{174}$ Moreover, patients do not tend to report on psychological problems to their physician, because they often feel embarrassed to report, for example, depressive symptoms. ${ }^{175}$ Thus both patients and physicians are reluctant to mention psychological problems. ${ }^{176}$

The growing awareness of the need to identify psychosocial problems among patients in cancer care has led to the development of screening instruments. ${ }^{51}$ These instruments may prevent the under-diagnosis of psychosocial problems and encourage adequate treatment to prevent further deterioration in patients. ${ }^{25}$ Feedback about patients' self-reported well-being can be useful for physicians. It can increase physicians' awareness of patients' concerns and may improve patient-physician communication. ${ }^{34,51,52,65}$

Several studies exist on the development and use of screening instruments. $43,49,86,105$ However, it is worth noting that randomized controlled trials to study the effectiveness of these instruments rarely include patients receiving RT. ${ }^{60,177}$ Therefore, we used an optimal design to test the hypotheses that routine screening for psychosocial problems in cancer patients receiving RT results in: 1) detection of psychosocial problems, resulting in higher numbers of patients referred to psychosocial caregivers in a timely fashion, and 2) facilitation of communication between patients and radiotherapists resulting in improved patient satisfaction with radiotherapist-patient communication. 


\section{Methods}

\section{Study design}

A cluster randomized controlled trial was conducted (NCT00859768). To correct for potential effects of the baseline assessment on outcomes, a Solomon Four Group design with two experimental and two control groups was used. A baseline assessment was only conducted in one experimental and one control group (Figure 1). Radiotherapists were randomly allocated to the experimental or control group. Patients were linked to therapists and randomized to the group with or without baseline assessment. A detailed description of this design can be found elsewhere. ${ }^{156}$

\section{Participants}

Radiotherapists working at the Institute Verbeeten (BVI), a radiation oncology department in the Netherlands, participated in this study.

Patients receiving RT were eligible if they: had a cancer diagnosis of the lung, prostate, bladder, rectum, breast, cervix, skin, endometrial or Non-Hodgkin lymphoma; were at least 18 years old; had no metastases; and were able to provide written informed consent. Patients were excluded if they: received palliative treatment; were receiving $<10$ fractions of RT; were unable to read and speak Dutch; or unable to complete the questionnaires (e.g. too sick). Ethical approval was obtained from the local Medical Ethics Committee.

\section{Intervention}

The Screening Inventory of Psychosocial Problems (SIPP) was chosen as the intervention screening instrument because it is a short instrument and assesses multiple aspects of psychosocial problems (physical and psychological complaints; social/financial and sexual problems) in cancer patients. A previous study confirmed the reliability and validity of the SIPP as well as its specificity and sensitivity in detecting psychiatric co-morbidity. ${ }^{178}$

Before the start of this study, radiotherapists in the experimental groups $(n=7)$ were trained in using and interpreting the SIPP. Since research showed that most patients experience a need for psychosocial support at the beginning and end of $\mathrm{RT}^{160}$, patients received the SIPP before the first consultation (SIPP1) and before the consultation at the end of RT (SIPP2). On both occasions, the radiotherapists checked the scores to obtain an overview of potential psychosocial problems and patients' needs for psychosocial care. Potential problems were discussed with the patients. Potential referral to a caregiver was based on the scores of the SIPP ${ }^{178}$ in combination with the radiotherapists' judgement. 
Control group patients received standard care. There were no psychosocial screening guidelines at BVI. Patients were referred to psychosocial caregivers when judged necessary by the radiotherapist.

\section{Procedures}

Potential patients who met the eligibility criteria received information about the study by mail to their home address. Before the first consultation (about 3 weeks before RT), patients randomized to groups with baseline assessment were asked to complete questionnaires in the waiting room (secluded area). Patients allocated to the experimental groups were also asked to complete the SIPP. Outcomes were measured after the first consultation and 3 and 12 months post-intervention (Figure 1).

\section{Measures}

Primary outcome measures were the number of referred patients and type of referral measured using self-developed questionnaires. Three months after baseline patients were asked whether they had been referred to psychosocial caregivers in the past 3 months. Questions covered who took the initiative for referring (e.g. patient), to whom patients were referred, who was the referee (e.g. radiotherapist), what types of problems (e.g. social support) were mentioned, if there was a link between problems experienced and cancer, and whether the patient had a psychosocial history. Twelve months after baseline patients were asked to complete four questions about whether they had been referred to a psychosocial caregiver in the last 9 months, for what type of problems, the referee and to whom patients were referred (e.g. psychologist). In addition, data from the registration records of two social workers working at BVI were collected. These data comprised information on: whether a patient received psychosocial support, the referee, type of problems, and the date on which the patient was referred.

A secondary outcome was patients' satisfaction with patient-radiotherapist communication regarding psychosocial aspects, measured using five selfdeveloped questions and completed after the first consultation at BVI. Four questions measured whether physical complaints, psychological complaints, and social and sexual problems were discussed with the radiotherapist. Patients could indicate "Yes (2)", “More or less (1)", "No (0)" and "Not Applicable (0)". A fifth question measured the patients' general opinion about communication with the radiotherapist during the first consultation. Scores ranged from "very bad" (1) to "very good" (6).

At baseline and post-intervention, psychological symptoms of patients in both groups was measured using the Hospital Anxiety and Depression Scale 
(HADS) 90 and the General Health Questionnaire-12 version (GHQ-12) ${ }^{91}$. The HADS is a 14-item instrument with two subscales for symptoms of anxiety and depression, respectively. Scores range from 0 to 21 on each subscale. The GHQ12 assesses symptoms of distress using 12 items. Scores range from 0 to 12 . On both questionnaires higher scores indicate more symptoms. ${ }^{90,91}$

Patients' socio-demographic data were collected on a short-form completed by patients after the first consultation. Disease characteristics (Table 1) were collected from the medical records at BVI. Radiotherapists' socio-demographic characteristics were obtained from personnel records.

\section{Statistical methods}

Sample size calculation showed that 92 patients were required per group to compare the percentages of referred patients to psychosocial caregivers between conditions with $80 \%$ power and a significance level of 0.05 (onesided). ${ }^{156}$ To account for the cluster design the sample size was multiplied by the design effect. With an expected dropout rate of $20 \%$, the corrected total sample size for the four groups (i.e. experimental and control groups with and without baseline assessment) was determined as 520 patients. ${ }^{156}$

Before starting the analyses, a potential test-effect of the baseline assessment on outcomes was identified using backward regression analyses. Independent variable was the experimental or the control group, both with and without baseline assessment, and the covariates were gender, age, educational level, and tumour sites. Non-significant covariates were dropped from the model. Dependent variables were scores on the subscales of SIPP1 and total scores on the HADS and GHQ-12 3 months after the baseline. If differences between groups with and without baseline assessment were identified, the four groups would need to be handled separately in the analyses.

Socio-demographic and medical characteristics as well as the extent of psychological problems at baseline were compared between experimental and control group by means of Chi-square test, Mann- Whitney U tests and Students ttest for independent samples.

Next, univariate, multivariate and descriptive techniques were applied to gain insight into the intervention effect on (the type of) referral. Several outcomes were analysed. First, the intervention effect on numbers of referred patients was evaluated using three different analyses. Three dichotomous outcome variables were being referred during the first 3 months, the last 9 months, and the total study period. Being referred was coded as one. Group differences in these outcomes were analysed using Generalized Estimating Equations with patients at level one and radiotherapists at level two. Second, time differences between the first consultation and being referred to social workers (BVI) were evaluated by linear regression analyses. Third, outcomes on communication aspects between groups were compared using a mixed-effects model with co- 
variance structure "compound symmetry", with patients at level one and radiotherapists at level two. The independent variable group (experimental, control) and covariates (cancer diagnosis, gender, age and education level) were included in the model as well as two-way interactions: group x covariates. Backward method was used, meaning that non-significant covariates were dropped from the models, starting with the interaction effects. All models were adjusted for baseline differences with respect to gender and cancer diagnosis. Analyses were taken on an intention-to-treat principle. Level of statistical significance for the intervention effect was set at 0.05 (one-tailed), as planned when the study was initially set up. For covariates the level of statistical significance was set at 0.05 (two-tailed). Analyses were performed using SPSS 17.0 for Windows statistical software.

\section{Results}

\section{Participants' characteristics}

Of the radiotherapists allocated to the control group ( $\mathrm{n}=7)$, two were female and the mean age was 44.8 years $(S D=9.2$, median=46.9). On average they had worked for 17.1 years (range 2-29 years) as a radiotherapist. Of the radiotherapists allocated to the experimental group $(n=7)$, three were female and the mean age was 44.6 years ( $\mathrm{SD}=10.0$, median=44.6). On average they had worked for 14.1 years (range 4-35 years) as a radiotherapist.

In total, $568(50.6 \%)$ eligible patients agreed to take part in the study (Figure 1). Participants were recruited between April 2008 and October 2009. Most patients $(n=491: 86.4 \%)$ completed the trial (baseline assessment plus at least the 12-month follow-up assessment). Drop-out rate was less than expected $(13.6 \% \text { instead of } 20 \%)^{156}$, and was similar in both groups $(14.2 \%$ and $13.0 \%$ in control and intervention group, respectively). The most prevalent reason for dropout was death. 


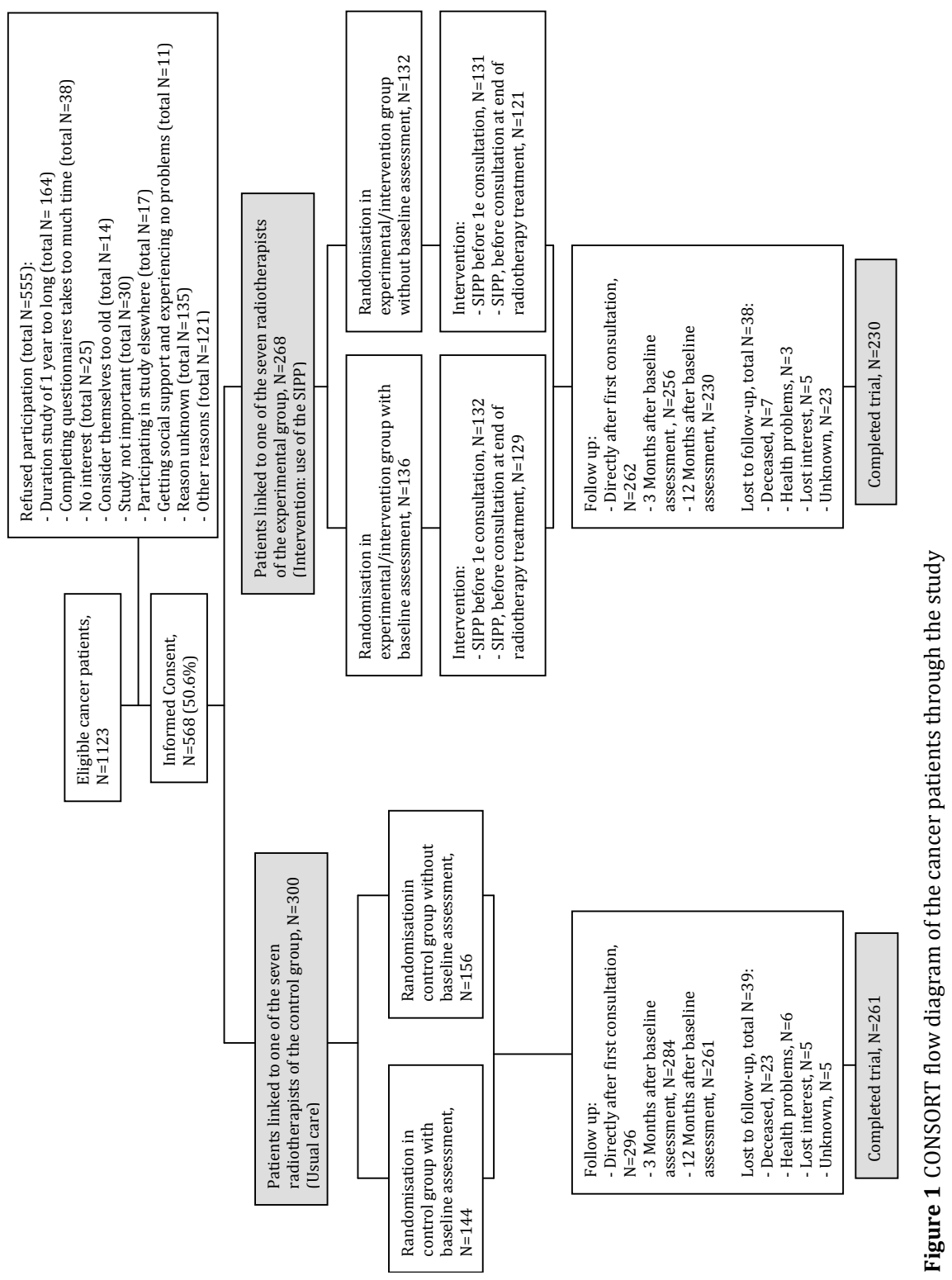


Socio-demographic characteristics of the patients in the control groups with and without baseline assessment and experimental groups with and without baseline assessment were similar (not tabulated). Patients' extent of psychological symptoms at baseline was similar (all $P$-values $\geq 0.34$ ): mean scores on the HADS anxiety and depression subscales of patients allocated to the control group were 5.45 ( $\mathrm{SD}=4.12$ ) and $3.61(\mathrm{SD}=3.89$ ) respectively, and those of patients allocated to the experimental group were $5.04(\mathrm{SD}=3.76)$ and $3.17(\mathrm{SD}=3.51)$ respectively. Mean scores on the GHQ-12 were 2.89 (SD=3.29) for the control group and 3.16 $(\mathrm{SD}=3.49$ ) for the experimental group (not tabulated). The groups were well balanced for the baseline characteristics except for gender, and cancer diagnosis (Table 1).

\section{Potential test-effect}

The results showed no significant differences on the SIPP1 subscales between patients in the experimental groups with $(n=132)$ and without $(n=131)$ baseline assessment ( $P$-values varied between 0.053 and 0.83 ). No significant differences were found for psychological symptoms on the HADS total scores 3 months after baseline between patients in the experimental groups with $(n=129)$ and without $(n=125)$ baseline assessment $(P=0.43)$ and between patients in the control groups with $(\mathrm{n}=144)$ and without $(\mathrm{n}=156)$ baseline assessment (HADS, $P=0.38)$. Furthermore, no significant differences were found for psychological symptoms on the GHQ-12 3 months after baseline between patients in the experimental groups with $(n=127)$ and without $(n=126)$ baseline assessment $(P=0.79)$ or between patients in the control groups with $(n=137)$ and without $(n=147)$ baseline assessment (GHQ-12, $P=0.13$ ). We may conclude that the baseline assessment had no significant effect on outcomes. Therefore we combined the two experimental and control groups to form one experimental $(n=268)$ and one control group $(n=300)$. 
Table 1 Patients' baseline socio-demographic and medical characteristics $(n=568)$

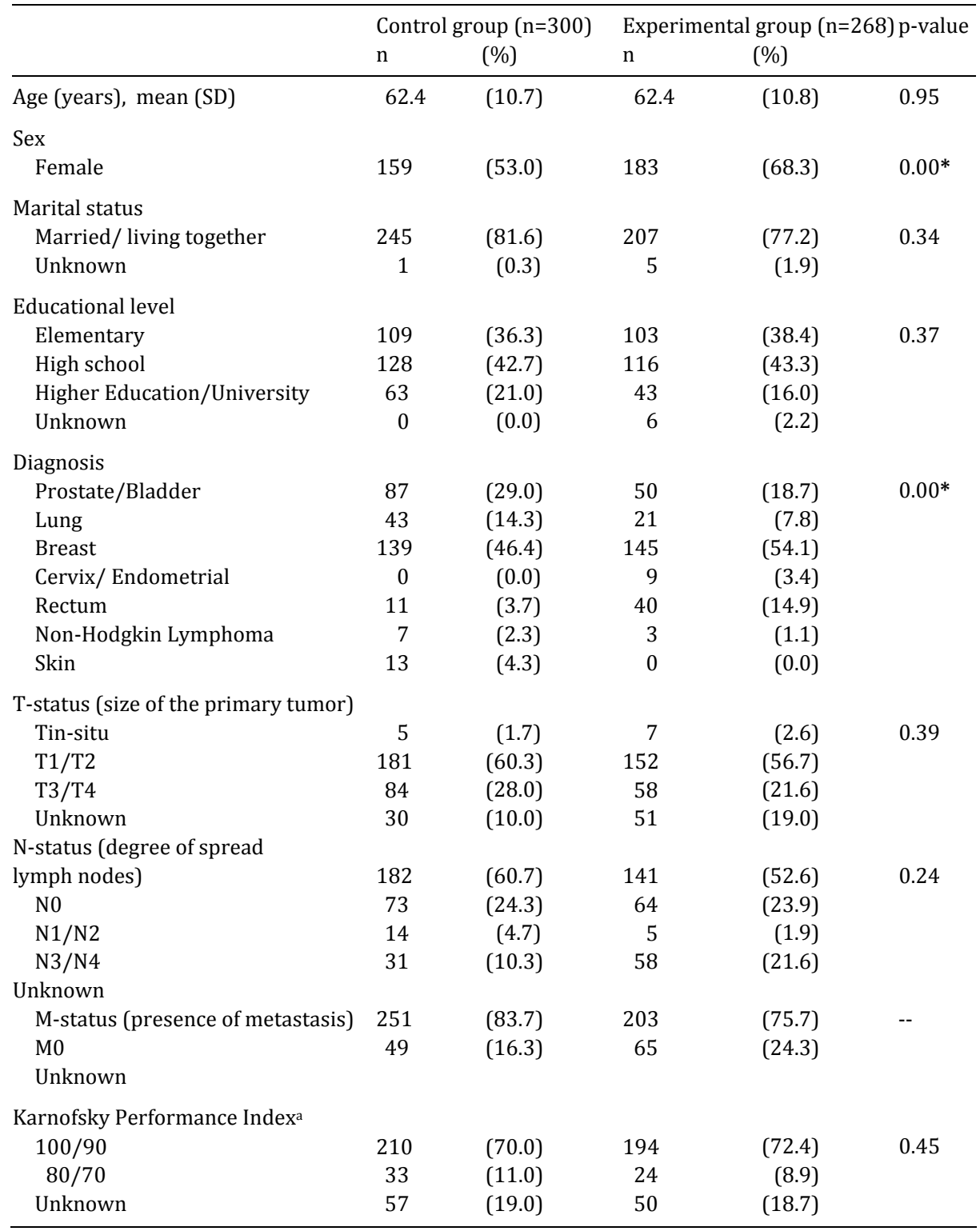

*Significant $P$-value (two-tailed). A Holm-Bonferroni was applied for post hoc pair-wise comparisons.

aScore range 0-100, higher score indicates better physical performance.

\section{Primary outcome measures}

No significant intervention effects were observed for the total number of patients referred to psychosocial caregivers (Table 2). Figure 2 shows the num- 
bers of patients referred, and gives an overview of the type of referral in both groups. Most referred patients in the control and experimental group were female ( $81.8 \%$ and $75.0 \%$, respectively), had breast cancer $(68.2 \%$ and $56.8 \%)$, were married/living together $(76.7 \%$ and $81.8 \%)$, or had been educated to high school level (40.9\% and $47.7 \%$ ) (not tabulated). Mean age of patients in the experimental and control group was $56.7(\mathrm{SD}=11.2)$ and $57.3(\mathrm{SD}=9.3)$ respectively. Some referred patients in the control $(n=19)$ and experimental group $(n=13)$ had received psychosocial support before the start of this study, mostly for anxiety and/or depression (total $n=22$ ) (not tabulated).

There were several intervention effects on the type of referral. A group difference was identified for the patients' initiative in highlighting their need for psychosocial care during consultation. Six control group patients and 13 experimental group patients brought up their need for care (chi-square $=4.27$, $P=0.04)$. Multiple regression analyses on the data from the social workers' records at BVI showed that patients allocated to the experimental group were referred to them at an earlier stage than control group patients $(\beta=2.88$, $\mathrm{SE}=0.76, P<0.01)$. The mean time between the first consultation and being referred was 4.06 weeks for control group patients $(S D=2.94$, range from 0 to 12 weeks) and 1.05 weeks for experimental group patients ( $\mathrm{SD}=1.86$, range: 0-6 weeks). Moreover, detailed analyses showed that four patients in the control group were referred in the first week after consultation versus 17 patients in

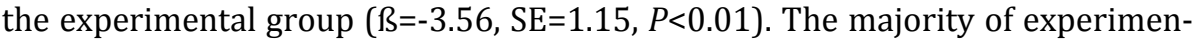
tal group patients ( $\mathrm{n}=20$, compared to $\mathrm{n}=12$ in the control group) were referred by their radiotherapist to social workers at BVI (chi-square $=6.44, P=0.01$ ).

\section{Secondary outcome measures}

Table 3 shows descriptive results of patients' outcomes on patientradiotherapist communication during the first consultation. In both groups physical problems were discussed more often than other problems. The results showed that using the SIPP tended to improve the discussion of emotional problems although this difference was not significant.

Table 4 shows the test results regarding communication for the experimental and control groups. Five final mixed-effect models are presented. There was no significant intervention effect on improving patient-radiotherapist communication in terms of discussing various psychosocial problems, nor was there any effect on patients' satisfaction with communication with the radiotherapist during the first consultation (Table 4). Furthermore, 48.7\% ( $n=146)$ of the control group patients and $42.9 \%(\mathrm{n}=115)$ of the experimental group patients reported their satisfaction with patient-physician communication to be 'very good' (a maximum score of 6) (not tabulated and not statistically significant). 


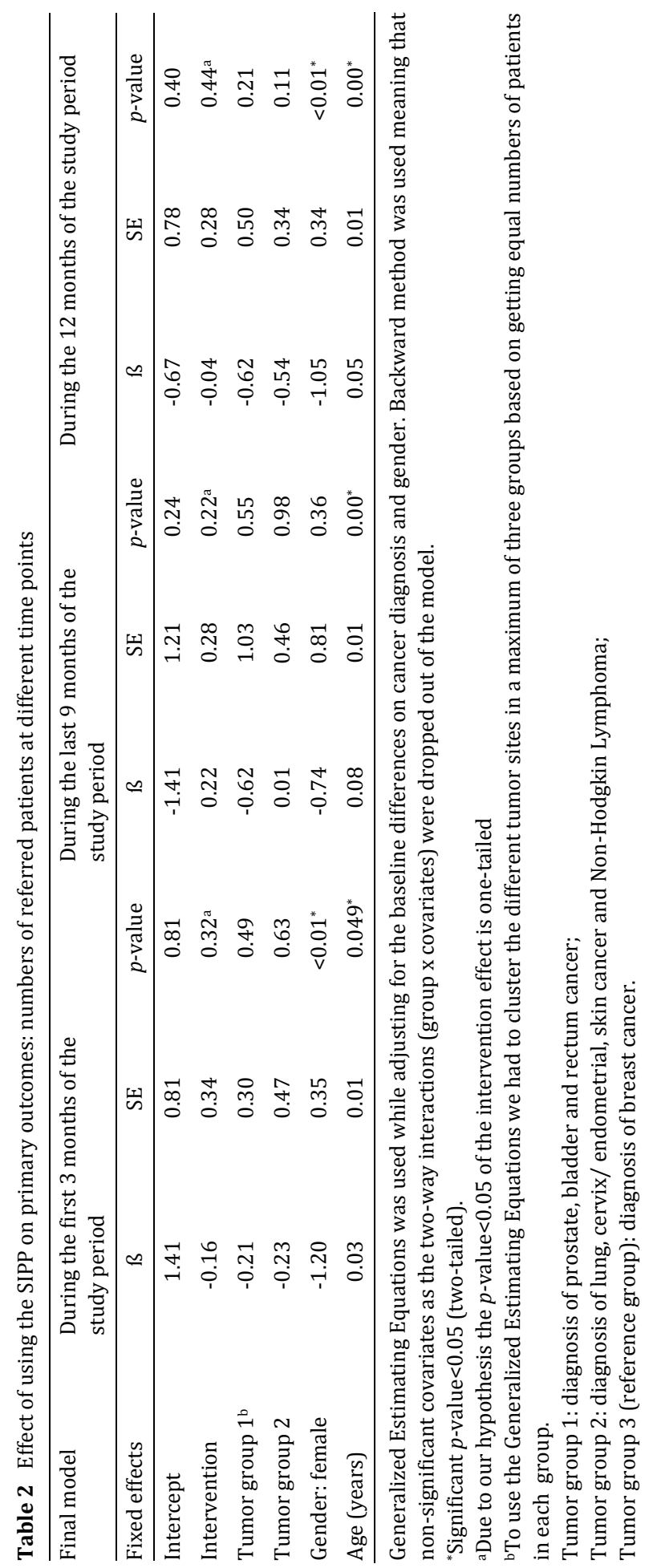




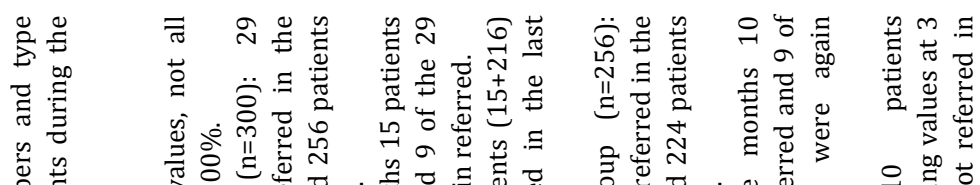

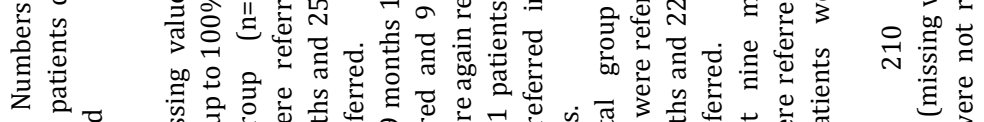

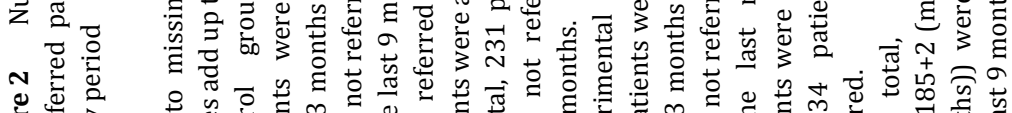
焉焉

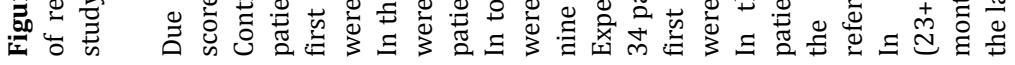
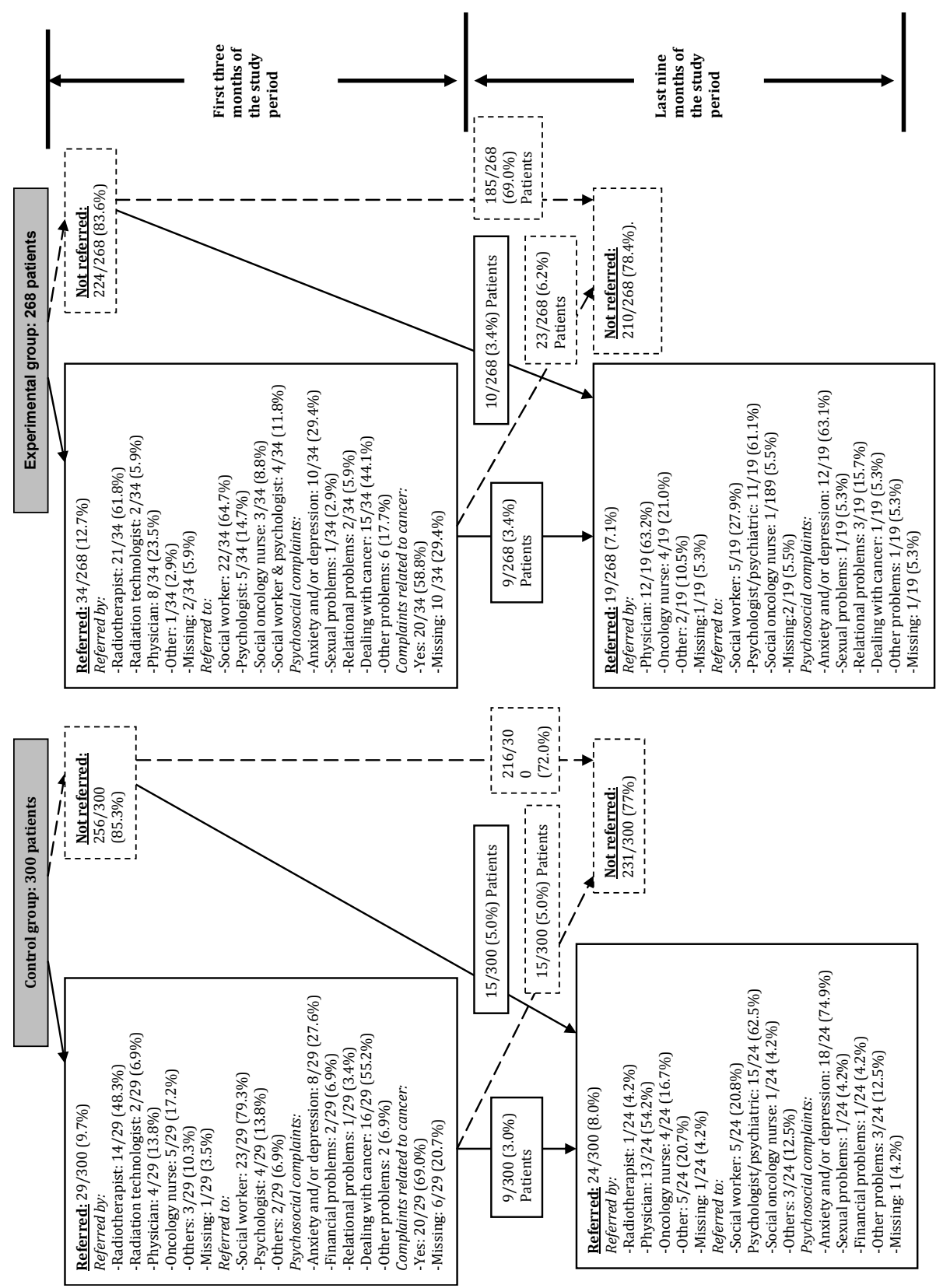


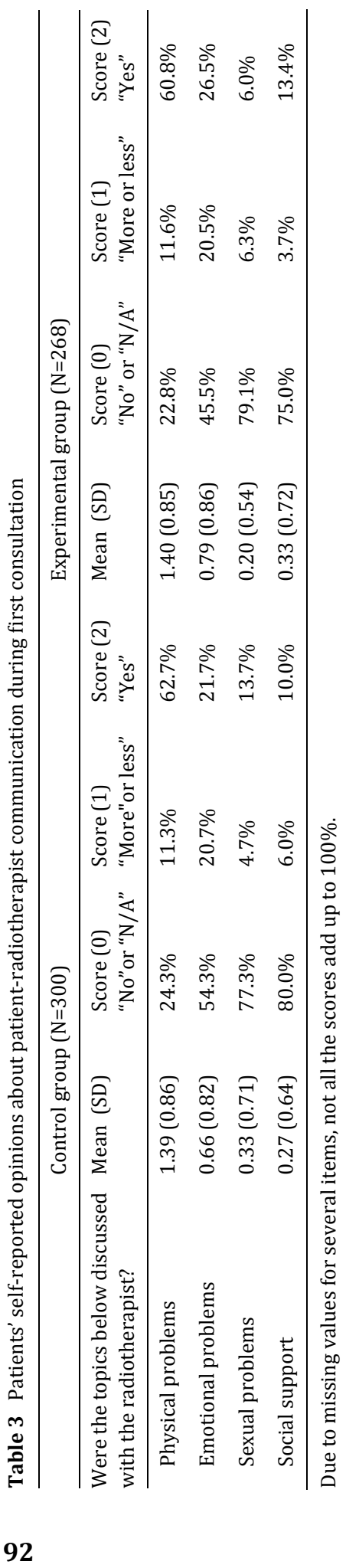




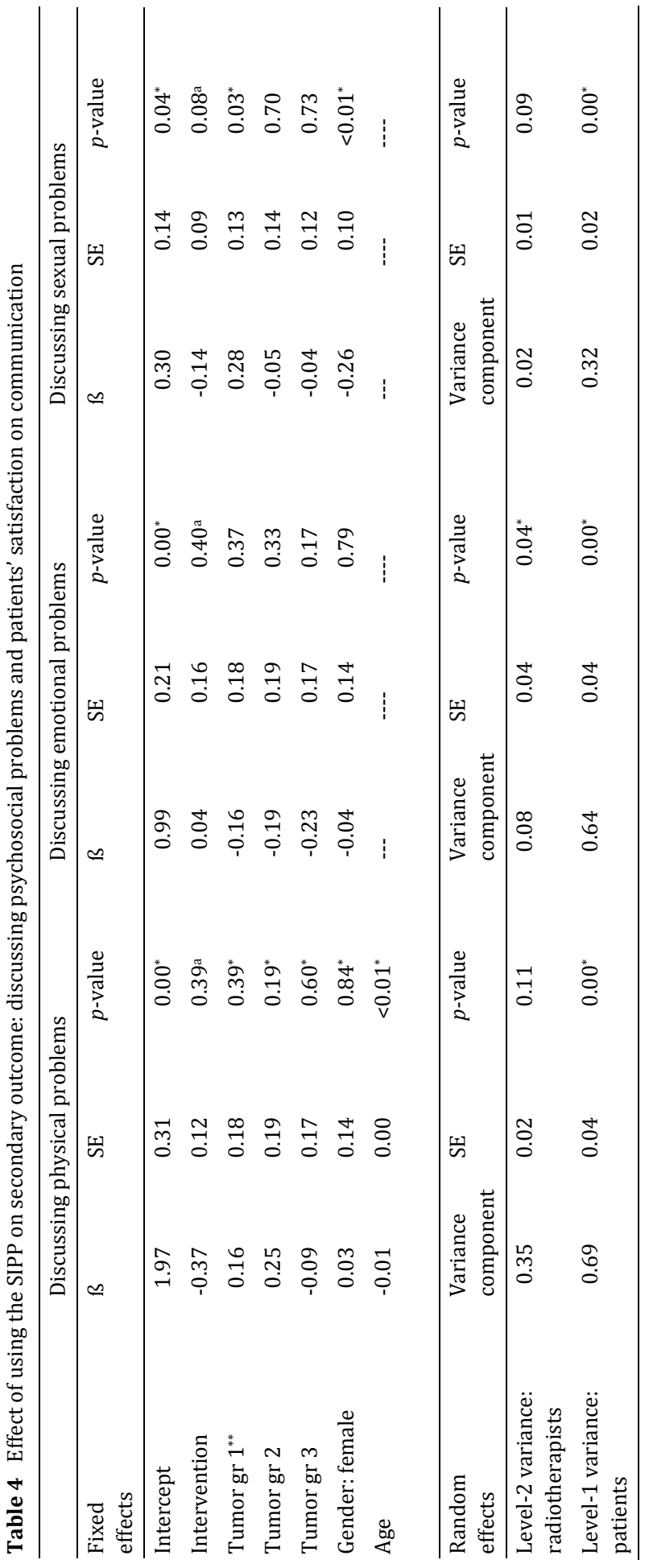




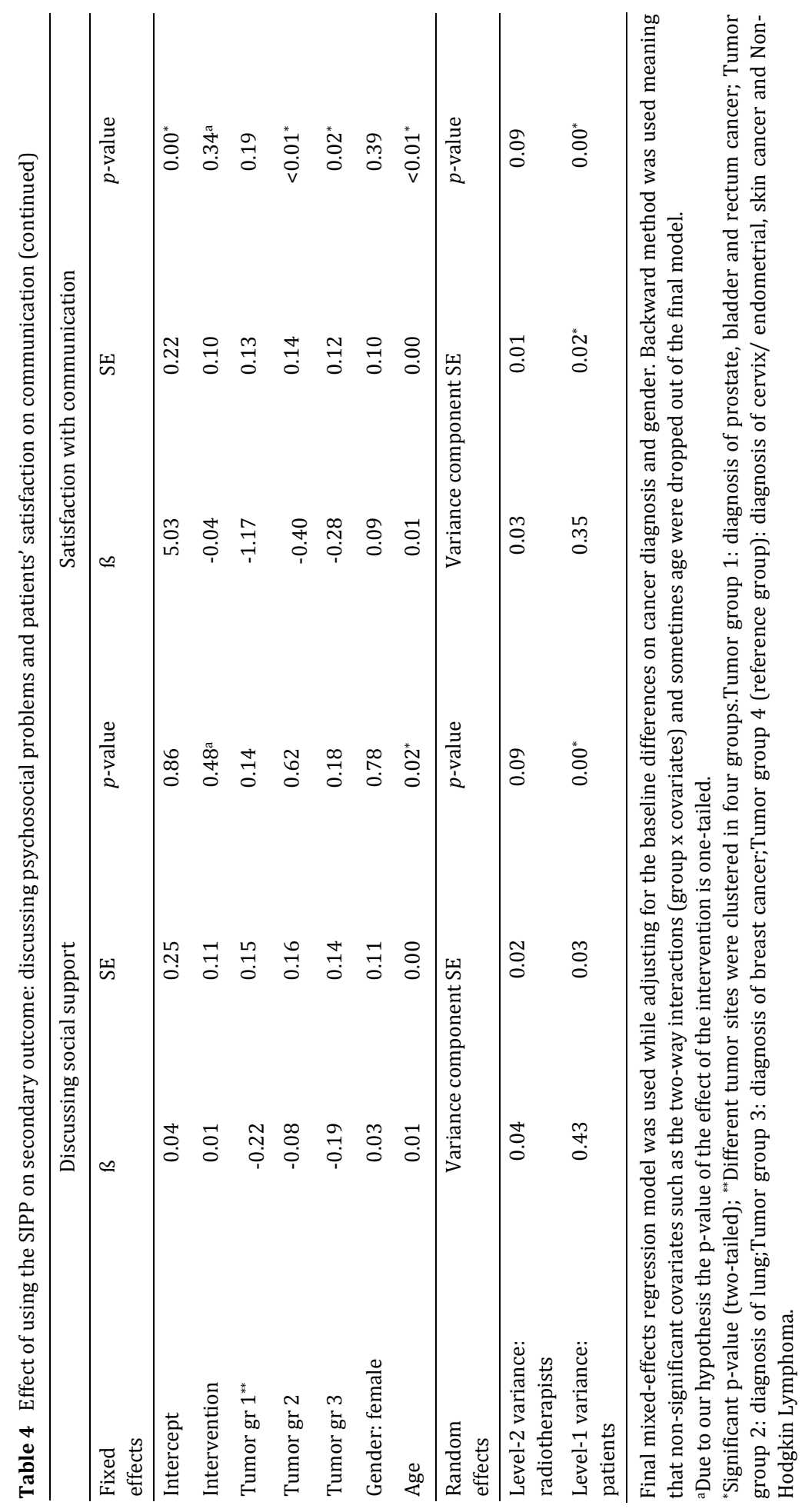




\section{Discussion}

This study examined whether using a screening instrument, SIPP to identify psychosocial problems in cancer patients receiving RT had positive effects on the number of patients referred to psychosocial caregivers, the type of referral, patient-radiotherapist communication, and patients' satisfaction regarding communication with their radiotherapist. Our primary hypothesis ('higher numbers of patients referred to psychosocial caregivers in a timely fashion') was partially confirmed since some aspects of the type of referral were altered. Results show that using a screening instrument did not seem to be sufficient to improve the number of referral. Furthermore, results did not confirm our second hypothesis that using a screening instrument improves discussing psychosocial aspects during patient-radiotherapist consultation and thus patient satisfaction.

Regarding our outcome on the type of referral, completing a screening instrument seemed to encourage patients to discuss their need for psychosocial care, although this did not result in higher numbers of actual referral. Similar to previous study ${ }^{163,179}$ our results showed that among those patients who were screened and referred to the social workers working at BVI, the mean time to referral was on average 3 weeks shorter than for patients who were not screened for psychosocial problems, and that most were referred during the first week after consultation. Thus, using screening instruments may improve the detection of psychosocial problems and ensure treatment at an earlier stage. This is important because timely treatment at an early stage may prevent further deterioration and the development of possible psychiatric disorders in cancer patients ${ }^{48}$, and potentially improves quality of life. ${ }^{150}$ It should be noted that data on referrals to external caregivers (outside BVI) were not collected systematically, but there is no reason to assume that these would have been different from internal referrals. Additionally, since the majority of experimental group patients were referred by their radiotherapist to the social workers working at BVI, it seems that when using a screening instrument radiotherapists prefer to refer patients to social workers within their own department. This could improve the quality of care because the social workers are well informed about the impact and side effects of RT and are able to share information with the radiotherapist. Moreover, patients can combine their RT with additional visits to these social workers (same day, same location). This may be more convenient and less time consuming, especially for ill patients.

Our results support another study in which no effects of using a screening instrument on total numbers of referral to psychosocial caregivers were identified. ${ }^{163}$ However, in contrast Pruyn and colleagues reported that more patients with psychosocial problems were referred when using a screening instrument (preliminary version of the SIPP). ${ }^{86}$ The lack of short-term intervention effects in our study might be influenced by the fact that the current standard of care 
(including that for our control group patients), as provided by health care professionals, appears to be high, because many of the patients' psychosocial functions are already adequately addressed. ${ }^{65}$

With regards the secondary hypothesis, using a screening instrument did not seem to improve patient-radiotherapist communication in terms of discussing psychosocial problems. This result is comparable with outcomes of other studies. ${ }^{64,66,67}$ Main focus of both radiotherapists and patients may be on treatment, side effects and prognosis. Our results confirmed that discussion of physical problems was emphasized in both groups. Previous studies reported that physicians showed a preference for dealing with physical rather than psychosocial problems. ${ }^{34,148,149,180}$ Barriers against discussing psychosocial problems could be insufficient time ${ }^{154}$, and the lower priority given to psychosocial problems ${ }^{170}$, especially during the first consultation. An alternative could be to screen at other time points and to improve the communication skills of radiotherapists. Furthermore, in line with other studies we found no effect of intervention on patients' satisfaction with communication. ${ }^{63,67} \mathrm{An}$ explanation could be that there was little room for improvement since the patients' level of satisfaction was already high, as seen in the control group.

This trial had many strengths: the design, number of participating patients and the high follow-up rates. However, there were also some limitations that may have affected the results. First, despite our study design potential contamination between groups could have occurred due to the heightened awareness of the study's aims in radiotherapists of the control group. Radiotherapists in the experimental group were asked not to discuss this intervention with colleagues. However, it was difficult to avoid radiotherapists in the control group becoming at least partially aware of this study. In addition, the behaviour of health care professionals other than radiotherapists may have changed as a result of a heightened awareness of the study's aims, particularly since some participated in handing out questionnaires to participating patients. As the study was conducted in one institution, institutional bias may have occurred. While this could have been prevented by the randomization of clinics to either standard care or the intervention condition, such randomization could lead to another limitation linked with potential differences between clinics. Second, the number of radiotherapists participating in this study was rather small. Part of the success of the intervention depends on radiotherapists' attitude regarding the screening of psychosocial problems. If some radiotherapists were not enthusiastic about such screening this could have resulted in less favourable outcomes. Third, the observed lack of effect on communication and patients' satisfaction regarding radiotherapist-patient communication could be related to the tool used. To minimize response burden, a limited number of four questions was administered to measure communication aspects and only one to measure patients satisfaction. More detailed questionnaires might have given us more in-depth information on potential effects. Fourth, due to our randomization procedure, 
randomizing radiotherapists instead of patients among groups, and since each radiotherapist is specialized in the treatment of specific cancer types, there were baseline differences with respect to gender and cancer diagnosis between groups. Although this may have affected our results in a negative way, we have included both variables as covariates in our multivariate models.

Conclusion, these results suggest that a simple psychosocial screening procedure may be valuable in the timely treatment of psychosocial problems and in preventing further development of psychiatric disorders. Future efforts should be directed at adequate timing of screening and enhancing physicians' awareness regarding the importance of identifying and treating psychosocial problems. 


$$
6
$$




\section{Psychosocial screening effects on health related outcomes in patients receiving radiotherapy}

This chapter has been submitted as:

Anna P. B. M. Braeken, Gertrudis I. J. M. Kempen, Daniëlle B. P. Eekers, Ruud M. A. Houben, Francis C. J. M. van Gils, Ton Ambergen and Lilian Lechner Psychosocial screening effects on health related outcomes in patients receiving radiotherapy 


\begin{abstract}
Purpose: This study examined the short- and long-term effects of using a screening instrument on psychological distress and health-related quality of life (HRQoL) among cancer patients receiving radiotherapy. In addition, we investigated the effect of early psychosocial treatment on patients' overall healthrelated outcomes as previous research showed that patients in the screening condition were referred to a psychosocial caregiver at an earlier stage.
\end{abstract}

Patient and Methods: A randomised controlled trial with a cluster randomisation at the levels of 14 radiotherapists, 568 patients and repeated measurements was conducted. Patients were asked to complete questionnaires at three and twelve month follow-ups.

Results: Mixed models analyses showed no significant intervention effects on patients' overall extent of psychosocial distress and HRQoL, both in the shortand the long term. Post-hoc analyses revealed significant interactions of the intervention with early referral and improved HRQoL and anxiety, suggesting that earlier referral might influence short-term HRQoL and experience of anxiety in patients.

Discussion: Our results suggest that psychosocial screening does not improve patients' overall health-related outcomes. Further research into potential effects in specific groups of patients of using a screening instrument in oncology settings seems warranted. For this, one of the challenges is to get insight into the effects of early referral of cancer patients for psychosocial support since early referral might have a favourable effect on some of the patients' health-related outcomes. 


\section{Introduction}

Cancer must be considered as a biopsychosocial illness ${ }^{181}$ since cancer and its treatment may lead to psychosocial problems involving symptoms of anxiety and depression. Although a certain amount of these problems is common, approximately $30 \%$ of the cancer patients experience symptoms of anxiety and depression ${ }^{47,173}$ severe enough to adversely affect treatment outcomes and health-related outcomes such as quality of life (HRQoL). ${ }^{38,46,47}$ Along with other vital signs (e.g. pain), emotional well-being has been discussed as the "sixth vital sign" in cancer care.35,181,182. Despite radiotherapy treatment (RT) commonly being used in the treatment of malign tumours, many patients perceive this treatment as frightening, which may adversely affect emotional functioning. ${ }^{63,183}$ Patients may experience psychosocial problems prior to the initiation of RT, as well as during and after the period of treatment. ${ }^{183}$ Patients with psychosocial problems may benefit from pharmacological and nonpharmacological treatment 184,185 , nevertheless fewer than $10 \%$ of the cancer patients with these problems are actually identified and referred for psychosocial help. ${ }^{186}$ Feedback about patients' self-reported emotional well-being and functioning by using screening instruments can be useful for physicians given that their awareness of patients' concerns and well-being may increase and patient-physician communication may improve. ${ }^{34,51,52,65}$ As a result, using these tools may prevent underdiagnosis of psychosocial problems and enhance adequate treatment. ${ }^{25}$

International $54,57,186,187$ as well as Dutch ${ }^{59}$ practice guidelines recommend that every adult cancer patient should be screened for psychosocial problems at periods of increased vulnerability during the illness trajectory to prevent the development of more significant disorders, such as major depression. Despite the growing recognition of the need to identify psychosocial problems in cancer patients, large-scale, well-designed trials establishing evidence of the effect of psychosocial screening are scarce. ${ }^{53,60}$

We conducted a cluster randomised controlled trial to examine the short(three months) and long-term effects (12 months) of using a screening instrument on psychological distress and HRQOL among cancer patients receiving RT. Our hypothesis is that since radiotherapists would become more aware of patients' psychosocial problems, they would take appropriate action by referring patients for psychosocial support. This would result in better health-related outcomes of the patients, including lower psychological distress and better HRQoL, both in the short and the long term. Results of our previous study showed that the referral rate of cancer patients to psychosocial caregivers did not significantly increase by using a screening instrument. However, patients in the screening condition were referred to psychosocial support at an earlier stage (approximately three weeks) (submitted article, available upon request). Although similar results have been found by other researchers ${ }^{179,188}$, the clinical significance of earlier treatment on patients' outcomes remains unclear. Our 
hypothesis is that referring and treating patients at risk at an earlier stage may improve their extent of psychological distress and HRQoL.

\section{Patients and methods}

\section{Study design}

A randomised controlled trial with a cluster randomisation at the levels of radiotherapists, patients and repeated measurement was conducted (NCT00859768). Detailed description of this design can be found elsewhere. ${ }^{156}$ In short, a Solomon Four Group design, with two experimental and two control groups, was followed in order to eliminate possible influences on the patients' reported screening outcomes resulting from the completion of questionnaires at baseline as pre-test. Thus, a baseline assessment was only conducted in one experimental and one control group (Figure 1). To reduce contamination bias, radiotherapists were randomly allocated to the experimental or control group. Patients providing written informed consent were linked to their radiotherapist and individually randomised to the group with or without pre-measurement.

\section{Participants}

Patients receiving RT at the Institute Verbeeten (BVI), a radiation oncology department in the south of the Netherlands, were eligible if they had a cancer diagnosis of the lung, prostate, bladder, rectum, breast, cervix, skin, endometrial or non-Hodgkin's lymphoma; had an age over 18 years; had no metastases; and were able to provide written informed consent. Patients were excluded if they received palliative treatment; had $\leq 10$ fractions of RT; were unable to read and speak Dutch; or were unable to complete the questionnaires (e.g. too sick). All participating patients provided written informed consent.

All radiotherapists working at the BVI were invited to participate. The Medical Ethics Committee of the Twee Steden Hospital in the south of the Netherlands approved the study protocol. 


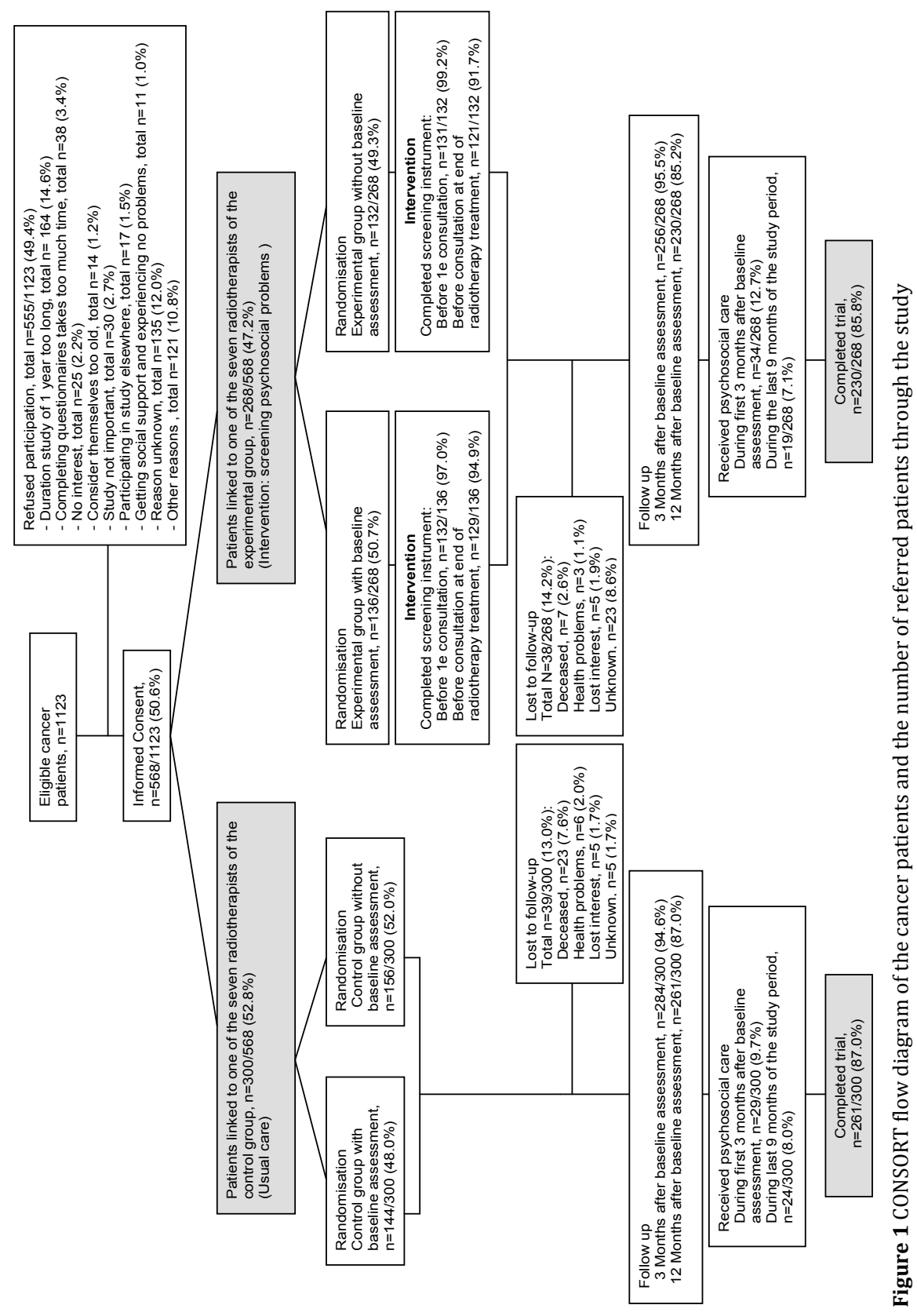




\section{Procedures}

Eligible patients received information about the study by mail to their home address. Before the first consultation with the radiotherapist (approximately three weeks before the start of RT), patients randomised to groups with baseline assessment were asked to complete questionnaires in a secluded area of the waiting room. Patients allocated to the experimental groups were also asked to complete a screening instrument to identify potential psychosocial problems (see next section). Psychological distress and HRQoL were measured by means of mailed questionnaires at three and twelve months after baseline assessment (Figure 1).

\section{Intervention}

The Dutch Screening Inventory of Psychosocial Problems (SIPP) was chosen as the intervention screening instrument since this tool is specifically developed for use in cancer patients. ${ }^{156,178}$ It is short, easy to score, and can be quickly interpreted by medical staff. The SIPP comprises 24 items and assesses multiple aspects of psychosocial problems (physical and psychological complaints; social/financial problems and sexual problems). The SIPP provides referral advice in relation to the patient's self-reported scores on two items to verify whether the patient would like help or advice for their reported physical, psychosocial and/ or sexual problems. Previous study confirmed its reliability and validity ${ }^{178}$. Several studies have included the SIPP, and it is nowadays used in several Dutch hospitals. $86,152,158,189$

Before the start of the study, seven radiotherapists in the experimental group received training in using and interpreting the SIPP. Patients received the SIPP twice: just before the first consultation with the radiotherapist and before the consultation at the end of the RT. On both occasions, the radiotherapists checked the scores to obtain an overview of psychosocial problems and patients' needs and/or preference for psychosocial care. Potential referral for psychosocial support was based on the scores of the SIPP178 in combination with the radiotherapists' judgement about the patients' needs and/or preference for psychosocial care.

Patients of the control group received standard care. No guidelines for routine screening of psychosocial problems in patients existed. Patients were referred to psychosocial caregivers when judged necessary by the radiotherapist. 


\section{Measures}

\section{Socio-demographics and medical characteristics}

At baseline, patients' socio-demographic data were collected on a short form completed by patients. Medical characteristics (Table 1) were collected from patients' medical records.

Relevant socio-demographic data of the radiotherapists were obtained from personnel records.

\section{The extent of psychological distress}

The Hospital Anxiety and Depression Scale (HADS) is a 14-item selfadministered rating scale with two subscales for symptoms of anxiety and depression. ${ }^{90}$ It is a well-validated instrument ${ }^{90,98}$ and widely used in studies among cancer patients. ${ }^{31,84}$ Total scores on each subscale theoretically range from 0 to 21 and classify patients' anxiety and depression symptom levels as low (0-7), and moderate to high (8-21). The Goldberg's General Health Questionnaire-12 version (GHQ-12) is a validated instrument ${ }^{91}$ that has also frequently been used in studies among cancer patients. ${ }^{77,131,133,140}$ The GHQ-12 assesses with 12 items whether patients considers themselves better, the same, worse or much worse over the previous four weeks than they "usually" are. Those who indicate that their symptoms have increased receive a score of 1 . Total scores range from 0 to 12 . A conservative cut-off score of 3 was selected. ${ }^{91}$ Higher scores on both the HADS and GHQ-12 indicate higher levels of symptoms.

\section{Health-related quality of life ( $H R Q o L)$}

HRQoL was measured by the European Organisation for Research and Treatment of Cancer Quality of Life Questionnaire (EORTC QLQ-C30). ${ }^{130}$ This 30-item cancer-specific questionnaire is validated and widely used in clinical studies. ${ }^{190,191}$ It comprises (a) five functional subscales on physical, role, emotional, cognitive, and social functioning; (b) an overall global health status and quality of life subscale; (c) three symptom subscales on fatigue, pain, nausea/vomiting; and (d) six single items on dyspnoea, sleep disturbance, appetite loss, constipation, diarrhoea, and financial impact. Items of the functional and the symptom scales as well as the single items each have four response options: 1 (not at all), 2 (a little), 3 (quite a bit) and 4 (very much). Both items of the global health status/quality of life subscale use a 7-point visual analogue scale (VAS) ranging from 1 (very poor) to 7 (excellent). ${ }^{139}$ Raw scores on the subscales, the single items and the VAS were linearly transformed to 0-100 scores. Higher scores on the functional subscale and the global health status/quality of life subscale indicate better functioning. Higher scores on the symptom scales and the single items indicate more symptoms including poorer functioning. 


\section{Statistical Methods}

Before starting the analyses, a potential test-effect of the baseline assessment on the outcomes was identified using backward regression analyses. Dependent variables were scores on the HADS and GHQ-12, 3 and 12 months after the baseline measurement. The independent variable was the status of the experimental or the control group condition, both with and without baseline assessment. The covariates were gender, age, educational level and tumour sites. Non-significant covariates were dropped from the model. If differences between groups with and without baseline assessment had been identified, the four groups would be need to be handled separately in the analyses.

Socio-demographic and medical characteristics as well as the extent of psychological problems at baseline were compared between groups using chisquare test for categorical variables and the Students t-test or the MannWhitney $U$ tests for continuous variables. To gain insight into the intervention effect on the outcomes (extent of psychological distress and HRQoL) different analyses were used.

First, mixed effects' modelling was employed for the analyses of the continuous outcomes. An advantage of this method is that the missing data of the patients without baseline assessment do not constitute a problem for the application of hierarchical linear models. ${ }^{192}$ The outcomes were analysed using mixed-effects models with a "Toeplitz Heterogeneous" covariance structure since this structure fitted most outcomes.

Second, group differences in the dichotomous distress outcome (no or at least moderate distress) were analysed using generalised estimating equations.

All the analyses were undertaken at the patient level, including adjusting for patients clustering within radiotherapists and repeated measurements clustering within patients. The independent variable group (experimental versus control group) and the covariates (tumour sites; gender; age; education level and time (two dummies: 3 and 12 months after baseline)) were included in the models as well as the 2 -way interaction group $\mathrm{x}$ time (two dummies). The backward method was used in which that non-significant covariates were dropped from the model.

Third, mixed-effects models with a "Toeplitz Heterogeneous" covariance structure were performed to identify potential associations between being referred in an earlier stage and the extent of psychological distress and HRQoL in the short and long term. The independent variable group (experimental versus control group), the covariates (tumour sites; gender; age; education level; time (two dummies: 3 and 12 months after baseline)) and referral (being referred during the first 3 months of the study was coded as 1) were included in the models as well as the 2-way interactions group $\mathrm{x}$ time (two dummies); group $\mathrm{x}$ referral; time $\mathrm{x}$ referral and the 3 -way interaction group $\mathrm{x}$ time (two dummies) $\mathrm{x}$ referral. 
Regarding the hypothesis of this study, the level of statistical significance for an intervention effect was set at 0.05 (one-tailed). For other analyses the level of statistical significance was set at 0.05 (two-tailed). Analyses were performed according to the intention-to-treat principle using SPSS 17.0 for Windows statistical software.

\section{Results}

\section{Participants' characteristics}

The study was carried out between April 2008 and October 2010. Figure 1 is a CONSORT flowchart with patients' progress through the study. In total, 1123 eligible cancer patients were invited to participate in the study and 555 (49.4\%) patients refused to participate. More than $85 \%$ of the participating patients completed the study. There was no significant difference in the dropout rate between the intervention and the control groups.

The baseline characteristics of the participating patients $(n=568)$ are listed in Table 1. Patients' characteristics were well balanced between the two groups, although the groups were significantly different for gender and tumour sites. Table 2 presents the extent of psychological distress and HRQoL at baseline of the patients of both groups with baseline assessment ( $n=144$ and $n=136$, respectively). Both groups were balanced for patients' extent of psychological distress and HRQoL at baseline.

All 14 radiotherapists working at BVI participated in the study. The mean age of the seven radiotherapists allocated to the control group was 44.8 years $(\mathrm{SD}=9.2$ ), five of which were male and two of which were female. On average they had worked for 17.1 years (range 2-29 years) as a radiotherapist. The mean age of the seven radiotherapists allocated to the experimental group was 44.6 years $(S D=10.0)$ and four were male, three were female. On average they had worked for 14.1 years (range 4-35 years) as a radiotherapist.

\section{Psychological distress outcome}

The results of the mixed effects models for psychological distress scores and the results of the generalised estimating equation models for the number of patients with distress are presented in Table 3. No significant intervention effects were observed for patients' extent of psychosocial distress and the proportion of patients with distress, both in the short and the long term. 


\section{Health-related QoL outcome}

The results of the mixed effects model for the EORTC-C30 scores are presented in Table 4. No significant intervention effects were observed on HRQoL in the short and long term. However, the control group patients reported better role functioning on the short term compared to patients in the experimental group $(P=0.04)$.

\section{Subgroup post-hoc analyses}

Four significant interactions between group, time (three month follow-up) and referral (three months) were identified: anxiety symptoms $(\beta=-2.16$ and $P=0.03)$, emotional functioning $(\beta=15.16$ and $P=0.02)$, appetite loss $(\beta=15.67$ and $P=0.04)$, and financial problems $(\beta=-11.39$ and $P=0.01)$. These results suggest that earlier referral might influence short-term HRQoL aspects and anxiety in patients. 
OUTCOMES: PSYCHOLOGICAL DISTRESS AND QOL

Table 1 Baseline characteristics of the patients in control or experimental group

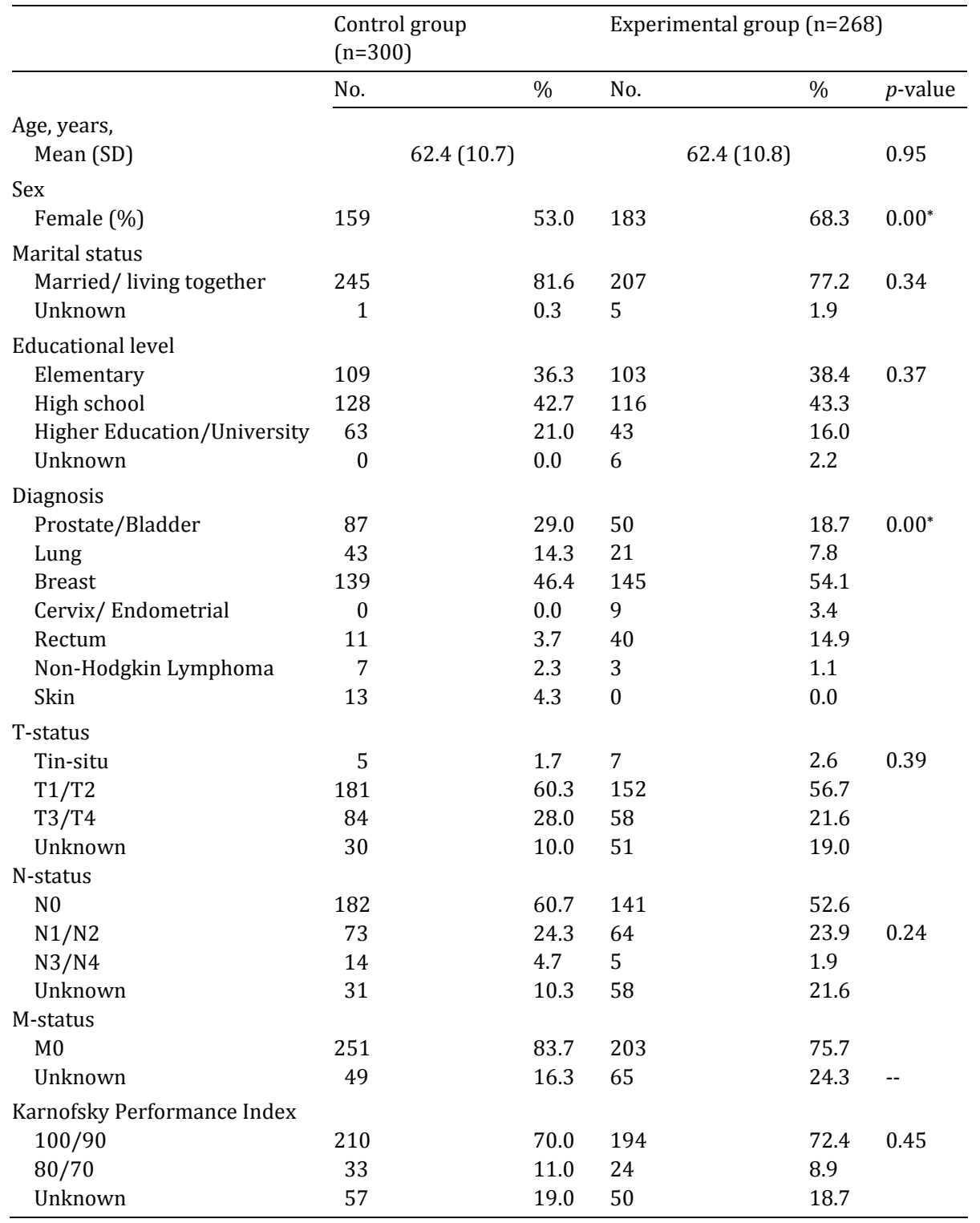

Abbreviations: SD, standard deviation.

*Significant $P$-value was set at .05 (two-tailed). 


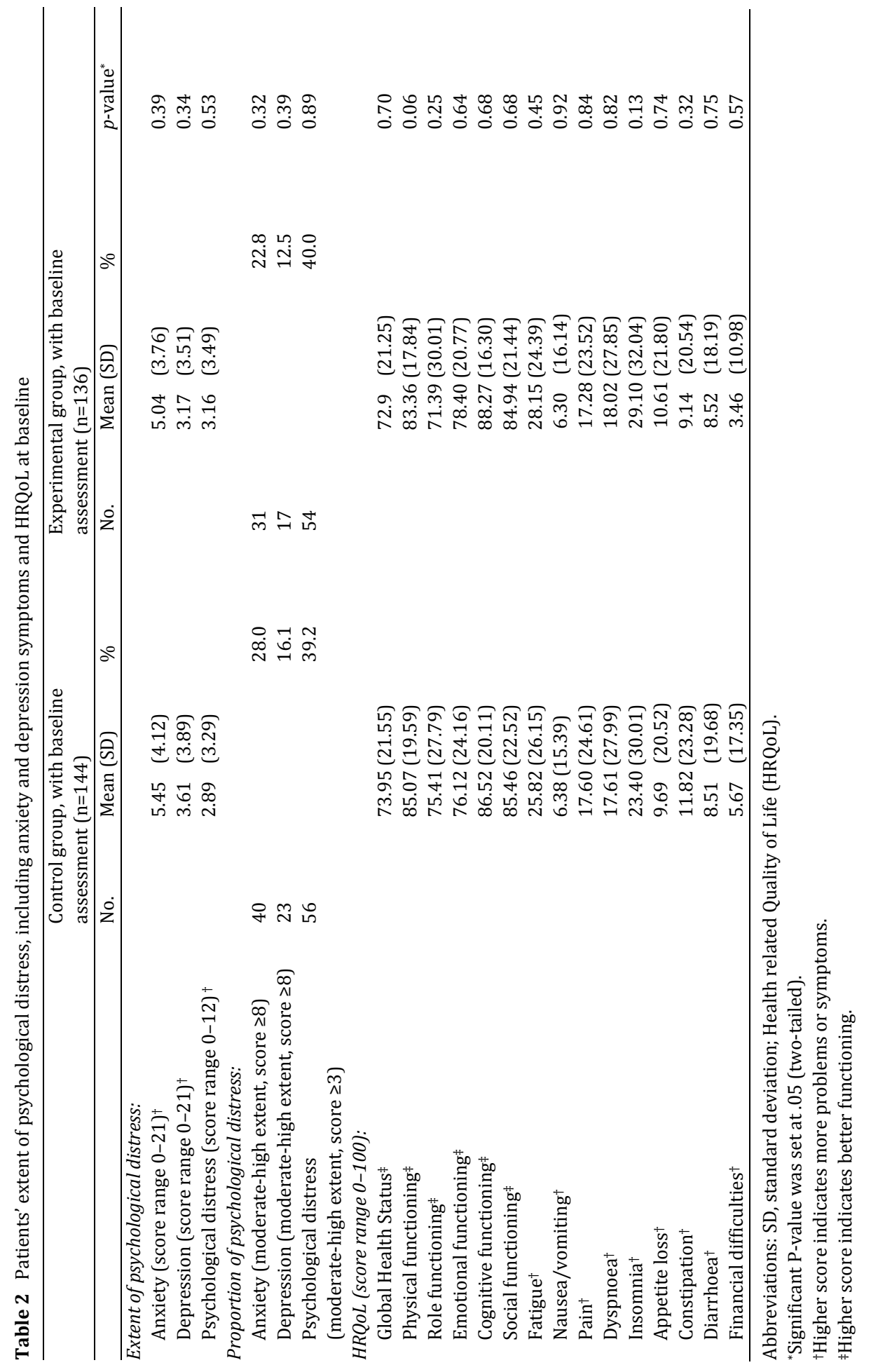


Table 3 Effects of the intervention on primary outcomes on the short (3 months) and long term (12 months)

\begin{tabular}{|c|c|c|c|c|c|c|c|c|}
\hline & \multicolumn{2}{|c|}{$\begin{array}{l}\text { Control group } \\
(\mathrm{n}=300)\end{array}$} & \multirow[b]{2}{*}{$\%$} & \multicolumn{3}{|c|}{$\begin{array}{l}\text { Experimental group } \\
(\mathrm{n}=268)\end{array}$} & \multirow[t]{2}{*}{$\begin{array}{l}\text { Intervention } \\
\text { effect } P^{*}\end{array}$} & \multirow[t]{2}{*}{$\begin{array}{l}\text { Estimate } \\
\text { of effects }\end{array}$} \\
\hline & $\mathrm{n}$ & Mean (SD) & & $\mathrm{n}$ & Mean (SD) & $\%$ & & \\
\hline \multicolumn{9}{|l|}{$\begin{array}{l}\text { Anxiety (score } \\
\text { range } 0-21)^{a}\end{array}$} \\
\hline 3 months follow-up & & $4.86(3.81)$ & & & $4.66(3.68)$ & & 0.44 & -0.06 \\
\hline 12 months follow-up & & $4.98(4.24)$ & & & $4.57(3.90)$ & & 0.33 & 0.18 \\
\hline \multicolumn{9}{|l|}{$\begin{array}{l}\text { Depression } \\
{\text { (score range } 0-21)^{\text {a }}}^{\text {sere }}\end{array}$} \\
\hline 3 months follow-up & & $3.72(3.76)$ & & & $3.69(4.11)$ & & 0.25 & -0.24 \\
\hline 12 months follow-up & & $3.70(4.08)$ & & & 3.45 (3.78) & & 0.49 & 0.01 \\
\hline \multicolumn{9}{|l|}{$\begin{array}{l}\text { Psychological distress } \\
\text { (score range } 0-12)^{\mathrm{a}}\end{array}$} \\
\hline 3 months follow-up & & $2.85(3.38)$ & & & $2.74(3.26)$ & & 0.19 & 0.32 \\
\hline 12 months follow-up & & $2.14(3.22)$ & & & $1.96(3.14)$ & & 0.12 & 0.46 \\
\hline \multicolumn{9}{|l|}{$\begin{array}{l}\text { Anxiety (moderate- } \\
\text { high extent, score } \geq 8 \text { ) }\end{array}$} \\
\hline 3 months follow-up & 64 & & 21.3 & 57 & & 21.3 & 0.15 & -1.06 \\
\hline 12 months follow-up & 61 & & 20.3 & 42 & & 15.7 & 0.50 & $<0.01$ \\
\hline \multicolumn{9}{|l|}{$\begin{array}{l}\text { Depression (moderate- } \\
\text { high extent, score } \geq 8 \text { ) }^{\text {b }}\end{array}$} \\
\hline 3 months follow-up & 23 & & 7.7 & 17 & & 6.3 & 0.11 & 0.45 \\
\hline 12 months follow-up & 46 & & 15.3 & 46 & & 17.2 & 0.49 & 0.01 \\
\hline \multicolumn{9}{|l|}{$\begin{array}{l}\text { Psychological distress } \\
\text { (moderate-high extent, } \\
\text { score } \geq 3 \text { ) }\end{array}$} \\
\hline $\begin{array}{l}3 \text { months } \\
\text { follow-up }\end{array}$ & 117 & & 39.00 & 103 & & 38.40 & 0.36 & -0.10 \\
\hline $\begin{array}{l}12 \text { months } \\
\text { follow-up }\end{array}$ & 74 & & 24.70 & 65 & & 24.30 & 0.39 & -0.08 \\
\hline
\end{tabular}

Abbreviations: SD, standard deviation.

aMixed-effects regression model was used while adjusting for the baseline differences in cancer diagnosis and gender.

Backward method was used meaning that non-significant covariates were dropped out of the final model.

${ }^{\mathrm{b}}$ Generalized Estimating Equations was used while adjusting for the baseline differences in cancer diagnosis and gender.

Backward method was used meaning that non-significant covariates were dropped out of the final model.

'Estimate of effects of the interaction: time ( 3 or 12 months follow-up) $\mathrm{x}$ group.

Significant $P$-value for the two-way interaction was set at 05 (one-tailed).

Higher score indicate more symptoms. 
Table 4 Effects of the intervention on secondary outcomes on the short ( 3 months) and long term (12 months)

\begin{tabular}{|c|c|c|c|c|}
\hline & $\begin{array}{l}\text { Control group } \\
(n=300) \\
\text { Mean (SD) }\end{array}$ & $\begin{array}{l}\text { Experimental group } \\
(\mathrm{n}=268) \\
\text { Mean (SD) }\end{array}$ & $\begin{array}{l}\text { Intervention } \\
\text { effect } P\end{array}$ & $\begin{array}{l}\text { Estimate } \\
\text { of effects }\end{array}$ \\
\hline \multicolumn{5}{|l|}{ Global Health Status ${ }^{\ddagger}$} \\
\hline 3 months follow-up & $71.48(19.62)$ & $72.61(20.08)$ & 0.14 & -2.49 \\
\hline 12 months follow-up & $76.09(17.53)$ & $75.95(18.70)$ & 0.19 & -2.11 \\
\hline \multicolumn{5}{|l|}{ Physical functioning, } \\
\hline 3 months follow-up & $81.78(17.83)$ & $79.63(21.02)$ & 0.44 & -2.73 \\
\hline 12 months follow-up & $85.00(17.76)$ & $81.99(18.06)$ & 0.48 & -0.07 \\
\hline \multicolumn{5}{|l|}{ Role functioning, $\neq$} \\
\hline 3 months follow-up & $72.87(27.52)$ & $72.77(29.77)$ & $0.04^{*}$ & -5.73 \\
\hline 12 months follow-up & $82.44(24.70)$ & $80.26(26.65)$ & 0.09 & -4.71 \\
\hline \multicolumn{5}{|l|}{ Emotional functioning, ${ }^{\ddagger}$} \\
\hline 3 months follow-up & $79.46(20.68)$ & $78.38(22.75)$ & 0.24 & 1.59 \\
\hline 12 months follow-up & $81.23(20.60)$ & $83.66(20.80)$ & 0.24 & -1.69 \\
\hline \multicolumn{5}{|l|}{ Cognitive functioning, } \\
\hline 3 months follow-up & $84.27(19.49)$ & $83.92(19.73)$ & 0.17 & 1.85 \\
\hline 12 months follow-up & $82.82(19.98)$ & $82.46(22.11)$ & 0.26 & 1.35 \\
\hline \multicolumn{5}{|l|}{ Social functioning ${ }^{\ddagger}$} \\
\hline 3 months follow-up & $81.81(22.37)$ & $83.46(23.57)$ & 0.05 & -4.08 \\
\hline 12 months follow-up & $87.55(19.10)$ & $86.99(20.73)$ & 0.17 & -2.26 \\
\hline \multicolumn{5}{|l|}{ Fatigue $^{\dagger}$} \\
\hline 3 months follow-up & $32.94(25.18)$ & $33.07(26.64)$ & 0.10 & 3.35 \\
\hline 12 months follow-up & $23.71(22.63)$ & $25.93(24.15)$ & 0.26 & 1.72 \\
\hline \multicolumn{5}{|l|}{ Nausea/vomiting, ${ }^{\dagger}$} \\
\hline 3 months follow-up & $4.23(12.20)$ & $7.15(18.51)$ & 0.14 & -2.26 \\
\hline 12 months follow-up & $3.77(12.90)$ & $3.14(10.43)$ & 0.22 & 1.52 \\
\hline \multicolumn{5}{|l|}{ Pain ${ }^{\dagger}$} \\
\hline 3 months follow-up & $18.66(23.49)$ & $17.91(25.44)$ & 0.33 & 1.30 \\
\hline 12 months follow-up & $13.67(23.22)$ & $14.84(22.02)$ & 0.48 & 1.53 \\
\hline \multicolumn{5}{|l|}{ Dyspnoea $^{\dagger}$} \\
\hline 3 months follow-up & $18.56(27.52)$ & $17.59(25.95)$ & 0.22 & 2.29 \\
\hline 12 months follow-up & $15.05(24.97)$ & $14.10(20.73)$ & 0.17 & 2.81 \\
\hline \multicolumn{5}{|l|}{ Insomnia $^{\dagger}$} \\
\hline 3 months follow-up & $28.17(30.13)$ & $26.61(30.19)$ & 0.08 & 8.22 \\
\hline 12 months follow-up & $22.05(28.42)$ & $24.27(30.27)$ & 0.11 & 4.38 \\
\hline \multicolumn{5}{|l|}{ Appetite loss ${ }^{\dagger}$} \\
\hline 3 months follow-up & $8.57(21.36)$ & $14.04(26.00)$ & 0.08 & -4.07 \\
\hline 12 months follow-up & $6.64(18.22)$ & $5.99(17.37)$ & 0.15 & 2.74 \\
\hline
\end{tabular}




\begin{tabular}{|c|c|c|c|c|}
\hline & $\begin{array}{l}\text { Control group } \\
(\mathrm{n}=300) \\
\text { Mean (SD) }\end{array}$ & $\begin{array}{l}\text { Experimental group } \\
(\mathrm{n}=268) \\
\text { Mean (SD) }\end{array}$ & $\begin{array}{l}\text { Intervention } \\
\text { effect } P\end{array}$ & $\begin{array}{l}\text { Estimate } \\
\text { of effects }\end{array}$ \\
\hline \multicolumn{5}{|l|}{$\overline{\text { Constipation }^{\dagger}}$} \\
\hline 3 months follow-up & 10.37 (21.98) & $8.40(18.73)$ & 0.31 & 1.37 \\
\hline 12 months follow-up & $7.46(17.73)$ & $4.97(14.50)$ & 0.19 & 2.37 \\
\hline \multicolumn{5}{|l|}{ Diarrhoea $^{\dagger}$} \\
\hline 3 months follow-up & 11.47 (22.29) & $9.71(19.71)$ & 0.11 & 3.12 \\
\hline 12 months follow-up & $7.59(17.80)$ & 7.78 (17.55) & 0.38 & 0.70 \\
\hline \multicolumn{5}{|l|}{ Financial difficulties ${ }^{\dagger}$} \\
\hline 3 months follow-up & $6.86(17.34)$ & $5.12(15.54)$ & 0.27 & -0.95 \\
\hline 12 months follow-up & $6.77(19.42)$ & $7.02(17.96)$ & 0.12 & -2.15 \\
\hline
\end{tabular}

Abbreviations: SD, standard deviation. Mixed-effects regression model was used while adjusting for the baseline differences on cancer diagnosis and gender. Backward method was used meaning that non-significant covariates were dropped out of the final model.

aEstimate of effects of the interaction: time (3 or 12 months follow-up) x group.

*Significant P-value for the three-way interaction was set at .05 (one-tailed).

*Score range $0-100$, higher score indicates better functioning.

†Score range 0-100, higher score indicates more problems or symptoms.

\section{Discussion}

This cluster randomised controlled trial examined potential improvement of the cancer patient's extent of psychological problems and HRQoL by repeated screening of the patient's psychosocial problems with feedback to the treating radiotherapist. With this trial we addressed some methodological problems of other similar studies $63,65-68,193$, including an appropriate sample size, staff training and an optimal design to prevent contamination ${ }^{60}$ and pre-test effect bias. ${ }^{156}$ The results showed no overall intervention effect on patients' self-reported psychological and HRQoL outcomes in the short (three months after baseline) and the long term (one year after baseline). The in-depth post-hoc analyses showed significant interactions between group, time (three month follow-up) and referral (three months) on anxiety symptoms, emotional well-being, appetite loss, and financial problems. This suggests that early referral to the social workers might have a favourable effect on some aspects of patients' healthrelated outcomes.

Consistent with previous randomised controlled trials $62,63,66,67$, our hypotheses that using a screening instrument would generally result in better patient heath-related outcomes in the short and long term for the total patient group was not confirmed.

Some possible reasons for the limited intervention effect on patients' overall psychological and HRQoL outcomes should be considered. First, in our previous 
study we found no significant group differences regarding the referral rate of patients to a psychosocial caregiver (submitted article is available upon request), which may explain the finding of no intervention effect in the short and long term. Next, the results of the process evaluation that was conducted along the trial showed that a minority of the involved radiotherapists in the screening condition considered the screening instrument (SIPP) to be useful and feasible ${ }^{194}$. Therefore, it is possible that this intervention did not change the radiotherapists' behaviour sufficiently to result in a measurable effect on the patients' outcomes. In addition, previous studies reported that physicians do not consider the detection of psychosocial distress as their responsibility. ${ }^{195,196}$ Finally, comparable to other studies ${ }^{63,193,197}$, the opportunity to achieve measurable improvements in well-being were limited as the majority of the patients with premeasurement reported low levels of psychological distress at baseline (Table 2). The mean scores on the anxiety and depression subscale of the HADS and the overall distress on the GHQ-12 were lower than the standard cut-off score for moderate-high distress. It should be noted that we used a Solomon Four Group to prevent pre-test bias resulting in about half of all patients did not completing questionnaires at baseline. Consequently, we did not have any information about their emotional well-being at baseline. However, the participating patients were allocated at random to the group with or without baseline assessment. Therefore, we can rightfully assume that patients in the intervention and control group without baseline assessment would have reported similar levels of psychological distress comparable to the patients in the groups with baseline assessment.

We recognise that our study has some limitations. First, the small numbers of radiotherapists allocated to the intervention group may have resulted in less favourable outcomes. If one or two out of seven radiotherapists were not enthusiastic about using a screening instrument this could have detrimental effects on the results found. Hence, the process study indicated that one radiotherapist did not discuss the screening instrument with his patients during the consultations ${ }^{194}$. Second, the exclusion criteria may have resulted in relatively wellfunctioning patients. Since the duration of this study was one year, we decided to exclude the patients who received RT with palliative intent, and who were too sick.

In conclusion, the results suggest that psychosocial screening does not improve patients' overall health-related outcome. Therefore, wider evaluation of potential effects of using a screening instrument in oncology settings seems warranted. Furthermore, the challenge is to get an insight into the effect of early referral of cancer patients for psychosocial support since it might have a favourable effect on some aspects of patients' health-related outcomes. 
OUTCOMES: PSYCHOLOGICAL DISTRESS AND QOL 


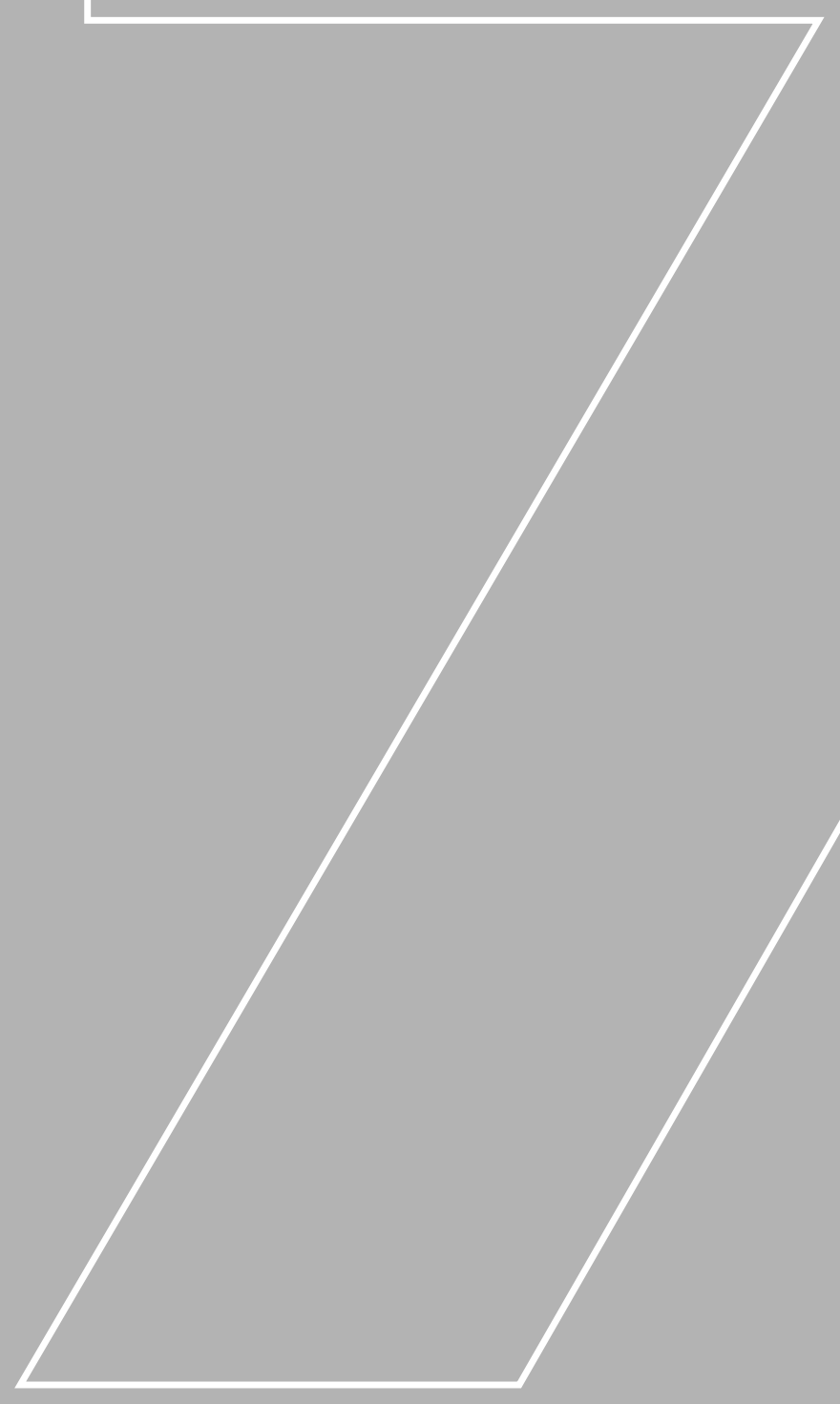




\section{Chapter 7}

\section{Psychometric Properties of the Dutch version of the Mental Adjustment to Cancer Scale in Dutch Cancer Patients}

This chapter was published as:

Anna P. B. M. Braeken1, Gertrudis I. J. M. Kempen, Maggie Watson, Ruud M. A. Houben, Francis C. J. M. v. Gils and Lilian Lechner (2010)

Psychometric Properties of the Dutch version of the Mental Adjustment to Cancer Scale in Dutch Cancer Patients

Psycho-Oncology, 19, pp. 742-749 


\begin{abstract}
Objectives: The measurement of adjustment to cancer is relevant for research purposes and daily practice. In this study the psychometric properties of the original five subscales and the two recently proposed summary scales of the Mental Adjustment to Cancer (MAC) scale were examined in Dutch cancer patients.
\end{abstract}

Methods: Data from 289 cancer patients were assessed with the Dutch version of the MAC scale and the Hospital and Anxiety Depression scale (HADS); 259 patients completed the MAC scale for a second time.

Results: In total, $85.5 \%$ of the participants completed the full MAC-scale. The internal consistency of the five subscales and the summary scales were mostly similar to the original versions. The test-retest reliability of the Fighting Spirit, Helplessness/Hopelessness, Anxious Preoccupation, Summary Positive Adjustment and Summary Negative Adjustment subscales were moderate and the test-retest reliability of the Fatalism and Avoidance subscales were low. Correlations between the original and the two summary scales of the MAC scale and the depression and anxiety subscales of the HADS indicated good convergent validity. The structure of the five original subscales as well as the structure of the two proposed summary scales was adequate as shown by construct validity using confirmatory factor analyses.

Conclusion: The Dutch version of the MAC scale is a feasible questionnaire and appeared to have comparable psychometric properties as demonstrated by studies in the UK. The psychometric properties of the summary scales and Fighting Spirit and Helplessness/Hopelessness subscales seem to be acceptable. This supports the cross-national usefulness of the MAC scale. 


\section{Introduction}

Cancer has a considerable impact on patients' lives and often leads to psychosocial distress. ${ }^{198,199}$ Earlier studies have demonstrated that the prevalence of psychosocial distress in cancer patients varies from 5 to $53 \%$, depending on the method of assessment used and study population observed. ${ }^{199-204}$ For those patients in whom psychosocial distress does not decrease over time, psychosocial interventions may be appropriate, and it is important to identify these patients as soon as possible. ${ }^{205}$ Several studies have used the Mental Adjustment to Cancer (MAC) scale to measure adjustment to cance. ${ }^{206-208}$ The MAC scale was developed in the UK. ${ }^{209}$ Watson and colleagues developed a questionnaire with adequate psychometric properties to address MAC, defined as cognitive and behavioural responses made by an individual to a cancer diagnosis. ${ }^{209}$ Mental adjustment comprises (1) appraisal (i.e. how patients perceive implications of cancer) and (2) ensuing reactions (i.e. what patients think and do to reduce the threat posed by cancer). ${ }^{210}$ The MAC scale comprises five subscales: Fighting Spirit, Helplessness/Hopelessness, Anxious Preoccupation, Fatalism, and Avoidance. Positive mental adjustment such as the Fighting Spirit and Avoidance are associated with absence of depression and anxiety, whereas negative mental adjustment such as Helplessness/ Hopelessness, Anxious Preoccupation, and Fatalism are associated with psychological distress ${ }^{206-208,211}$, and a lower quality of life. ${ }^{208}$

The MAC scale is widely used in different countries. ${ }^{211-219}$ Several studies have replicated and refined the MAC scale. 213,215,216,218,219 Watson and colleagues suggested two ways of scoring ${ }^{209,220}$ : first method includes five separate subscales ${ }^{209}$ and second method combines and rearranges different subscales ${ }^{209}$ into positive and negative adjustment to cancer. Recently, Watson and Homewood have evaluated the original factor structure and established psychometric properties of the MAC scale in a larger sample $(\mathrm{N}=1255) .220$ Outcomes of this study resulted in a new two-factor structure, namely the Summary Positive Adjustment Scale and Summary Negative Adjustment Scale. ${ }^{220}$ It was suggested that the five subscales be used to identify specific adjustment styles and the summary scales to identify more general adjustment styles for cancer. ${ }^{220}$

Notwithstanding the fact that the MAC scale is considered an adequate tool to measure adjustment responses to cancer, no psychometric analysis has yet been made in Dutch patients. De Bruin and colleagues developed an adapted Dutch version of the MAC scale, which had 78 items instead of the original 40 items. ${ }^{221}$ Moreover, the robustness of the new two-factor structure has as yet not been tested outside the UK.

In this study the psychometric properties of the original five subscales and the two recently proposed summary scales of the Dutch version of the MAC scale are examined in Dutch cancer patients. 


\section{Methods}

\section{Subjects}

Subjects were recruited from the patient population of MAASTRO Clinic, a radiation facility in the south of the Netherlands. Eligibility criteria included diagnosis of lung, breast, prostate, or gynaecological cancer, understanding of Dutch language, age over 18, and ability to provide informed consent. Eight hundred and eighty-nine patients who received radiotherapy (RT) between January 2006 and March 2008 were identified as potentially eligible and contacted by their radiation oncologist. Ethical approval for the study was obtained from MAASTRO's ethics committee.

\section{Procedure}

In the study, a design with two measurements was used to explore the psychometric properties. At first consultation, prior to initiation of RT, patients were asked to participate. Patients who agreed received information about the study, informed consent form, questionnaire that assessed socio-demographic data, the Dutch version of the Hospital Anxiety and Depression Scale (HADS) to test construct validity, and the Dutch version of the MAC scale. Patients completed these questionnaires at home and returned them by pre-addressed envelope. To establish test-retest reliability, patients received the second MAC scale by mail at home approximately four days, after returning the completed questionnaires from first consultation, and ideally before initiation of RT.

\section{Measures}

The Dutch version of the Mental Adjustment to Cancer scale (MAC scale)

The original MAC scale was translated into Dutch by three translators, independently. A consensus version of these translations was produced by using the criteria that items should be in Dutch colloquial language and as close to the meaning of the items in the original English version. This Dutch version of the MAC scale was translated back into English independently by a native English speaker to check the validity of the translation. Based on the outcomes, a final Dutch version was produced.

The MAC-scale is a 40 -item self-rating questionnaire (see appendix). ${ }^{209}$ Ratings are made on a four-point Likert scale ranging from 1 ("definitely does not apply to me") to 4 ("definitely applies to me"). The original five subscales of the MAC scale are: Fighting Spirit (16 items, score range 16-64, cut-off $\geq 47$ ); Helplessness/Hopelessness ( 6 items, score range 6-24, cut-off $\geq 11$ ); Anxious Preoccupation ( 9 items, score range $9-36$, cut-off $\geq 25$ ); Fatalism (8 items, score range 
8-32, cut-off $\geq 22$ ) and Avoidance ( 1 item, score range $1-4$, cut-off $\geq 3$ ). ${ }^{209,210}$ The new proposed general subscales are: Summary Positive Adjustment Scale $(17$ items, score range 17-68, cut-off $\geq 47$ ) and Summary Negative Adjustment Scale (16 items, score range $16-64$, cut-off $\geq 36$ ). 220

The Dutch version of the Hospital Anxiety and Depression Scale (HADS)

The HADS was developed to identify symptoms of anxiety and depression in patients. ${ }^{222}$ It comprises 14 items resulting in a score ranging from 0 to 21 both on the anxiety (7 items) and depression (7 items) subscale.222 The HADS is a valid and reliable instrument that is widely used in oncology settings. ${ }^{93,223}$ Psychometric properties of the Dutch version of the HADS for general medical patients are good (Cronbach's alpha's range from 0.84-0.90).224 In several studies the HADS is used to examine construct validity of the MAC scale. ${ }^{212-214,216,218}$

\section{Demographic and clinical characteristics}

Patients reported their age, gender, marital status, and level of education. Tumour site and WHO score were extracted from patient records.

\section{Statistical analysis}

Reliability of the Dutch version of the MAC scale was determined through calculation of Cronbach's $\alpha$ for internal consistency and Intraclass Correlation Coefficient (ICC, method one-way random) for test-retest reliability. The latter was further assessed by calculating mean differences between total scores over the two time periods and comparing this using paired t-test. Patients who completed the second MAC scale before the start of RT were used in the analysis (n= 247). Convergent validity was assessed in two ways: first, to study the relationship between the subscales by calculating the inter-scale Pearson correlations; second, to explore associations between the MAC subscales and psychological distress by examining Pearson correlations between the five subscales and two summary scores of the MAC scale, on the one hand, and anxiety and depression subscales of the HADS, on the other. Construct validity was assessed using confirmatory factor analysis by examining the hypothesized factor structures of the Dutch version of the MAC scale. Polychoric correlations between each item were used as input as well as an unweighted least squares estimation method due to the ordinal property of the responses. Owing to the relatively small sample size model fit was based on Satorra-Bentler Scaled Chi square statistic, Comparative Fit Index (CFI) and Non-Normed Fit Index (NNFI). ${ }^{225}$ For CFI and NNFI, values above 0.90 are considered to be an indication of acceptable fit.

If less than $10 \%$ of the items were missing in any given subscale for a patient, these were replaced by means of Corrected Item Mean substitution. ${ }^{111}$ This was only done for analyses that concerned convergent validity. For all other analyses, raw data were used, excluding missing values. 
Confirmatory factor analysis was performed using LISREL 8.71.226 For other data analyses SPSS 15.0 was used. Level of statistical significance was set at .05 (two-tailed).

\section{Results}

\section{Subjects}

Two hundred and eighty-nine cancer patients (response 32.5\%) completed questionnaires at home and returned them by pre-addressed envelope. Mean time between first consultation at MAASTRO Clinic and completing questionnaires at home was 2.5 days ( $S D=3.33)$. Two hundred and forty-seven patients (85\%) completed the second MAC scale and returned them by pre-addressed envelope. Mean time between completing first and second MAC-scale was 7.11 days $(\mathrm{SD}=3.44)$. Most patients were male $(86.2 \%)$ with prostate cancer $(70.5 \%)$. Mean age was 67.44 years ( $\mathrm{SD}=8.85)$. Most patients were married or lived with a partner $(84.8 \%)$ and had received elementary or lower education $(43.9 \%)$. Most reported responses to cancer were Fighting Spirit (58.8\%), Helplessness/Hopelessness (37.7\%), and the Summary Positive Adjustment Scale (78.2\%) (Table 1). With respect to non-participants $(n=600)$, most were male $(64.4 \%$ versus $86.2 \%$ among participants; $\mathrm{p}<.001)$ and had prostate cancer (61.6\% versus $70.6 \%$; $p .001)$; mean age was $67.75(\mathrm{SD}=10.18$ ) years versus 67.44 (SD=8.85) among participants (not significant).

\section{Feasibility}

In total, $85.5 \%$ of the participants (responders) completed the full MAC-scale. $14.5 \%$ of the participants had one or more missing values (non-responders), which $8.7 \%$ had one missing value, $4.8 \%$ had between 2 and 11 missing values and $1.0 \%$ had between 11 and 23 missing values. There were no significant differences between responders and non-responders regarding demographic and medical variables. 
Table 1 Patient characteristics $(n=289)$

\begin{tabular}{|c|c|c|}
\hline Characteristics & $n$ & $\%$ \\
\hline \multicolumn{3}{|l|}{ Age (years) } \\
\hline \multicolumn{3}{|l|}{ Mean (SD) } \\
\hline Min-max & $67.44(8.85)$ & \\
\hline Gender & $23-91$ & \\
\hline Male & 249 & 86.2 \\
\hline \multicolumn{3}{|l|}{ Marital status } \\
\hline Married/ lived with a partner & 245 & 84.8 \\
\hline \multicolumn{3}{|l|}{ Educational level } \\
\hline Elementary school /Lower education & 127 & 43.9 \\
\hline High school /Intermediate Education & 93 & 32.2 \\
\hline Higher Education/University & 67 & 23.1 \\
\hline Unknown & 2 & 0.8 \\
\hline \multicolumn{3}{|l|}{ Diagnosis } \\
\hline Prostate & 204 & 70.6 \\
\hline Lung & 58 & 20.1 \\
\hline Breast & 8 & 2.8 \\
\hline Gynaecological & 19 & 6.5 \\
\hline \multicolumn{3}{|l|}{ WHO-performance scale } \\
\hline 0 & 194 & 67.1 \\
\hline 1 & 44 & 15.2 \\
\hline 2 & 12 & 4.2 \\
\hline 3 & 1 & 0.4 \\
\hline Unknown & 38 & 13.1 \\
\hline \multicolumn{3}{|l|}{$\begin{array}{l}\text { Prevalence adjustment responses } \\
\text { (MAC-scale) according to cut offs }{ }^{209,220}\end{array}$} \\
\hline Fighting Spirit & $170(24)^{*}$ & 58.8 \\
\hline Helplessness/Hopelessness & $109(10)$ & 37.7 \\
\hline Anxious Preoccupation & $34(14)$ & 11.8 \\
\hline Fatalism & $16(22)$ & 5.5 \\
\hline Avoidance & $94(4)$ & 32.5 \\
\hline Summary Positive Adjustment & $226(9)$ & 78.2 \\
\hline Summary Negative Adjustment & $62(9)$ & 21.5 \\
\hline
\end{tabular}

*Numbers between brackets refer to patients with missing scores.

\section{Reliability}

Table 2 shows Cronbach's $\alpha$ coefficients. These are compared with the coefficients reported by Watson and colleagues in $1988^{209}$ and 2008. ${ }^{220}$ The avoidance scale was excluded because it consists one item. For internal consistency of the original five subscales of the MAC scale, Cronbach's $\alpha$ coefficients varied in our study from 0.45 to 0.78. Coefficients for the Summary Positive Adjustment Scale and Summary Negative Adjustment Scale were 0.78 and 0.84 , respectively. Table 2 shows a similar overall pattern of scale reliability between coefficients of 
this study and two previous studies by Watson and colleagues. ${ }^{209,220}$ However in this study, the Cronbach's $\alpha$ for subscales Anxious Preoccupation and Fatalism, were much lower as the Cronbach's $\alpha$ for these subscales reported in Watson's studies. $^{209,220}$

Table 2 Internal consistency of the MAC-scale

\begin{tabular}{llll}
\hline MAC-subscales & \multicolumn{3}{l}{ Cronbach's $\alpha$} \\
\hline Fighting Spirit & $\begin{array}{l}\text { Present study } \\
(n=289)\end{array}$ & $\begin{array}{l}\text { Watson et al. } 209 \\
(n=235)\end{array}$ & $\begin{array}{l}\text { Watson et al. }{ }^{220} \\
(n=1255)\end{array}$ \\
\cline { 2 - 4 } Helplessness/Hopelessness & 0.78 & 0.84 & 0.84 \\
Anxious Preoccupation & 0.75 & 0.79 & 0.77 \\
Fatalism & 0.55 & 0.65 & 0.66 \\
Avoidance & 0.45 & 0.65 & 0.56 \\
Summary Positive Adjustment & ---- & ---- & -.84 \\
Summary Negative Adjustment & 0.78 & $-\cdots$ & 0.84 \\
\hline
\end{tabular}

For the subscales Fighting Spirit, Helplessness/Hopelessness, Anxious Preoccupation, Fatalism, and Avoidance, test-retest reliability of the patients' response yielded ICCs of $0.64,0.68,0.74,0.40$, and 0.45 , respectively (Table 3 ). ICCs of the Summary Positive Adjustment Scale and Summary Negative Adjustment Scale were 0.68 and 0.79 , respectively. Pearson's correlations of the five subscales varied from 0.45 to $0.74(p<0.001)$. Pearson's correlations of the Summary Positive Adjustment Scale and Summary Negative Adjustment Scale were 0.68 and $0.79(p<0.001)$, respectively. Mean scores of the two measurement points in time for the five subscales were not significantly different $(p>0.05)$ except Fatalism $(p<0.001)$. Mean scores of the Summary Positive Adjustment Scale and Summary Negative Adjustment Scale were not significantly different for T1 and T2 $(p>0.05)$.

Table 3 Test-retest reliability: Intra Class Correlation, Pearson's correlation and paired sample ttest of the MAC-subscales

\begin{tabular}{|c|c|c|c|c|c|c|}
\hline $\begin{array}{l}\text { MAC subscales }^{a} \\
\text { (score range) }\end{array}$ & $\begin{array}{l}\mathrm{T} 1 \\
\text { mean } \\
(\mathrm{SD})\end{array}$ & $\begin{array}{l}\mathrm{T} 2 \\
\text { mean } \\
(\mathrm{SD})\end{array}$ & $\begin{array}{l}95 \% \text { Confidence } \\
\text { interval of the } \\
\text { differences }\end{array}$ & ICC & $\begin{array}{l}\text { Pearson's } \\
\text { Correlation }\end{array}$ & $\begin{array}{l}\text { Paired- } \\
\text { sample } \\
\text { t-test } \\
\text { value }\end{array}$ \\
\hline $\begin{array}{l}\text { Fighting Spirit } \\
(16-64)\end{array}$ & $\begin{array}{l}49.07 \\
(6.27)\end{array}$ & $\begin{array}{l}49.44 \\
(6.29)\end{array}$ & $-0.63-0.12$ & $0.64^{*}$ & $0.64^{*}$ & -0.96 \\
\hline $\begin{array}{l}\text { Helplessness/ } \\
\text { Hopelessness (6-24) }\end{array}$ & $\begin{array}{c}9.98 \\
(2.88)\end{array}$ & $\begin{array}{l}10.28 \\
(2.89)\end{array}$ & $-1.28-0.39$ & $0.68^{*}$ & $0.68^{*}$ & -1.90 \\
\hline $\begin{array}{l}\text { Anxious } \\
\text { Preoccupation (9-36) }\end{array}$ & $\begin{array}{l}20.30 \\
(3.50)\end{array}$ & $\begin{array}{l}20.23 \\
(3.68)\end{array}$ & $-0.29-0.43$ & $0.74^{*}$ & $0.74^{*}$ & 0.38 \\
\hline Fatalism (8-32) & $\begin{array}{l}16.94 \\
(2.82)\end{array}$ & $\begin{array}{l}18.71 \\
(2.97)\end{array}$ & $-2.53--1.76$ & $0.40^{*}$ & $0.58^{*}$ & $-11.09^{*}$ \\
\hline
\end{tabular}




\begin{tabular}{lcclccc}
\hline $\begin{array}{l}\text { MAC subscales } \\
\text { (score range) }\end{array}$ & $\begin{array}{l}\text { T1, } \\
\text { mean } \\
\text { (SD) }\end{array}$ & $\begin{array}{l}\text { T2, } \\
\text { mean } \\
\text { (SD) }\end{array}$ & $\begin{array}{l}\text { 95\% Confidence } \\
\text { interval of the } \\
\text { differences }\end{array}$ & ICC & $\begin{array}{l}\text { Pearson's } \\
\text { Correlation }\end{array}$ & $\begin{array}{l}\text { Paired- } \\
\text { sample } \\
\text { t-test } \\
\text { value }\end{array}$ \\
\hline Avoidance (1-4) & $\begin{array}{l}2.10 \\
(0.94)\end{array}$ & $\begin{array}{c}2.15 \\
(0.92)\end{array}$ & $-0.19-0.08$ & $0.45^{*}$ & $0.45^{*}$ & 0.78 \\
Summary Positive & 52.25 & 51.58 & $-0.09-1.43$ & $0.68^{*}$ & $0.68^{*}$ & 1.74 \\
Adjustment (17-68) & $(6.59)$ & $(6.67)$ & & & & \\
Summary Negative & 30.77 & 31.34 & $-1.21-0.07$ & $0.79^{*}$ & $0.79^{*}$ & 1.75 \\
Adjustment (16-64) & $(6.99)$ & $(7.05)$ & & & & \\
\hline
\end{tabular}

Higher scores indicate higher levels of the concepts mentioned. ${ }^{*} p<0.001$ (two-tailed).

an ranges from 189-206.

\section{Validity}

Convergent validity of the five subscales and the Summary Positive Adjustment Scale and Summary Negative Adjustment Scale was assessed by examining the inter-scale correlations and Pearson's correlation with symptoms of anxiety and depression as assessed with the HADS (Table 4).

For the subscales, scores for Fighting Spirit correlated negatively with Helplessness/Hopelessness, but not with the other subscales. Helplessness/ Hopelessness correlated positively with Anxious Preoccupation, Fatalism, and Avoidance. Anxious Preoccupation correlated positively with Fatalism but not with Avoidance. Fatalism correlated positively with Avoidance. There was a strong positive correlation of the Summary Positive Adjustment with Fighting Spirit, but a weak negative correlation with Helplessness/Hopelessness. Furthermore, the Summary Negative Adjustment Scale demonstrated a strong positive correlation with Helplessness/Hopelessness and a weaker positive correlation with Anxious Preoccupation. The Summary Positive Adjustment Scale showed a negative correlation with the Summary Negative Adjustment Scale.

Helplessness/Hopelessness, Anxious Preoccupation, Fatalism had positive correlations with anxiety and depression HADS subscales, whereas Fighting Spirit had negative correlations with both HADS subscales. The Summary Positive Adjustment Scale had negative correlations with symptoms of anxiety and depression, whereas the Summary Negative Adjustment Scale correlated positively with the two HADS subscales.

Construct validity was assessed using confirmatory factor analysis by examining the factor structures of the Dutch version of the MAC scale: five subscales ${ }^{209}$ and two summary scales. ${ }^{220}$ The five subscales as well as the two summary scales fit the data very well. Support was found for the five subscales, $\chi^{2}(730)=1415.03, p=0.00 ; \mathrm{CFI}=0.93$, and NNFI $=0.92$ and also for the two summary scales, $\chi^{2}(494)=947.38, p=0.00 ; \mathrm{CFI}=0.94$ and NNFI $=0.94$. 


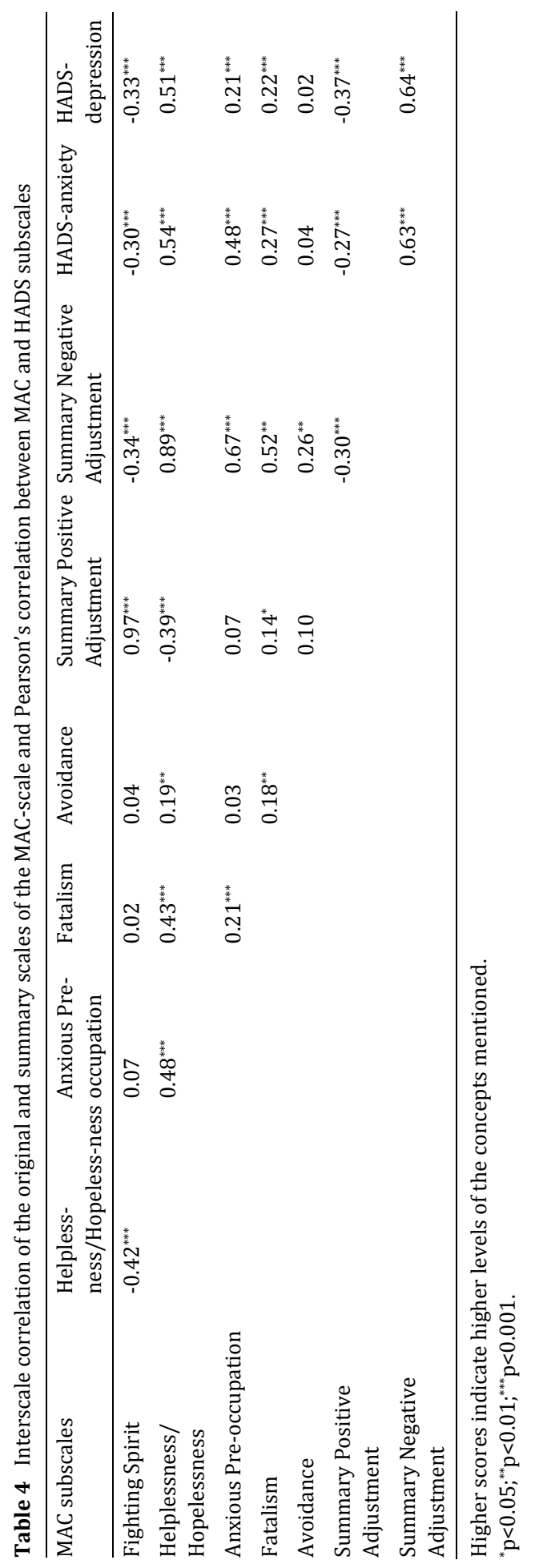




\section{Discussion}

The present study evaluated the psychometric properties of the original five subscales and new Summary Positive and Summary Negative Adjustment scale of the 40-item Dutch version of the MAC scale in Dutch cancer patients.

The Dutch version of the MAC-scale seems to be a feasible questionnaire due to $85.5 \%$ of all participants (responders) completed the full MAC-scale. In this study the internal consistency of Fighting Spirit and Helplessness/Hopelessness subscales was relatively high. Cronbach's $\alpha$ coefficients were comparable with studies of Watson and colleagues 209,220 and other psychometric studies of the MAC scale. ${ }^{212,213,215,216,219}$ Anxious Preoccupation and Fatalism subscales displayed lower Cronbach's $\alpha$ coefficients in our study than those reported by Watson and colleagues ${ }^{209,220}$, and as reported in other studies. ${ }^{212,215,216,219}$ with exception of studies by Cayrou (Fatalism, $\alpha=0.40$ ) [19] and Schwartz (Anxious Preoccupation, $\alpha=0.43$ ).213,219 According to the classical theory ${ }^{227}$, an explanation for the low Cronbach's $\alpha$ coefficient for Anxious Preoccupation and Fatalism subscales in our study might be that our study population is very homogenous, which is reflected in the large number of male patients (86.2\%) with prostate cancer $(70.6 \%)$. The classical theory depicts reliability as being "a ratio of variances, specifically, it is the variance attributed to differences among subjects divided by the total variance". ${ }^{227}$ Variance attributed to differences among subjects in a homogeneous study population is smaller than in a heterogeneous population resulting in lower (scale) reliability. The homogenous characteristic of our patient group under study is reflected by the data on the standard deviations of the subscales, which, with exception of Fighting Spirit, were all lower than the standard deviation of the subscales derived from the study by Watson and colleagues. ${ }^{209}$ Difference between the standard deviations of the two studies for Helplessness/Hopelessness, Anxious Preoccupation, and Fatalism subscales were $0.52,1.03$, and 0.60 , respectively. In addition to a homogeneous sample, a low $\alpha$ value might also indicate a heterogeneous scale. This could mean that Anxious Preoccupation and Fatalism subscales in Dutch are more heterogeneous than the original subscales. Indeed, Anxious Preoccupation does not seem to be a homogeneous subscale. It may be confounded by four items indicating positive and active responses, i.e. changing diet, exercising, seeking support, and getting information, while the other five items indicate responses of negative feelings (anxiety) and beliefs. With removal of these four positive and active items, Cronbach's $\alpha$ for Anxious Preoccupation subscale increases to 0.70, and thus would be acceptable. Furthermore, the five retained items would still measure the same concept. Removal of the exact same four items has already been suggested in previous studies. ${ }^{213,218}$ Overall pattern of the five subscales reliability was similar to both of Watson and colleagues' studies. ${ }^{209,220}$ Internal consistencies of the Summary Positive Adjustment Scale and Summary Negative 
Adjustment Scale were acceptable and comparable with a recent study by Watson and Homewood. 220

Test-retest reliability was tested using patients who completed the MACscale at two different time points before RT. ICC and Pearson's correlation demonstrated acceptable test-retest reliability for all subscales, with exception of Fatalism and Avoidance. Furthermore, there were no significant differences in mean scores between the time points for all subscales, apart from Fatalism subscale. Mean score of Fatalism on T2 (just before entering RT) was significantly higher compared to the mean score on $\mathrm{T} 1$. This may imply that this subscale is not a reliable scale but rather speculative. It might also mean that patients react with more stoic acceptance shortly before the initiation of their RT and it might measure state rather than trait reaction. It is known that patients entering RT suffer from specific distress, such as fear of RT. ${ }^{78}$ Reliability of Fatalism might improve if the test-retest were to take place during a more "emotionally" stable time period. An obvious explanation for a low test-retest correlation coefficient for Avoidance is that this subscale comprises only one item. This means that the Avoidance subscale is more sensitive to misinterpretation. ICC and Pearson's correlation of Anxious Preoccupation including only the five items is 0.75 for both whereas it was 0.74 for the original Anxious Preoccupation subscale including nine items. The Summary Positive Adjustment Scale and Summary Negative Adjustment Scale showed acceptable test-retest reliability, ICC, as well as Pearson's correlations.

Correlation coefficients between the original MAC subscales in this study were comparable with previous studies. ${ }^{209,213,220}$ As expected, there was a negative correlation between Helplessness/Hopelessness and Fighting Spirit. In the original study by Watson and colleagues, a principal components analysis with an orthogonal rotation was used and four factors were extracted. First factor had a bipolar dimension with Fighting Spirit subscale loading positively and Helplessness/Hopelessness subscale negatively. ${ }^{209}$ Although the responses of Fighting Spirit and Helplessness/Hopelessness loaded on a bipolar dimension, Watson and colleagues recommended further research to "isolate" these two responses. ${ }^{209}$ Our results confirmed the bipolar dimension of those subscales.

There were positive correlations between Helplessness/Hopelessness and Anxious Preoccupation and Fatalism. These subscales measure different specific responses to cancer, but are negative responses to cancer. The Summary Positive Adjustment Scale and Summary Negative Adjustment Scale were significant negatively correlated. These results reinforced the suggestion by Watson and Homewood that the Summary Positive Adjustment Scale and the Summary Negative Adjustment Scale are independent factors, rather than being a bipolar factor, such as Fighting Spirit and Helplessness/Hopelessness. ${ }^{220}$ Furthermore, the correlation coefficient of the Summary Positive Adjustment Scale and Summary Negative Adjustment Scale in this study was comparable to the correlation coefficient as reported by Watson and Homewood. ${ }^{220}$ 
Significant correlations between depression and anxiety as measured with the HADS and the original MAC subscales demonstrated comparable patterns as reported by Watson and Homewood. ${ }^{220}$ Correlation between Anxious Preoccupation and anxiety is higher than the correlation between Anxious Preoccupation and depression as measured with the HADS. The Anxious Preoccupation subscale and the anxiety subscale of the HADS measure the same construct (feelings of anxiety). Of all the subscales, Avoidance was the only subscale that was not significantly correlated with both subscales of the HADS. Some investigators, as well as the original authors, reported a limited validity of the Avoidance subscale (one item) and they omitted Avoidance of the MAC scale. 209,213,215,218,219 Significant correlations between the depression and anxiety subscales of the HADS and the Summary Positive Adjustment Scale demonstrated comparable patterns as reported by Watson and Homewood. ${ }^{220}$ Summary Positive Adjustment showed lower negative correlations and lower shared variances with the anxiety (7.3\%) and depression (13.7\%) subscales of the HADS. Unlike both subscales of the HADS, the Summary Positive Adjustment Scale measures positive attitudes and active responses ("I try to have a positive attitude"). This confirmed Watson and Homewood's suggestion that the items in the Summary Positive Adjustment Scale are about attitudes and actions. ${ }^{220}$ Summary Negative Adjustment showed a strong correlation and a high shared variance with anxiety (40\%) and depression (41\%) as assessed with the HADS. The Summary Negative Adjustment Scale, as well as both subscales of the HADS, consists of items composed of "negative" feelings. The high correlation and shared variance between Summary Negative Adjustment Scale and the subscales of the HADS may suggest that this subscale of the MAC scale reflect pathological responses, such as symptoms of anxiety and depression.

Construct validity was assessed using confirmatory factor analysis on the hypothesized factor structures. In contrast to two previous studies ${ }^{213,215}$, in our study the factor structure of the original five subscales was supported by confirmatory factor analysis. These two studies rejected Watson's orthogonal model with respect to the global fit indices by the root mean square error (RMSEA) and CFI. Results did not reach the chosen cut-off points of RMSEA $<0.08$ and CFI $>0.90 .213,215$ In our study, model fit was based on the NNFI index with regard to the sample size of 289 patients, in combination with CFI. Despite the small sample size in our study, using RMSEA as fit index (in present study RMSEA $=0.06,<0.08$ ) there is still no reason to reject the factor structure of the original five subscales. Confirmatory factor analysis also supported the hypothesized factor structure of the recently proposed two summary scales by Watson and Homewood.220 The structure with Summary Positive Adjustment Scale and Summary Negative Adjustment Scale fitted the data very well.

Our study has some limitations. Our findings cannot be generalized to all Dutch cancer patients, since our study population consists of patients receiving RT, most patients were male, a large percentage had prostate cancer, and the 
response rate is rather low (32.5\%). However, the data do provide an indication of the qualities of the Dutch version of the MAC scale when used among some groups of cancer patients in the Netherlands. It is recommended that this study is reproduced among the general Dutch population of cancer patients and, that this follow up study needs to have a larger proportion of women since gender may have played a role. Results showed that most patients had positive adjustment responses to cancer. Male cancer patients may report less distress which is

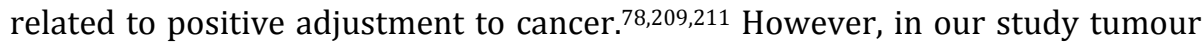
type can also play an important role how patients adjust to cancer. In our study most patients had prostate cancer, which implicated that these patients had a relative good prognosis and relative fewer complaints, and therefore, a more positive adjustment response to cancer. Another possible limitation relates to the procedure of this study. Patients completed the second MAC scale (testretest) at home. This may implicate that they received help with completing these questionnaires, even though patients were instructed to fill in the questionnaire without help from others. For completing the second MAC-scale in a short period after the first one, we were forced to mail this questionnaire at patients' home as some patients had no scheduled visits to MAASTRO Clinic within two weeks (depending on the kind of treatment they received). Finally, the sample size of this study was relatively small with regard to the sample size necessary to examine the goodness-of-fit indices of both factor structures, as the recommended sample size is 10 patients per item; however, we corrected for this by using the fit indices NNFI.

\section{Conclusions}

The Dutch version of the MAC scale is a feasible questionnaire and appeared to have psychometric properties that are comparable with previous UK studies of Watson and colleagues in 1988 and 2008. Therefore, we may conclude that no large cultural differences exist in the interpretation of the items.

Psychometric properties of the Summary Positive Adjustment Scale and Summary Negative Adjustment Scale and the original Fighting Spirit and Helplessness/Hopelessness subscales appear to be acceptable. Summary subscales of the MAC scale are useful constructs to measure general responses to cancer, such as positive and negative adjustment to cancer in patients in clinical settings as well as in research. For insight into more specific responses to cancer in patients, the specific subscales Fighting Spirit and Helplessness/Hopelessness provide useful constructs, and probably also the subscale Anxious Preoccupation with only five items. Fatalism and Avoidance should probably be discarded. Accordingly, further studies are recommended to examine the reliability of the Anxious Preoccupation subscale in a more heterogeneous Dutch cancer patient population and to examine the psychometric properties of the five-item Anxious Preoccupation subscale. 
The Dutch version of the MAC scale is a useful questionnaire for measuring adjustment to cancer in Dutch cancer patients, and using the scale in clinical settings could lead to more adequate psychosocial care in oncology settings.

\section{Appendix}

\begin{tabular}{|c|c|c|}
\hline Item & $\begin{array}{l}\text { Original } \\
\text { subscales }^{209 *}\end{array}$ & $\begin{array}{l}\text { New summary } \\
\text { scales } 220^{*}\end{array}$ \\
\hline 1. Changed my diet & AP & Drop \\
\hline 2. Can't cheer myself up & $\mathrm{HH}$ & SNA \\
\hline 3. Prevent plans & AP & SNA \\
\hline 4. Believe positive attitude & FS & SPA \\
\hline 5. Don't do well & FS & Drop \\
\hline 6. Get better & FS & SPA \\
\hline 7. Nothing makes a difference & $\mathrm{F}$ & SNA \\
\hline 8. Left all to my doctors & $\mathrm{F}$ & Drop \\
\hline 9. Life is hopeless & $\mathrm{HH}$ & SNA \\
\hline 10. Exercise & AP & Drop \\
\hline 11. Life precious & FS & SPA \\
\hline 12. Hands of God & $\mathrm{F}$ & SPA \\
\hline 13. Future plans & FS & SPA \\
\hline 14. Worry worse & AP & SNA \\
\hline 15. Bonus & $\mathrm{F}$ & SPA \\
\hline 16. Mind makes difference & FS & SPA \\
\hline 17. Nothing to help & $\mathrm{HH}$ & SNA \\
\hline 18. Carry on & FS & SPA \\
\hline 19. Contact with others & AP & Drop \\
\hline 20. Determined & FS & SPA \\
\hline 21. Difficult believing & $\mathrm{AP}$ & SNA \\
\hline 22. Anxiety & AP & SNA \\
\hline 23. Not hopeful & $\mathrm{HH}$ & SNA \\
\hline 24. One day at a time & $\mathrm{F}$ & SNA \\
\hline 25. Giving up & $\mathrm{HH}$ & SNA \\
\hline 26. Humour & FS & SPA \\
\hline 27. Others worry & FS & SPA \\
\hline 28. Other worse off & FS & SPA \\
\hline 29. Get information & $\mathrm{AP}$ & Drop \\
\hline 30. Can't control & $\mathrm{F}$ & SNA \\
\hline 31. Try positive attitude & FS & SPA \\
\hline 32. Keep busy & FS & SPA \\
\hline 33. Avoid information & $\mathrm{F}$ & Drop \\
\hline 34. Challenge & FS & SPA \\
\hline 35. Fatalistic & $\mathrm{F}$ & SNA \\
\hline 36. At a loss & $\mathrm{HH}$ & SNA \\
\hline 37. Angry & $\mathrm{AP}$ & SNA \\
\hline 38. Don't have cancer & A & SNA \\
\hline 39. Count blessings & FS & SPA \\
\hline 40. Fight illness & FS & SPA \\
\hline
\end{tabular}

*FS:Fighting Spirit; HH:Helplessness/Hopelessness; AP:Anxious Preoccupation; F:Fatalism; A:Avoidance; SPA:Summary Positive Adjustment;

SNA:Summary Negative Adjustment. 


$$
(0
$$




\section{Chapter 8}

\section{General Discussion}


CHAPTER 8 


\section{Discussion}

Cancer must be considered as a biopsychosocial illness because cancer patients experience, in addition to physical impairment, significant psychological and social problems. ${ }^{39}$ Given a mean prevalence rate of psychosocial problems of $30 \%$ among cancer patients ${ }^{173}$, the need to identify these problems is considered to be a clinical necessity within oncology care. ${ }^{39}$ Patients commencing radiotherapy treatment are likely to experience additional stressors such as anxiety or fear about the treatment ${ }^{78}$, and it is acknowledged that a lack of emotional support may lead to higher levels of psychosocial problems among such patients. ${ }^{82,83}$ Psychosocial problems may influence several health and treatment related outcomes, such as adherence to therapy ${ }^{46,76}$ and quality of life..$^{38,46,76,85}$ Nevertheless, medical staff often fail to detect these problems in their patients, and psychosocial problems are consequently undertreated. ${ }^{29,34,84}$ In order to detect and treat psychosocial problems in cancer patients, effective screening forms an important component of care. ${ }^{76}$ The use of screening instruments may prevent the underdiagnosis of this important patient problem. ${ }^{71,84}$ In addition, the use of a screening instrument may also facilitate better communication between patients and medical staff. $34,51,52$

A number of agencies in several countries, including the Dutch Society for Psychosocial Oncology, have published recommendations to routinely screen for psychosocial problems by using a screening instrument in all hospitals and/or radiation departments.35,59,228 Yet, large-scale, well-designed, randomised controlled trials establishing evidence of the effects of psychosocial screening are lacking. ${ }^{39,53,60}$ Moreover, until now, insight into the effects of psychosocial screening - in particular radiotherapy settings - is scarce. Our aim, therefore, was to perform a study to gain insight into the feasibility and effectiveness of using the Dutch Screening Inventory of Psychosocial Problems (SIPP) among cancer patients receiving radiotherapy treatment. The objectives of the study were:

- To assess the reliability and validity of the SIPP to identify potential psychosocial problems in cancer patients.

- To evaluate whether using the SIPP was considered as useful and feasible by patients and radiotherapists.

- To evaluate the effectiveness of routine psychosocial screening by using the SIPP on:

- the percentages of patients referred to psychosocial caregivers by their radiotherapists;

- patients' satisfaction with radiotherapist-patient communication;

- the extent of psychological distress and health-related quality of life (HRQOL) in both the short-term and the long-term.

In addition, as adaption to a stressful life event as cancer is important, we studied the validity and usefulness of the Dutch version of the Mental Adjustment to 
Cancer scale (MAC-scale) to assess the adjustment to cancer among patients receiving radiotherapy. We used the MAC-scale for the validation purposes of the SIPP

This final chapter summarises the main findings of the separate studies, as presented in Chapters 2 through to 7, followed by a reflection from a methodological and theoretical perspective. Lastly, overall conclusions and the implications for clinical practice and future research are provided.

\section{Main findings}

First, a study was conducted to assess the reliability and validity of the Screening Inventory of Psychosocial Problems (SIPP) (Chapter 2). There was sufficient psychometric evidence to support the use of the SIPP as a useful screening instrument to identify psychosocial problems in cancer patients. The (test-retest) reliability of the SIPP was acceptable. The hypothesised factor structure of the SIPP was supported by confirmatory factor analysis and by inter-item correlation analysis. The convergent validity, studied by using the Hospital Anxiety and Depression Scale (HADS), was found to be acceptable since there was a consistent pattern of moderate to high correlations between the subscales of the SIPP and the depression and anxiety subscales of the HADS. The divergent validity, using the MAC scale, was supported by moderate correlations between the SIPP and adjustment responses to cancer. In addition, divergent validity was supported by the findings that younger patients and women reported higher levels of distress compared to older patients and men since these findings were consistent with previous studies. Finally, the outcomes of the receiver operation curve (ROC) analysis as assessed by using a semi-structured clinical interview indicated that the SIPP discriminated between the presence and absence of psychosocial problems with a good level of accuracy.

Second, a randomised controlled trial was conducted to evaluate the effects of using the SIPP on the number of patients referred to psychosocial caregivers, including the type of referral, the communication between patients and radiotherapists, and the extent of psychological distress and HRQoL over both the short-term and the long-term. A cluster randomised control trial was developed (described in Chapter 3) using a Solomon Four Group design (two experimental groups and two control groups) in which a baseline assessment was only conducted in one experimental and one control group in order to control for test effects. Randomisation took place at the level of the radiotherapist: fourteen participating radiotherapists were randomly allocated to the experimental group (n=7) or the control group (n=7). Between April 2008 and October 2009, patients receiving radiotherapy treatment (RT) with curative intent at the Institute Verbeeten in Tilburg, the Netherlands, were recruited. The 568 participating patients (response rate $=50.6 \%$ ) were linked to their radiotherapist. In total, 
300 control group patients and 268 experimental group patients were randomised into two subgroups with a baseline assessment $(n=144$ and $n=136$, respectively) and without a baseline assessment ( $n=156$ and $n=132$, respectively). In the experimental conditions, the patients received the SIPP before the both first consultation and the last consultation at the end of the RT with their radiotherapist. On both occasions, the radiotherapists had to check the scores of the SIPP to get an impression of the psychosocial problems of patients and their need for psychosocial care. Any problems identified had to be discussed with the patients and referrals to caregivers were to be based on the scores of the SIPP in combination with the radiotherapists' judgement. The control group patients received standard care. The self-reported assessments were conducted on four occasions: a pre-test at baseline before the first consultation for two subgroups (see above) and a post-test directly following the first consultation, and then at three and twelve months after the baseline assessment.

A process evaluation study (Chapter 4) was conducted to evaluate the feasibility and usefulness of the SIPP according to the patients and radiotherapists of the experimental groups. According to the total score on the SIPP, the prevalence of patients with at least a moderate degree of psychosocial problems was $55.6 \%$ before RT and $34.7 \%$ at the end of the RT period. In addition, during the treatment trajectory patients seemed to experience different problems at different points in time (e.g. the extent of physical complaints was highest at the end of the treatment trajectory). Furthermore, there was a discrepancy between radiotherapists' and patients' perspectives of the feasibility and usefulness of the SIPP. In general, patients' perspectives of the feasibility and usefulness of the SIPP were moderate to good. Nearly all of the patients completed the SIPP twice, at the beginning and at the end of RT. The perspectives of the radiotherapists were generally more negative, and only a minority of radiotherapists considered the SIPP to be useful and feasible; nevertheless, their evaluations were mixed.

Before starting the analyses, with respect to the effects of the SIPP, a potential test-effect of the baseline assessment on the psychological outcomes was studied. The results showed that the baseline assessment had no significant effect on the outcomes. Therefore, the two experimental groups and the two control groups could be combined into one experimental $(n=268)$ and one control group $(n=300)$. No intervention effects were observed on the number of referred patients, nor for the improvement of patient-radiotherapist communication (Chapter 5). Nevertheless, the results showed that using the SIPP had a positive effect on referring patients to additional psychosocial care for psychosocial problems at an earlier stage. The mean time to referral was, on average, three weeks shorter for patients in the experimental conditions (who were screened and referred to the social workers working at Institute Verbeeten) than for patients in the control conditions (who were not screened and were referred to the social workers working at Institute Verbeeten). 
We found no intervention effect on overall psychological distress and HRQoL for the short-term (three months after baseline) and the long-term (one year after baseline) (Chapter 6). The in-depth, post-hoc analyses showed significant interactions between group, time (three months follow-up) and referral (three months) on anxiety symptoms, emotional well-being, appetite loss and financial problems. Possibly, early referral to the social workers had favourable shortterm effects on some aspects of patients' health-related outcomes.

In addition, we studied (Chapter 7) the reliability and validity of the Dutch version of the Mental Adjustment to Cancer scale (MAC-scale), since the MAC scale is widely-used and validated in different countries and no psychometric analysis has yet been made among Dutch patients. In the present thesis, we used the MAC-scale for the validation purposes of the SIPP (Chapter 2). The results of the validation study of the MAC scale (Chapter 7) showed that there was sufficient psychometric evidence to support the use of the Dutch version of the MAC scale to assess cancer patients' coping style.

\section{Considerations}

In order to facilitate the interpretation of the results, some methodological and theoretical issues should be considered. The current section will mainly focus on some general considerations. First, the methodological issues, regarding strengths and limitations will be discussed, following which the theoretical issues will be commented upon.

\section{Methodological considerations}

A large-scale, clustered randomised controlled trial with a Solomon Four Group design was used to establish evidence of the feasibility and effectiveness of the use of the SIPP. This intervention study was designed as a pragmatic trial, since we measured the effect of using the SIPP in a real clinical radiotherapy setting. The advantage of pragmatic trials is that they inform healthcare providers and policy-makers on the most effective intervention in real clinical practice. ${ }^{229,230}$ To ensure that the results can be generalised, a pragmatic trial seeks to maximise external validity. However, the danger is that internal validity becomes severely compromised. ${ }^{230}$ Therefore, a balance between internal and external validity is important and to achieve this we used several strategies. ${ }^{156}$

\section{Internal validity}

There was a risk that if an individual radiotherapist treated patients from both the intervention groups and the control groups, their behavioural change caused by the intervention (e.g. as altering their communication style or their attentiveness to patients' psychosocial distress) would affect the management of 
patients in the control group. To increase the internal validity, we used cluster (group) randomisation in order to reduce the likelihood of contamination bias. ${ }^{230}$ Therefore, radiotherapists rather than patients were randomised to the experimental group or the control group. In addition, all of the patients were linked to their radiotherapist and thus enrolled into the group to which their physician has been assigned. There are critical issues that need to be considered as a consequence of a cluster randomised controlled trial with a Solomon Four Group design.

The first critical issue is that the randomisation of radiotherapists resulted in an unequal distribution of patients' cancer diagnoses and gender among the two groups, which we corrected for in our statistical analyses. Although the equal distribution of differences by randomisation was not absolute, we think that it was the most optimal way of achieving internal validity in a trial that seeks to maximise external validity.

The second issue which needs to be considered is that the outcome for each patient cannot be assumed to be independent. In the trial, the individual radiotherapist formed a cluster and patients were allocated to a specific radiotherapist (cluster). Since patients were not sampled independently, the patients of a given cluster will be more like one another than they are like the patients of other clusters, resulting in correlated outcomes of the patients within a cluster. It is more likely that significant differences will be found if there are large variances between the patients than if there are small variances. ${ }^{231}$ The latter has implications for the study power. Therefore, the standard sample size was multiplied by the design effect so as to get the number of patients required for the cluster design to retain sufficient power. ${ }^{231,232}$

A third issue is that it was hard to avoid radiotherapists in the control group becoming at least partially aware of this study. A potential contamination between groups could have occurred due to the heightened awareness of the study's aims among the radiotherapists of the control group. We did not measure whether control group radiotherapists were aware of the intervention during the study period, but it is likely that they were. This potential contamination bias could have been prevented by conducting a multicenter trial and randomising between radiation departments instead of radiotherapists. However, on the other hand, a multicenter study would have led to another limitation linked to differences between clinics, as every clinic can be seen as "its own country," with its own culture, language and hierarchy. ${ }^{233}$

One advantage of conducting a multicenter study would be that the number of radiotherapists could be increased. This is especially relevant since the fourth issue which needs to be considered is the small number of radiotherapists $(n=7)$ allocated to the experimental group in our current study. This small number of radiotherapists could easily have resulted in less favourable outcomes if one or two radiotherapists in this group were not enthusiastic about psychosocial screening. Moreover, a small number of radiotherapists will increase the be- 
tween-cluster variability in the primary outcome. To prevent this variability in our study, the radiotherapists were stratified according to the general percentages of incoming patients they referred to a (psychosocial) caregiver in the year preceding our study. A possible solution would have been to increase the number of radiotherapists combined with not only randomising between radiation departments but also randomising between radiotherapists in each department. Hence, the problem of conducting a multicenter trial is partly logistical. Moreover, when using a multicenter trial the analyses would be more complex and it would be difficult to interpret the results appropriately because of the extra added level.

The last critical issue is that we used a Solomon Four Group design in order to check for potential pre-test effects on intervention outcomes. ${ }^{146}$ Based on our results, we concluded that the baseline assessment had no significant effect on the outcomes. Therefore, we combined the two experimental and control groups to form one experimental group $(n=268)$ and one control group $(n=300)$. The latter had positive implications for the power of the study as our sample size calculation resulted in 130 patients required per group, in order to compare the number of referred patients to (psychosocial) caregivers between groups with an $80 \%$ power and a significance level of 0.05 (one-sided). Yet, the sample size calculation was based on only one outcome and the total number of 568 participating patients gave us opportunities to provide sub-analyses. Furthermore, since we used a Solomon Four Group to prevent pre-test effects on the outcomes, about half of all patients did not complete questionnaires at baseline. However, since the participating patients were allocated at random to the group with or without baseline assessment, we can assume that patients in the intervention and control group without baseline assessment would have reported similar levels of psychological distress and HRQoL as the patients in the groups with the baseline assessment.

\section{External validity}

To maintain the external validity, patients aged 18 years and older were included and the exclusion criteria were minimised. However, to limit losses of patients during the 12 month study period, we had to exclude cancer patients receiving treatment with palliative intent. With respect to external validity, our findings cannot be generalised to all cancer patients, since our study population was limited to cancer patients receiving radiotherapy.

Furthermore, regarding the validation study of the SIPP and the Dutch version of the MAC scale, our study population was rather homogeneous and comprised primarily male patients $(86.2 \%)$ and patients with prostate cancer (70.5\%). Moreover, in both studies the low response rate (32\%) of participation should be considered as a limitation which may decrease the external validity. However, the non-response rate may be more disturbing for descriptive results (i.e. the prevalence of psychosocial distress) than for measures of association. ${ }^{234}$ 
In the intervention study, the SIPP was completed in a heterogeneous group of cancer patients and our results showed that the internal consistencies of the subscales of the SIPP were comparable with our previous findings of the validation study of the SIPP.

\section{Theoretical considerations}

Despite the fact that we chose for the Solomon Four Group design as being the most appropriate design for evaluating the feasibility and effectiveness of using the SIPP, two aspects of our intervention need to be considered as possible explanations for finding limited effectiveness, namely the effectiveness of the delivery of psychosocial care and its implementation.

\section{Effective delivery of psychosocial care}

The Institutes of Medicine recommended a model for the delivery of psychosocial care (Figure 1). ${ }^{235}$ The model is based on evidence and integrates five components (see figure 1).

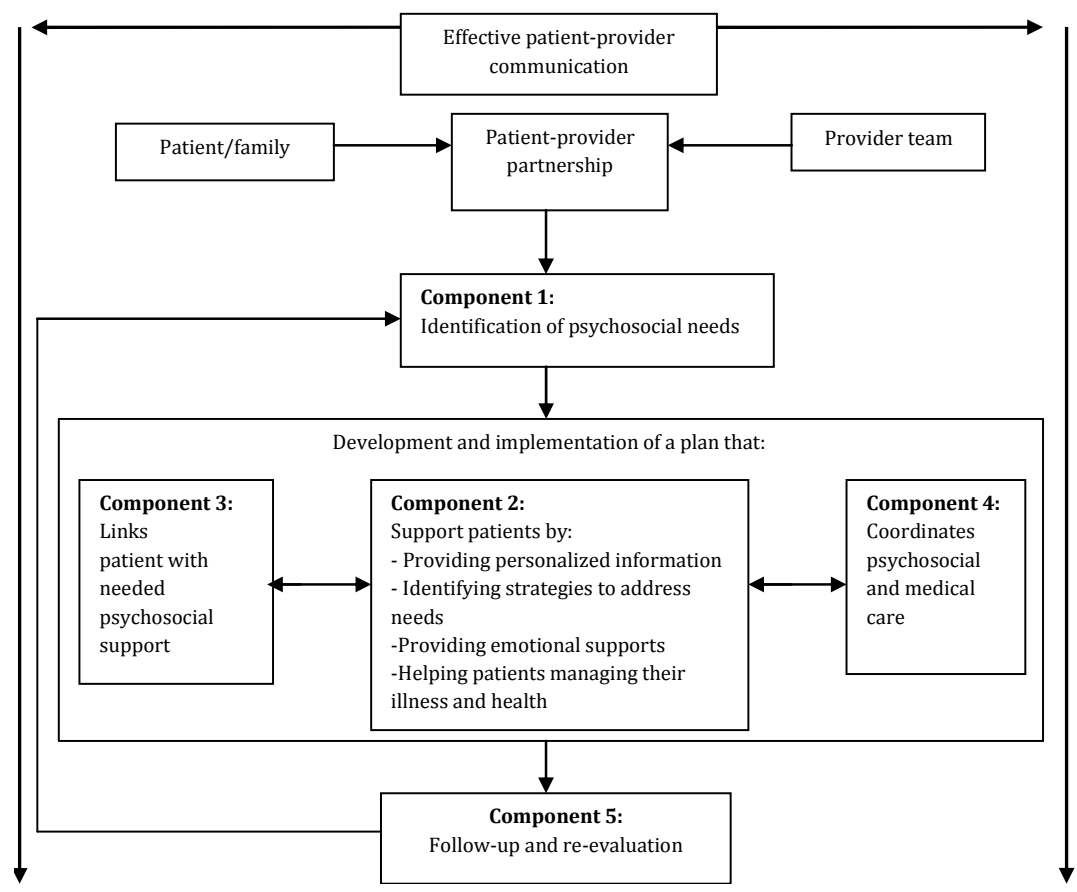

Figure 1 Model for the delivery of psychosocial care ${ }^{235}$

Within each component, there are strategies for the successful delivery of psychosocial care. In our intervention, the first three components were included. The first component refers to the identification of patients with psychosocial 
problems and needs. We used the SIPP - a validated brief screening instrument ${ }^{236}$ - with the aim of improving patients' and radiotherapists' awareness of patients' concerns. However, because we found a lack of favourable intervention effects it seems that simply using a screening instrument does not provide a sufficient guarantee of delivering the appropriate psychosocial care. There are several additional approaches needed which may enhance the identification of psychosocial problems among patients. One of the approaches is that additional meetings seemed warranted so as to alter the radiotherapists' attitudes toward discussing emotional problems, which may influence the detection of psychosocial problems. ${ }^{39}$ Radiotherapists should be made aware of their own role and responsibility in psychosocial screening in order to improve the identification and treatment of patients' problems and needs. It has been revealed previously that physicians are not convinced about the value of screening. ${ }^{195,237}$ Thus, it is important to give radiotherapists insight into the potential advantages in detecting psychosocial problems and in the benefits of using screening instruments. Moreover, such meetings are relevant for giving radiotherapists greater insight into interpreting and discussing the scores of screening instruments. An alternative, second approach is to screen for psychosocial problems at other times during the treatment trajectory than the ones used in the current study. Although the average time required to discuss the SIPP was less than five minutes, it is possible that the lack of time during the first consultation was a reason for not screening sufficiently. ${ }^{36,195}$ This timing is particularly relevant since during the first consultation patients will be often overloaded with information about the treatment and the potential side-effects, and they often get a medical examination. This leaves little time for additional subjects, such as patients' psychosocial experienced problems. A third additional approach regarding to the identification of patients with psychosocial problems and needs is using a computer-based screening instrument that forwards the screening data directly to an electronic medical record - especially since physicians tend to ignore raw scores on questionnaires when they have to add them up and interpret them themselves ${ }^{165}$. Using a computer-based screening instrument may improve the identification of psychosocial problems and needs and may thus result in the treatment of these problems. However, Boyes et al. reported that giving physicians feedback about patients' psychosocial well-being rarely contributed to physicians' decision-making about patient management. ${ }^{66}$ Finally, a two-step approach may be suitable since screening is a first step for briefly identifying the risks of having psychosocial problems. In a following second step, a more in-depth evaluation, such as a diagnostic assessment to get full insight in the patients' psychosocial problems and needs, might be warranted. ${ }^{235,238}$ Hence, the latter requires more time than screening and may become more of a burden on radiotherapists which may hamper the use of such a two-step approach in busy oncology settings. 
The second component of the model for the delivery of psychosocial care is to support patients. Psychosocial support by two social workers was available at the radiation department so as to address patients' problems and needs. If necessary, patients were referred to a psychologist or some other kind of psychosocial caregiver outside the department. However, we collected no data about the kind of psychosocial support patients' received (e.g. psycho-education, relaxation exercises to reduce stress, learning new coping skills etc.), nor whether the support was sufficient to cope with the psychosocial and medical aspects of the cancer. Furthermore, we developed no (psycho-) education programme to increase patients' awareness of the consequences of psychosocial problems on their health-related outcomes in our intervention study. Such programs can be effective in encouraging patients to discuss their problems and needs with their radiotherapist. ${ }^{239}$

The third component is about linking patients to psychosocial care. Referral to psychosocial caregivers is a mechanism for linking patients with caregivers. Although a manual was prepared with suitable cut-off scores for symptoms, more effort should be taken to link patients with psychosocial caregivers by more structured referral. The latter can be accomplished through using computer-based screening instruments which automatically generate referral to a psychosocial caregiver. ${ }^{30}$ Moreover, more effort should be made to motivate referred patients to accept psychosocial care, since one-third of the patients refused psychosocial care. A method which may improve the acceptance rate is that patients with psychosocial problems will be contacted by psychosocial caregivers or nurses to explore their emotional well-being and psychosocial needs. ${ }^{30}$ Moreover, at the same time the psychosocial caregivers or nurses can explain to the patients the possible negative impact of psychosocial problems on their emotional and physical well-being.

The success of all the components depends on effective patient-physician communication. Patients should be comfortable with asking questions and with expressing their needs, and radiotherapists should possess the communication skills to establish a good interpersonal relationship with the patient ${ }^{240}$, including responding to emotions. ${ }^{235}$ The lack of the effectiveness of our screening programme can partly be explained by the fact that patient-radiotherapist communication was not improved by using the SIPP. The results of our study revealed that using the SIPP did not improve the communication between radiotherapists and patients regarding discussing psychosocial problems, nor did it improve patients' satisfaction with their communication with their radiotherapist during the first consultation. The one hour training which the radiotherapists received before the start of this study might have been insufficient for improving their communication skills and making the radiotherapists aware of the need to identify psychosocial problems in their patients. This may also explain why none of the radiotherapists mentioned that their communication style was changed by using the SIPP. 


\section{Implementation}

Another important aspect in delivering psychosocial care is the successful implementation of the screening procedure. In a successful implementation process, several more general factors are important. ${ }^{241}$

The first factor refers to the characteristics of the screening procedure. It can be assumed that the first consultation was not at a suitable point in time for either patients or radiotherapists to discuss the patients' psychosocial wellbeing. The results of our process evaluation study showed that at that time physical problems were more frequently discussed than psychological problems. Furthermore, as stated above, the use of a computer-based screening instrument may be more suitable for radiotherapists to use.

The second factor concerns the decision-making process that occurs when healthcare professionals consider adopting a screening procedure. During the preparation phase of our study, a small number of all the involved personnel (one radiotherapist, one physician assistant, one administrative employee and two social workers and their manager) were engaged. For a successful implementation, a sense of ownership on the part of all of the involved healthcare professionals and the managers of several disciplines might be crucial. Probably, if we had engaged them - especially the managers and the heads of the subdepartments - more intensely before the start of the implementation trajectory, their sense of control would have increased and, therefore, possibly their support and acceptance of the use of a screening instrument to identify psychosocial problems. ${ }^{242}$

The third factor refers to the characteristics of the health care system and its individuals - including their attitudes and their skills - which make them likely to adopt an innovation ${ }^{241}$. Regarding the results of the present study, the question arises as to whether radiotherapists were the most suitable healthcare professionals for discussing psychosocial problems with the patients. In line with the study of Dolbeault et al. ${ }^{237}$, there was a certain amount of (initial) resistance. In our intervention study, two of the seven radiotherapists who were allocated to the experimental group did not recognise the value of using a screening instrument to identify psychosocial problems in cancer patients. Hence, one radiotherapist did not discuss the SIPP with the patients at all during consultation, which may have had a large impact on the outcomes of the study. In any future project, it should be considered whether nurse practitioners might be more suitable in discussing possible psychosocial problems with the patients.

A final factor is the communication procedure used in the implementation trajectory of the screening procedure. At the start of the study, the radiotherapists allocated to the intervention group received one hour of training about the study protocol, on the importance of screening for psychosocial problems and how to score and interpret the SIPP. In addition, the involved personnel - including the receptionists and physician assistants - received a short presentation on the purpose of the study and the study protocol. There were meetings with the 
research assistants, receptionists and other involved personnel on a regular basis, especially at the start of the study. However, no regular clinical meetings with the radiotherapists were scheduled in order to check if they were adhering to the screening procedure and to discuss situations that may have caused them difficulties in discussing psychosocial problems during the consultations. Such meetings also would have been important in reminding them of the value of identifying and discussing patients' psychosocial well-being, especially since we found that the majority of the patients rated the discussion with their radiotherapist about psychosocial problems as highly important ${ }^{194}$.

\section{Future directions}

The findings of this thesis have implications for both practice and further research.

\section{Recommendations for clinical practice}

From a holistic perspective, cancer care should incorporate the appropriate psychosocial care next to medical care. As mentioned above, the use of a psychosocial screening instrument is only a single element of effective psychosocial care - this depends on a combination of different elements. Therefore, appropriate psychosocial care should be ensured by: 1) effective communication between patients and radiotherapists; 2) designing a procedure which includes the different components as depicted in Figure 1 and discussed above; and 3) the successful implementation of psychosocial care in radiation departments.

First, strategies to improve patient-radiotherapist communication should focus on both patients and radiotherapists. Regarding the patients, it is important to stimulate their participation in their own care. For this, there are several effective approaches, such as (psycho-) education programmes 237 and videos with supporting materials aimed at increasing patients' knowledge about their disease and patient-physician communication ${ }^{243}$. These approaches may be effective in encouraging patients to write down their questions and concerns, and may improve not only the discussion of medical problems but also the discussion of psychosocial problems and needs with the radiotherapist during consultation. Regarding the radiotherapists, since they develop routines for interacting with patients early during their training as a physician, communication training and attentiveness to the psychosocial problems of their patients should occur early on in their education. ${ }^{237,244}$ To gain more confidence in discussing the psychosocial problems and needs of their patients, training on discussing psychosocial problems should comprise practical exercises. The training should include exercises taking corrective actions based on screening outcomes $^{245}$ to ensure adequate referral and treatment. In addition, the training 
should provide timely feedback and allow radiotherapists to work in groups with skilled trainers. ${ }^{244}$ Moreover, the training should be carried out over a long period of time. Further, periodically organised training sessions with, for example, one training day annually may be sufficient for training and updating their communication skills.

Second, the five effective delivery components (the identification of psychosocial needs; supporting patients; linking patients with caregivers; coordinating psychosocial and medical care; and follow-up and re-evaluation) together should be taken into account for delivering optimal psychosocial care in oncology. There are several approaches to improving the identification of psychosocial problems and needs among patients. One approach is to arrange supervision meetings on a regular basis for radiotherapists. These meetings could enhance the use and effectiveness of screening instruments since radiotherapists have the opportunity to provide feedback about the procedures to colleagues. A second approach to the identification of psychosocial needs is that instead of radiotherapists, rather psychosocial caregivers, case managers or nurses should check the scores on the screening instrument. If necessary, they can contact the patient to discuss their psychosocial problems and needs for care. Moreover, psychosocial caregivers or case managers are the persons designated to motivate patients to accept psychosocial care. To improve coordinating psychosocial and medical care, a multidisciplinary team - including oncologists, radiotherapists, social workers and specialised nurses etc. - is warranted. ${ }^{235}$ The last approach to getting a full insight into the patients' psychosocial problems and needs is a more in-depth evaluation that confirms the presence of those problems and needs which might be complementary to the use of a validated screening instrument. ${ }^{235}$ In addition, identifying patients' psychosocial problems and needs at different times during their illness trajectory is crucial in delivering optimal psychosocial care, especially when, as discussed in Chapter 1, patients experience different types of problems at different points in time during their illness trajectory. Regarding the component of supporting patients, it can be helpful to support patients with any psychosocial problems which are related to the cancer and the cancer treatment. Education programmes may be useful for increasing patients' awareness of the consequences of psychosocial problems on their health-related outcomes. Furthermore, such programmes may encourage patients to verbalise their problems and needs with their physician. Finally, systematic follow-up, re-evaluation and, if necessary, optimisation of psychosocial care might be crucial. Telephone calls or outpatients visits might be useful for monitoring patients' psychosocial well-being and determining which services or care patients are using and whether the patients are satisfied about $\mathrm{it}^{246}$.

Third, a condition for successful implementation is the radiotherapists' acceptance of and attitude towards using screening instruments. It is crucial to make them aware of patients' psychosocial needs and the value of identifying 
and discussing patients' psychosocial well-being. Furthermore, a final relevant condition is the creation of a sense of ownership among all of the involved healthcare professionals so as to get their support for and acceptance of using screening instruments as a part of psychosocial care, and that psychosocial care - is next to medical care - an important part of cancer care.

\section{Areas for future research}

Many barriers need to be overcome and a lot of effort should be taken to meet the psychosocial needs of cancer patients receiving radiotherapy. Therefore, further research should focus on the improvement of psychosocial care with screening as one of the multiple elements. In addition, future research should focus on the identification of conditions which are necessary for successful implementation.

First, research should focus on exploring effective methods for improving patient-radiotherapist communication regarding discussing psychosocial problems during consultation. Not only should effective methods for improving radiotherapists' communication skills be identified but also methods to encourage patients to discuss their emotional problems and needs.

Second, we recommend that future research should focus not only on one single component of psychosocial care but on the combination of all of the following components: the identification of psychosocial needs; supporting patients; linking patients with caregivers; coordinating psychosocial and medical care; and follow-up and re-evaluation. An important aspect for research is to get a full insight into patients' psychosocial needs and to improve the referral of patients to psychosocial caregivers. The focus should be on adequate screening moments in order to identify problems. Due to a lack of clarity regarding the adequate times for identifying distress, the Dutch Society Psychosocial Oncology (NVPO) recommend regular screening for psychosocial problems during curative and palliative treatment and during the follow-up period. The NVPO suggests that the first assessment for screening should take place during the first follow-up consultation with the physician or the nurse after the patient received his or her diagnosis. Other screening moments might be: a) during the treatment trajectory: at the start and end of each treatment, and/or every 3 months; b) during the follow-up period: by every follow-up consultation but not more than every 2-3 months; and c) at the last follow-up consultation. ${ }^{59}$ Despite these suggestions, it still remains unclear to hospitals and radiation departments in the Netherlands as to which assessment options mark the most adequate points in time for the optimal screening of psychosocial distress in cancer patients. Moreover, regarding the results of our intervention study, the screening moments at the start and the end of the RT may not be suitable screening moments, as we found no clear intervention effect on the referral rate (although referral occurred earlier in their treatment), communication and health-related out- 
comes. Nevertheless the results showed that screening at the start of the RT had a positive effect on referring patients to additional psychosocial care for psychosocial problems at an earlier stage. Further research is warranted so as to identify the optimal screening moments needed to identify psychosocial problems among cancer patients. Other aspects which need further research are the possible benefits of earlier referral. Moreover, more insight is needed into the reasons why referred patients refuse psychosocial care, and the identification of acceptable methods to encourage them to accept psychosocial support.

Third, future research should focus on barriers and facilitators - including acceptability - of the implementation of screening procedures, since both factors may play an important role in the successfulness of implementation strategies. Mitchell et al. stated that it is not the accuracy of a screening instrument that determines successful implementation but rather the healthcare professionals' acceptance of it. ${ }^{247}$ It is important to examine whether radiotherapists or other healthcare professionals are the professionals who are most suited to discussing psychosocial problems with patients. Nurses appeared to be more comfortable with exploring patients' emotional well-being than physicians ${ }^{195}$.

\section{Conclusions}

Our psychosocial screening procedure did have less favourable effects than expected on patients' psychological functioning and HRQoL in both the shortterm and the long term. Psychosocial distress screening in cancer patients receiving RT on its own does not sufficiently improve patients' general healthrelated outcomes. The effective delivery of psychosocial care to cancer patients depends upon a combination of elements rather than on a single element by itself. ${ }^{235}$ It is not only about the use of a specific screening instrument but also about taking effective actions based on the results of a screening instrument that may affect patients' outcomes. ${ }^{248,249}$ Based on our own findings and experiences, we do not recommend the implementation of the screening procedure in its current form. The successful implementation of a psychosocial screening procedure into the (radiation) oncology departments is a complex task and takes a lot of effort, but is essential to improve patient outcomes. Delivering successful psychosocial care in radiation oncology departments is a challenging and long term goal which will demand a multidisciplinary approach and further research. 
DISCUSSION 

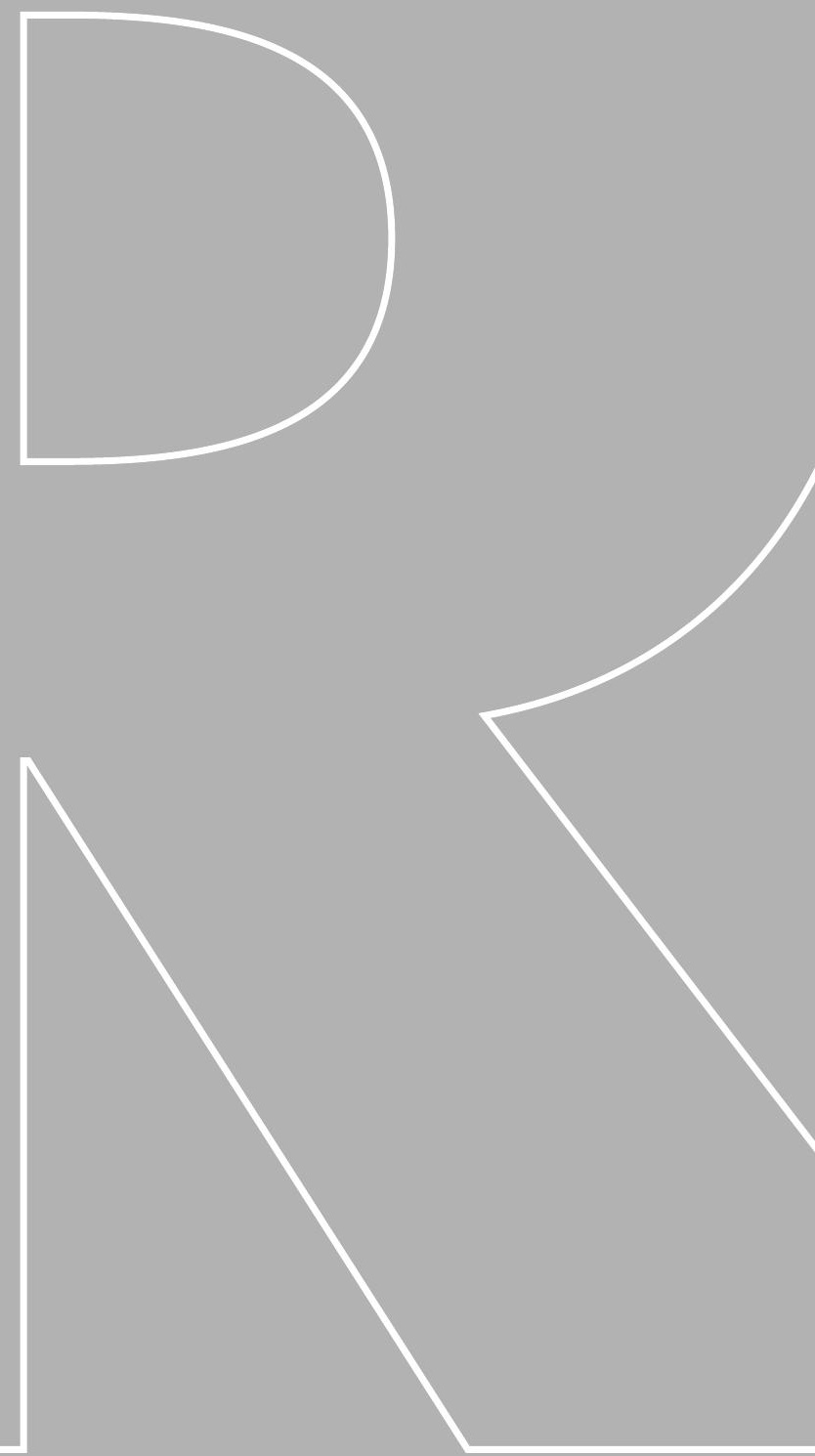


\section{References}




\section{References}

1. Phillips JL, Currow DC: Cancer as a chronic disease. Collegian 17:47-50, 2010

2. Garssen J, Hoogenboezem J: Kanker: lager risico, meer sterfgevallen, Centraal Bureau voor de Statistiek (CBS), 2011

3. Cancer WF: The facts, Fight Cancer part of KWF Kankerbestrijding, 2011

4. Adler NE, Page AEK: Cancer care for the whole patient, in Sciences NAo (ed), 2008

5. Begg AC, Stewart FA, Vens C: Strategies to improve radiotherapy with targeted drugs. Nature Reviews Cancer 11:239-250, 2011

6. Delaney G, Jacob S, Featherstone C, et al: The role of radiotherapy in cancer treatment: estimating optimal utilization from a review of evidence-based clinical guidelines. Cancer 104:119-1137, 2005

7. Leer JWH, Van Der Schueren E: Radiotherapeutische principes, in Zwaveling A, Bosman FT, Schaberg A, et al (eds): Oncologie. Houten/Zaventem, Bohn Stafleu Van Loghum, 1991

8. Holland JC: Psychological care of patients: psycho-oncology's contribution. Journal of Clinical Oncology 21:253s-265s, 2003

9. Garssen B, de Haes H, Watson M: Cancer, in Kaptein A, Appels A, Orth-Gomer K (eds): Psychology in medicine. Houten, Bohn Stafleu Van Loghum, 2000, pp 119-149

10. Engel GL: The need for a new medical model: a challenge for biomedicine Science 8:129-136, 1977

11. Kaptein A, Appels A, Orth-Gomer K: Psychology in medicine, in Kaptein A, Appels A, OrthGomer K (eds): Psychology in medicine. Houten/ Diegem, BohnStafleu Van Loghum, 2000, pp 7-9

12. Lakhaan SE: The Biopsychosocial Model of Health \& Illness, in Lakhaan SE (ed), Global Neuroscience Initiative Foundation (GNIF), 2006

13. Spiegel D, Giese-Davis J: Depression and cancer: mechanisms and disease progression. Biol Psychiatry 54:269-82, 2003

14. Services DoHaH: The fundamentals of mental health and mental illness, in Center for Mental Health Services NIoH, National Institute of Mental Health (ed): Mental Health: a Report of the Surgeon General-Executive Summary. Pittsburgh, U.S. Public Health Service, 1999

15. Gross J: Emotional expression in cancer onset and progression. Soc Sci Med 28:1239-1248, 1989

16. Holland JC: Lesson in psycho-oncology. Journal of BUON 7:187-194, 2002

17. Sandoval-Cros CJ: Common Psychological Problems in the Cancer Patient in Society AC (ed), 1999

18. Maes S, van Elderen T: Coping with Chronic Physical Illness, in Kaptein A, Appels A, OrthGomer K (eds): Psychology in medicine. Houten/Diegem, Bohn Stafleu Van loghum, 2000

19. Mehnert A, Koch U: Psychoosocial assessment in cancer patients, IPOS online curiculum, International Psycho-Oncology Society, 2010-2011

20. Greer S, Morris T, Pettingale KW, et al: Psychological response to breast cancer and 15-year outcome. The Lancet 335:49-50, 1990

21. Watson M, Greer S, Rowden L, et al: Relationships between emotional control, adjustment to cancer and depression and anxiety in breast cancer patients. Psychological medicine 21:51-7, 1991

22. Cordova MJ, Giese-Davis J, Golant M, et al: Mood disturbance in community cancer support groups. The role of emotional suppression and fighting spirit. Journal of Psychosomatic Research 55:461-7, 2003

23. Akechi T, Okuyama T, Imoto S, et al: Biomedical and psychosocial determinants of psychiatric morbidity among postoperative ambulatory breast cancer patients. Breast cancer research and treatment 65:195-202, 2001

24. Watson M, Greer S, Young J, et al: Development of a questionnaire measure of adjustment to cancer: the MAC scale. Psychological medicine 18:203-9, 1988 
25. Akechi T, Okuyama T, Sugawara Y, et al: Major depression, adjustment disorders, and posttraumatic stress disorder in terminally ill cancer patients: associated and predictive factors. J Clin Oncol 22:1957-65, 2004

26. Chen AM, Jennelle RL, Grady V, et al: Prospective study of psychosocial distress among patients undergoing radiotherapy for head and neck cancer. International journal of radiation oncology, biology, physics 73:187-93, 2009

27. Derogatis LR, Morrow GR, Fetting J, et al: The prevalence of psychiatric disorders among cancer patients. Jama 249:751-7, 1983

28. Hahn CA, Dunn R, Halperin EC: Routine screening for depression in radiation oncology patients. Am J Clin Oncol 27:497-9, 2004

29. Hopwood P, Stephens RJ: Depression in patients with lung cancer: prevalence and risk factors derived from quality-of-life data. J Clin Oncol 18:893-903, 2000

30. Kendall J, Glaze K, Oakland S, et al: What do 1281 distress screeners tell us about cancer patients in community cancer center? Psycho-Oncology 20:594-600, 2011

31. Maraste R, Brandt L, Olsson H, et al: Anxiety and depression in breast cancer patients at start of adjuvant radiotherapy. Relations to age and type of surgery. Acta Oncol 31:641-3, 1992

32. Mitchell AJ, Hussain N, Grainger L, et al: Identification of patient-reported distress by clinical nurse specialists in routine oncology practice: a multicentre UK study. Psycho-Oncology 20:1076-83, 2011

33. Norton TR, Manne SL, Rubin S, et al: Prevalence and predictors of psychological distress among women with ovarian cancer. J Clin Oncol 22:919-26, 2004

34. Passik SD, Dugan W, McDonald MV, et al: Oncologists' recognition of depression in their patients with cancer. J Clin Oncol 16:1594-600, 1998

35. Holland JC, Bultz BD: The NCCN guideline for distress management: a case for making distress the sixth vital sign. J Natl Compr Canc Netw 5:3-7, 2007

36. Fallowfield L, Ratcliffe D, Jenkins V, et al: Psychiatric morbidity and its recognition by doctors in patients with cancer. Br J Cancer 84:1011-5, 2001

37. Fawzy FI: Psychosocial Interventions for Patients with Cancer: What Works and What Doesn't. European Journal of Cancer 35:1559-1564, 1999

38. Carlsen K, Jensen AB, Jacobsen E, et al: Psychosocial aspects of lung cancer. Lung Cancer 47:293-300, 2005

39. Mitchell AJ, Coyne JC: Screening for depression in clinical practice: an evidence-based guide. New York, Oxford University Press, Inc., 2010

40. Sehlen S, Hollenhorst H, Schymura B, et al: Psychosocial stress in cancer patients during and after radiotherapy. Strahlenther Onkol 179:175-180, 2003

41. Holland JC, Reznik I: Pathways for psychosocial care of cancer survivors. Cancer 28:2654-2637, 2005

42. Maguire $\mathrm{P}$, Tait A, Brooke $\mathrm{M}$, et al: Effect of counselling on the psychiatric morbidity associated with mastectomy. British medical journal 29:1454-1456, 1980

43. Roth AJ, Kornblith AB, Batel-Copel L, et al: Rapid screening for psychologic distress in men with prostate carcinoma: a pilot study. Cancer 82:1904-8, 1998

44. Ibbotson T, Maguire P, Selby P, et al: Screening for anxiety and depression in cancer patients: the effects of disease and treatment. European Journal of Cancer 30A:37-40, 1994

45. Association AP: Diagnostic and statistical manual of mental disorders (ed Fourth). Washington DC, American Psychiatric Publishing, 1994

46. DiMatteo MR, Lepper HS, Croghan TW: Depression is a risk factor for noncompliance with medical treatment: meta-analysis of the effects of anxiety and depression on patient adherence. Arch Intern Med 160:2101-7, 2000

47. Zabora J, BrintzenhofeSzoc K, Curbow B, et al: The prevalence of psychological distress by cancer site. Psycho-Oncology 10:19-28, 2001

48. Cull A, Gould A, House A, et al: Validating automated screening for psychological distress by means of computer touchscreens for use in routine oncology practice. Br J Cancer 85:1842-9, 2001 
49. Sollner W, DeVries A, Steixner E, et al: How successful are oncologists in identifying patient distress, perceived social support, and need for psychosocial counselling? Br J Cancer 84:17985,2001

50. Carlson LE, Angen M, Cullum J, et al: High levels of untreated distress and fatigue in cancer patients. Br J Cancer 90:2297-304, 2004

51. Kruijver IP, Garssen B, Visser AP, et al: Signalising psychosocial problems in cancer care :the structural use of a short psychosocial checklist during medical or nursing visits. Patient Educ Couns 62:163-77, 2006

52. Dugan W, McDonald MV, Passik SD, et al: Use of the Zung Self-Rating Depression Scale in cancer patients: feasibility as a screening tool. Psycho-Oncology 7:483-93, 1998

53. Bultz BD, Johansen C: Screening for distress, the 6th vital signal:where are we, and where are we going? Psycho-Oncology 20:569-571, 2011

54. NHS: How to change practice, National Institute for HEalth and Clinical Excellence (NICE), 2007

55. Holland JC, Andersen B, Breitbart W, et al: Distress Management. Journal of the National Comprehensive Cancer Network 8:448-485, 2010

56. Initiative NBCCNCC: Clinical Practice Guidelines for the Psychosocial Care of adults With Cancer, 2003

57. Canada A: Cancer Care and Oncology Services Standards, 2008-2009

58. Gezondheidszorg I: Zorgketen voor kankerpatienten moet verbeteren. Den Haag, 2009

59. NVPO: Richtlijn detecteren behoefte psychosociale zorg, Dutch Society for Psychosocial Oncology, 2009

60. Bidstrup PE, Johansen C, Mitchell AJ: Screening for cancer-related distress: Summary of evidence from tools to programmes. Acta Oncol 50:194-204, 2011

61. Mitchell AJ: Are one or two simple questions sufficient to detect depression in cancer and palliative care? A Bayesian meta-analysis. British journal of cancer 98:1934-43, 2008

62. Maunsell E, Brisson J, Deschenes L, et al: Randomized trial of a psychologic distress screening program after breast cancer: effects on quality of life. Journal of clinical oncology : official journal of the American Society of Clinical Oncology 14:2747-55, 1996

63. McLachlan SA, Allenby A, Matthews J, et al: Randomized trial of coordinated psychosocial interventions based on patient self-assessments versus standard care to improve the psychosocial functioning of patients with cancer. J Clin Oncol 19:4117-25, 2001

64. Detmar SB, Muller MJ, Schornagel JH, et al: Health-related quality-of-life assessments and patient-physician communication: a randomized controlled trial. Jama 288:3027-34, 2002

65. Velikova G, Booth L, Smith AB, et al: Measuring quality of life in routine oncology practice improves communication and patient well-being: a randomized controlled trial. J Clin Oncol 22:714-24, 2004

66. Boyes A, Newell S, Girgis A, et al: Does routine assessment and real-time feedback improve cancer patients' psychosocial well-being? Eur J Cancer Care (Engl) 15:163-71, 2006

67. Rosenbloom SK, Victorson DE, Hahn EA, et al: Assessment is not enough: a randomized controlled trial of the effects of HRQL assessment on quality of life and satisfaction in oncology clinical practice. Psycho-Oncology 16:1069-79, 2007

68. Carlson LE, Groff SL, Maciejewski O, et al: Screening for distress in lung and breast cancer outpatients: a randomized controlled trial. J Clin Oncol 28:4884-91, 2010

69. Akechi T, Okuyama T, Imoto S, et al: Biomedical and psychosocial determinants of psychiatric morbidity among postoperative ambulatory cancer patients. Breast Cancer Research and Treatment 65:195-202, 2001

70. Akizuki N, Akechi T, Nakanishi T, et al: Development of a brief screening interview for adjustment disorders and major depression in patients with cancer. Cancer 97:2605-13, 2003

71. Akizuki N, Yamawaki S, Akechi T, et al: Development of an Impact Thermometer for use in combination with the Distress Thermometer as a brief screening tool for adjustment disorders and/or major depression in cancer patients. J Pain Symptom Manage 29:91-9, 2005 
72. Carlson LE, Bultz BD: Cancer distress screening. Needs, models, and methods. J Psychosom Res 55:403-9, 2003

73. Jenkins C, Carmody TJ, Rush AJ: Depression in radiation oncology patients: a preliminary evaluation. J Affect Disord 50:17-21, 1998

74. Maher EJ, Mackenzie C, Young T, et al: The use of the Hospital Anxiety and Depression Scale (HADS) and the EORTC QLQ-C30 questionnaires to screen for treatable unmet needs in patients attending routinely for radiotherapy. Cancer Treat Rev 22 Suppl A:123-9, 1996

75. Sellick SM, Edwardson AD: Screening new cancer patients for psychological distress using the hospital anxiety and depression scale. Psycho-Oncology 16:534-542, 2007

76. Zabora J, BrintzenhofeSzoc K, Curbow B, et al: The prevalence of psychological distress by cancer site. Psycho-Oncology 10:19-28, 2001

77. Nosarti C, Roberts JV, Crayford T, et al: Early psychological adjustment in breast cancer patients: a prospective study. J Psychosom Res 53:1123-30, 2002

78. Sehlen S, Hollenhorst H, Schymura B, et al: Psychosocial stress in cancer patients during and after radiotherapy. Strahlenther Onkol 179:175-80, 2003

79. McCaul KD, Sandgren AK, King B, et al: Coping and adjustment to breast cancer. PsychoOncology 8:230-236, 1999

80. Watson M, Greer S, Young J, et al: Development of a questionnaire measure of adjustment to cancer: the MAC scale. Psychol Med 18:203-9, 1988

81. Nordin K, Berglund G, Terje I, et al: The Mental Adjustment to Cancer Scale--a psychometric analysis and the concept of coping. Psycho-Oncology 8:250-9, 1999

82. Schroevers MJ, Ranchor AV, Sanderman R: The role of social support and self-esteem in the presence and course of depressive symptoms: a comparison of cancer patients and individuals from the general population. Soc Sci Med 57:375-85, 2003

83. Baider L, Ever-Hadani P, Goldzweig G, et al: Is perceived family support a relevant variable in psychological distress?. A sample of prostate and breast cancer couples. J Psychosom Res 55:453-60, 2003

84. Fritzsche K, Liptai C, Henke M: Psychosocial distress and need for psychotherapeutic treatment in cancer patients undergoing radiotherapy. Radiother Oncol 72:183-9, 2004

85. Wong WS, Fielding R: Change in quality of life in Chinese women with breast cancer: changes in psychological distress as a predictor. Support Care Cancer 15:1223-30, 2007

86. Pruyn JF, Heule-Dieleman HA, Knegt PP, et al: On the enhancement of efficiency in care for cancer patients in outpatient clinics: an instrument to accelerate psychosocial screening and referral. Patient Educ Couns 53:135-40, 2004

87. Versloot J: Evaluatie van een driejarig project psychosociale oncologie van het Sint Lucas Andreas ziekenhuis en het Integrale Kanker Centrum. Amsterdam, 2002

88. Borsboom L, Bolman C, van Helden C, et al: Signalering van psychosociale problematiekBehoefte aan zorg niet altijd onderkend. Oncologica 01:40-44, 2009

89. Knipscheer-Kuipers M: Vroegsignalering in de psychosociale oncologie: ervaringen met het werken met de signaleringslijst in een algemeen ziekenhuis. Amsterdam, Integraal kankercentrum Amsterdam en Sint Lucas Andreas ziekenhuis, 1997

90. Zigmond AS, Snaith RP: The hospital anxiety and depression scale. Acta Psychiatr Scand 67:361-70, 1983

91. Goldberg D, Williams P: A user's guide to the General Health Questionnaire. Windsor, NFERNelson, 1988

92. Dolbeault S, Bredart A, Mignot V, et al: Screening for psychological distress in two French cancer centers: feasibility and performance of the adapted distress thermometer. Palliat Support Care 6:107-17, 2008

93. Jacobsen PB, Donovan KA, Trask PC, et al: Screening for psychologic distress in ambulatory cancer patients. Cancer 103:1494-502, 2005

94. Galdon MJ, Dura E, Andreu Y, et al: Psychometric properties of the Brief Symptom Inventory-18 in a Spanish breast cancer sample. J Psychosom Res 65:533-9, 2008 
95. Wilson KG, Chochinov HM, Faye BJ: Handbook of psychiatry in palliative medicine. New York, Oxford University Press, 2000

96. Higginson IJ, Carr AJ: Measuring quality of life: Using quality of life measures in the clinical setting. Bmj 322:1297-300, 2001

97. Zigmond AS, Snaith RP: The Hospital Anxiety and Deprssion Scale. Acta psychiatric scand 67:361-370, 1983

98. Spinhoven P, Ormel J, Sloekers PP, et al: A validation study of the Hospital Anxiety and Depression Scale (HADS) in different groups of Dutch subjects. Psychol Med 27:363-70, 1997

99. Keller M, Sommerfeldt S, Fischer C, et al: Recognition of distress and psychiatric morbidity in cancer patients: a multi-method approach. Ann Oncol 15:1243-9, 2004

100. Razavi D, Delvaux N, Farvacques C, et al: Screening for adjustment disorders and major depressive disorders in cancer in-patients. Br J Psychiatry 156:79-83, 1990

101. Rodgers J, Martin CR, Morse RC, et al: An investigation into the psychometric properties of the Hospital Anxiety and Depression Scale in patients with breast cancer. Health and Quality of Life Outcomes 3:41, 2005

102. Leopold KA, Ahles TA, Walch S, et al: Prevalence of mood disorders and utility of the PRIMEMD in patients undergoing radiation therapy. Int J Radiat Oncol Biol Phys 42:1105-12, 1998

103. Walker J, Postma K, McHugh GS, et al: Performance of the Hospital Anxiety and Depression Scale as a screening tool for major depressive disorder in cancer patients. J Psychosom Res 63:83-91, 2007

104. Watson M, Homewood J: Mental Adjustment to Cancer Scale: psychometric properties in a large cancer cohort. Psycho-Oncology 17:1146-51, 2008

105. Tuinman MA, Gazendam-Donofrio SM, Hoekstra-Weebers JE: Screening and referral for psychosocial distress in oncologic practice: use of the Distress Thermometer. Cancer 113:8708,2008

106. Zwahlen D, Hagenbruch N, Carley M, et al: Screening cancer patients'families with the distress thermometer (DT): a validation study. Psycho-Oncology 17:959-966, 2008

107. Greer S, Moorey S, Watson M: Patients' adjustment to cancer: the Mental Adjustment to Cancer (MAC) scale vs clinical ratings. J Psychosom Res 33:373-7, 1989

108. Braeken APBM, Kempen GJM, Watson M, et al: Psychomertic properties of the Dutch version of the Mental Adjustment to Cancer scale in Dutch cancer patients. Psycho-Oncology 19:742-749, 2010

109. First MB, Spitzer RL: Structured Clinical Interview for DSM-IV Axis I Disorders- Patient Edition (SCID-I/P, Version 2.0). New York, New York, biometrics research Department, New York State Psychiatric Institute., 1996

110. Bouter LM, Dongen van MCIM: Epidemiologisch onderzoek, opzet en interpretatie (ed Vierde, herziene druk). Houten/ Diegem, Bohn Stafleu Van Loghum, 2000

111. Huisman M: Simple and effective methods to treat missing items responses., in statistiek Rvv (ed): Kwantitatieve methoden: the Netherlands electronical journal of quantitative methods. Rotterdam, 2002, pp 57-78

112. Jöreskog K, Sörbom D: WINDOWS LISREL. Version 8.71. Scientific Software International. Chicago, 2004

113. Strong V, Waters R, Hibberd C, et al: Emotional distress in cancer patients: the Edinburgh Cancer Centre symptom study. Britisch Journal of Cancer 96:868-874, 2007

114. Lintz K, Moynihan C, Steginga S, et al: Prostate cancer patients' support and psychological care needs: survey from a non-surgical oncology clinic. Psycho-Oncology 12:769-783, 2003

115. Kempen GI, van Sonderen E: Psychological attributes and changes in disability among lowfunctioning older persons: does attrition affect the outcomes? J Clin Epidemiol 55:224-9, 2002

116. Newport DJ, Nemeroff CB: Assessment and treatment of depression in the cancer patient. J Psychosom Res 45:215-37, 1998

117. Dugan W, McDonald MV, Passik SD, et al: Use of the Zung Self-Rating Depression Scale in cancer patients: feasibility as a screening tool. Psycho-Oncology 7:483-93, 1998 
118. Knipscheer-Kuipers M: Screening in the psychosocial oncology: experiences of using a screeningsinstrument in a general hospital. . Amsterdam, Integraal kankercentrum Amsterdam en Sint Lucas Andreas ziekenhuis, 1997

119. Wilson KG, Chochinov HM, Faye BJ: Handbook of Psychiatry in Palliative Medicine. New York, Oxford University Press, 2000

120. Eldridge S, Ashby D, Bennett C, et al: Internal and external validity of cluster randomised trials: systematic review of recent trials. Bmj 336:876-80, 2008

121. Campbell MK, Elbourne DR, Altman DG: CONSORT statement: extension to cluster randomised trials. Bmj 328:702-8, 2004

122. Campbell MK, Grimshaw JM: Cluster randomised trials: time for improvement. The implications of adopting a cluster design are still largely being ignored. Bmj 317:1171-2, 1998

123. Versloot J: De oncologie-psycholoog in een algemeen ziekenhuis. Evaluatie van een driejarig project psychosociale oncologie van het Sint Lucas Andreas ziekenhuis en het Integrale Kanker Centrum. Amsterdam, IKA, 2002

124. Lenth RV: Java Applets for Power and Sample size (Computer software, 2006-9), (ed 23rd), 2006, pp from http://www.stat.uiowa.edu/ rlenth/Power

125. Elbourne DR, Campbell MK: Extending the CONSORT statement to cluster randomized trials: for discussion. Stat Med 20:489-96, 2001

126. Kramer JA, Curran D, Piccart M, et al: Randomised trial of paclitaxel versus doxorubicin as firstline chemotherapy for advanced breast cancer: quality of life evaluation using the EORTC QLQC30 and the Rotterdam symptom checklist. Eur J Cancer 36:1488-97, 2000

127. Eldridge S, Cryer C, Feder G, et al: Sample size calculations for intervention trials in primary care randomizing by primary care group: an empirical illustration from one proposed intervention trial. Stat Med 20:367-76, 2001

128. Cumming RG, Sherrington C, Lord SR, et al: Cluster randomised trial of a targeted multifactorial intervention to prevent falls among older people in hospital. Bmj 336:758-60, 2008

129. Isaakidis P, Ioannidis JP: Evaluation of cluster randomized controlled trials in sub-Saharan Africa. Am J Epidemiol 158:921-6, 2003

130. Aaronson NK, Ahmedzai S, Bergman B, et al: The European Organization for Research and Treatment of Cancer QLQ-C30: a quality-of-life instrument for use in international clinical trials in oncology. J Natl Cancer Inst 85:365-76, 1993

131. Atesci FC, Baltalarli B, Oguzhanoglu NK, et al: Psychiatric morbidity among cancer patients and awareness of illness. Support Care Cancer 12:161-7, 2004

132. Chambers SK, Schover L, Halford K, et al: ProsCan for Couples: randomised controlled trial of a couples-based sexuality intervention for men with localised prostate cancer who receive radical prostatectomy. BMC Cancer 8:226, 2008

133. Gessler S, Low J, Daniells E, et al: Screening for distress in cancer patients: is the distress thermometer a valid measure in the UK and does it measure change over time? A prospective validation study. Psycho-Oncology 17:538-47, 2008

134. Janda M, Steginga S, Dunn J, et al: Unmet supportive care needs and interest in services among patients with a brain tumour and their carers. Patient Educ Couns 71:251-8, 2008

135. Kornblith $\mathrm{AB}$, Powell M, Regan MM, et al: Long-term psychosocial adjustment of older vs younger survivors of breast and endometrial cancer. Psycho-Oncology 16:895-903, 2007

136. Ockhuysen-Vermey CF, Henneman L, van Asperen CJ, et al: Design of the BRISC study: a multicentre controlled clinical trial to optimize the communication of breast cancer risks in genetic counselling. BMC Cancer 8:283, 2008

137. Zwahlen D, Hagenbuch N, Carley MI, et al: Screening cancer patients' families with the distress thermometer (DT): a validation study. Psycho-Oncology 17:959-66, 2008

138. Snaith RP, Zigmond AS: The hospital anxiety and depression scale. Br Med J (Clin Res Ed) 292:344, 1986

139. Bowling A: Measuring disease (ed Second). Buckingham, Open University Press, 2001

140. Chen CC, David A, Thompson K, et al: Coping strategies and psychiatric morbidity in women attending breast assessment clinics. J Psychosom Res 40:265-70, 1996 
141. Lintz K, Moynihan C, Steginga S, et al: Prostate cancer patients' support and psychological care needs: Survey from a non-surgical oncology clinic. Psycho-Oncology 12:769-83, 2003

142. Pijls-Johannesma MC, Pijpe A, Kempen GI, et al: Health related quality of life assessment instruments: a prospective study on preference and acceptability among cancer patients referred for radiotherapy. Eur J Cancer 41:2250-6, 2005

143. Budischewski K, Fischbeck S, Mose S: Quality of life of breast cancer patients in the course of adjuvant radiotherapy. Support Care Cancer 16:299-304, 2008

144. Fehlauer F, Tribius S, Mehnert A, et al: Health-related quality of life in long term breast cancer survivors treated with breast conserving therapy: impact of age at therapy. Breast Cancer Res Treat 92:217-22, 2005

145. TNM Classification Help, Manual for cancer staging

146. Polit F, Tatano Beck C: Nursing Research: Principles and Methods (ed 7). Philadelphia, Lippincott Wiliams \& Wilkins, 2004

147. Stiegelis HE, Ranchor AV, Sanderman R: Psychological functioning in cancer patients treated with radiotherapy. Patient Educ Couns 52:131-41, 2004

148. Fagerlind H., Lindblad A.K., Bergström I., et al: Patient-physician communication during oncology consultations. Psycho-Oncology 17:975-985, 2008

149. Rodriguez KL, Bayliss N, Alexander SC, et al: How oncologists and their patients with advanced cancer communicate about health-related quality of life. Psycho-Oncology 19:490-9, 2010

150. Carlson LE, Bultz BD: Efficacy and medical cost offset of psychosocial interventions in cancer care: making the case for economic analyses. Psycho-Oncology 13:837-49; discussion 850-6, 2004

151. Gross R, Brammli-Greenberg S, Tabenkin H, et al: Primary care physicians' discussion of emotional distress and patient satisfaction. Int J Psychiatry Med 37:331-45, 2007

152. Knipscheer-Kuipers M: Screening in the psychosocial oncology: experiences of using a screeningsinstrument in a general hospital. Amsterdam, Integraal kankercentrum Amsterdam en Sint Lucas Andreas ziekenhuis, 1997

153. Garssen B, Van Der Lee M: Re: Screening for Emotional Distress in Cancer Patients: A Systematic Review of Assessment Instruments. J Natl Cancer Inst, 2009

154. Mitchell AJ, Kaar S, Coggan C, et al: Acceptability of common screening methods used to detect distress and related mood disorders-preferences of cancer specialists and non-specialists. Psycho-Oncology 17:226-36, 2008

155. Levinson W, Roter D: Physicians' psychosocial beliefs correlate with their patient communication skills. J Gen Intern Med 10:375-9, 1995

156. Braeken AP, Lechner L, van Gils FC, et al: The effectiveness of the Screening Inventory of Psychosocial Problems (SIPP) in cancer patients treated with radiotherapy: design of a cluster randomised controlled trial. BMC Cancer 9:177, 2009

157. Braeken AP, Lechner L, Houben RM, et al: Psychometric properties of the Screening Inventory of Psychosocial Problems (SIPP) in cancer patients treated with radiotherapy. European Journal of Cancer Care, In press

158. Borsboom L: Evaluatie van een scholing voor verpleegkundigen bij implementatie van een signaleringslijst psychosociale problematiek voor kankerpatiënten., Open Universiteit Nederland. Heerlen, 2006

159. Versloot J: De oncologie-psycholoog in een algemeen ziekenhuis. Evaluatie van een driejarig project psychosociale oncologie van het Sint Lucas Andreas ziekenhuis en het Integrale Kanker Centrum. Amsterdam, IKA, 2002

160. Brix C, Schleussner C, Fuller J, et al: The need for psychosocial support and its determinants in a sample of patients undergoing radiooncological treatment of cancer. J Psychosom Res 65:541-8, 2008

161. Verdonck-de Leeuw IM, de Bree R, Keizer AL, et al: Computerized prospective screening for high levels of emotional distress in head and neck cancer patients and referral rate to psychosocial care. Oral Oncol 45:e129-33, 2009 
162. Girgis A, BReen S, Stacey F, et al: Impact of two supportive care interventions on anxiety, depression, quality of life, and unmet needs in patients with nonlocalized breast and colorectal cancers. Journal of Clinical Oncology 27:6180-6190, 2009

163. Thewes B, Butow P, Stuart-Harris R: Does routine psychological screening of newly diagnosed rural cancer patients lead to better patient outcomes? Results of a pilot study. Aust J Rural Health 17:298-304, 2009

164. Livingston PM, White VM, Hayman J, et al: The psychological impact of a specialist referral and telephone intervention on male cancer patients: a randomised controlled trial. PsychoOncology 19:617-25, 2010

165. Gilbody SM, House AO, Sheldon TA: Routinely administered questionnaires for depression and anxiety: systematic review. Bmj 322:406-9, 2001

166. Curry C, Cossich T, Matthews JP, et al: Uptake of psychosocial referrals in an outpatient cancer setting: improving service accessibility via the referral process. Support Care Cancer 10:54955,2002

167. Jacobsen PB, Ransom S: Implementation of NCCN distress management guidelines by member institutions. J Natl Compr Canc Netw 5:99-103, 2007

168. Sollner W, Maislinger S, Konig A, et al: Providing psychosocial support for breast cancer patients based on screening for distress within a consultation-liaison service. Psycho-Oncology 13:893-7, 2004

169. Shimizu K, Akechi T, Okamura $M$, et al: Usefulness of the nurse-assisted screening and psychiatric referral program. Cancer 103:1949-56, 2005

170. Morasso G, Di Leo S, Caruso A, et al: Evaluation of a screening programme for psychological distress in cancer survivors. Support Care Cancer 18:1545-52, 2010

171. Ong LM, de Haes JC, Hoos AM, et al: Doctor-patient communication: a review of the literature. Soc Sci Med 40:903-18, 1995

172. Breitbart W, Jacobsen PB: Psychiatric symptom management in terminal care. Clin Geriatr Med $12: 329-47,1996$

173. Greer S: Psycho-oncology: its aims, achievement and future tasks. Psycho-oncology 3:87-101, 1994

174. Newell S, Sanson-Fisher RW, Girgis A, et al: How well do medical oncologists' perceptions reflect their patients' reported physical and psychosocial problems? Data from a survey of five oncologists. Cancer 83:1640-51, 1998

175. Valente SM, Saunders JM, Cohen MZ: Evaluating depression among patients with cancer. Cancer Pract 2:65-71, 1994

176. Hack TF, Degner LF, Parker PA: The communication goals and needs of cancer patients: a review. Psycho-Oncology 14:831-45; discussion 846-7, 2005

177. Richardson A, Medina J, Brown V, et al: Patients' needs assessment in cancer care: a review of assessment tools. Support Care Cancer 15:1125-44, 2007

178. Braeken AP, Lechner L, Houben RM, et al: Psychometric properties of the Screening Inventory of Psychosocial Problems (SIPP) in cancer patients treated with radiotherapy. European Journal of Cancer Care 20:305-314, 2011

179. Ito T, Shimizu K, Ichida Y, et al: Usefulness of pharmacist-assisted screening and psychiatric referral program for outpatients with cancer undergoing chemotherapy. Psycho-Oncology 20:647-654, 2011

180. Regan M, Ristevski E, Jones R, et al: Examining the introduction of a supportive care screening and referral process for cancer patients: how does practice compare with protocols? Support Care Cancer 20:119-126, 2012

181. Bultz BD, Carlson LE: Emotional distress: the sixth vital sign--future directions in cancer care. Psycho-Oncology 15:93-5, 2006

182. Bultz BD, Carlson LE: Emotional distress: the sixth vital sign in cancer care. J Clin Oncol 23:6440-1, 2005 
183. Karlsson JA, Andersen BL: Radiation Therapy and Psychological Distress in Gynecologic Oncology Patients: Outcomes and Recommendations for Enhancing Adjustment. Journal of Psychosomatic Obstetrics \& Gynecology 5:283-294, 1986

184. Newell SA, Sanson-Fisher RW, Savolainen NJ: Systematic review of psychological therapies for cancer patients: overview and recommendations for future research. J Natl Cancer Inst 94:55884,2002

185. Bruera E, Neumann CM: The uses of psychotropics in symptom management in advanced cancer. Psycho-Oncology 7:346-58, 1998

186. Oncology NCCNCPGi: NCCN Practice guidelines for the management of psychosocial distress, 2010

187. National Institute for Clinical Excellence. Improving supportive and palliative care for adults with cancer: The manual. London, United Kingdom, National Institute for clinical excellence, 2004

188. Thewes B, Butow P, Stuart-Harris R: Does routine psychological screening of newly diagnosed rural cancer patients lead to better patient outcomes? Results of a pilot study. The Australian journal of rural health 17:298-304, 2009

189. Versloot J: De oncologie-psycholoog in een algemeen ziekenhuis. Evaluatie van een driejarig project psychosociale oncologie van het Sint Lucas Andreas ziekenhuis en het Integrale Kanker Centrum. Amsterdam, IKA, 2002

190. Bottomley A, Coens C, Efficace F, et al: Symptoms and patient-reported well-being: do they predict survival in malignant pleural mesothelioma? A prognostic factor analysis of EORTCNCIC 08983: randomized phase III study of cisplatin with or without raltitrexed in patients with malignant pleural mesothelioma. J Clin Oncol 25:5770-6, 2007

191. Pijls-Johannesma M, Houben R, Boersma L, et al: High-dose radiotherapy or concurrent chemoradiation in lung cancer patients only induces a temporary, reversible decline in QoL. Radiother Oncol 91:443-8, 2009

192. Snijders AB, Bosker RJ: Multilevel Analysis: An introduction to basic and advanced multilevel modeling. London, Sage Publications Ltd, 2004, pp 52

193. Girgis A, Cockburnb, Butow $P$, et al: Improving patient emotional functioning and psychological morbidity: Evaluation of a consultation skills training program for oncologists. Patient Educ Couns 77:456-462, 2009

194. Braeken AP, Kempen GI, Eekers D, et al: The usefulness and feasibility of a screening instrument to identify psychosocial problems in patients receiving curative radiotherapy: a process evaluation. BMC Cancer 11:479, 2011

195. Absolom K, Holch P, Pini S, et al: The detection and management of emotional distress in cancer patients: the views of health-care professionals. Psycho-Oncology 20:601-8, 2011

196. Detmar SB, Aaronson NK, Wever LD, et al: How are you feeling? Who wants to know? Patients' and oncologists' preferences for discussing health-related quality-of-life issues. J Clin Oncol 18:3295-301, 2000

197. Girgis A, Breen S, Stacey F, et al: Impact of two supportive care interventions on anxiety, depression, quality of life, and unmet needs in patients with nonlocalized breast and colorectal cancers. Journal of Clinical Oncology 20:6180-6190, 2009

198. Hopwood P, Stephens RJ: Depression in patients with lung cancer: prevalence and risk factors derived from quality-of-life data. Journal Clinical Oncology 18:893-903, 2000

199. Maraste R, Brandt L, Olsson H, et al: Anxiety and depression in breast cancer patients at start of adjuvant radiotherapy. Acta Oncology 31:641-643, 1992

200. Zabora J, Brintzenhofeszok K, Curbow B, et al: The prevalence of psychological distress by cancer site. Psycho-Oncology 10:19-28, 2001

201. Norton T, Manne S, Rubin S, et al: Prevalence and predictors of psychological distress among women with ovarian cancer. Journal of Clinical Oncology 22:919-925, 2004

202. Carlosn L, Bultz B: Cancer distress sreening needs, models and methods. Journal of Psychosomatic Research 55:403-409, 2003 
203. Passik SD, Dugan W, mcDonald MV, et al: Oncologists' recognition of depression in their patients with cancer. Journal Clinical Oncology 16:1594-1600, 1998

204. Garssen B, Haes de H, Watson M: Cancer, in Kaptein A, Appels A, Orth-Gomér K (eds): Psychology in Medicine. Houten/ Diegem, Bohn Stafleu Van Loghum, 2000, pp 119-135

205. Nordin K, Glimelius B: Predicting delayed anxiety and depression in patients with gastrointestinal cancer. British Journal of Cancer 79:525-529, 1998

206. Watson M, Greer S, Rowden L: Relationships between emotional control, adjustment to cancer and depression and anxiety in breast cancer patients. Psychological Medicine 21:51-57, 1991

207. Cordova MJ, Giese-Davis J, Golant M, et al: Mood disturbance in community cancer support groups. The role of emotional suppression and fighting spirit. J Psychosom Res 55:461-7, 2003

208. Schnoll RA, Harlow LL, Stolbach LL, et al: A structural model of the relationships among stage of disease, age, coping, and psychological adjustment in women with breast cancer. PsychoOncology 7:69-77, 1998

209. Watson M, Greer S, Young J, et al: Development of a questionnaire measure of adjustment to cancer: the MAC scale. Psychological Medicine 18:203-209, 1988

210. Greer S, Moorey S, Watson M: Patients'adjustment to cancer: the mental adjustment to cancer (MAC) scale vs clinical ratings. Journal of Psychosomatic Research 33:373-377, 1989

211. Akechi T, Okuyama T, Imoto S, et al: Biomedical and psychosocial determinants of psychiatric morbidity among postoperative ambulatory breast cancer patients. Breast Cancer Research and Treatment 65, 2001

212. Akechi T, Fukue-Saeki M, Kugaya A, et al: Psychometric properties of the Japanese version of the mental adjustment to cancer (MAC) scale. Psycho-Oncology 9:395-401, 2000

213. Cayrou S, Dickès $P$, Gauvain-Piquard A, et al: The mental adjustment to cancer (MAC) scale: French replication and assessment of positive and negative adjustment dimensions. PsychoOncology 12:8-23, 2003

214. Schnoll RA, Harlow LL, Brandt U, et al: Using two factor structures of the mental adjustment to cancer (MAC) scale for assessing adaption to breast cancer. Psycho-Oncology 7:424-435, 1998

215. Mystakidou K, Watson M, Tsilika E, et al: Psychometric analyses of the mental adjustment to cancer (MAC) scale in a Greek palliative care unit. Psycho-Oncology 14:16-24, 2005

216. Nordin K, Berglund G, Terje I, et al: The mental adjustment to cancer scale: a psychometric analysis and the concept coping. Psycho-Oncology 8:250-259, 1999

217. Tacon AM, Caldera YM, Ronaghan C: Mindfulness-based stress reduction in women with breast cancer. Families, Systems, \& Health 22:193-203, 2004

218. Osborne RH, Elsworth GR, Kissane DW, et al: The Mental Adjustment to Cancer (MAC) scale: replication and refinement in 632 breast cancer patients. Psychol Med 29:1335-45, 1999

219. Schwartz CE, Daltroy LH, Brandt U, et al: A psychometric analysis of the Mental Adjustment to Cancer scale. Psychol Med 22:203-10, 1992

220. Watson M, Homewood J: Mental Adjustment to Cancer Scale: psychometric properties in a large cancer cohort. Psycho-Oncology 17:1146-1151, 2008

221. Bruin de EJ, Garssen B, Dijk van M, et al: Psychometric evaluation of a Dutch version of the mental adjustment to cancer (MAC) scale. Rotterdam, Helen Dowling Institute for Biopsychosocial Medicine, 1994

222. Zigmund AS, Snaith RD: The Hospital Anxiety and Depression Scale. Acta Psychiatric Scandinavica 67:361-370, 1983

223. Akechi T, Okuyama T, Nakano T, et al: Major depression, adjustment disorders, and posttraumatic stress disorder in terminally ill cancer patients: associated and predictive factors. Journal Clinical Oncology 22:1957-1965, 2004

224. Spinhoven P, Ormel J, Sloekers PP, et al: A validation study of the Hospital Anxiety and Depression scale (HADS) in different groups of Dutch subjects. Psychological Medicine 27:363370, 1997

225. Tabachnick BG, Fidell LS: Using multivariate statiistics (ed 4). Needham Heights, Allyn and Bacon, a Pearson Education Company 2001 
226. Jöreskog K, Sörbom D: WINDOWS LISREL, (ed Version 8.71). Chicago, Scientific Software International, 2004

227. Nunnally JC: Psychometric Theory (ed 2). New York, McGraw-Hill Book Co, 1978

228. Carlson LE, Bultz BD: Cancer distress screening: Needs, models and methods. Journal of Psychosomatic Research 55:403-409, 2003

229. Zwarenstein M, Treweek S, Gagnier JJ, et al: Improving the reporting of pragmatic trials: an extension of the CONSORT statement. Bmj 337:a2390, 2008

230. Godwin M, Ruhland L, Casson I, et al: Pragmatic controlled clinical trials in primary care: the struggle between external and internal validitiy. BMC Medical Research Methodology 3, 2003

231. Bland JM: Sample size in guidelines trials Family Practice 17:S17-S20, 2000

232. Campbell MK, Elbourne DR, Altman DG: CONSORT statement: extension to cluster randomised trials. British medical journal 328:702-708, 2004

233. Loscalzo MJ, Clark KL, Holland JC: Succesful strategies for implementing biopsychosocial screening. Psycho-Oncology 20:455-462, 2011

234. Kempen GIJM, Van Sonderen E: Psychological attributes and changes in disability among lowfunctioning, older persons: does attrition affect the outcomes? J Clin Epidemiol 55, 2002

235. Medicine Io: Cancer care for the Whole Patient: Meeting Psychosocial Health Needs, in Adler NE, OPage AEK (eds). Washington, DC, National Academies Press, 2008

236. Braeken AP, Lechner L, Houben RM, et al: Psychometric properties of the Screening Inventory of Psychosocial Problems (SIPP) in Dutch cancer patients treated with radiotherapy. European Journal of Cancer Care 20:305-14, 2011

237. Dolbeault S, Boistard B, Meuric J, et al: Screening for distress and supportive care needs during the initial phase of the care process: a qualitative description of a clinical pilot experiment in a French cancer center. Psycho-Oncology 20:585-593, 2011

238. Magruder KM, Yeager DE: Screening for depression in primary care: can it become more efficient?, in Mitchell AJ, Coyne J (eds): Screening for depression in clinical practice. Oxford, Oxford University press, 2010

239. Ferrell BR, Rivera LM: Cancer pain education for patients. Seminars in oncology nursing 13:428,1997

240. Arora NK: Interacting with cancer patients: the significance of physicians' communication behavior. Social science \& medicine 57:791-806, 2003

241. Rogers EM: Diffusion of innovations (ed Fifth edition). New York, Free Press, 2003

242. Loscalzo M, Clark KL, Holland J: Successful strategies for implementing biopsychosocial screening. Psycho-Oncology 20:455-62, 2011

243. Brown RF, Butow PN, Sharrock MA, et al: Education and role modelling for clinical decisions with female cancer patients. Health expectations : an international journal of public participation in health care and health policy 7:303-16, 2004

244. Epstein RM, Street RL: Patient-centered communication in cancer care: Promoting healing and reducing suffering., in Publication N (ed). Bethesda, National Cancer Institute, 2007

245. Carlson LE, Clifford SS, Groff SL: Screening in cancer care, Mitchell A. J., Coyne, J. C.(eds):Screening for Depression in Clinical Practice: A Practical Guide to the Detection and Diagnosis of Mood Disorders in Primary and Secondary Care. New York, Oxford University Press Inc, 2010, pp 265-295

246. Gilbody S, Bower P, Fletcher J, et al: Collaborative care for depression: a cumulative metaanalysis and review of longer-term outcomes. Archives of internal medicine 166:2314-21, 2006

247. Mitchell AJ, Vahabzadeh A, Magruder K: Screening for distress and depression in cancer settings: 10 lessons from 40 years of primary-care research. Psycho-Oncology 20:572-84, 2011

248. Garssen B, E. dK: Letter to the editor:How useful is a screening instrument? Psycho-Oncology 17:726-728, 2008

249. Velikova G, Booth L, Smith AB, et al: Measuring quality of life in routine oncology practice improves communication and patient well-being: a randomized controlled trial. Journal of clinical oncology : official journal of the American Society of Clinical Oncology 22:714-24, 2004 
REFERENCES 


\section{Appendix}


The Screening Inventory of Psychosocial Problems (SIPP)

English version

Having cancer may lead to various complaints.

Please indicate which of the following complaints apply to you.

\begin{tabular}{|c|c|c|c|c|}
\hline & $\begin{array}{c}\text { Yes } \\
\text { (Score 2) }\end{array}$ & $\begin{array}{l}\text { Sometimes } \\
\text { (Score 1) }\end{array}$ & $\begin{array}{c}\text { No } \\
\text { (Score 0) }\end{array}$ & $\begin{array}{l}\text { Not Applicable } \\
\text { ( Score 0) }\end{array}$ \\
\hline \multicolumn{5}{|l|}{ Subscale 1} \\
\hline Fatigue & $\square$ & $\square$ & $\square$ & \\
\hline Sleep disorder & $\square$ & $\square$ & $\square$ & \\
\hline Weight loss & $\square$ & $\square$ & $\square$ & \\
\hline Lack of appetite & $\square$ & $\square$ & $\square$ & \\
\hline Restriction in daily functioning & $\square$ & $\square$ & $\square$ & \\
\hline Dizziness & $\square$ & $\square$ & $\square$ & \\
\hline Pain & $\square$ & $\square$ & $\square$ & \\
\hline \multicolumn{5}{|l|}{ Subscale 2} \\
\hline Worrying & $\square$ & $\square$ & $\square$ & \\
\hline Restlessness & $\square$ & $\square$ & $\square$ & \\
\hline Sense of loneliness & $\square$ & $\square$ & $\square$ & \\
\hline Sense of distress & $\square$ & $\square$ & $\square$ & \\
\hline Sense of loss & $\square$ & $\square$ & $\square$ & \\
\hline Inability to control emotions & $\square$ & $\square$ & $\square$ & \\
\hline Reduced self-confidence & $\square$ & $\square$ & $\square$ & \\
\hline Fear of cancer or treatment & $\square$ & $\square$ & $\square$ & \\
\hline Feeling low & $\square$ & $\square$ & $\square$ & \\
\hline Sense of desperation & $\square$ & $\square$ & $\square$ & \\
\hline \multicolumn{5}{|l|}{ Subscale 3} \\
\hline $\begin{array}{l}\text { Feel uncomfortable discussing } \\
\text { illness with others }\end{array}$ & $\square$ & $\square$ & $\square$ & \\
\hline Lack of social support & $\square$ & $\square$ & $\square$ & \\
\hline Financial problems & $\square$ & $\square$ & $\square$ & \\
\hline $\begin{array}{l}\text { Would you like to discuss } \\
\text { these problems with someone? }\end{array}$ & $\square$ & $\square$ & $\square$ & \\
\hline \multicolumn{5}{|l|}{ Subscale 4} \\
\hline Intimacy problems with partner & $\square$ & $\square$ & $\square$ & $\square$ \\
\hline Less interest in sex & $\square$ & $\square$ & $\square$ & $\square$ \\
\hline $\begin{array}{l}\text { Would you like to discuss these } \\
\text { problems with someone? }\end{array}$ & $\square$ & $\square$ & $\square$ & $\square$ \\
\hline
\end{tabular}


The Screening Inventory of Psychosocial Problems (SIPP)

\section{Nederlandse versie}

De ziekte kanker kan leiden tot klachten.

Wilt $u$ in deze lijst aangeven of deze klachten op u van toepassing zijn.

\begin{tabular}{|c|c|c|c|c|}
\hline & $\begin{array}{c}\text { Ja } \\
\text { (Score 2) }\end{array}$ & $\begin{array}{c}\text { Soms } \\
\text { (Score 1) }\end{array}$ & $\begin{array}{c}\text { Nee } \\
(\text { Score 0) }\end{array}$ & $\begin{array}{l}\text { Niet van toepassing } \\
\text { ( Score } 0 \text { ) }\end{array}$ \\
\hline \multicolumn{5}{|l|}{ Blok 1} \\
\hline Moeheidklachten & $\square$ & $\square$ & $\square$ & \\
\hline Slaapproblemen & $\square$ & $\square$ & $\square$ & \\
\hline Gewichtsverlies & $\square$ & $\square$ & $\square$ & \\
\hline Slechte eetlust & $\square$ & $\square$ & $\square$ & \\
\hline Beperking in dagelijks functioneren & $\square$ & $\square$ & $\square$ & \\
\hline Duizeligheid & $\square$ & $\square$ & $\square$ & \\
\hline Pijnklachten & $\square$ & $\square$ & $\square$ & \\
\hline \multicolumn{5}{|l|}{ Blok 2} \\
\hline Piekeren & $\square$ & $\square$ & $\square$ & \\
\hline Rusteloosheid & $\square$ & $\square$ & $\square$ & \\
\hline Gevoelens van eenzaamheid & $\square$ & $\square$ & $\square$ & \\
\hline Gevoelens van verdriet & $\square$ & $\square$ & $\square$ & \\
\hline Gevoelens van verlies & $\square$ & $\square$ & $\square$ & \\
\hline Minder grip op eigen emoties & $\square$ & $\square$ & $\square$ & \\
\hline Verminderd zelfvertrouwen & 口 & $\square$ & $\square$ & \\
\hline Angst voor ziekte of behandeling & $\square$ & $\square$ & $\square$ & \\
\hline Gevoelens van neerslachtigheid & $\square$ & $\square$ & $\square$ & \\
\hline Gevoelens van wanhoop & $\square$ & $\square$ & $\square$ & \\
\hline \multicolumn{5}{|l|}{ Blok 3} \\
\hline $\begin{array}{l}\text { Onvoldoende kunnen praten over } \\
\text { het feit dat u kanker heeft }\end{array}$ & $\square$ & $\square$ & $\square$ & \\
\hline $\begin{array}{l}\text { Onvoldoende steun door de mensen } \\
\text { in uw omgeving. }\end{array}$ & $\square$ & $\square$ & $\square$ & \\
\hline Financiële problemen & $\square$ & $\square$ & $\square$ & \\
\hline $\begin{array}{l}\text { Zou u graag met een hulpverlener } \\
\text { willen praten? }\end{array}$ & $\square$ & $\square$ & $\square$ & \\
\hline \multicolumn{5}{|l|}{ Blok 4} \\
\hline $\begin{array}{l}\text { Problemen met intimiteit met uw } \\
\text { partner }\end{array}$ & $\square$ & $\square$ & $\square$ & $\square$ \\
\hline Minder zin om te vrijen & $\square$ & $\square$ & $\square$ & $\square$ \\
\hline $\begin{array}{l}\text { Wenst } u \text { voor dit probleem } \\
\text { begeleiding door een hulpverlener? }\end{array}$ & $\square$ & $\square$ & $\square$ & $\square$ \\
\hline
\end{tabular}



Summary 


\section{Summary}

The treatment of cancer is complex and it can be invasive for patients. About $50 \%$ of all cancer patients receive radiotherapy treatment either alone or in combination with other treatment modalities such as surgery, chemotherapy and hormone therapy. When patients receive the diagnosis of cancer they may experience emotional responses, like symptoms of anxiety and depression, partly as a "normal" response to the diagnosis. Nevertheless, in many patients these responses may persist, causing additional burden during treatment. Previous studies reported that the prevalence rate of psychosocial problems among cancer patients varies from 5\% to 58\% depending on the study method, point of assessment and the study population. For those patients in whom psychosocial problems do not decrease over time, psychosocial interventions may be appropriate since they may improve health-related outcomes including quality of life and may prevent the development of psychiatric co-morbidity. In recent years the interest in psychosocial oncology has grown significantly. National guidelines with regard to psychosocial oncology have been produced in the United Kingdom (UK), United States (US), Australia, and the Netherlands. These guidelines provide advice on supporting cancer patients and their families throughout the cancer trajectory.

The use of self-reported screening instruments may help to prevent under diagnosis of psychosocial problems. Moreover, such instruments can be adequate tools for facilitating patient-physician communication with respect to discussing psychosocial problems. Although several studies suggested that using screening instruments are indeed helpful in identifying and discussing psychosocial problems, large-scale randomised controlled trials establishing evidence of the effect of psychosocial screening are lacking. The overall objective of this thesis was to study the feasibility and effectiveness of using a screening instrument to identify psychosocial problems among cancer patients. We addressed the following research questions:

- What was the reliability and validity of the Screening Inventory of Psychosocial Problems (SIPP) to identify potential psychosocial problems in cancer patients?

- To what extent was using the SIPP considered useful and feasible by patients and radiotherapists?

- What was the effectiveness of using the SIPP on:

- The percentages of patients referred to psychosocial caregivers by their radiotherapists?

- Patients' satisfaction with radiotherapist-patient communication?

- The extent of psychological distress and health-related quality of life in the short and the long term?

In addition we studied the validity and usefulness of the Dutch version of the Mental Adjustment to Cancer (MAC) scale. First of all we used the validated 
MAC-scale to evaluate the psychometric properties of the SIPP. Second, we wanted to get insight into how cancer patients deal with their illness by assessing their adjustment skills to cancer.

Chapter 2 presents the results of a study exploring the psychometric properties of the SIPP. The SIPP is a simple and short questionnaire (fits to one side sheet of A4 paper) for detecting of multidimensional aspects (physical, psychological, social, financial and sexual problems) of psychosocial problems among cancer patients in clinical settings. The study was conducted among 289 cancer patients treated with radiotherapy at MAASTRO Clinic, a radiation oncology department in Maastricht in the Netherlands. The SIPP was administered alongside the Hospital Anxiety and Depression Scale (HADS) and the Dutch version of the MAC-scale. In-depth semi-structured clinical interviews were also conducted with a selection of 76 patients. The psychometric properties of the SIPP are promising with respect to its reliability, construct validity as evaluated with confirmatory factor analysis, and convergent and divergent validity. Due to its convenient format, the SIPP may easily be used to assess multidimensional aspects of psychosocial distress in cancer patients as a routine part of the clinical consultation.

Chapter 3 comprises a description of the design of a cluster randomised controlled trial (CRCT) using a Solomon four-group approach to evaluate the effect of using the SIPP among cancer patients receiving curative radiotherapy treatment at Verbeeten Institute, a radiation oncology department in Tilburg in the Netherlands. Radiotherapists, instead of cancer patients, were randomly allocated to the experimental or control groups. Within these groups, all included cancer patients were randomised into two sub-groups: with and without pre-measurement to check for possible pre-assessment testing effects. Before the start of the study, the radiotherapists in the experimental condition were trained in using and interpreting the SIPP. Since research showed that most patients experience a need for psychosocial support at the beginning and at the end of radiotherapy treatment (RT), patients completed the SIPP before the first consultation and before the consultation at the end of RT. On both occasions the radiotherapists checked the scores to obtain an overview of potential psychosocial problems and patients' needs for psychosocial care. Problems were discussed with the patients. Potential referral to a psychosocial caregiver was based on the score of the SIPP in combination with the radiotherapist's judgement. Patients in the control group received care as usual. Before the first consultation, patients randomised to groups with pre-assessment were asked to complete questionnaires in the waiting room. Patients allocated to the experimental groups were also asked to complete the SIPP. Outcomes were measured after the first consultation and three and 12 months post-intervention. The process evaluation data on the radiotherapists' and patients' perspectives of the usefulness and feasibility of the SIPP were collected using self-report questionnaires. The questionnaires were completed directly after the first consultation. 
Seven and 13 months after the start of the study, the radiotherapists completed a questionnaire on the usefulness and feasibility of the SIPP in general.

Chapter 4 provides the results of the process evaluation study on the usefulness and feasibility of the SIPP. Data were collected using self-report questionnaires completed by seven radiotherapists and 268 cancer patients from the experimental group. In total, 23 patients did not complete the SIPP either the first or the second time, of which one patient did not complete the SIPP either time. One radiotherapist never checked the SIPP for potential psychosocial problems for all participating patients. The prevalence rate of psychosocial problems among patients receiving RT with curative intent was in line with previous studies. A relatively small proportion of patients suffering from at least sub-clinical (7.1-20.8\%) or clinical (9.3-30.1\%) symptoms of psychosocial problems was offered the opportunity to visit a psychosocial care provider by their radiotherapist and the majority of the patients (63.6\%) accepted psychosocial care.

There is a discrepancy between radiotherapists' and patients' perspectives of the usefulness and feasibility of the SIPP. Patients' judgements of the usefulness and feasibility of the SIPP were moderate to good in general. Patients were positive about the content of the SIPP and, on average, completing the SIPP took 5.3 minutes. Regarding the radiotherapists' perspectives, only a minority of radiotherapists considered the SIPP to be useful and feasible. Radiotherapists were most positive about the fact that the SIPP gave better insight into the psychosocial well-being of the patients but they were less positive about the fact that the SIPP invited them to ask about the patients' psychosocial well-being. None of the radiotherapists decided to change their communication style as a result of using the SIPP. In $90.1 \%$ of all consultations, the time required to discuss the instrument was less than five minutes. Furthermore, patients were more likely to report that discussing the items of the SIPP with their radiotherapist was pleasant if the radiotherapist considered the SIPP to be a useful tool to discuss psychosocial well-being.

Chapter 5 presents the effects of using the SIPP on referral patterns to psychosocial caregivers and communication between radiotherapists and patients. In total, 14 radiotherapists (and their 568 patients) were randomly allocated between experimental $(n=7)$ and control groups $(n=7)$. Experimental $(n=268)$ and control $(n=300)$ patients were requested to complete questionnaires concerning psychosocial care at three and 12 months after baseline assessment, and a questionnaire concerning patient-physician communication regarding psychosocial aspects was completed directly after the first consultation. In total, $86.4 \%$ of the patients completed the trial. The groups were well balanced for the baseline characteristics except for gender and cancer diagnosis. Outcomes of the statistical analyses were adjusted for these baseline differences. The analyses showed no overall intervention effects for the number of referred patients, or for improvement of patient-radiotherapist communication. However, the data 
from the social workers' records showed that patients allocated to the experimental group were referred to them at an earlier stage than control group patients. The mean time between the first consultation and being referred was 4.1 weeks for control group patients and 1.1 weeks for experimental group patients.

In chapter 6 the effects of using the SIPP on patients' extent of psychological distress and health-related quality of life (HRQoL) during a period of 12 months are presented. Our hypothesis was that, since radiotherapists would be aware of patients' psychosocial problems, they would take appropriate action by referring patients for psychosocial support. This would result in better health-related outcomes, including lower extent of psychological distress and better HRQoL in the short and long run. The results of our study as presented in chapter 5 showed that the referral rate of cancer patients to psychosocial caregivers did not significantly increase by using the SIPP, but that patients were referred at an earlier stage. No favourable intervention effects were observed for patients' overall extent of psychosocial distress, and HRQoL both in the short and the long term. However, the in-depth post-hoc analyses showed significant interactions between group, time (three month follow-up) and referral (three months) on anxiety symptoms, emotional well-being, appetite loss, and financial problems. This suggests that early referral to social workers might have a favourable effect on some aspects of patients' health-related outcomes. Yet our hypotheses that using a screening instrument would generally result in better patient heathrelated outcomes in the short and long term for the total patient group was not confirmed.

Chapter 7 evaluates the psychometric properties of the original five subscales and the more recent developed Summary Positive and Summary Negative Adjustment scales of the 40-item Dutch version of the MAC-scale among 289 cancer patients treated with radiotherapy at MAASTRO Clinic. We used the validated MAC-scale for validation purposes of the SIPP (see chapter 2). The Dutch version of the MAC-scale seems to be a feasible questionnaire due to the fact that $85.5 \%$ of all participants completed the full MAC-scale. The most reported adjustment responses to cancer were fighting spirit (58.8\%), helplessness/hopelessness (37.7\%), and the Summary Positive Adjustment Scale (78.2\%). The psychometric properties of the Summary Positive Adjustment Scale and Summary Negative Adjustment Scale and the original fighting spirit and helplessness/hopelessness sub-scales appear to be acceptable. Summary sub-scales of the MAC-scale are useful constructs to measure general responses to cancer, such as positive and negative adjustment to cancer in patients. For insight into more specific responses to cancer, the specific sub-scales fighting spirit and helplessness/hopelessness can be considered useful constructs. The Dutch version of the MAC-scale is a feasible questionnaire and appeared to have comparable psychometric properties as demonstrated by studies in the UK. The psychometric properties of the summary scales as well as the fighting spirit and 
helplessness/hopelessness sub-scales seem to be acceptable. This supports the cross-national usefulness of the MAC-scale.

In chapter 8 the main findings of this thesis are discussed. Several methodological and theoretical considerations as well as the implications for clinical practice and further research are presented. Based on our own findings and experiences, we do not recommend the implementation of the screening procedure in its current form. Psychosocial distress screening in cancer patients receiving RT on its own does not sufficiently improve patients' general healthrelated outcomes. The use of a psychosocial screening instrument is only a single element of effective psychosocial care. The successful implementation of a psychosocial screening procedure into the (radiation) oncology departments is a complex task and takes a lot of effort, but seems to be essential to improve patient outcomes. Delivering successful psychosocial care in radiation oncology departments is a challenge which will demand a multidisciplinary approach and further research. 
SUMMARY 

Samenvatting 


\section{Samenvatting}

De behandeling van kanker is complex en voor veel patiënten invasief. Bij ongeveer $50 \%$ van alle kankerpatiënten maakt radiotherapie deel uit van de behandeling, hetzij als enige behandeling, dan wel in combinatie met andere behandelingen zoals chirurgie, chemotherapie en hormoontherapie. De diagnose kanker roept bij veel patiënten verschillende gevoelens en emoties op, zoals gevoelens van angst en depressie. Deze gevoelens en emoties vormen veelal een normale reactie op de diagnose kanker. Desalniettemin kunnen langdurige emotionele reacties leiden tot psychosociale problemen waarvan patiënten jarenlang last kunnen hebben. Eerdere studies rapporteerden dat de prevalentie van psychosociale problemen bij kankerpatiënten varieert van 5 tot $58 \%$ afhankelijk van de meetmethode, het tijdstip van meting en de groep patiënten die is onderzocht. Psychosociale interventies kunnen nuttig zijn voor patiënten met psychosociale problemen omdat zij gezondheidsgerelateerde aspecten zoals kwaliteit van leven kunnen verbeteren. Tevens kan door interventie de ontwikkeling van psychiatrische comorbiditeit worden voorkomen. In de afgelopen jaren is de aandacht voor psychosociale oncologie toegenomen in diverse landen. In bijvoorbeeld Engeland, de Verenigde Staten, Australië en Nederland zijn nationale richtlijnen met betrekking tot psychosociale zorg in de oncologie ontwikkeld. Deze richtlijnen geven advies over psychosociale ondersteuning van kankerpatiënten en hun families.

Screeningsinstrumenten hebben de potentie om onderdiagnostiek van psychosociale problematiek bij kankerpatiënten te voorkomen. Daarnaast kunnen dergelijke instrumenten de communicatie tussen arts en patiënt met betrekking tot het bespreken van psychosociale problemen vergemakkelijken. Hoewel diverse studies suggereerden dat het gebruik van screeningsinstrumenten nuttig kan zijn bij het identificeren en bespreken van psychosociale problemen, is er weinig systematisch grootschalig onderzoek uitgevoerd naar de effecten van psychosociale screening bij kankerpatiënten. Het onderzoek dat in dit proefschrift wordt beschreven is gericht op de haalbaarheid en het effect van het gebruik van de Nederlandse Screening Inventory of Psychosocial Problems (SIPP) voor het signaleren van psychosociale problematiek bij kankerpatiënten. De specifieke onderzoeksvragen zijn:

- Wat is de betrouwbaarheid en validiteit van de Screening Inventory of Psychosocial Problems (SIPP) om potentiële psychosociale problemen bij kankerpatiënten te identificeren?

- In welke mate werd het gebruik van de SIPP als nuttig en haalbaar beschouwd door patiënten en radiotherapeuten?

- Wat was het effect van het gebruik van de SIPP op:

- Het aantal (\%) verwezen patiënten naar psychosociale hulpverleners door hun radiotherapeuten? 
- Patiënttevredenheid betreffende de communicatie met hun radiotherapeut?

- De mate van psychologische problemen en gezondheidsgerelateerde kwaliteit van leven van patiënten op korte en lange termijn?

Tevens hebben we de psychometrische eigenschappen van de Nederlandse Mental Adjustment to Cancer scale (MAC-scale) geëvalueerd. Allereerst hebben we de gevalideerde Nederlandstalige MAC-scale gebruikt om de psychometrische eigenschappen van de SIPP te kunnen evalueren. Ten tweede hebben we met de MAC-scale inzicht gekregen op welke manier kankerpatiënten die een radiotherapeutische behandeling krijgen omgaan met hun ziekte.

Hoofdstuk 2 presenteert de resultaten van de studie naar de psychometrische eigenschappen van de SIPP. De SIPP is een eenvoudige en korte vragenlijst (passend op één A4) voor het signaleren van multidimensionele aspecten (lichamelijke, psychische, sociale, financiële en seksuele problemen) van psychosociale problematiek bij kankerpatiënten in klinische settings. De studie werd uitgevoerd bij 289 kankerpatiënten behandeld met radiotherapie in MAASTRO Clinic te Maastricht. De SIPP werd samen met de vragenlijst Hospital Anxiety and Depression scale (HADS) en de Nederlandse MAC-scale door de patiënten ingevuld. Daarnaast werden klinische semigestructureerde interviews gehouden met een selectie van de patiënten $(n=76)$. De psychometrische eigenschappen van de SIPP met betrekking tot de betrouwbaarheid, construct validiteit zoals geëvalueerd met confirmatieve factoranalyse, en de convergente en divergente validiteit zijn veelbelovend. Dankzij het handige formaat, kan de SIPP gemakkelijk worden gebruikt ter beoordeling van multidimensionele aspecten van psychosociale problemen in patiënten met kanker als een routine onderdeel van een klinisch consult.

Hoofdstuk 3 beschrijft de onderzoeksopzet van de studie naar de effecten van het gebruik van de SIPP bij kankerpatiënten die een curatieve radiotherapeutische behandeling (RT) ondergaan in het Verbeeten Instituut te Tilburg. Voor het meten van de effecten werd een cluster gerandomiseerde experimentele studie met behulp van het Solomon Four Group design (twee controle groepen en twee experimentele groepen) uitgevoerd. Radiotherapeuten, in plaats van kankerpatiënten, werden willekeurig toegewezen aan de experimentele of controlegroep. De patiënten waren gekoppeld aan hun behandelende radiotherapeut en werden willekeurig toegewezen aan één van de twee experimentele groepen met en zonder voormeting, of aan één van de twee controlegroepen met en zonder een voormeting om te controleren of er sprake is van een effect van de voormeting op de onderzoeksresultaten. Vóór het begin van de studie kregen de radiotherapeuten in de experimentele groep een training van één uur. Tijdens deze training werd besproken hoe ze de SIPP konden gebruiken en hoe ze de scores op de SIPP konden interpreteren. Aangezien eerder onderzoek heeft aangetoond dat de meerderheid van de kankerpatiënten behoefte heeft aan psychosociale ondersteuning aan het begin en aan het einde van de RT, 
werd patiënten gevraagd de SIPP vóór het eerste consult en vóór het consult aan het einde van de RT in te vullen. Bij beide gelegenheden controleerden de radiotherapeuten de scores op de SIPP om een overzicht te krijgen van mogelijke psychosociale problemen en de behoeften aan psychosociale zorg. Eventuele problemen werden met de patiënten besproken. Een verwijzing naar een psychosociale hulpverlener vond plaats op basis van de scores op de SIPP in combinatie met het oordeel van de behandelende radiotherapeut. Patiënten in de controlegroep ontvingen de gebruikelijke standaard zorg. Vóór het eerste consult werden de patiënten toegewezen aan de controle en experimentele groepen met de voormeting gevraagd om vragenlijsten in de wachtkamer in te vullen. Patiënten uit de experimentele groepen (met en zonder voormeting) werden gevraagd eveneens de SIPP in te vullen. De mogelijke effecten van het gebruik van de SIPP werden gemeten direct na het eerste consult en op drie en 12 maanden na de start van de studie. De procesevaluatie naar het nut en haalbaarheid van het gebruik van de SIPP vond plaats bij de radiotherapeuten en de patiënten uit de experimentele groep met behulp van vragenlijsten. Deze werden zowel door de radiotherapeuten als door de patiënten direct na het eerste consult ingevuld. $\mathrm{Na}$ zeven en 13 maanden vulden de radiotherapeuten een vragenlijst in over het nut en de haalbaarheid van de SIPP in het algemeen.

Hoofdstuk 4 beschrijft de resultaten van de procesevaluatie waarin het nut en de haalbaarheid van de SIPP werden geëvalueerd. Gegevens zijn verzameld via vragenlijsten ingevuld door de zeven radiotherapeuten en 268 kankerpatienten uit de experimentele groep. In totaal, hebben 23 patiënten de SIPP de eerste of de tweede keer niet ingevuld, waarvan één patiënt de SIPP op beide tijdstippen niet heeft ingevuld. Daarnaast was er één radiotherapeut die de door zijn patiënten ingevulde SIPP niet controleerde op potentiële psychosociale problemen. De prevalentie van psychosociale problemen bij patiënten die een radiotherapeutische behandeling kregen was vergelijkbaar met eerdere studies. Een relatief klein deel van de patiënten met minimaal subklinische $(7,1 \%$ $20,8 \%)$ of klinische $(9,3 \%-30,1 \%)$ symptomen van psychosociale problemen werd door de radiotherapeut doorverwezen naar een psychosociale zorgverlener. De meerderheid van deze patiënten $(63,6 \%)$ accepteerde de psychosociale hulp. Met betrekking tot het nut en de haalbaarheid van de SIPP is er een discrepantie tussen de evaluatie van de radiotherapeuten en de evaluatie van de patiënten. Patiënten evalueerden het algemene nut en de haalbaarheid van de SIPP als matig tot goed. Tevens waren de patiënten overwegend positief over de inhoud van de SIPP. Gemiddeld nam het invullen van de SIPP door de patiënten 5,3 minuten in beslag. Van de radiotherapeuten beschouwde slechts een minderheid de SIPP als nuttig. Ze waren het meest positief over het feit dat de SIPP hen meer inzicht gaf in het psychosociale welzijn van de patiënt. Ze waren echter minder positief over de vraag of de SIPP hen uitgenodigde om de patiënten naar hun psychosociaal welbevinden te vragen. Geen van de radiotherapeuten gaf aan de manier van communicatie als gevolg van het gebruik van de SIPP te 
veranderen. In 90,1\% van alle consulten was de tijd die nodig was om de SIPP te bespreken minder dan vijf minuten. Patiënten beschouwden het bespreken van de SIPP met hun radiotherapeuten vooral als aangenaam indien hun behandelend radiotherapeut de SIPP als een nuttig instrument beschouwde voor het bespreken van psychosociaal welzijn.

Hoofdstuk 5 bevat een beschrijving van de effecten van het gebruik van de SIPP op het verwijzingspatroon en de communicatie tussen radiotherapeuten en patiënten. In totaal werden 14 radiotherapeuten (met hun 568 patiënten) willekeurig toegewezen aan de experimentele $(n=7)$ of de controle groepen $(n=7)$. Alle deelnemende patiënten toegewezen aan de experimentele $(n=268)$ of de controle $(n=300)$ groepen werd gevraagd vragenlijsten in te vullen over hun psychosociaal functioneren op drie en 12 maanden na de start van de studie. Tevens werd aan de deelnemende patiënten van beide groepen gevraagd om direct na het eerste consult een vragenlijst over de patiënt-arts communicatie aangaande psychosociale aspecten in te vullen. In totaal voltooide $86,4 \%$ van alle deelnemende patiënten het onderzoek. De groepssamenstelling van patiënten betreffende medische- en achtergrondkenmerken zoals leeftijd en opleidingsniveau was tussen de groepen evenredig verdeeld met uitzondering van de kenmerken geslacht en kankerdiagnose. In de multivariate analyse is daarom gecorrigeerd voor deze verschillen. De resultaten laten geen algemene effecten van de interventie zien op het aantal patiënten dat is verwezen naar een psychosociale hulpverlener, noch op de verbetering in de communicatie tussen patiënt en radiotherapeut. Echter, uit de verzamelde patiëntengegevens via de maatschappelijk werkers (werkzaam bij het Verbeeten Instituut) bleek dat patienten uit de experimentele groep in een vroeger stadium naar hen waren verwezen in vergelijking met de patiënten uit de controle groep. De gemiddelde tijd tussen het eerste consult en de verwijzing naar maatschappelijk werk was 4,1 week voor patiënten uit de controle groep en 1,1 week voor patiënten uit de experimentele groep.

In hoofdstuk 6 worden de effecten van het gebruik van de SIPP op de mate van psychologische problemen en gezondheidsgerelateerde kwaliteit van leven (HRQoL) gedurende een periode van 12 maanden gepresenteerd. Onze hypothese was dat door het gebruik van de SIPP radiotherapeuten zich bewust(er) werden van de mate van psychosociale problematiek van hun patiënten. Daardoor zouden ze eerder passende maatregelen nemen door hun patiënten naar psychosociale hulpverleners te verwijzen. Dit laatste zou kunnen resulteren in een afname van psychische klachten en een betere HRQoL zowel op de korte als op de lange termijn. Uit de resultaten in hoofdstuk 5 blijkt echter dat door het gebruik van de SIPP het aantal verwezen patiënten naar psychosociale hulpverleners niet significant was toegenomen, maar wel dat patiënten in een vroeger stadium werden verwezen. De resultaten laten zowel op de korte als op de lange termijn geen verbetering zien in de mate van psychische problemen en HRQoL. Een van de toekomstige uitdagingen is om inzicht te krijgen in de effecten van 
vroegtijdig verwijzen van kankerpatiënten naar psychosociale hulpverleners op psychische problematiek en HRQoL. De aanvullende post-hoc analyses lieten significante interacties zien tussen groep (controle versus experimentele groep), tijd (drie maanden follow-up) en verwijzing (drie maanden) op de symptomen van angst, emotioneel welzijn, verlies van eetlust en financiële problemen. Dit suggereert dat vroege verwijzing naar maatschappelijk werk wellicht een gunstig effect heeft op sommige gezondheidsgerelateerde uitkomsten. Desalniettemin, onze hypothese dat het gebruik van een screeningsinstrument voor het signaleren van psychosociale problematiek bij de groep kankerpatiënten als geheel zou resulteren in betere gezondheidsgerelateerde uitkomsten op de korte en lange termijn, werd niet bevestigd.

Hoofdstuk 7 evalueert de psychometrische eigenschappen van de vijf originele subschalen en de twee recent ontwikkelde algehele positieve en negatieve subschalen van de Nederlands versie van de MAC-scale. De MAC-scale is in onderhavig proefschrift gebruikt om een uitspraak te kunnen doen over de divergente validiteit van de SIPP (zie hoofdstuk 2). De MAC-scale is een vragenlijst die meet hoe kankerpatiënten omgaan met hun ziekte - welke copingstijlen zij hebben. De studie is uitgevoerd onder 289 kankerpatiënten behandeld met radiotherapie in MAASTRO Clinic; 85,5\% van de deelnemende kankerpatiënten hebben de MAC-scale ingevuld. De resultaten toonden aan dat de meest voorkomende copingstijlen bij kankerpatiënten die RT ontvangen zijn: vechtlust (58,8\%), hulpeloosheid/hopeloosheid $(37,7 \%)$ en een algemene positieve copingstijl $(78,2 \%)$. De subschalen voor het meten van positieve en negatieve coping in het algeheel alsmede de subschalen voor de specifieke copingstijlen vechtlust en hulpeloosheid/hopeloosheid lieten adequate psychometrische eigenschappen zien. De twee subschalen van de MAC-scale voor het meten van algemene positieve en negatieve coping lijken nuttige subschalen voor het meten van hoe patiënten omgaan met de ziekte kanker in het algemeen (op een positieve of een negatieve manier). Voor het meten van diverse specifieke methoden die patiënten kunnen toepassen bij het omgaan met kanker, lijken de specifieke subschalen vechtlust en hulpeloosheid/hopeloosheid adequate schalen. De Nederlandse versie van de MAC-scale laat vergelijkbare psychometrische eigenschappen zien als eerdere studies in Engeland. De uitkomsten uit de crossnationale validering ondersteunen de kwaliteit van de MAC-scale.

De belangrijkste bevindingen van dit proefschrift worden in hoofdstuk 8 besproken. Diverse methodologische en theoretische overwegingen, evenals de gevolgen voor de klinische praktijk en verder onderzoek komen in dit hoofdstuk aan de orde. Gelet op onze bevindingen en ervaringen, raden we af de screeningsprocedure zoals deze werd toegepast in onze studie te implementeren. Psychosociale screening op zichzelf lijkt bij kankerpatiënten die RT krijgen onvoldoende om algemene gezondheidsgerelateerde uitkomsten, zoals de mate van psychologische problemen en HRQoL te verbeteren. Psychosociale zorg in de oncologie bestaat uit meerdere elementen en het gebruik van een screenings- 
instrument is slechts één element hiervan. Het leveren van succesvolle psychosociale zorg binnen de radiotherapeutische instellingen is complex en vergt een multidisciplinaire aanpak. Het is een weg van de "lange adem". 
<smiles>C1CC2CCC2C1</smiles> 


\section{Dankwoord}




\section{Dankwoord}

Aan het afronden van mijn proefschrift leek geen einde te komen, maar nu is dan het moment aangebroken om het laatste hoofdstuk te schrijven, wellicht het moeilijkste hoofdstuk van dit proefschrift. Er zijn veel mensen die ik wil bedanken en ik hoop dat ik niemand vergeet.

Allereerst wil ik de patiënten en de radiotherapeuten van het Verbeeten Instituut en MAASTRO Clinic bedanken voor hun deelname aan mijn onderzoek. Zonder hen was dit promotieonderzoek niet mogelijk geweest.

Vervolgens wil ik mijn promotieteam bedanken, te weten mijn promotoren Ruud Kempen en Lilian Lechner en mijn co-promotor Francis van Gils. Dit proefschrift was nooit tot een goed einde gekomen zonder jullie onvoorwaardelijke steun, geduld en vertrouwen in mij. We waren dan ook een goed team. Ruud en Lilian, betere begeleiders had ik me niet kunnen wensen. Ik kon altijd bij jullie terecht met mijn vragen en ondanks jullie drukke agenda's kreeg ik altijd snel een reactie op mijn mails. Ik moest wel eens slikken met jullie kritische commentaar maar ik heb er veel van geleerd en uiteindelijk heeft het tot dit proefschrift geleid. Francis, je was een grote steun en hulp bij het zoeken naar een geschikte promotor en een instelling voor het uitvoeren van de effectstudie. Daarnaast had je als radiotherapeut oncoloog altijd wel een oplossing voor een praktisch onderzoeksprobleem. Tevens wil ik je bedanken voor de nominatie voor de MAASTRO award die ik dan ook in ontvangst heb mogen nemen. De award was een waardering voor "mijn inzet voor het onderzoek naar psychosociale zorg", dit had op geen beter moment kunnen komen.

De leden van de beoordelingscommissie, prof. dr. H.W. van den Borne, dr. B.G. Baumert, prof. dr. R. Sanderman, prof. dr. I.M. Verdonck-de Leeuw en prof. dr. G.D.E.M. van der Weijden wil ik bedanken voor het lezen en beoordelen van mijn proefschrift.

Gedurende het promotietraject zijn er veel personen geweest waarmee ik zeer prettig heb samengewerkt. Ruud Houben, jij was en bent nog steeds mijn steun en toeverlaat bij het uitvoeren en interpreteren van de statistische analyses. Niet alleen voor de analyses kon ik bij je terecht maar ook voor een luisterend oor. Ik ben blij dat je op deze belangrijke dag mij steunt door als paranymf naast mij te staan. Daniëlle Eekers, zonder jouw daadkracht en volharding op momenten waarop het nodig was en jouw enthousiasme, was het onderzoek in het Verbeeten Instituut niet mogelijk geweest. Ik ben je hier erg dankbaar voor. Cockie en Jolanda, jullie inzet was onmisbaar. Jullie waren de personen die de hele logistiek betreffende het onderzoek coördineerden. Daarnaast zorgden jullie voor het grootste deel van de dataverzameling. Ondanks dat jullie geen ervaring met onderzoek hadden, hadden jullie het niet beter kunnen doen. Nelly en Lindsey, ook jullie wil ik heel erg bedanken voor jullie inzet en enthousiasme voor dit onderzoek. De momenten dat we samen de lijsten met patiënten die naar jullie waren verwezen voor psychosociale hulp bekeken waren altijd gezel- 
lig. Ruud van Rijen wil ik bedanken voor de mogelijkheid om het onderzoek binnen het Verbeeten Instituut te kunnen uitvoeren en het meedenken in de logistieke uitvoer. De receptionisten: Ietje, Francy, Hanneke en alle anderen die ik vergeet te noemen, wil ik bedanken voor hun medewerking aan dit onderzoek. Aan de receptie konden de patiënten zich melden als ze wilden deelnemen aan het onderzoek en jullie regelden dat ze de juiste vragenlijsten kregen om in de wachtkamer in te vullen. Door de drukte aan de receptie was dit niet altijd een makkelijke taak. Als laatste wil ik de doktersassistenten en de afsprakenplanners bedanken voor hun waardevolle inzet en medewerking aan het onderzoek. Voor mijn onderzoek bij MAASTRO Clinic wil ik de datamanagers: Ann, Annette, Chantal en Sylvia bedanken voor de dataverzameling. Ook wil ik de maatschappelijk werkers van MAASTRO Clinic, Marlies en Annette bedanken voor het verzorgen van de training in het Verbeeten Instituut en hun belangstelling voor mijn onderzoek. Cary wil ik bedanken voor het vertalen van de Engelse MAC-scale naar het Nederlands. Tenslotte wil ik Ton Ambergen bedanken voor zijn ondersteuning bij de multilevel analyses.

De vier jaar dat ik bij de universiteit aan mijn onderzoek heb mogen werken heb ik als een mooie tijd ervaren die ik niet had willen missen. Ik dank de medewerkers van de voormalige vakgroep Verpleging \& Verzorging voor het delen van ervaringen en kennis. De collega's van de vierde verdieping van UNS40: Silke, Tine, Kitty, Ine, Astrid, Bart, Ramon, Michel, Jill, Floor en Yvonne wil ik bedanken voor de gezellige lunch-breaks.

Daniëlle, ik heb samen met jou bij de vakgroep Medische Sociologie gezeten. Helaas werd deze vakgroep opgesplitst. Ik ging naar de vakgroep Verpleging \& Verzorging en jij naar de vakgroep Sociale Geneeskunde. Ondanks deze splitsing bleef ons contact heel hecht. Ik kon altijd bij je terecht voor advies en steun. Ik ben blij dat je mijn paranymf wilt zijn en dat je me ook nu steunt tijdens de verdediging van mijn proefschrift.

Mijn collega's van MAASTRO Clinic wil ik bedanken voor hun steun en interesse in mijn onderzoek. Huub, ik wil je bedanken dat je me de kans gaf om mijn onderzoek bij de Universiteit Maastricht te kunnen uitvoeren. Petra en Floor, mijn huidige kamergenootjes, ook jullie wil ik bedanken voor jullie begrip en belangstelling voor het afronden van mijn proefschrift. Bianca wil ik bedanken voor haar steun en hulp met het controleren van de lay-out van dit boekje.

Marco, Miriam, Marjon, Wil, Bianca en Marlies vanaf nu heb ik meer tijd voor gezellige avondjes, winkelen, koffie drinken bij Starbucks, etentjes, workshops en andere activiteiten. We moeten snel weer eens de agenda's naast elkaar leggen.

Mijn zusje Kim wil ik bedanken voor haar geduld en begrip. Nu heb ik meer tijd om samen leuke dingen te gaan ondernemen. Pap en mam, ik wil jullie bedanken voor de goede hulp in en rondom ons huis. Mam, jou wil ik speciaal bedanken voor de opbeurende (telefoon)gesprekken. Op iedere moment van de 
dag kon en kan ik bij je terecht, zelfs om 6.30 in de ochtend. Ik laat het meestal niet merken, maar ik ben je hier erg dankbaar voor.

Last but not least, wil ik Jeroen bedanken. Jeroen, ik weet dat je het niet altijd eens was met mijn keuzes, maar desondanks bleef je me steunen. Ik ben je dankbaar voor je oneindige geduld en de ruimte die je me gaf. Vanaf vandaag kan ik je weer helpen met het afronden van een ander groot project: onze tuin.

Vivian 
DAN KWOORD 



\section{Curriculum Vitae}


CURRICULUM VITAE

192 
Anna (Vivian) Braeken was born in Heerlen, the Netherlands on October 11970. After completing her secondary education (HAVO) at the Bernardinuscollege in Heerlen she started an apprenticeship as an x-ray technician at Atrium Medical Centre in Heerlen, and graduated in 1994. The same year she started an apprenticeship to be a radiation technologist at the former 'Radiotherapeutisch Instituut Limburg (RTIL)' (currently the MAASTRO Clinic) and graduated in 1996. From 1996 until 2007 she worked at MAASTRO Clinic as a radiation technologist. Simultaneously, in 2000 she started studying Mental Health Sciences at the Faculty of Health, Medicine and Life Sciences of Maastricht University, which resulted in a Master's degree in 2003.

In 2006 she started her first PhD project on evaluating the psychometric properties the Screening Inventory of Psychosocial Problems (SIPP) and the Mental Adjustment to Cancer (MAC) scale at MAASTRO Clinic. Simultaneously, in 2006 she started studying Psychological Research at the Faculty of Psychology of the Open University of the Netherlands, which resulted in a Master's degree in 2010. In 2007 she received the MAASTRO award for her contribution to the field of psycho-oncology research. In 2008 she started her second PhD project on the feasibility and effectiveness of using the SIPP in cancer patients receiving radiotherapy at the former Department of Health Care and Nursing Science (currently the Department of Health Research Services) in the Faculty of Health, Medicine and Life Sciences at Maastricht University, and Open University of the Netherlands. All studies described in this thesis are conducted as part of this $\mathrm{PhD}$ project.

Since April 2011 until now she has been partly working as a policy officer (research) at MAASTRO Clinic. In addition, since November 2011 until now she has been working on a research project on the feasibility and acceptability of using a shared decision-making aid (serious game) among lung cancer patients receiving radiotherapy at MAASTRO Clinic. Recently, she started partly working as a radiation technologist at MAASTRO Clinic. 